\title{
Transportation Institutional Plan
}

August 1986

U.S. Department of Energy

Office of Civilian Radioactive Waste Mangement

Washington, DC 20585

\section{MASTLW}




\section{DISCLAIMER}

This report was prepared as an account of work sponsored by an agency of the United States Government. Neither the United States Government nor any agency Thereof, nor any of their employees, makes any warranty, express or implied, or assumes any legal liability or responsibility for the accuracy, completeness, or usefulness of any information, apparatus, product, or process disclosed, or represents that its use would not infringe privately owned rights. Reference herein to any specific commercial product, process, or service by trade name, trademark, manufacturer, or otherwise does not necessarily constitute or imply its endorsement, recommendation, or favoring by the United States Government or any agency thereof. The views and opinions of authors expressed herein do not necessarily state or reflect those of the United States Government or any agency thereof. 


\section{DISCLAIMER}

Portions of this document may be illegible in electronic image products. Images are produced from the best available original document. 


\section{Department of Energy}

Washington, DC 20585

\section{JUL 311989}

\section{T0: All Recipients}

SUBJECT: Publication of the Transportation Institutional Plan

The Office of Civilian Radioactive Waste Management (OCRWM) is pleased to release this Transportation Institutional Plan. We consider it a foundation for our projected interactions in establishing a system for transporting spent fuel and high-level radioactive waste under provisions of the Nuclear Waste Policy Act (NWPA). We recognize, of course, that al1 long-range planning must accommodate contingencies, and that adjustments wi 11 be required as program implementation proceeds.

We believe this Plan represents a truly cooperative effort that has benefitted significantly from early and continuing participation by many interested parties. Comments received on the draft of the Plan, which was published in September 1985, and at the Transportation Institutional Workshop in At lanta, Georgia, in November 1985, were carefully reviewed and are reflected throughout this revised version. The Comment Response Document included in this mailing reviews the categories of comments and provides OCRWM responses to each.

As amplified in the attached text, this Institutional Plan is the central element of three elements to be included in a comprehensive Transportation Plan. The first iteration of the comprehensive plan is expected to be released by the OCRWM in 1987. Information included in this institutional element will be updated and integrated with information from the Transportation Business Plan, which was released in January 1986. The framework for the third and final element--the operational planning for the NWPA transportation system--will be developed over the coming year, with opportunity for public comment and participation.

Not only does the OCRWM appreciate your past and future assistance in developing our transportation plans, but we also urge your support and participation in their implementation. In the near future, we have several initiatives in the area of issue resolution that will be handled through contractual arrangements. The OCRWM contractors, in turn, will be soliciting participation in seeking solutions from interested parties who are particularly knowledgeable of the issues being addressed. Such participation will be drawn from all categories of the transportation communication network described in Chapter 2 of this Plan. Near-term 
effort will focus on aspects of routing, inspection and enforcement, cask safety and testing, overweight trucks, and emergency response. Appendix A of this Plan reviews these and other issues that are subject to cooperative resolution efforts. Another area of concentrated institutional effort over the coming months will be the development of effective resources for providing accurate, objective transportation information to the public.

Comments and suggestions on all elements of our transportation planning and activities are welcome at any time and should be addressed to:

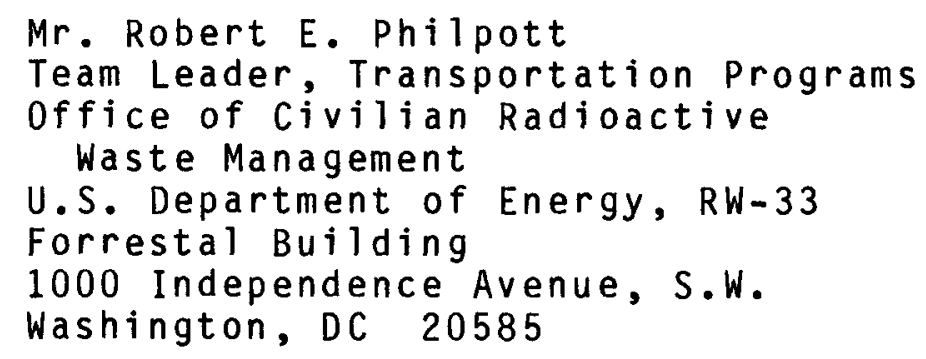

Additional copies of this Transportation Institutional plan can be obtained by telephoning (202) 252-5575, by direct pick-up at the address shown below, or by writing to:

U.S. Department of Energy

Room 1E-206

Forrestal Building

1000 Independence Avenue, S.W.

Washington, DC 20585

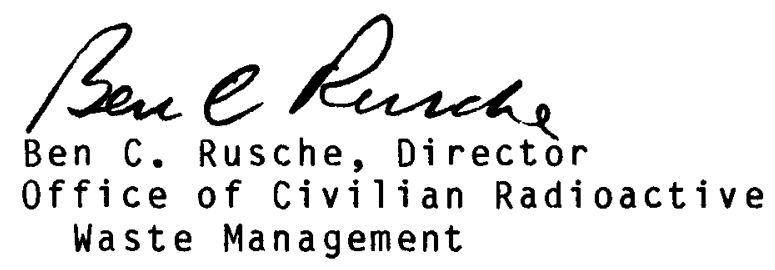


TRANSPORTATION INSTITUTIONAL PLAN

July 1986

OFFICE OF STORAGE AND TRANSPORTATION SYSTEMS OFFICE OF CIVILIAN RADIOACTIVE WASTE MANAGEMENT

U.S. DEPARTMENT OF ENERGY 
Preface

The Department of Energy (DOE) recognizes that the success of its program to develop and implement a national system for nuclear waste* management and disposal, as directed by the Nuclear Waste Policy Act of 1982 (NWPA), depends not only on safety, but on broad-based public understanding of and confidence in program activities and objectives. While each program element has its particular sensitivity, the transportation of the waste to facilities developed under the NWPA may be the most visible element nationwide. Therefore, the DOE's Office of Civilian Radioactive Waste Management (OCRWM) has developed this Transportation Institutional P1an to lay the foundation for interaction among all interested parties for the purpose of productive cooperation and resolution of issues related to establishment and operation of the NWPA transportation system. The information contained in this document is an extension and elaboration of the transportation information in the Mission Plan.**

This Institutiona1 $\mathrm{P} 1$ an is divided into three chapters. Chapter 1 provides background information, discusses the purposes of the Plan and the policy guidance for establishing the transportation system, and describes the projected system and the plans for its integrated development. Chapter 2 discusses the major participants who must interact to build the system. Chapter 3 suggests mechanisms for interaction that will foster wide participation in program planning and implementation and provides a framework for managing and resolving the issues related to development and operation of the transportation system. A 1 ist of acronyms and a glossary are included for the reader's convenience. Also included in this $\mathrm{Pl}$ an are four appendices. Of particular importance is Appendix A, which includes detailed discussion of specific transportation issues. Appendices B, C, and D provide supporting material to assist the reader in understanding the roles of the involved institutions.

As a network for communication and interaction among interested groups begins to function and as program decisions define the details of the transportation system, a comprehensive plan for the transportation program will evolve. This Transportation Institutional Plan will be combined with the Transportation Business Plan*** to provide guidance in the integrated development of a network of program participants and the acquisition of the hardware and procedures to support shipping under provisions of the NWPA. Before

* The term "waste" is used here to include both spent fuel generated during the production of electricity in nuclear power plants and high-level waste (reprocessed spent fuel) generated primarily in the production of nuclear materials for national defense.

**: Mission Plan for the Civilian Radioactive Waste Management Program, DOE/RW-0005, June 1985 .

***- Transportation Business Plan, DOE/RW-0046, January 1986. 
the system begins operations, a third plan element will be required to delineate operational contacts, requirements, and procedures. It is currently projected that in 1987 the OCRWM will issue an early iteration of a comprehensive transportation plan that will combine the institutional and business elements and provide a framework for an operational element. 
PREFACE $\ldots \ldots \ldots \ldots \ldots \ldots \ldots \ldots \ldots \ldots \ldots \ldots \ldots \ldots \ldots \ldots \ldots \ldots \ldots \ldots \ldots \ldots \ldots \ldots$ i

CHAPTER 1. INTRODUCTION $\ldots \ldots \ldots \ldots \ldots \ldots \ldots \ldots \ldots \ldots \ldots \ldots \ldots \ldots \ldots \ldots \ldots \ldots \ldots \ldots . . \ldots$

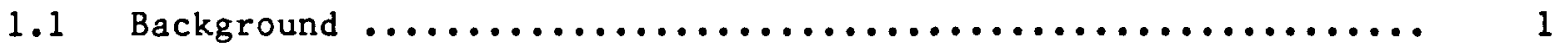

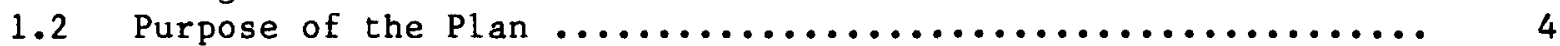

1.3 Planning Principles ............................ 4

1.3.1 Protection of Public Health and Safety and the

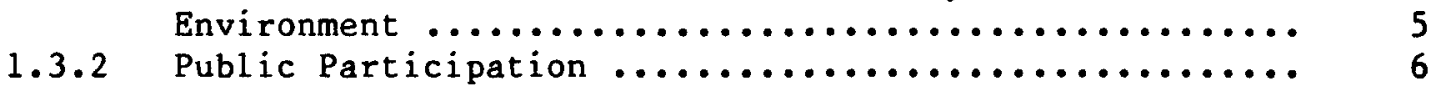

1.3.3 Cost Effectiveness .......................... 6

$1.4 \quad$ Plan Development $\ldots \ldots \ldots \ldots \ldots \ldots \ldots \ldots \ldots \ldots \ldots \ldots \ldots \ldots \ldots \ldots \ldots \ldots$

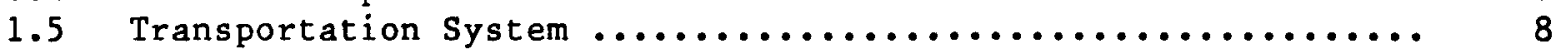

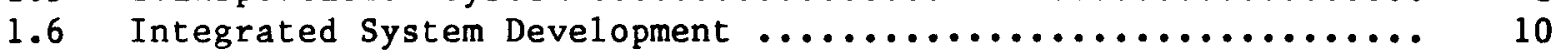

CHAPTER 2. THE COMMUNICATION NETWORK ........................ 19

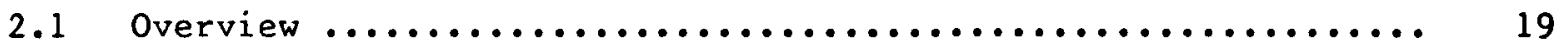

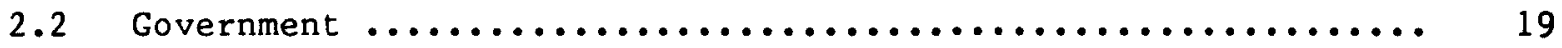

2.2.1 The Department of Energy ..................... 19

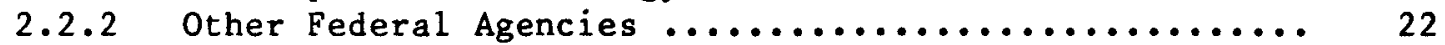

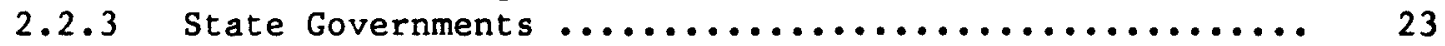

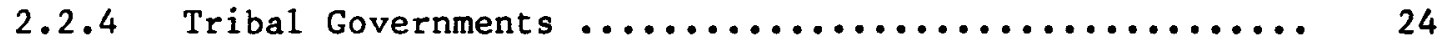

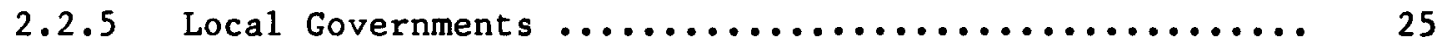

2.2.6 Intergovernmental Organizations $\ldots \ldots \ldots \ldots \ldots \ldots \ldots \ldots \ldots . \ldots 26$

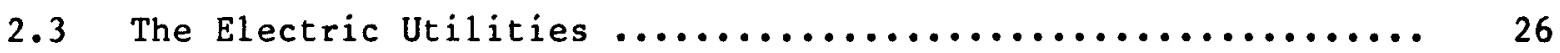

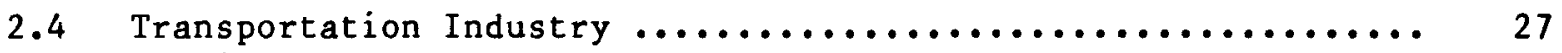

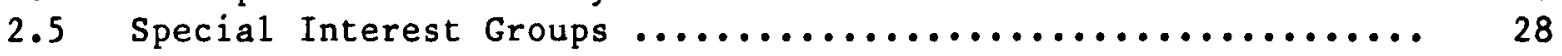

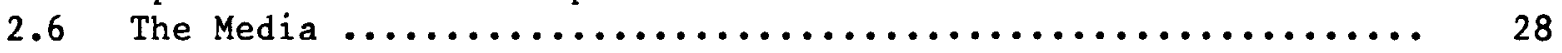

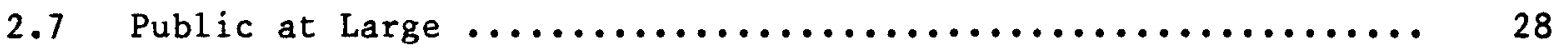

CHAPTER 3. NETWORK INTERACTIONS $\ldots \ldots \ldots \ldots \ldots \ldots \ldots \ldots \ldots \ldots \ldots \ldots \ldots \ldots \ldots \ldots \ldots . . \ldots . \ldots$

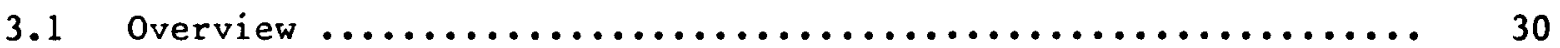

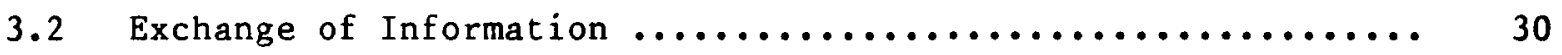

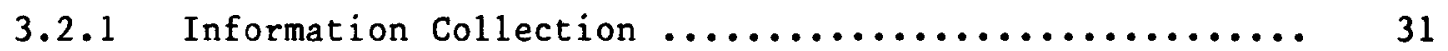

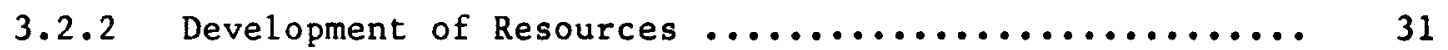

3.2 .3 Information Dissemination by the OCRWM ........... 32

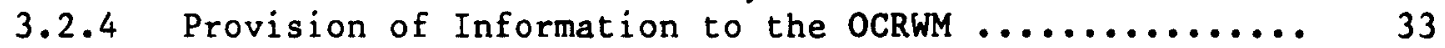

3.2 .5 Coordination of Activities ................... 33 


\section{TABLE OF CONTENTS}

(Continued)

$\underline{\text { Page }}$

3.3 Involvement in the Planning Process $\ldots \ldots \ldots \ldots \ldots \ldots \ldots \ldots \ldots . \ldots . \ldots 33$

3.3.1 Example 1. Development of Transportation

Operational Procedures ....................... 33

3.3.2 Example 2. Selection of Alternative Highway

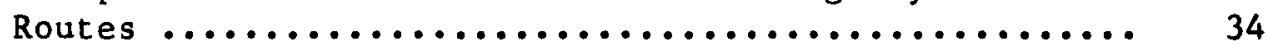

3.3.3 Example 3. Development of a Uniform Nationwide

System of Waste Shipment Inspections ............. 34

3.4 Management of Specific Issues $\ldots \ldots \ldots \ldots \ldots \ldots \ldots \ldots \ldots \ldots \ldots \ldots \ldots$

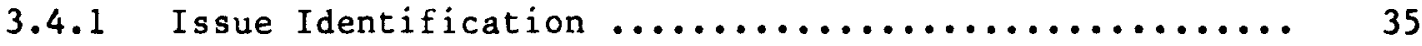

3.4.2 Process for Addressing Transportation Issues ........ 36

3.5 Support for Transportation Activities $\ldots \ldots \ldots \ldots \ldots \ldots \ldots \ldots \ldots .40$

3.5.1 Program Participation ....................... 42

3.5 .2 Principles for Support of Participation .......... 43

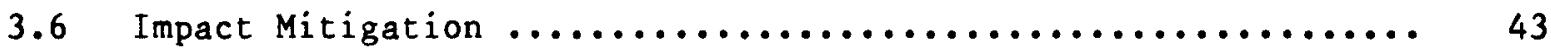

LIST OF ACRONYMS $\ldots \ldots \ldots \ldots \ldots \ldots \ldots \ldots \ldots \ldots \ldots \ldots \ldots \ldots \ldots \ldots \ldots \ldots \ldots \ldots \ldots \ldots . \ldots 44$

GLOSSARY $\ldots \ldots \ldots \ldots \ldots \ldots \ldots \ldots \ldots \ldots \ldots \ldots \ldots \ldots \ldots \ldots \ldots \ldots \ldots \ldots \ldots \ldots \ldots \ldots \ldots$

APPENDIX A. DISCUSSION OF TRANSPORTATION ISSUES $\ldots \ldots \ldots \ldots \ldots \ldots \ldots \ldots \ldots \ldots$ A-1

APPENDIX B. FEDERAL AGENCY TRANSPORTATION RESPONSIBILITIES AND
APPLICABLE REGULATIONS AND ORDERS $\ldots \ldots \ldots \ldots \ldots \ldots \ldots \ldots \ldots \ldots \ldots \ldots$ B-1

APPENDIX $c$. SUMMARY OF AGENCY AGREEMENTS $\ldots \ldots \ldots \ldots \ldots \ldots \ldots \ldots \ldots \ldots \ldots \ldots \ldots . . \ldots$

APPENDIX D. DIRECTORY OF ORGANIZATIONAL CONTACTS $\ldots \ldots \ldots \ldots \ldots \ldots \ldots \ldots \ldots$ D-1 


\section{LIST OF FIGURES}

$\underline{\text { Page }}$

Figure 1. Nuclear Power Plants in the United States .............. 2

Figure 2. Evolution of the Transportation Plan ................. 9

Figure 3. Improved Performance Transportation System .............. 11

Figure 4. Transportation Program Schedule ..................... 13

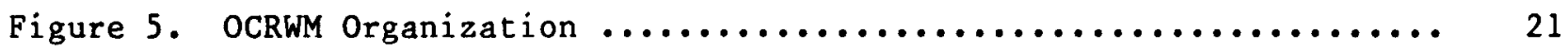

Figure 6. Issue Resolution Process ......................... 41

\section{LIST OF TABLES}

Table 1. Relationship Between Technical Development and

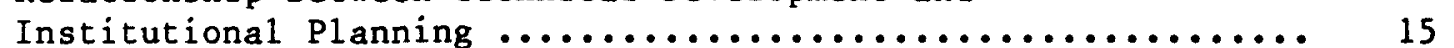


Chapter 1

INTRODUCTION

\subsection{Background}

Recent Department of Energy (DOE) statistics indicate that 101 commercial nuclear power plants were in operation in the United States at the beginning of July 1986 (see Figure 1), with some 29 additional reactors projected to come on-line in the foreseeable future. By 1984 these plants had produced spent fuel totaling about 12,000 metric tons of uranium (MTU). The Energy Information Administration of the DOE projects that, using a middlecase forecast, the spent fuel inventory will rise to almost 42,000 MTU by the year 2000 and to approximately 106,000 MTU by the year 2020.* These projections assume that future fuel burnups would gradually increase to 30 percent above current levels by 1993 and then remain constant. They also assume substantial additions of nuclear capacity in the United States after the year 2000 . If, however, the case assuming no new orders for nuclear power plants is used, spent fuel discharge projections would be less than 40,000 MTU by the year 2000 and less than 75,000 by the year 2020. Most of the existing commercial spent fuel is stored in pools at the reactor sites. A small amount has been reprocessed, generating liquid waste that is now stored at a processing site in West Valley, New York.

The spent fuel generated in atomic energy defense activities is routinely reprocessed, and the resulting high-level waste is stored at three DOE

facilities: the Savannah River Plant in South Carolina, the Idaho National Engineering Laboratory, and the Hanford Reservation in Washington State. Approximately 368,000 cubic meters of defense high-level waste had accumulated as of 1984. The OCRWM has developed an OCRWM Backgrounder which provides additional information on both the commercial spent fuel and the defense highlevel waste that is being stored. $* *$

Although these wastes can be safely stored on a temporary basis, ultimately they must be isolated from the biosphere for many thousands of years. In the course of three decades of worldwide research and development, the technological basis and data have been established to support the design and construction of systems for safe, permanent waste disposal. A scientific

* Energy Information Administration, U.S. Department of Energy, World Nuclear Fuel Cycle Requirements, 1985 , p. 91.

** OCRWM Backgrounder: Characteristics and Inventories of Nuclear Waste, DOE/RW-0086, April 1986. 


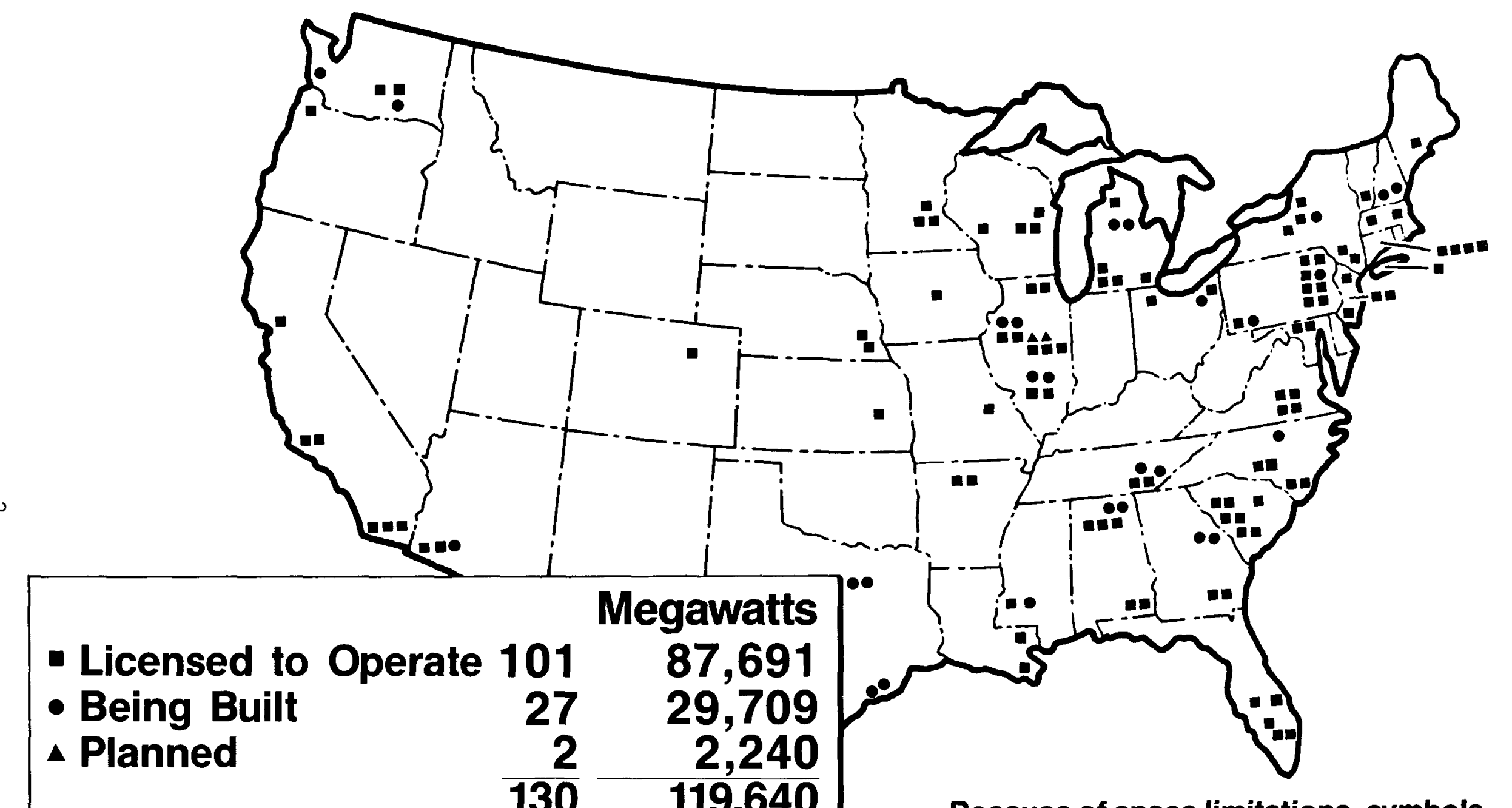

Because of space limitations, symbols do not reflect precise locations.

$6 / 86$

\section{Nuclear Electrical Generating Capacity}


consensus has emerged that the most promising approach to permanent waste isolation is disposal in deep geologic repositories. The United States formally embraced this approach by enacting the Nuclear Waste Policy Act of 1982 (NWPA). The NWPA established a program for the siting of two geologic repositories and the development of other components of a waste-management system. The NWPA assigns primary responsibility for the establishment and operation of the waste management system to the DOE; a new Departmental entity, the Office of Civilian Radioactive Waste Management (OCRWM), was created to implement NWPA provisions. The NWPA also recognizes the need for involvement in the waste management program by States, Indian Tribes, and other interested parties.

In May 1986, the Secretary of Energy announced that sites in Nevada, Texas, and Washington had been recommended to the President for site characterization for a first repository, and that the President had approved the recommendation. The Secretary further announced that the plans for any site-specific work related to a second repository were being indefinitely postponed. This decision reflected the progress that has been made in selecting a first repository site and the hope that Congress will authorize a monitored retrievable storage (MRS) facility as an integrated part of the overall disposal system. In addition, while projections are uncertain about the amount of spent fuel to be generated, it is apparent that the volume is growing more slowly than previously anticipated. In light of these changed projections, the first repository, which the NWPA permits to hold 70,000 metric tons of waste, will provide adequate disposal capacity in the foreseable future.

In addition to provisions for disposal of commercial waste, the NWPA provided that the President was to evaluate options for disposal of the highlevel defense waste. As a result of this evaluation, in April 1985, the President directed the Secretary of Energy to proceed with plans and actions to dispose of the defense waste in the commercial repository. Development and operation of the waste management system is financed for spent fuel disposal through fees on electricity generated in nuclear power plants and for defense waste disposal by Congressional appropriations.

Transportation is an integral and essential part of the projected waste management system. The United States has a long history of transporting radioactive material. Commercial spent fuel has been shipped for over 20 years and high-level waste from defense activities for an even longer period. These shipments have been conducted without any accidents causing death or environmental damage due to the radiological nature of the cargo. The DOE is taking measures to ensure that this safety record continues. An extensive program is under way to develop equipment and procedures that can accommodate the expected increase in the number of shipments when NWPA facilities begin operating in the late 1990s. Under the NWPA, the OCRWM will accept commercial waste at reactor sites or point of origin for transport to a repository or intermediate storage facility. In addition, an intra-agency agreement was signed in July 1986 whereby the OCRWM will accept defense waste at a designated loading area adjacent to the Department's high-level waste processing facilities; the OCRWM will then transport it to the repository in a cask certified by the Nuclear Regulatory Commission (NRC). Both spent fuel and high-level waste shipments will be in compliance with all applicable 
Federal regulations and OCRWM procedures in effect at the time of transfer to a repository. In addition, State, Tribal, and local requirements that are consistent with Federal law will be followed.

A successful transportation system must be not only safe and efficient but also widely acceptable. To achieve the necessary public understanding, a number of questions and issues regarding the establishment and operation of the transportation system must be addressed. While issue resolution is complicated by the differing--and frequently conflicting--interests of the parties involved, it is an important key to program implementation.

\subsection{Purpose of the Plan}

The purpose of this Plan is to define a comprehensive process for effective interaction among those who are affected by development of an NWPA transportation system. Such a process will necessarily involve the identification of the interested parties who may participate in, or may be affected by, waste transportation. Moreover, the relationship among these parties will be outlined, and an interactive communication network will be established. Elements of the network are categorized as (1) governmental (including Federal, State, Tribal, and local governments); (2) the electric utilities; ( 3 ) the transportation industry; (4) special interest groups; (5) the media; and (6) the public at large. The Plan further outlines formal mechanisms for the identification of transportation issues; describes the process for addressing and resolving issues in a responsive, timely manner; and discusses the status of specific issues. The intent is to foster cooperative effort and to focus on communication and negotiation rather than conflict.

\subsection{Planning Principles}

The OCRWM goal is to develop, within the overall principles of the Mission Plan, a safe, secure, efficient, and cost-effective program for waste transportation to Federal facilities established under the NWPA. To meet this goal, the OCRWM has determined that, at a minimum, the NWPA transportation program must--

- Meet the safety and security requirements of the Department of Transportation (DOT) and the NRC.

- Develop an operational transportation system on a schedule that is consistent with NWPA requirements.

- Recognize and conform to all established transportation safety requirements of State, Tribal, and local governments wherever such requirements are consistent with Federal law.

- Encourage public confidence through excellence in performance and effective communication that transportation risks are at an acceptable level that meets all applicable regulations and are not disproportionate to other societal risks associated with the transportation of hazardous material. 
- Estab1ish and implement a process for identifying and addressing transportation issues, and foster broad-based participation in seeking avenues for issue resolution.

- Conduct program activities in such a way as to ensure prudent and appropriate expenditure of the Nuclear Waste Fund.

The OCRWM recognizes that planning for waste transportation to facilities developed under the NWPA and methods of addressing and resolving transportation issues must be consistent with Congressional findings and purposes contained in section 111 of the NWPA. In its implementation of the Act, the OCRWM has identified three goals for program activities:

- Protection of public health and safety and the quality of the environment. This goal is the cornerstone of all program activity.

- Public participation in activities related to the waste management program.

- Cost effectiveness.

\subsubsection{Protection of Public Health and Safety and the Environment}

As stated in the NWPA (section $111[a][7]), " .$. high-level radioactive waste and spent nuclear fuel have become major subjects of public concern, and appropriate precautions must be taken to ensure that such waste and spent fuel do not adversely affect public health and safety and the environment for this or future generations." Inherent in planning for the transportation of the waste is the need for the OCRWM to identify those factors that will affect the safety and security of transportation and to establish criteria that can be used to determine which impacts can and should be mitigated. In addition, areas of uncertainty with regard to the risks of transportation under provisions of the NWPA must be identified, and plans must be developed for reducing such uncertainty.*

When engaged in future activities related to the transportation of waste to NWPA facilities, the OCRWM will meet all applicable DOT and NRC safety and

* It should be noted that the NRC, in its final environmental statement on the shipment of nuclear materials, evaluated the risks of transporting radioactive materials and found "the average radiation dose to the population at risk from normal transportation is a small fraction of the limits recommended for members of the general public from all sources of radiation other than natural and medical sources ... and is a small fraction of natural background dose." and that "the radiological risk from accidents in transportation is small, amounting to about one-half percent of the normal transportation risk on an annual basis." (U.S. Nuclear Regulatory Commission, Final Environmental Statement on the Shipment of Nuclear Materials, NUREG-0170, Washington, D.C., 1977). 
security standards that exist at the time of shipment as well as all applicable safety requirements of State, Tribal, and local governments that are not inconsistent with the Federal requirements. If the results of OCRWM studies or experience indicate the existing standards should be either moderated or made more stringent, the OCRWM will advocate the desired modification to the agency of authority.

While the NWPA requires the OCRWM to "... utilize by contract private industry to the fullest extent possible in each aspect of such transportation" (section 137 [a][2]), the OCRWM is nevertheless the responsible party for overseeing the development and operation of the transportation system to ensure that it will be safe, economical, on schedule, publicly acceptable and in full compliance with the applicable regulatory requirements. To ensure that all contracted activities are performed in a manner that will contribute to achievement of these goals, a quality assurance plan for the transportation program is being developed. This plan will describe quality assurance (QA) responsibilities, authorities, management organization and requirements, and the appropriate governing documents. It is intended also to provide QA guidance to all participating organizations in such areas as oversight, QA methodologies, and problem reporting. It supplements and is to be used in conjunction with the following three governing documents: the Transportation Business P1an; the Quality Assurance Management Policies and Requirements, * which provides QA guidance for all OCRWM programs; and the office of Storage and Transportation Systems QA policy directive, which is currently under development.

\subsubsection{Public Participation}

The NWPA recognizes that spent fuel and high-level waste have become subjects of public concern and that public and private sector participation in the planning and development of the waste management program is essential to promote better understanding and to foster public confidence in the safety of waste management and disposal. In keeping with this NWPA finding, the OCRWM recognizes that expressions of public concern must be substantively addressed and, accordingly, has included opportunities for public participation in the Mission Plan and subsequent program documents. To meet the responsibility for addressing the transportation of the waste, the OCRWM will work actively with interested parties throughout the planning process to ensure that transportation safety factors are identified, evaluated, and adequately incorporated into program decisions. This $\mathrm{Plan}$ is the implementing document for such interaction. Chapter 3 discusses mechanisms that will enable interested parties to participate in all facets of the transportation program.

\subsubsection{Cost Effectiveness}

The NWPA requires that the costs of radioactive waste disposal be borne by the owners and generators of such waste and provides for the establishment

* Quality Assurance Management Policies and Requirements, DOE/RW-0032, October 1985. 
of a Nuclear Waste Fund for this purpose. Those who will ultimately bear the major share of the cost incurred in establishing the waste disposal system are the ratepayers throughout the country who are the consumers of electricity generated by nuclear power plants. As previously stated, the disposal of defense waste will be funded by the taxpayer through annual Congressional appropriations.

The OCRWM recognizes its responsibility to ensure that program activities financed by the Nuclear Waste Fund are conducted in an efficient and costeffective manner. In expending Waste Fund resources for the development and operation of the NWPA transportation system, the OCRWM will use, as a primary guide, the criterion of whether the necessity for the activity to be undertaken can be attributed to passage of the NWPA. The OCRWM will also fully consider all activities currently funded by other Federal, State, Tribal, and local agencies (e.g., the improvements to the highway infrastructure funded by the DOT and the emergency response training funded by the Federal Emergency Management Agency [FEMA]) in order to avoid duplication of effort and imprudent expenditures. The OCRWM also understands the necessity to consider institutional as well as technical impacts in evaluating cost effectiveness. For example, reasonable funding of activities to expand public understanding and to reinforce confidence in the program would be considered highly costeffective.

\subsection{Plan Development}

The Transportation Institutional P1an supplements the transportation information provided in the OCRWM Mission Plan and is complementary to the Transportation Business Plan. It is consistent with the prospective overall OCRWM institutional planning for policy and program implementation and interaction. Furthermore, it meets the planning requirements specified in the OCRWM Program Management System Manual **

This Plan has been developed through a process of public review and comment. In response to recommendations received both at the Atlanta Transportation Institutional Plan Workshop in November 1985 and in written comments on the Draft Transportation Institutional Plan, ** the OCRWM has accelerated its schedule to produce a comprehensive transportation plan that integrates all the planning elements of program development into a single document. As a first step, the issue discussion papers that were originally intended to be published separately have been incorporated into this Institutional Plan as Appendix A.

A second major step toward plan integration is scheduled for 1987 with the release of a single comprehensive document containing three planning elements. The information currently contained in the Business $\mathrm{P} 1$ an and in this Institutional Plan will be combined and the framework for an operations plan will be introduced. An operations plan, when fully developed, will outline the procedures under which the waste will be transported. It will

\footnotetext{
* Program Management System Manual, DOE/RW-0043, January 1986. ** Draft Transportation Institutional Plan, DOE/RW-0031, September 1985 .
} 
include such information as the scheduling for shipments, permissible routes, the regulatory authority under which the shipment is made, procedures for maintenance and inspection, and requirements for carrier qualifications. Many of the issue discussion papers in Appendix A address options for the operational procedures. Decisions on these procedures will enable the continued development of the operations plan.

The comprehensive transportation plan will be updated and re-issued periodically to reflect influencing events that occur, policy decisions that are made, and comments and suggestions that are received from interested parties. Depending on changes in conditions and issue status, discussion papers could be revised and released individually on an interim basis.

The OCRWM's goal in providing a comprehensive transportation plan is to offer information and guidance to all who may be affected by, and participate in, waste transportation activities conducted under the NWPA. The evolution of the comprehensive transportation plan is shown in Figure 2.

\subsection{Transportation System}

In implementing the DOE's mandate under the NWPA, the OCRWM will develop and operate a transportation system to move waste from the commercial reactors and the DOE facilities, where it is generated and currently stored, to the repositories or other facilities that may be included in the waste management system. This system requires development of the physical equipment (hardware) and transportation services to transport the waste as well as an institutional framework that will act to facilitate the effective development and operation of the system. It should be noted that the mission to develop a transportation system for NWPA shipments is separate from the DOE's ongoing activities related to transportation of other materials, including nuclear materials for weapons. These DOE shipments that are not related to NWPA activities will continue to be conducted under the auspices of the Office of Defense Programs within the DOE. Many of these non-OCRWM shipments are classified for national security purposes, and procedures relating to them must accommodate security requirements.

The foundation for the projected NWPA transportation system is already in place. The current operational procedures of the DOE, the electric utilities, and the transportation industry for transporting radioactive material provide a strong basis for the development of a system uniquely appropriate to the increased requirements for shipping under provisions of the NWPA. In addition, the existing regulatory systems of the DOT and the NRC provide the framework of standards that will guide the OCRWM's development of equipment and procedures.

The projected physical transportation system will consist of shipping casks, carriage equipment, and associated ancillary equipment. The services required will include the carriage of the fuel by commercial transport companies, the maintenance of the casks and other equipment, and the training of system operators such as drivers, maintenance personnel, and inspectors. In accordance with the NWPA, the Secretary of Energy "... shall utilize by contract private industry to the fullest extent possible ..." to develop and operate this system. 


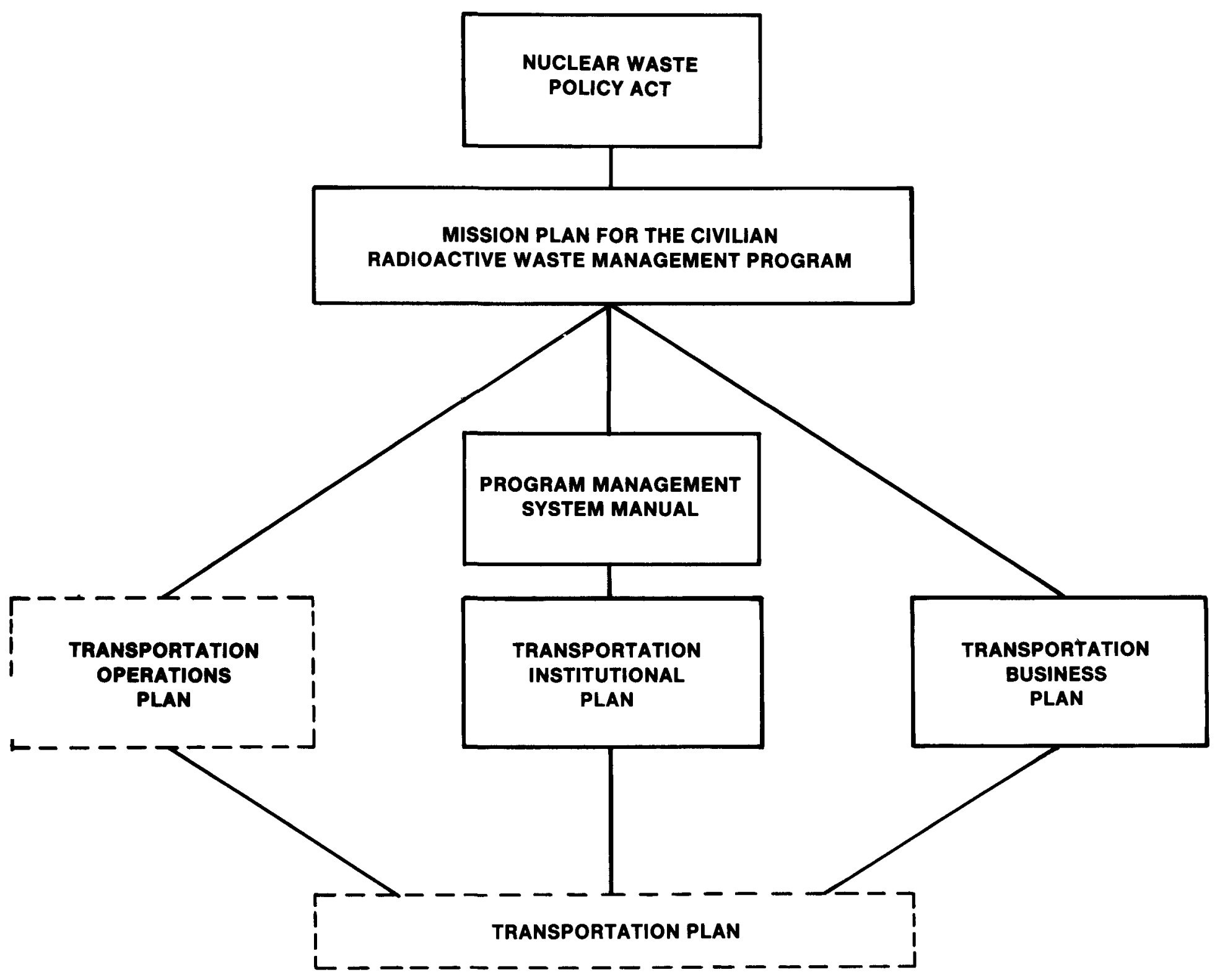

AVAILABLE DOCUMENT

PROJECTED DOCUMENT

Figure 2. Evolution of the Transportation Plan. 
Two waste-management system strategies are described in the Mission Plan: the Authorized System, as defined by the NWPA, and the Improved-Performance System. Under the former strategy, the OCRWM would take title to the waste at the point of origin (principally commercial reactors) and transport it directly to a repository by truck, rail, and/or barge. Preparation of waste for disposal would occur at the repository, which would begin operations in 1998. In addition, if requested by the utilities and approved by the NRC, limited interim storage of waste would be provided at Federal facilities if necessary to accommodate the growing inventory of spent fuel prior to repository availability. This storage option is not expected to be necessary.

Under the Improved-Performance Transportation System strategy (see Figure 3), spent fuel would be first shipped by truck, train, and/or barge to a facility for monitored retrievable storage (MRS), where it would be consolidated and packaged for disposal and, if necessary, temporarily stored. Movement from the MRS facility to repositories is anticipated to be made by train; however, other modal options will be maintained for operational flexibility. The OCRWM would take title to the waste at the reactors and begin operating the transportation system as early as 1996. As directed by the NWPA, the OCRWM has developed a proposal for an MRS facility for submission to Congress. The OCRWM's cask development plans are designed to accommodate the strategy of either the Authorized System or the Improved-Performance System.

The OCRWM is further directed by the NWPA to enter into cooperative programs with utilities to demonstrate technologies for enhanced at-reactorstorage capability. Over the next several years, a number of spent fuel shipments will be made related to these cooperative research and development (R\&D) programs. Until the NWPA transportation system is more completely defined, existing Departmental procedures will be applied to these R\&D shipments. As the OCRWM develops the shipping procedures that will be used when the NWPA system is fully operational, they will be introduced incrementally as procedures for the R\&D shipments.

\subsection{Integrated System Development}

To foster a coordinated, effective transportation program, institutional activities must be synchronized with the technical development and the eventual operation of the transportation system. As described in the Transportation Business Plan, technical development and acquisition of the system is divided into two phases: (1) cask development, and (2) acquisition of equipment and services. The first phase is further subdivided into three initiatives for the development of from-reactor casks; MRS-to-repository casks (subject to Congressional approval of an MRS facility); and casks for nonstandard spent fuel and nonfuel components.* Activities conducted during the second phase (acquisition of equipment and services) include procurement of a

* Pursuant to a recent DOE intra-agency agreement, the OCRWM is also responsible for the development of casks for shipping defense waste to a repository. Preliminary planning for such a design effort has begun. 


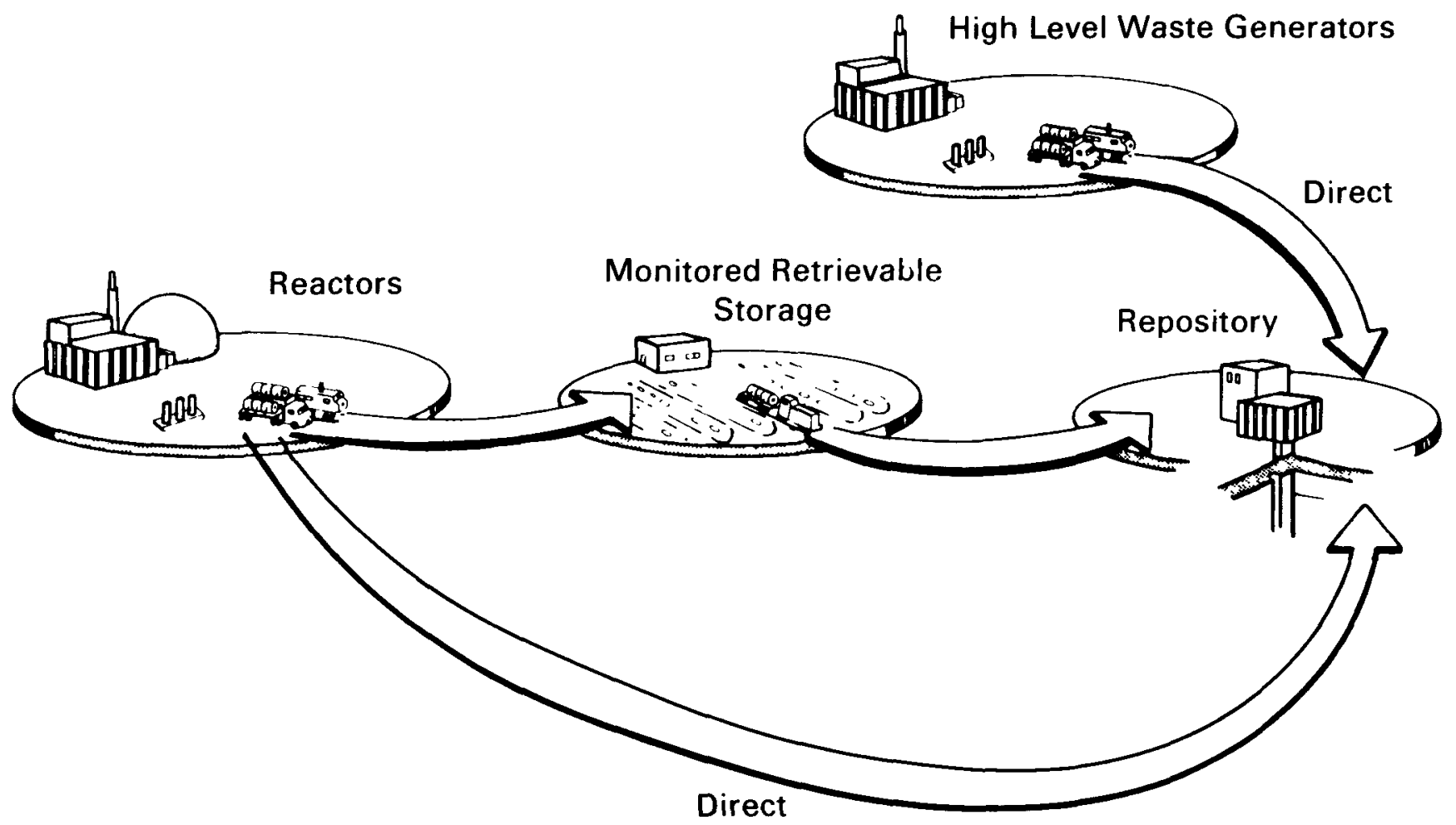

Figure 3. The improved performance transporation system. 
fleet of casks and procurement of the services of contractors who will operate the system. The summary schedule for the acquisition of the transportation system is shown in Figure 4.

Current activities include the definition of the requirements for the overall transportation system in terms of needs, safety, capabilities, schedules, costs, and operating constraints. The major institutional activities are developing a transportation network* and planning and initiating public information activities. The network members are involved in program planning in the following ways: (1) by commenting on the performance specifications and interface guidelines for the from-reactor casks prior to the solicitation of cask design concepts from industry, and (2) assisting the OCRWM in the identification of transportation issues and determination of resolution mechanisms. The OCRWM is participating in seminars on cask design, testing, and safety to assist in this process.

In mid-1986, the OCRWM will invite industry proposals for the engineering design and development, prototype fabrication, testing, and certification of from-reactor casks. It is anticipated that at least two casks of each modal type (truck and train/barge) will be selected for engineering development and certification.

Throughout the cask development process, the OCRWM will consult with regulatory agencies and advise the utilities and industry on potential changes to the regulations that could affect cask development. The OCRWM will also work closely with contractors and will provide the network with information on the evolution of cask designs, the development of testing programs, and quality assurance requirements. In addition, the OCRWM will seek to develop national or regional agreements among states and Indian Tribes for coordination and standardization of inspection and enforcement, emergency planning, and other activities related to transportation safety.

The main thrust of the procurement for operational services will begin in 1990, when the request for proposals from the service contractors will be issued. Training programs for operating personnel will be developed. Design parameters for prototype casks will facilitate planning for preferred modes of transportation, frequency of shipments, and other operational parameters. Institutional interactions during this time will be directed toward the more site-specific and route-specific concerns of the potentially affected network members. Operating procedures will continue to be defined, and a fully developed operations plan will be included as the third element of the comprehensive transportation plan.

* The network consists of parties who may interact in the development and operation of the NWPA transportation system. Network membership will be drawn from other Federal agencies; State, Tribal, and local governments; the electric utilities; the transportation industry; special interest groups; the media; and the public at large. 


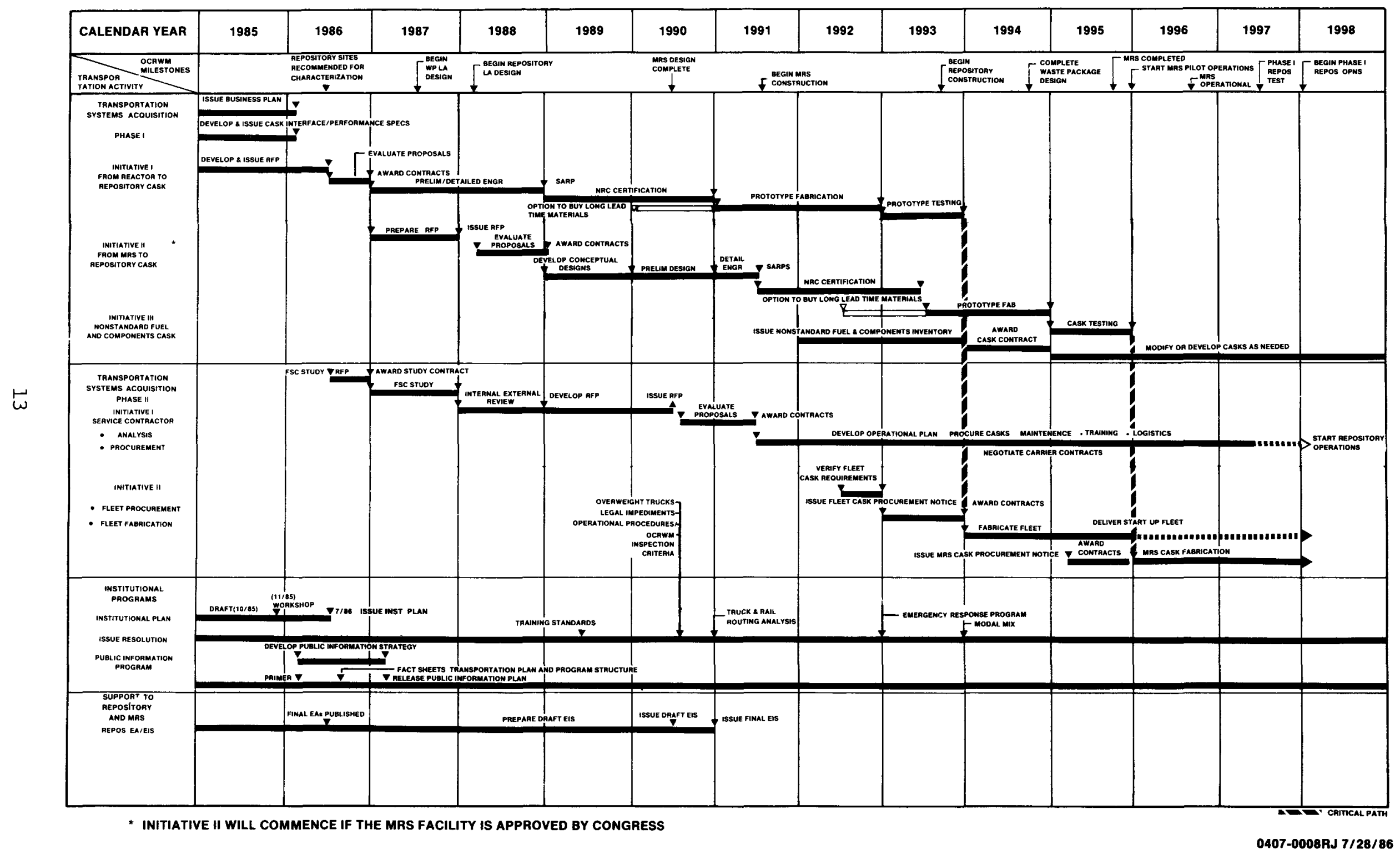

Figure 4. Transportation program scedule. 
As transportation operations begin, the OCRWM will comply with applicable DOT and NRC transportation regulations and State, Tribal, or local requirements that are not inconsistent with Federal regulations. The OCRWM will also cooperate with the Federal regulatory agencies and the States in comprehensive inspection programs. In addition to providing quality assurance and quality control for transportation industry services, the OCRWM will work with the utilities and industry to plan for further development and improvement of the transportation system. Finally, a program of public information and interaction will be conducted to keep interested citizens fully informed of program activity.

The relationship between technical activities and the probable institutional activities and information resources is depicted in Table 1 for four time frames: 1986, 1987-91, 1992-95, and 1996 through the end of the program. 
TABLE 1. RELATIONSHIP BETWEEN TECHNICAL DEVELOPMENT AND INSTITUTIONAL PLANNING

\begin{tabular}{|c|c|c|c|}
\hline $\begin{array}{c}\text { Time Frame } \\
\text { (Calendar } \\
\text { Years) }\end{array}$ & Technical Activities/Resources & Institutional Activities & Information Resources \\
\hline 1986 & $\begin{array}{l}\text { - Define equipment/facility interface } \\
\text { criteria } \\
\text { - Define performance specifications } \\
\text { for first (from-reactor) cask devel- } \\
\text { opment initiative } \\
\text { - Issue request for proposals (RFP) } \\
\text { for from-reactor cask } \\
\text { - Develop cask testing plan } \\
\text { - Develop quality assurance/quality } \\
\text { control plan } \\
\text { - Award from-reactor cask development } \\
\text { contracts } \\
\text { - Analyze operational options } \\
\text { - Full-service contractor } \\
\text { - Cask ownership } \\
\text { - Prepare RFP for initiative } 2 \\
\text { (from-MRS) cask development* } \\
\text { - Issue RFP for full-service contractor } \\
\text { study }\end{array}$ & $\begin{array}{l}\text { - Continue } 1 \text { iaison with DOT, NRC, and } \\
\text { other Federal agencies } \\
\text { - Continue establishment and maintenance } \\
\text { of State and Tribal contacts } \\
\text { - interact through Project offices and } \\
\text { OGR Desk Officers } \\
\text { - participate in conferences } \\
\text { - participate in ISCG meetings } \\
\text { - Develop public information plan } \\
\text { - Interact with utilities } \\
\text { - Interact with industry } \\
\text { - Dialogue with communication network via } \\
\text { discussion papers } \\
\text { - Develop analyses and models } \\
\text { - risk assessment } \\
\text { - issue analyses } \\
\text { - routing analyses } \\
\text { - modal studies }\end{array}$ & $\begin{array}{l}\text { - Publish Transportation Business Plan } \\
\text { - Issue cask procurement information } \\
\text { package } \\
\text { - Hold cask information seminar } \\
\text { - Publish Transportation Institutional } \\
\text { Plan (including } 16 \text { issue discussion } \\
\text { papers) } \\
\text { - Hold workshops/meetings on: } \\
\text { - cask safety and testing } \\
\text { - selection of routing factors } \\
\text { - etc. } \\
\text { - Develop and disseminate pamphlets/ } \\
\text { brochures } \\
\text { - Transportation of Spent Fuel: An } \\
\text { Overview }\end{array}$ \\
\hline
\end{tabular}

*If MRS is approved by Congress. 
TABLE 1. RELATIONSHIP BETWEEN TECHNICAL DEVELOPMENT AND INSTITUTIONAL PLANNING (Page 2 of 4 )

\begin{tabular}{|c|c|c|c|}
\hline $\begin{array}{c}\text { Time Frame } \\
\text { (Calendar } \\
\text { Years) }\end{array}$ & Technical Activities/Resources & Institutional Activities & Information Resources \\
\hline $\begin{array}{c}1986 \\
\text { (Cont inued) }\end{array}$ & & $\begin{array}{l}\text { - Award contracts to study issues and } \\
\text { facilitate resolutions } \\
\text { - regional organizations } \\
\text { - transportation organizations } \\
\text { - Continue implementation of issue resolu- } \\
\text { tion process }\end{array}$ & $\begin{array}{l}\text { - Possible production of transporta- } \\
\text { tion videotape on cask development } \\
\text { - Develop organizational and network } \\
\text { directories } \\
\text { - Speak at conferences } \\
\text { - Announce intended issuance of RFP } \\
\text { and contract awards in Federal } \\
\text { Register and Commerce Business Daily }\end{array}$ \\
\hline $1987-91$ & $\begin{array}{l}\text { - From-reactor cask development (first } \\
\text { initiative) } \\
\text { - Complete preliminary designs } \\
\text { - Complete and approve engineering } \\
\text { designs } \\
\text { - Receive NRC certifications } \\
\text { - From-MRS cask development (second } \\
\text { initiative)* } \\
\text { - Issue RFP } \\
\text { - Award contracts } \\
\text { - Complete preliminary design } \\
\text { - Complete and approve engineering } \\
\text { designs }\end{array}$ & $\begin{array}{l}\text { - Maintain activities with regulatory } \\
\text { agencies, identifying concerns with } \\
\text { current regulations and potential } \\
\text { rulemaking that would impact cask } \\
\text { certifications or other transportation } \\
\text { programs } \\
\text { - Continue interaction with electric } \\
\text { utilities and industry } \\
\text { - Coordinate contractor activities with } \\
\text { network participation (e.g., testing } \\
\text { program, design documents, QA require- } \\
\text { ments); evaluate and incorporate recom- } \\
\text { mendations, where appropriate }\end{array}$ & $\begin{array}{l}\text { - Publish comprehensive transportation } \\
\text { plan } \\
\text { - Update and release for comment trans- } \\
\text { portation issue discussion papers } \\
\text { - Develop and publish brochures, } \\
\text { pamphlets, and other written material } \\
\text { for public information } \\
\text { - Develop transportation films and } \\
\text { exhibits } \\
\text { - Hold public information meetings on } \\
\text { program products and issue resolution } \\
\text { progress }\end{array}$ \\
\hline
\end{tabular}

*If MRS is approved by Congress. 
TABLE 1. RELATIONSHIP BETWEEN TECHNICAL DEVELOPMENT AND INSTITUTIONAL PLANNING (Page 3 of 4 )

\begin{tabular}{|c|c|c|c|}
\hline $\begin{array}{c}\text { Time Frame } \\
\text { (Calendar } \\
\text { Years) }\end{array}$ & Technical Activities/Resources & Institutional Activities & Information Resources \\
\hline $\begin{array}{c}1987-91 \\
\text { (Cont inued) }\end{array}$ & $\begin{array}{l}\text { - Implement QA/QC into cask development } \\
\text { activities } \\
\text { - Transportation Services } \\
\text { - Complete full-service contractor } \\
\text { study } \\
\text { - Issue RFP and award contract for } \\
\text { FSC }\end{array}$ & $\begin{array}{l}\text { - Develop, through cooperative effort with } \\
\text { Dot, States, and Tribes, factors for } \\
\text { evaluating specific routes } \\
\text { - Encourage multi-State/Tribal participa- } \\
\text { tion in developing national/regional } \\
\text { standards } \\
\text { - inspection and enforcement } \\
\text { - emergency response } \\
\text { - overweight trucks } \\
\text { - training standards } \\
\text { - etc. }\end{array}$ & $\begin{array}{l}\text { - Develop and distribute information on } \\
\text { cask types } \\
\text { - Announce procurement opportunities } \\
\text { and awards in Federal Register and } \\
\text { Commerce Business Daily }\end{array}$ \\
\hline $1992-95$ & $\begin{array}{l}\text { - From-reactor cask development } \\
\text { - Fabricate and test prototypes } \\
\text { - From-MRS cask development* } \\
\text { - Receive NRC certification } \\
\text { - Fabricate and test prototypes } \\
\text { - Non-standard-fuel cask development } \\
\text { - Issue RFP*: } \\
\text { - Award contracts } \\
\text { - Complete and approve engineering } \\
\text { designs }\end{array}$ & $\begin{array}{l}\text { - In close coordination with industry and } \\
\text { utilities, develop operational plan to } \\
\text { define: } \\
\text { - transportation mode and State- } \\
\text { preferred routes } \\
\text { - shipment frequency } \\
\text { - defense-waste parameters } \\
\text { - inspection and enforcement activities } \\
\text { - incident reporting } \\
\text { - Continue work with network to address } \\
\text { local issues related to site selection } \\
\text { and route selection; participation by } \\
\text { local governments, utilities, states, } \\
\text { Tribes }\end{array}$ & $\begin{array}{l}\text { - Hold cask prototype demonstrations } \\
\text { for public } \\
\text { - Conduct workshops on operational } \\
\text { plan for network participants } \\
\text { - Issue operational plan for support } \\
\text { services } \\
\text { - Issue revisions of Transportation } \\
\text { plan and issue discussion papers } \\
\text { - Make training materials for operat- } \\
\text { ing personnel available to State, } \\
\text { Tribal, and local officials, as we11 } \\
\text { as the interested public }\end{array}$ \\
\hline
\end{tabular}

$*$ If MRS is approved by Congress

* Initiative 1 designs will be reviewed prior to starting Initiative 3 


\begin{tabular}{|c|c|c|c|}
\hline $\begin{array}{c}\text { Time Frame } \\
\text { (Calendar } \\
\text { Years) }\end{array}$ & Technical Activities/Resources & Institutional Activities & Information Resources \\
\hline $\begin{array}{c}1992-95 \\
\text { (Cont inued) }\end{array}$ & $\begin{array}{l}\text { - Initiate fleet assembly } \\
\text { - Deliver start-up fleet } \\
\text { - Develop training programs for oper- } \\
\text { ating personnel } \\
\text { - operators } \\
\text { - inspectors } \\
\text { - maintenance } \\
\text { - security }\end{array}$ & $\begin{array}{l}\text { - Continue evaluation of regulatory con- } \\
\text { cerns: coordinate with network on } \\
\text { State, Tribal, and local ordinances, } \\
\text { cooperative efforts for inspection and } \\
\text { enforcement, etc. }\end{array}$ & $\begin{array}{l}\text { - Conduct route-related public } \\
\text { information activities. } \\
\text { - Conduct public information programs } \\
\text { that include: } \\
\text { - cask demonstrations } \\
\text { - cost/risk analyses using route- } \\
\text { - specific detail constraints } \\
\text { - safety/environmental analyses } \\
\text { using route-specific constraints }\end{array}$ \\
\hline $\begin{array}{c}1996- \\
\text { Program End }\end{array}$ & $\begin{array}{l}\text { - Oversee shipment operations } \\
\text { - procurement } \\
\text { - personnel training } \\
\text { - maintenance } \\
\text { - transport operations } \\
\text { - traffic management } \\
\text { - Conduct future development and } \\
\text { improvement studies }\end{array}$ & $\begin{array}{l}\text { - Maintain network contacts; identify } \\
\text { issues; monitor program activities; } \\
\text { plan improvements, incorporating new } \\
\text { developments. Conduct Federal/State } \\
\text { inspection program, emergency response, } \\
\text { etc. }\end{array}$ & $\begin{array}{l}\text { - Revise Transportation Plan } \\
\text { - Continue public information pro- } \\
\text { grams with utility participation in } \\
\text { localized route-specific forums } \\
\text { - Conduct workshops for network partici- } \\
\text { pants on new developments }\end{array}$ \\
\hline
\end{tabular}

*If MRS is approved by Congress. 
Chapter 2

THE COMMUNICATION NETWORK

\subsection{Overview}

This chapter describes the composition of a transportation communication network whose members will participate in establishing the system for shipping waste under the provisions of the NWPA. The OCRWM has identified six major categories or group units that constitute the communication network. These categories are (1) Federal, State, Tribal, and local governments; (2) the electric utilities; (3) the transportation industry; (4) special interest groups; (5) the media; and (6) the public at large. It is important that the OCRWM interact with all groups to better understand their positions and interests. It is also important that the groups interact with each other in order to gain appreciation of the differing viewpoints. The OCRWM seeks to serve as a catalyst in facilitating compromise and fostering cooperative effort in securing public and private sector understanding and support for the transportation program.

\subsection{Government}

The transportation of radioactive waste is a responsibility shared by several Federal agencies, as provided for in the NWPA and other Federal statutes. In addition, State, Tribal, and local governments have authorities and obligations in regulating the transport of the waste. The Federal perspective is necessarily one of ensuring a transportation system that protects the welfare of the Nation as a whole. The States, Tribes, and localities have responsibilities of a more regional or local nature that affect their positions. The challenge in working together is to strike a responsible balance in ensuring a national system that is safe, consistent, and equitable while fully respecting regional and local interests and requirements.

\subsubsection{The Department of Energy}

The NWPA assigned to the DOE the primary responsibility for the development and operation of a national system for the management and disposal of spent fuel and high-level radioactive waste and created the OCRWM to carry out the associated program functions. Certain provisions of the NWPA direct and control the OCRWM's transportation strategy. These provisions require the OCRWM to--

- Accept commercial spent fuel at the reactor site or point of origin for transport to a repository or intermediate storage facility. Under this provision, the OCRWM is the "shipper of record."

- Use the private sector "to the maximum extent possible" in establishing and operating the transportation system.

- Seek to enter into written consultation and cooperation agreements (that may contain provisions applicable to transportation) with potential repository and MRS host States and affected Indian Tribes. 
The OCRWM organization is illustrated in Figure 5. Within the OCRWM, the office of Storage and Transportation Systems (OSTS) is responsible for the transportation activities of the program. These responsibilities include the development and implementation of the Transportation Business Plan, this Plan, and, ultimately, the comprehensive Transportation Plan, which will encompass the business, institutional, and operational planning elements for the NWPA transportation system. The principal objective of the OSTS is to ensure that transportation activities are performed in a safe, secure, and cost-effective manner, in accordance with all applicable laws and regulations, and in a way that fosters public understanding and acceptance of program goals. Utilizing the systems integration approach that underlies all OCRWM program planning, the OSTS coordinates activities with the OCRWM's Office of Geologic Repositories (OGR), the office of Resource Management, and the Office of Policy and Outreach (OPO) to ensure that program schedules and other required interfaces are accommodated.

The DOE's Chicago Operations office $(\mathrm{CH} / \mathrm{O})$ has been designated the lead support organization for OSTS institutional activities related to transportation. The primary responsibility of the $\mathrm{CH} / \mathrm{O}$ is to implement the transportation program developed by the OSTS in Washington and to manage the projects related to addressing and resolving transportation issues. Interactions related to contractual arrangements will be directed to $\mathrm{CH} / 0$ while broad policy planning interactions will remain with the OSTS. In addition, the Idaho Operations office is responsible for development of transportation casks and related equipment, and the Oak Ridge Operations office is examining and evaluating long-range options for operating the transportation system.

Because of the requirement to integrate overall OCRWM activities, the OSTS will work with the repository project offices* in support of initiation and maintenance of contacts with the potential host States and affected Tribes in their respective areas. This $\mathrm{Plan}$ recognizes the lead role that the potential host States--Nevada, Texas, and Washington--and the affected Indian Tribes--the Nez Perce, the Umatilla, and the Yakima--will play in identifying and resolving issues. Transportation-related liaison with the project offices will be coordinated through the OGR. In the event of the approval of an MRS facility and site by Congress, the project office in the host state will have lead responsibility for local interactions. Liaison will be coordinated with the OCRWM Storage Division. The experience of the project offices in relating to the residents in their areas, including an awareness of regional interests and sensitivities, makes them uniquely valuable to the development of interaction strategies.

* The Basalt Waste Isolation Project (BWIP) in Richland, Washington; the Nevada Nuclear Waste Storage Investigations (NNWSI) in Las Vegas, Nevada; and the Salt Repository Project Office (SRPO) in Columbus, Ohio. In light of the decision to postpone indefinitely site-specific activities for a second repository, interaction with the Repository Technology Program (formerly the Crystalline Repository Project Office) in Chicago, Illinois, will focus on technical studies that are not site-specific. 


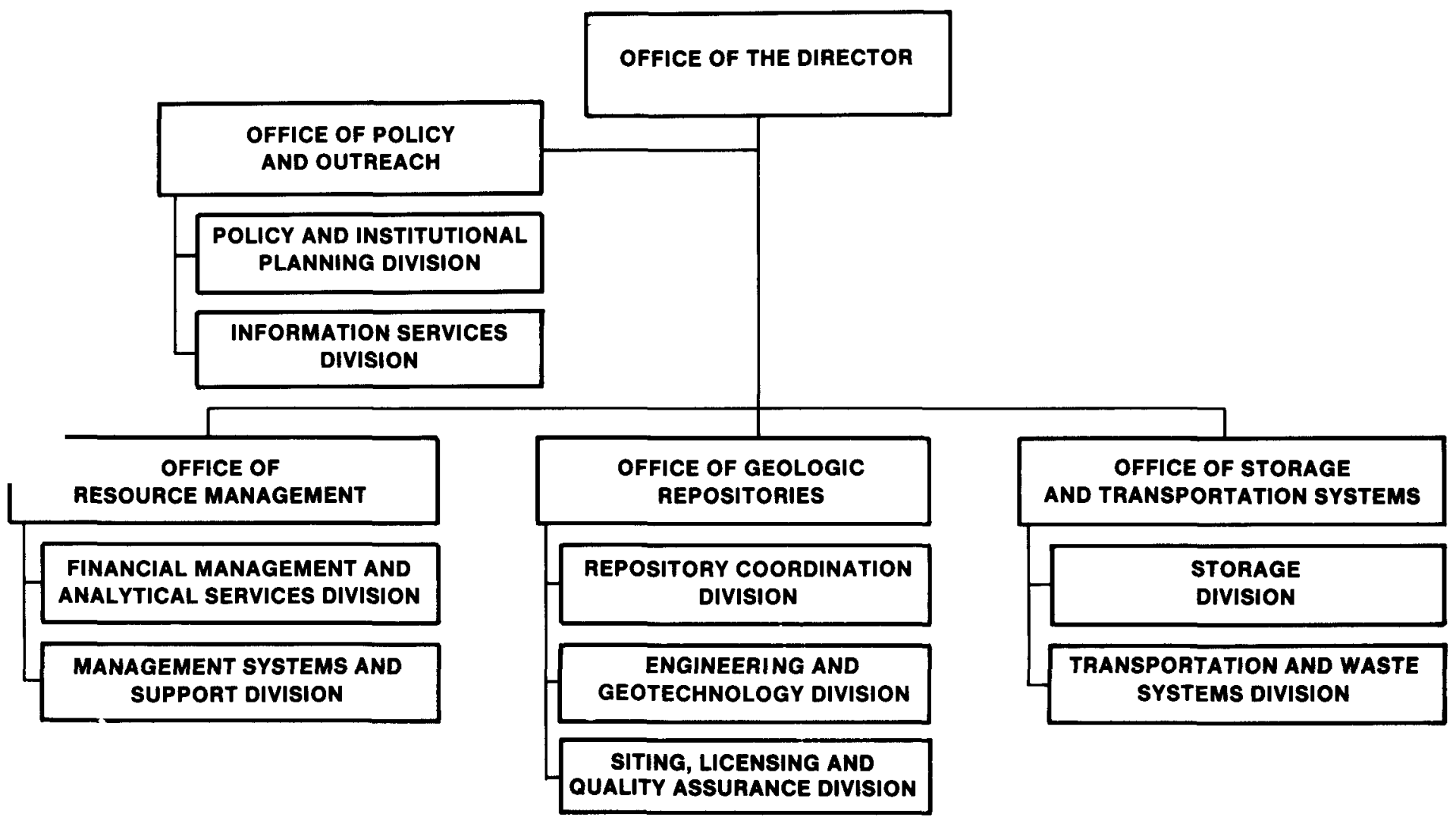

Figure 5. OCRWM organization. 
For interactions more specifically directed to the repository program, the OGR has developed Guidelines for Intergovernmental and Public Participation Activities. That document provides guidance for informing and involving States, Indian Tribes, local governments, and the general public throughout the four phases of the repository program, i.e., prenotification, notification/nomination of potentially acceptable sites, site characterization, and construction. OCRWM Public Information Guidelines* provide principles for implementation of NWPA and Mission Plan requirements related to the provisions of accurate and objective public information.

The existing DOE transportation programs for shipping noncommercial nuclear materials are centralized under the direction of the Assistant Secretary for Defense Programs. This DOE transportation capability provides a source of expertise for operations, policy and procedures, cask certification, and research and development. The OCRWM will build on this foundation, taking the additional NWPA requirements and considerations into account. While the two programs, which derive from separate legislative authorities, have different responsibilities and missions, each organization is committed to work together to ensure that all decisions and activities are in the DOE's overall best interests. Certain program activities will be integrated (e.g., safety and base technology development); other segments will be distinct.

Other Federal agencies also have responsibilities in the transportation of spent fuel and high-level radioactive waste. The responsibilities of these agencies and the roles of State governments, Indian Tribal governments, local governments, and intergovernmental organizations are described below.

\subsubsection{Other Federal Agencies}

The OCRWM's successful implementation of the transportation system will depend, in large measure, on coordination of the transportation activities with appropriate Federal agencies and conscientious compliance with the pertinent regulations and orders promulgated by these agencies. Because of the Federal responsibility to protect the general welfare of citizens, hazardous waste transportation--and particularly radioactive waste transportation--is intensely regulated. The DOE, the NRC, and the DOT are the major Federal agencies involved in the transportation of radioactive materials. For NWPA shipments, the DOE/OCRWM is the shipper of record and the NRC and the DOT are the primary regulating agencies.

The OCRWM will interact on a regular basis with the NRC, the DOT, the FEMA, and others as appropriate. The purpose of these interactions is to coordinate with these agencies and to ensure that all applicable regulatory requirements are met. In addition, if studies and experience show that a particular regulation or standard should be either more stringent or more moderate, the OCRWM, in coordination with other DOE transportation programs, will work with the agency of authority to try to effect the indicated modification.

* Public Information Guidelines, DOE/RW-0089, June 1986. 
Interdepartmental interactions may also be guided by memoranda of understanding (MOU) or other formal agreements between or among the involved Federal agencies. In 1979, the DOT and the NRC entered into an MOU to outline their respective areas of primary regulatory jurisdiction over the transportation of commercial radioactive materials. Briefly, the DOT is responsible for regulating safety in the transportation of all hazardous materials. In addition, the NWPA invests in the secretary of Transportation the authority to determine, in consultation with the Secretary of Energy, whether private industry is able and willing to provide transportation services to facilities developed under the NWPA at reasonable cost, and, if industry is unwilling and unable, to direct Federal services for such transportation. The safeguard aspects of transportation operations are regulated by the NRC. The NRC is also responsible for the regulation of the packaging that is used by NRC 1 icensees to transport spent nuclear fuel.

A procedural agreement between the DOE and the NRC has been established whereby the OCRWM will use NRC-certified packaging for waste shipments from NRC-1icensed facilities to NWPA facilities. In addition, an MOU has been developed between the DOE and the DOT that relates to the exchange of information.

The OCRWM will also interact with other Federal agencies regarding technical information exchange, operations planning, and institutional concerns. The Project Decision Schedule notes formal action required by other Federal agencies in the development of the OCRWM system.*

Appendix $B$ reviews the statutory roles and responsibilities of the major Federal agencies with whom the OCRWM will interact. Appendix $C$ summarizes the agreements under which the interactions are conducted.

\subsubsection{State Governments}

The NWPA states that the Secretary of Energy must seek to enter into written consultation and cooperation agreements with potential repository and MRS host States and affected Indian Tribes. Those agreements will cover all OCRWM program activities, including transportation. Such agreements serve as negotiating instruments, initiating an official means of dialogue between the OCRWM and the States or Tribes during preliminary or final site selection, and may include a financial assistance agreement.

As required by the NWPA, the Secretary of Energy nominated five sites as candidates for the first geologic repository and recommended three of them to the President for site characterization. On May 28, 1986, the DOE announced that the President had approved three recommended sites. These sites are Yucca Mountain in Nevada (in tuff host rock), Deaf Smith County in Texas (in salt), and Hanford in Washington (in basalt). The selection was based on the development and public review of extensive geologic and environmental data gained from site studies which began before enactment of the NWPA and on the

* Project Decision Schedule, DOE/RW-0067, March 1986. 
information contained in the repository environmental assessments.* The OCRWM has established contact with the States having candidate sites, and the States have, in turn, appointed or designated key representative offices (see Appendix D). Concurrently with the announced selection of the three candidate sites for a first repository, the DOE announced the indefinite postponement of site-specific work for a second repository.

With respect to the MRS program, the OCRWM is working closely with officials of the State of Tennessee, where three potential sites for the MRS facility have been identified. Interactions at this stage center chiefly on provision of information to support state and local evaluation of and participation in OCRWM planning. Should Congress approve an MRS facility, interaction with the host and adjacent States will become more focused.

Although the NWPA only addresses interactions with States directly affected by repository siting programs, it is the intent of the OCRWM to interact with all States through whose jurisdictions NWPA shipments will transit. The OCRWM will encourage states to establish a point of contact within the State to interact with the OCRWM on transportation matters relating to the OCRWM program. The representative could communicate directly with the OCRWM to provide information on State concerns and issues and, in turn, would be responsible for keeping appropriate State officials informed on OCRWM programmatic matters. In some instances, the OCRWM will also seek direct contact with individuals having specialized transportation expertise within the State governments.

The OCRWM is working with the States to develop a transportation system that engenders confidence that public health and safety will be protected. In pursuit of this objective, States are being provided access to planning procedures regarding waste transportation to a repository. The areas of major concern to the states will be addressed, and opportunity will be allowed for the States to communicate with the OCRWM and to participate in program development. In this manner, the OCRWM hopes to eliminate or lessen the underlying concerns of State and local authorities. (See Appendix D for existing State contacts.)

\subsubsection{Tribal Governments}

Indian Tribes (Nations) occupy a unique position in the governmental structure. The NWPA acknowledges the sovereign status of Indian Tribes and outlines a clear role for Tribal governments that is similar to but distinct from the role for State governments. It reinforces the government-togovernment relationship between the Federal Government and the Tribes, reaffirmed by President Reagan in his January 1983 Indian Policy Statement.

* Environmental Assessment, DOE/RW-0069, DOE/RW-0070, DOE/RW-0071, DOE/RW0072 , and DOE/RW-0073, May 1986. 
The NWPA specifies that affected Indian Tribes, along with the potential host States for the repository, be involved in the planning process. The NWPA states that the Secretary of Energy must seek to enter into written consultation and cooperation agreements with the governing body of an affected Indian Tribe when a Tribe requests or, in any event, when a Tribe is affected by the approval of a site for characterization. This agreement serves as a negotiating instrument, initiating an official means of dialogue between the OCRWM and the Tribe during preliminary and final site selection, and may include a financial assistance agreement.

To date three Tribes--the Yakima Tribe, the Nez Perce Tribe, and the Umatilla Tribe--have been identified as having "affected" status with regard to establishment of a repository.

The OCRWM will work with the affected Tribes and organizations representing Tribal interests to develop a transportation system that engenders confidence that the public health and safety will be protected. In pursuit of this objective, Tribes are being provided access to planning procedures regarding waste transportation to a repository. The areas of major concern to the Tribes will be addressed and opportunity will be provided for the Tribes to communicate with the OCRWM and to participate in program development. In this manner, the OCRWM hopes to eliminate or lessen the underlying concerns of affected Tribes. (See Appendix D for existing Tribal contacts.)

The OCRWM recognizes that there may be cultural, religious, and legal considerations unique to Indian Tribes and is committed to maintaining an open and continuing dialogue to ensure that Tribal interests and concerns are addressed and considered.

\subsubsection{Local Governments}

The transportation of radioactive waste to facilities developed under the NWPA will concern communities throughout the nation. The OCRWM seeks to establish relations with local governments and will provide community and local officials with accurate and understandable transportation information. In turn, the OCRWM recognizes that local officials are uniquely qualified to provide information on transportation conditions and impacts within their areas of jurisdiction and, accordingly, are important participants in developing procedures for the transportation system. In planning for safe and secure shipping operations and emergency response capability, the OCRWM will cooperate with the FEMA and the DOT in arranging for any necessary training and technical support to local fire, police, and emergency agencies that have primary responsibility for responding to transportation accidents that are related to NWPA shipments. Interactions with local governments will be both through designated State 1 iaison representatives and directly, as particular transportation issues or situations indicate. Direct contact will occur at workshops, public meetings, and through exchange of correspondence.

At present, most of the OCRWM's interactions with local governments are limited to the vicinity of the potentially acceptable sites. To direct these 
more localized activities, the OCRWM has developed guidelines for local interactions.* As the siting process narrows, OCRWM/local government interaction related to transportation issues will become both more focused and more intensive. The primary OCRWM points of contact for local governments will be the repository project offices and the MRS project office if an MRS facility is approved by Congress.

\subsubsection{Intergovernmental Organizations}

Intergovernmental organizations may include State, Tribal, or local officials with the same or similar responsibilities. While not a substitute for direct contact with the State, Tribal, or local governments, working with such groups has the benefit of reaching significantly larger constituencies than would otherwise be possible.

The OCRWM will build on existing arrangements or establish arrangements with State, Tribal, and local groups for the purpose of studying transportation issues from a regional perspective, facilitating interaction among network participants, and developing potential options for issue resolution for OCRWM use in policy development. These groups could also serve as the organizing instruments for regional workshops and meetings.

\subsection{The Electric Utilities}

The waste acceptance contracts negotiated by the DOE and the utilities stipulate that the DOE will take title to the spent fuel at the reactor site in return for a specified fee. Because more than 100 reactors will be involved, the technical interfaces between reactors of different designs and the shipping casks and related equipment that the OCRWM plans to develop will necessitate substantial utility interactions during the cask design phases with both the OCRWM and the engineers and technicians of the transportation industry. Utility interactions with State, Tribal, and local governments as well as special interest groups and the public at large are important in the task of providing information. The well-developed public information techniques and programs of the utilities could be most effective in the area of public education.

Utilities have a strong interest in the activities associated with developing and operating the waste transportation system, including the OCRWM's schedules for receiving the fuel; developing casks; planning for transportation operations; establishing cask-handling procedures; integrating transportation service with existing facilities at the plant site; and coordinating with State, Tribal, and local transportation interests.

* Internal Guidelines for Interactions with Communities and Local Governments, $\mathrm{DOE} / \mathrm{RW}-0039$, November 1985. 
To coordinate utility involvement, the Electric Utility Companies' Nuclear Transportation Group currently serves as the utilities' primary contact for interaction with the communication network regarding development of the NWPA transportation system. The group represents investor-owned and publicly-owned electric utilities responsible for the construction or operation of most of the nuclear power plants in the United States.

\subsection{Transportation Industry}

The NWPA directs the DOE to "... utilize by contract private industry to the fullest extent possible in each aspect of such transportation." In effect, selected contractors will be responsible for completing all tasks needed to design and manufacture the required shipping casks and to ship the waste from generators to facilities developed pursuant to the NWPA. It should be emphasized, however, that the OCRWM, through quality assurance and quality control programs and other mechanisms, will maintain continuous oversight of development and operation of the transportation system to ensure that it will be safe, economical, timely, publicly acceptable, and in full compliance with the applicable regulatory requirements.

Two major industry elements will be involved in development of the transportation system: (1) cask designers and manufacturers; and (2) carriers and transportation service contractors. Primary functions of cask designers and manufacturers will include cask design and engineering, prototype fabrication, and cask fleet fabrication. Interest from this group centers on the OCRWM's role in cask development and procurement, public input to cask design criteria, cask certification requirements, cask prototype fabrication, cask testing, cask procurement, the use of dual-purpose casks, and the use of existing casks.

Service contractor functions will include procurement of casks for a transport fleet, provision of carriage, maintenance of equipment, inspection of equipment and operations, and training of all operating personnel. The Transportation Business Plan specifies that all service guidelines and specifications will be developed by the OCRWM for implementation by its contractors. The OCRWM will consider the possibility of regional service contractors or multiple individual contractors as an alternative to the use of a single national comprehensive service contractor.

The OCRWM will require that operational safety training be conducted by service contractors, following OCRWM-established standards. Through its quality assurance and quality control program, the OCRWM will verify compliance with training requirements. The OCRWM will also address program needs regarding the training of drivers, maintenance and service mechanics, inspectors, and security personnel. Transportation procedures will be developed in close consultation with representatives of the carrier industries. As rail lines are generally privately owned and maintained, the OCRWM recognizes the special need to work with railroad companies and organizations to address unique issues associated with rail carriers. 
The Transportation Business Plan describes more precisely the interactions between the OCRWM and its industry contractors. These business interactions will follow established Federal and DOE procurement regulations.

\subsection{Special Interest Groups}

A number of special interest groups may wish to be involved in the cooperative effort to establish the NWPA transportation system. Such groups include local and national organizations of transportation-related professionals, local and national environmental organizations, local and national civic and citizen groups, consumer organizations, local and national chambers of commerce and many others.

The OCRWM views this category of the communication network as an important element in program planning and in addressing the transportation issues. Accordingly, special interest organizations--particularly those having transportation expertise--may be contracted with to study the issues and to develop procedures and mechanisms for answering questions and for resolving concerns.

In addition to these OCRWM-initiated activities, special interest organizations are invited to indicate their interest in receiving program information or to comment on program plans by corresponding directly with the OCRWM.

\subsection{The Media}

The media are important channels of communication between the OCRWM program and the general public. Of all the various approaches to disseminating information, the media can provide the most current information to the greatest numbers of people in the shortest time.

Interaction with members of the media will be in accordance with current OCRWM policy and will normally be handled by the OPO or, locally, by the project offices. To reinforce transmission of accurate information to media audiences, the OCRWM will establish media information programs and provide opportunities for media observance of program activities.

\subsection{Pub1ic at Large}

Implementation of the transportation program would be enhanced by a well informed public along the routes over which the waste will be transported. It is anticipated that many citizens will be interested in OCRWM program activities, both for assurances about safety and, as electricity consumers, for evidence that the revenues collected through fees for waste management and disposal are being spent wisely.

Through effective interaction, the concerns and interests of the public can be identified and activities initiated to address all significant issues. In addition to the program activities designed to facilitate interaction with the other elements of the transportation communication network, the OCRWM is developing a number of initiatives to encourage and stimulate informed participation by the interested public at large. These initiatives, consistent with overall OCRWM program goals, include: 
- Maintaining an efficient system for responding to information requests and to other correspondence that deals with transportation matters.

- Conducting meetings and briefings for interested civic groups and other public assemblies wherein information is exchanged.

- Developing educational resources concerning nuclear waste transportation and establishing effective mechanisms for dissemination.

- Ensuring that adequate, objective transportation information is included in community information offices. Such offices have already been established in some of the areas under consideration for a repository. In addition to program information and plans for interaction, these offices will identify OCRWM staff contacts for more detailed transportation information.

- Using the OCRWM Bulletin and other resources, including the OCRWM Electronic Bulletin Board (INFOLINK), to impart transportation news and information to the interested public.

The public is encouraged to note and use the contact points that have been established by the OCRWM to facilitate the flow of transportation information. Contact addresses and telephone numbers are provided in Chapter 3 and in Appendix D. 
Chapter 3

NETWORK INTERACTIONS

\subsection{Overview}

The OCRWM recognizes that active participation by members of the network (delineated in Chapter 2) is an important programmatic ingredient if the transportation functions supporting the NWPA program are to be carried out successfully. The interaction between the OCRWM and the other members of the network will generally fall into three categories:

- Information exchange.

- Involvement in the planning process.

- Management of specific issues.

The following discussion delineates how the OCRWM will foster network interaction in all aspects of program development.

\subsection{Exchange of Information}

As stated in the Mission Plan and OCRWM's Public Information Guidelines, it is the policy of the OCRWM to provide for full, open, and timely sharing of both general information and technical data and to ensure that accurate, understandable information about the NWPA program is communicated to interested parties. Effective public information activities are expected to encourage requests for information. The OCRWM will facilitate public accessibility to program information to the fullest extent possible recognizing certain limits established by the Privacy Act of 1974 (5 U.S.C. $552 a)$ and other applicable statutes.

Not only must the OCRWM provide information to the members of the network to ensure that they understand what is happening in the program, but also the OCRWM must be able to receive information from the network that will aid in solving technical and institutional problems. The active exchange of information among all parties interested in waste transportation is a basic ingredient in obtaining public understanding of waste management goals. It is also important to the development and operation of a safe and efficient transportation system.

Accordingly, the OCRWM will develop the necessary transportation informational resources and establish interactive mechanisms and procedures through which the information will be exchanged. The discussion that follows reviews general aspects of information collection, the subsequent development of information resources on transportation topics, the dissemination of information, and mechanisms intended to promote network members' provision of information to the OCRWM. 


\subsubsection{Information Collection}

Prior to the development and dissemination of informational resources, several activities must take place. The activities include:

- Identifying and anticipating institutional interests and concerns that require provision of information.

- Identifying intended audiences.

- Determining the potential involvement of interested groups in developing needed information.

- Identifying existing informational material that can be of use with minor updating and revision.

- Determining what resources need to be developed and in what order of priority.

The OCRWM is collecting and analyzing information on a wide range of transportation subjects and interests. The resulting information base will provide the raw materials for resource development.

Major categories of public interest (defined to date) for which information resources are required include the following:

- Information on other OCRWM programs that will affect transportation, such as facility descriptions and waste-acceptance schedules.

- History of nuclear materials transportation.

- Transportation information (both generic and specific to the OCRWM program), such as the regulations that govern waste shipments; identification of responsibilities (shipper, carrier, regulator, cask developer, etc.); and cask development and testing.

- Risk assessments and accident liability information.

\subsubsection{Development of Resources}

The OCRWM will develop transportation information resources consistent with the goals and policies of the overall program. These resources will cover several broad categories, including--

- Written material, such as pamphlets, brochures, fact sheets, program reports, and press releases to satisfy the information needs of many varied audiences (e.g., Congressional staffs, State legislatures, Tribal councils, business concerns, etc.).

- Visual aids, including films, slide presentations, exhibits, video tapes and demonstrations. 
- Transportation speakers who possess a thorough awareness of transportation policies and programs.

- Computer data bases. Models and data bases can be made available for independent analysis in areas such as routing and risk assessment.

- Technical reports. The OCRWM will make these reports available for all interested parties.

- Operational planning documents. These documents will also be made available to States, Tribes, localities, utilities, and other interested parties as an aid to their planning.

Schedules for developing these resources will reflect the various phases of the transportation program. For example, in the early stages of the program, the emphasis will be on production of generic transportation materials to reinforce public knowledge of transportation requirements and procedures. Following development of casks and announcement of cask fleet procurement awards, material will be generated to acquaint the public with the features of selected cask designs and transportation operational procedures.

\subsubsection{Information Dissemination by the OCRWM}

The resources developed will be used in a variety of complementary ways to inform the public and to provide for fuller participation by the communication network. In some cases, the information resources provided will be the first step in establishing dialogue between the OCRWM and special interest groups and the public at large. For this reason, timeliness and provision of appropriate information are critical to the success of the network operations. The use of the OCRWM INFOLINK system will aid in this process. INFOLINK is an on-line electronic bulletin board introduced by the OCRWM to provide quick and ready access to current information about the overall program.

Speakers on transportation issues will provide information to the public through conferences and meetings, seminars, workshops, press briefings, and Congressional or public hearings.

The OCRWM will give particular emphasis to routinely providing the media with background information and announcements of upcoming events and decisions. Another potential area of communication being evaluated is to provide educational resources to schools and universities.

Material will be produced and disseminated to the transportation business community regarding such areas of business interests as requirements for cask and equipment development and transportation services. Details of these business-related activities are provided in the Transportation Business Plan.

Information is also being developed on specific transportation issues. For issue discussions that affect many of the groups within the communication network, see Appendix A. 


\subsubsection{Provision of Information to the OCRWM}

As stated previously, the OCRWM needs information from the network to assist in the tasks of developing and operating a safe, efficient transportation system. It is anticipated that workshops, public hearings, and comments (both written and oral) on planning and policy documents will provide important opportunities for the OCRWM to receive the required information. In addition, members of the network are urged to initiate communication of their ideas, suggestions, concerns, or needs for information to the OCRWM at any time. It is the goal of the OCRWM to share information provided by interested parties (recognizing limits established by applicable statutes).

\subsubsection{Coordination of Activities}

To ensure consistency and to avoid duplication of effort, the OCRWM will coordinate public information policies and implementation plans with other OCRWM program elements, other DOE transportation programs, the regulatory agencies, and other elements of the communication network external to the OCRWM.

Identification of available capabilities most appropriate to develop and disseminate information to the public is an early and integral task of program implementation. For example, the regional expertise of a repository project office may qualify it as the most likely producer of information on facility/ transportation interfaces. In addition, the repository project offices are the logical source of information concerning transportation operations and impacts within a potential host State. The coordination activities of the OCRWM and its contractors will ensure that the most appropriate and efficient means are chosen. Network participation during these planning stages will further define the resources that will be useful and desirable.

\subsection{Involvement in the Planning Process}

Planning for development and operation of the transportation system is a complex, long-term effort that will involve many different parties. The degree of, and mechanisms for, involvement by these parties in the planning process will vary, depending on such factors as the nature of the task being planned and the party having ultimate responsibility for decisionmaking. Some examples of involvement mechanisms are provided below.

\subsubsection{Example 1. Development of Transportation Operational Procedures}

This is clearly a task for which the OCRWM is responsible. The interested parties include (but are not 1 imited to) States and localities, Tribes, the utilities whose waste is being shipped, the transportation industry, Federal agencies responsible for regulating such transport, and the OCRWM. The OCRWM, using input from the network, will develop preliminary operational procedures which will be included as part of the comprehensive transportation plan (to be published in draft form in 1987). The comprehensive plan would be revised periodically as the transportation system develops to reflect changing requirements, actual experience, and suggestions from the network. 


\subsubsection{Example 2. Selection of Alternative Highway Routes}

The DOT regulation HM-164 requires highway route-controlled quantities of radioactive materials to be transported on Interstate highways unless alternative routes are designated by the States and Tribes through whose jurisdictions the shipments will pass. The designation of alternative routes is of interest to the OCRWM, the DOT, the NRC, the utilities, the transportation industry, and affected local communities. The States or Tribes may study and select the alternative routes in consultation with all affected jurisdictions and provide this information to the OCRWM and others. If requested by the State or Indian Tribe, the OCRWM will assist in the selection process by providing technical services such as routing analysis codes. After review of the alternative route selections to determine their impact on the waste transportation mission and their consistency with Federal regulations, the OCRWM will provide them to the service contractor for use in planning shipping campaigns.

\subsubsection{Example 3. Development of a Uniform Nationwide} System of Waste Shipment Inspections

Ensuring the safety of radioactive waste transportation is the joint responsibility of Federal agencies and State and Tribal governments. A uniform inspection system of the transport vehicle and load that would be reciprocally accepted by the States and Tribes being traversed would enhance safety and increase efficiency by reducing the need for redundant inspections. It is currently projected that a proposal for this system will be developed by a national organization whose members have expertise in transportation safety and inspections. The uniform inspection system would be developed with input from interested States and Tribes. The OCRWM will present the proposed system to the States and Tribes, probably by means of regional workshops, with the goal of gaining support for its implementation. The decision whether to implement the uniform, reciprocal inspection system is a shared decision among States, Tribes, and the OCRWM.

\subsection{Management of Specific Issues}

Consistent with the planning principles discussed in Chapter 1, the OCRWM (in cooperation with interested parties) is working to resolve transportation issues in a manner that attempts to be responsive to State, Tribal, and local interests; which fosters responsible management of the transportation program and Nuclear Waste Fund expenditures; and which fulfills the DOE's contractual obligations to the electric utilities. Such a process requires the judicious weighing of interests in order to achieve satisfactory issue resolution.

In an effort to foster a climate conducive to the identification and resolution of transportation issues, the OCRWM has initiated a dialogue with a wide range of parties having an interest in waste transportation. These interactions have led to the identification of numerous issues related to the safety, security, procedural, operational, and financial implications of radioactive waste transportation. To promote public participation in the review and evaluation of various transportation options and to assist in information dissemination, the OCRWM initiated (in November 1984) a series of transportation discussion papers. The development of those papers, and their 
release for public comment, represented preliminary efforts of the OCRWM to identify and discuss transportation institutional issues. Appendix $A$ of this document provides the latest iteration of these discussion papers on the transportation issues. These papers (both revised and initial discussions) reflect many comments that the OCRWM has received from the network over the past two years. Mechanisms for continued issue identification and a framework for addressing and resolving issues are described in this chapter.

In general, an issue resolution process is designed to account for the wide variation in the nature and substance of transportation issues, and the diverse and often divergent views of interested parties. The process will also provide the flexibility to accommodate the fact that not all issues will follow the same critical path through issue resolution to implementation of policies and procedures. Finally, it is important to note that conflict is not an inevitable by-product of issue resolution. If the issue resolution processes are appropriately designed and are responsive to the needs of the OCRWM and other interested parties, issue resolution and closure will be facilitated and conflict minimized.

\subsubsection{Issue Identification}

Issues related to the transportation of spent fuel and high-level waste are being identified by the OCRWM through--

- Participation in meetings, briefings, and workshops.

- OCRWM review of current transportation developments.

- Submission of comments (written and oral) from interested parties to the OCRWM.

Through such activities and subsequent entry of pertinent information into the issues management system described in Section 3.4.2, the OCRWM wil1 increase its ability to anticipate, identify, and discuss transportation issues.

3.4.1.1 Meetings, Briefings, and Workshops. Transportation issues related to the waste management program may be raised at briefings and meetings involving the OCRWM and interested parties. In order to formally identify issues raised at such meetings and advise or notify all interested parties of those issues, the OCRWM will review transportation developments and issues in the OCRWM Bulletin. The OCRWM Bulletin is published by the office of Policy and Outreach approximately monthly. Interested parties can be added to the mailing 1 ist for receiving the Bulletin by contacting:

Office of Policy and Outreach

Office of Civilian Radioactive Waste Management, RW-43

U.S. Department of Energy

1000 Independence Avenue, S.W.

Washington, D.C. 20585

In addition to meetings and briefings, the OCRWM or its contractors will hold regional transportation workshops. The workshops will be designed to 
facilitate ongoing two-way communication between the OCRWM and all interested parties and will be conducted specifically for the purpose of identifying and defining transportation issues, clarifying OCRWM policy options, setting a time frame for OCRWM policy decisions, and resolving issues where possible. The workshops will be held as needed to focus on a given transportation issue or group of issues. In preparing for such workshops, the OCRWM will consult with other DOE program offices to ensure adequate coordination on transportation issues of common interest.

Notice of a workshop's date, location, and transportation issues of primary focus will be provided through letters of invitation and publication in the OCRWM Bulletin. Where broad interest and participation in a workshop are expected, notice of the workshop will be published in the Federal Register. In order to ensure that all interested parties are kept advised of the transportation issues discussed at such workshops, brief workshop summaries will also be published in the OCRWM Bulletin.

3.4.1.2 OCRWM Review of Current Transportation Developments. The OCRWM will continue to monitor current developments having an impact on waste transportation. Such developments may include:

- OCRWM activities in acquisition of the transportation system.

- Regulatory changes or actions at the Federal level.

- Court and Federal agency decisions, rulings, and orders.

- Proposed Federal legislation and Congressional activities.

- Electric utility and transportation industry activities that may affect waste transportation.

- Developments at the State, Tribal, or local levels that may affect waste transportation.

- Results of research and development and other studies that may affect transportation.

3.4.1.3 Submission of Public Comments. Public comment (either formal or informal) on OCRWM program documents is another mechanism for identifying issues. Frequently such response by interested parties is the instrument for initiating ongoing interactions to address the identified issues. Interactions between OCRWM and the host states and affected tribes allows the OCRWM to receive and discuss reactions to program activities that affect specific sites.

\subsubsection{Process for Addressing Transportation Issues}

The process of developing policies regarding transportation issues will depend on whether the DOE or some other Federal agency or State and Tribal government has the ultimate responsibility for decisionmaking regarding an issue. Where the DOE has this responsibility, transportation issues will be evaluated and addressed by the OCRWM through a flexible process that 
includes such strategies as the development of transportation discussion papers; workshops; contracts with national or regional organizations or with transportation-related organizations; and cooperative agreements or interactions with other Federal agencies and with State and Tribal governments.

Where another Federal agency has primary responsibility, the OCRWM will nonetheless work to ensure effective participation and representation of its interests. This objective may be accomplished by one or more of the following: participation in administrative review and comment procedures, reinforcement of Federal agency interactions through memoranda of understanding (MOU), rulemaking petitions, and petitions for exemption. Where State and Tribal governments have primary decisionmaking responsibility (as in highway route selection), the OCRWM will participate in issue resolution, consistent with the procedural requirements of the responsible agencies.

The OCRWM is currently developing a comprehensive issue management, analysis, and tracking system that will greatly facilitate the process of dealing with identified institutional issues that arise out of the transportation program. The transportation issue management system will be a computer-based process that focuses on four major components: (1) Issues and sub-issues organized in a logical framework; (2) Organization, as a frame of reference for identifying groups and organizations that have interests in issues; (3) Positions, as a way of understanding how groups and organizations stand on issues; and (4) Sources, as a bibliographic reference for the information that is abstracted in the management system.

Using these four system components, the transportation issue management system will be a useful tool for fostering a timely and effective issue resolution process. It will enable the OCRWM to enhance its interactions with all parties in the transportation area, and it will provide the capability for the ongoing monitoring and analysis of issues by keeping the most current information easily available.

3.4.2.1 Issue Discussion Papers. The process for addressing transportation issues will usually begin with the preparation and release for comment of transportation issue discussion papers. These discussion papers will be prepared in a standard format having the following elements:

- The background or an overview of the issue.

- A list of associated issue elements.

- A discussion of each issue element, including, where appropriate (and as planning continues), the following:

- OCRWM policy options, constraints to policy decisions (e.g., the need for related information or legal limits), elements of an issue that remain unresolved, and the predicted time frame for reaching an OCRWM policy decision.

- A description of the OCRWM's intended or anticipated role in the event that the DOE lacks authority to take a primary role in resolving an issue (e.g., the DOE may assume a reinforcing role by 
cooperating with other Federal, State, Tribal, or local agencies that are responsible for making a final decision on the issue or take no action).

- Opportunities for public involvement in the evaluation of OCRWM policy options.

Comment on these papers is invited as an impetus to continuing discussion among interested members of the communication network. The OCRWM will review and, where appropriate, revise its issue discussion papers in light of the comments received. It is the OCRWM's intention to revise the discussion papers as needed. See Appendix A for current discussions of 16 transportation issues and a preliminary schedule for issue resolution.

\subsubsection{Issue Resolution Mechanisms.}

Interaction at Transportation Workshops. As discussed above, regional transportation workshops will be sponsored by the OCRWM or its contractors in an effort to identify and discuss issues. In addition, the workshops are expected to assist the OCRWM in the development of transportation institutional policies.

Pursuit of Resolution Through Cooperative Effort. The OCRWM will initiate through the Chicago Operations Office contracts for the purpose of studying and resolving regional or specific transportation issues. These contracts will be with the national laboratories; organizations of State, Tribal, or local governments; regional organizations; and private-sector organizations of a transportation-related character.

Such contracts will require the contractor to consult and interact with parties having a particular expertise or interest in the issues being studied and to assimilate and evaluate the findings and recommendations. The intent is to permit an exchange of views and experience in order to gain maximum objectivity in issue analysis and equity in issue resolution. A resulting report will be provided to the OCRWM for consideration and evaluation of various policy options. Study group participation could be drawn from all six of the major categories of the communication network as identified in Chapter 2. Follow-on workshops could provide further opportunities for public participation in issue resolution.

The work product of all such contracts should provide a sound perspective on representative interests concerning the various transportation issues. The views and recommendations expressed will provide further input and balance to OCRWM decisionmaking. It should be emphasized, however, that these contractual relationships are designed to supplement and enhance direct OCRWM interaction with interested State, Tribal, and local governments or other network participants in efforts to work toward the resolution of identified issues.

Cooperation and Interaction with Other Federal Agencies. The OCRWM will strengthen its coordination with other Federal agencies (e.g., the DOT, the NRC, and the FEMA) having regulatory authority or responsibility that will affect the transportation of radioactive waste. Initial steps in this area 
have already been taken (and are discussed in Chapter 2). Continued coordination should allow the OCRWM to avoid the duplication of planning efforts and to identify and resolve, as early as possible, any regulatory issues or deficiencies that may impede waste transportation under provisions of the NWPA.

3.4.2.3 Procedures for Conflict Resolution. The OCRWM recognizes that the development of policy in important areas such as the transportation of radioactive waste is becoming increasingly more complicated, partly because of the increased participation of various organizations, groups, and individuals who have differing interests. This increases the likelihood that conflicts will arise over some issues, and that the issue resolution process may come to an impasse, impeding issue closure and policy decisionmaking. Given the importance of progress toward the goals set forth in the NWPA, the OCRWM will encourage approaches that reduce the likelihood of an impasse and that will help resolve conflicts if they do occur.

Avoiding Conflicts. The most effective way to formulate and implement the OCRWM's policies is to avoid conflicts to the extent that they can be avoided. The earlier sections of Chapter 3 have described the procedures that the OCRWM is considering in order to obtain the fullest participation of all interested parties. If concerns are identified and addressed at an early point in the process, it is more likely that they can be satisfactorily resolved before a serious conflict develops. The OCRWM is committed to cooperative and productive endeavor and will seek to resolve issues in a manner acceptable to the affected parties.

Resolving Conflicts. When transportation-related conflicts cannot be avoided, the OCRWM is committed to negotiating with affected parties to resolve problems. If not successful, there are formal techniques for conflict resolution that can be tried.

One technique is mediation, wherein a neutral third-party mediator facilitates but does not actually make a decision that resolves the conflict.* The goal of mediation is to arrive at a solution to the conflict that is acceptable to all of the parties involved. Mediation has several important advantages:

- It is applicable when many different parties are involved in a conflict.

- It has a record of successful resolution of complex, multiparty conflicts involving issues of national scope.

* In contrast to mediation, arbitration uses a neutral third party to help resolve issues and actually make a decision to resolve the conflict. Arbitration can be entered into voluntarily, and the parties involved may agree that the arbitrator's decision is binding on the parties and may be judicially imposed. Generally, the OCRWM does not envision entering into binding arbitration in order to resolve conflicts over policy issues. 
- It can be tailored to the specific type of conflict that must be resolved.

Settlement-oriented mediation is appropriate when an actual impasse has been reached. At this point, the relevant parties to the conflict have made themselves known by their earlier participation in the process, and the specific issues over which the parties are in dispute will have been clearly defined. Participation-oriented mediation, on the other hand, focuses on early involvement and education of participants in the planning effort. The early involvement of a mediator(s) helps ensure the identification and consideration of all alternative solutions to potential conflicts. The OCRWM is investigating a number of options in this category, including the character of the mediation process (OCRWM-program-wide or transportation specific); use of an individual mediator or a mediation board; and development of the process whereby mediation is initiated.

Finally, while it is the intent of the OCRWM to resolve issues without resorting to litigation, in some instances litigation may be the appropriate course of action for settling disputed issues.

3.4.2.4 Issue Closure and Policy Decision. Following consultation with all interested parties, a careful evaluation of the specific transportation issue involved, and, where appropriate, taking into consideration the results of the conflict resolution process, the OCRWM will announce a policy decision. Notice of the policy decision will be published in the OCRWM Bulletin or, under some conditions, in the Federal Register. The decision notice will include specific actions that the OCRWM will take to implement the decision. Such activities may include--

- OCRWM action, where the OCRWM has appropriate authority.

- Cooperation with other agencies, where such agencies have ultimate responsibility for activities or decisions.

After the resolution of specific transportation issues, the OCRWM may determine that direct action on the part of the DOE (consistent with the DOE's legal authority) is appropriate. Such actions may include--

- The development of new operating procedures, with the issuance of related orders.

- Recommendations to Congress for new legislation.

- Provision of technical or financial assistance.

Figure 6 is a schematic representation of the issue resolution process discussed in detail above.

\subsection{Support for Transportation Activities}

The NWPA defines two major types of potential financial assistance (made available from the Nuclear Waste Fund) related to establishing a national high-level waste management system: (1) assistance in support of participation in program development by those who are potentially affected by the 
ISSUE

IDENTIFICATION

AND DEFINITION

CONTROL AUTHORITY
PERIODIC

ADJUSTMENT OF TRANSPORTATION PLAN
ISSUE CLOSURE
CONFLICT RESOLUTION

IMPLEMENTATION

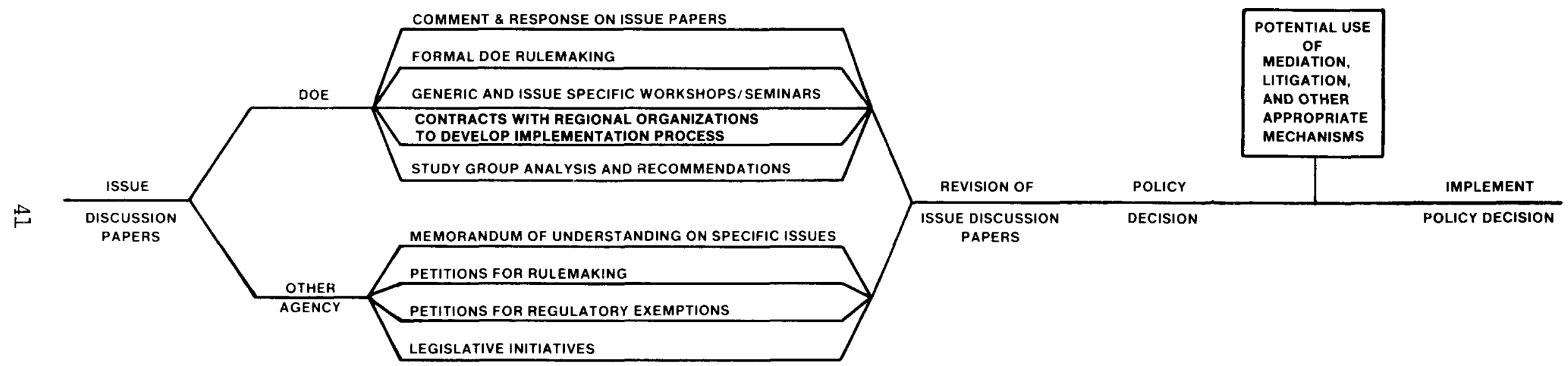

Figure 6. Issue resolution process 
siting of a repository and (2) assistance for the mitigation of impacts resulting from establishing and operating a repository, MRS facility, and test and evaluation facility (see Section 3.6). The NWPA defines those who are eligible for various types of financial assistance as--

- States - those States formally notified by the Secretary as having a potentially acceptable repository site, having a site authorized for characterization, or having a site authorized for repository construction, and States having potential sites for a test and evaluation facility.

- Affected Indian Tribes - any Indian Tribe (a) within whose reservation boundaries an MRS, test and evaluation facility, or a repository is proposed to be located or (b) whose federally defined possessory or usage rights to other lands outside the reservation boundaries arising out of congressionally ratified treaties may be substantially and adversely affected by the locating of such a facility, provided, that the Secretary of the Interior finds, upon the petition of the appropriate governmental officials of the Tribe, that such effects are both substantial and adverse to the Tribe.

- Local governments - those local governments within whose boundaries a repository, MRS facility, or test and evaluation facility may be constructed.

\subsubsection{Program Participation}

It is recognized that there is a distinction in the NWPA between host and potential host States and local governments, and affected Indian Tribes and other State, Tribal, and local governmental entities through which NWPA shipments will pass. The host and potential host states, related local governments and affected Tribes are specifically entitled to certain types of financial assistance while there is no specific reference to those other governmental entities affected only by transportation. In this early phase of transportation system development, the OCRWM will foster participation using the funding mechanisms discussed below.

1. Potential host States and affected Tribes. Potential repository or MRS host States/affected Tribes may use their grants to address transportation issues that have a bearing on the siting process. Additionally, for offsite transportation issues within a potential host state, the NWPA authorizes grants to the affected parties pursuant to written agreement with the DOE. Use of grants for this purpose will be in accordance with guidelines established by the OCRWM. An example of a funded activity would be the review of transportation planning documents as they relate to the siting of a waste management facility in the jurisdiction of a State or Tribe.

2. Interested parties other than potential host States and affected Tribes. Although there will be no direct grants for transportation activities by these parties, the OCRWM seeks to involve them in program planning. After examining a number of approaches, the OCRWM believes the most effective and equitable method of fostering program 
participation by transit state and Tribal entities is to use the regional and transportation-related organizations described in Sections 2.2 .6 and 2.5 to facilitate involvement. Under contractual arrangements with the OCRWM, these organizations can convene and provide financial reimbursement to the involved parties for their participation in cooperatively studying and working toward the resolution of transportation issues. This might include activities such as--

- Performing regional route analysis and assisting states in selecting preferred routes.

- Investigating the feasibility of regional emergency response programs.

- Recommending a nationwide standard inspection system for waste shipments.

Selection of contractors will be based on the capabilities that most nearly fulfill program requirements and will be in accordance with existing DOE procurement regulations.

3.5.2 Principles for Support of Participation

- Transportation activities supported must be both necessary and attributed solely to NWPA shipments.

- Participation will be cooperative and oriented toward activities that provide deliverables.

- Activities supported must facilitate safe and cost-effective transportation under the NWPA.

- Supported involvement will be proportional to the level of activity necessitated by the NWPA shipments.

- Program activities will be coordinated with other Federal, State, and local programs, and any payments from the Nuclear Waste Fund would be provided with full consideration of other available sources of assistance and funding (e.g., FEMA funding for emergency response training).

\subsection{Impact Mitigation}

Requests from host states and affected Tribes for funds to assist in the mitigation of transportation impacts, after the construction of a repository is authorized, will be administered by the OGR with input from the OSTS.

Similar requests for assistance to mitigate transportation impacts associated with the construction and operation of an MRS facility will be administered by the OSTS. 


\section{LIST OF ACRONYMS}

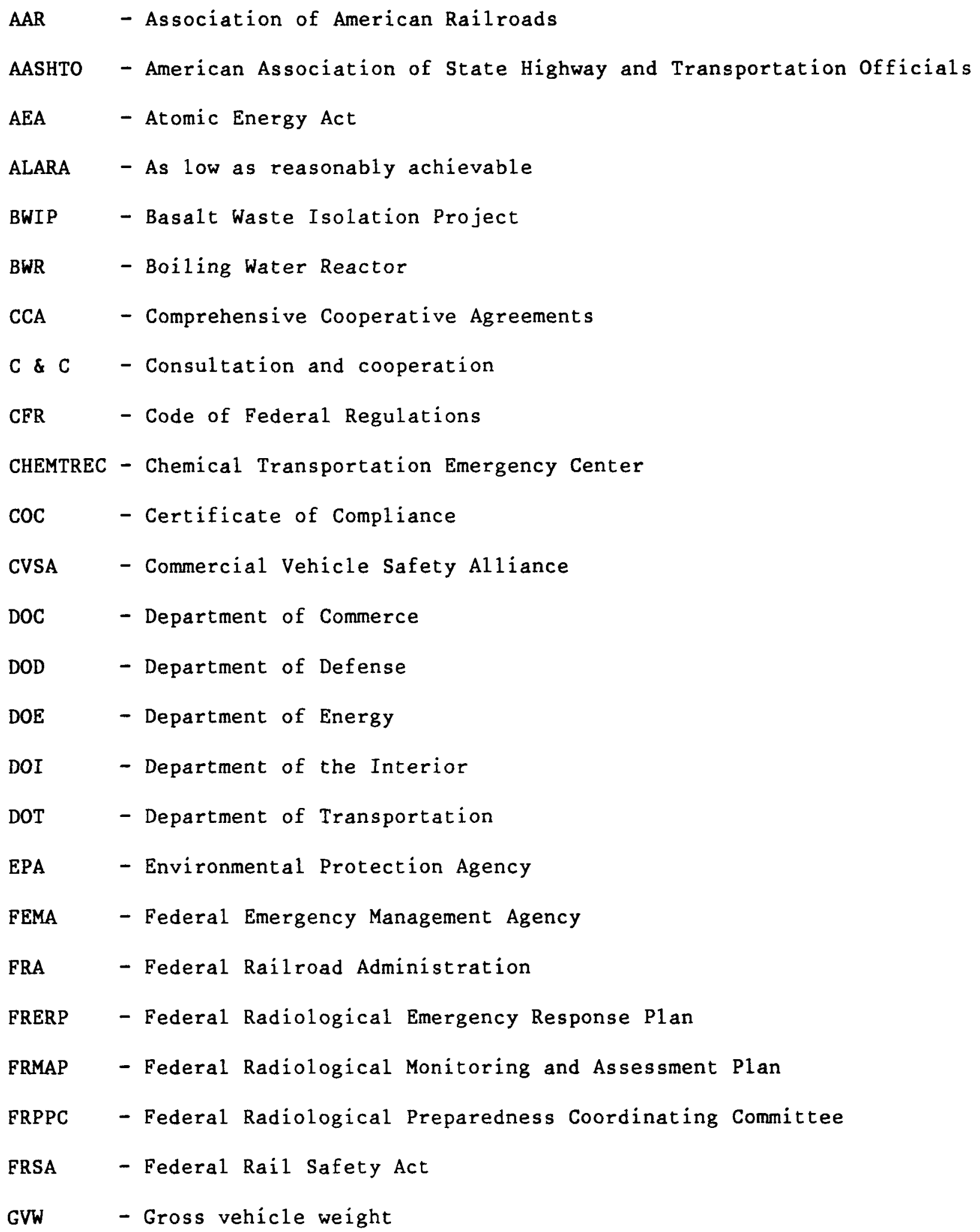




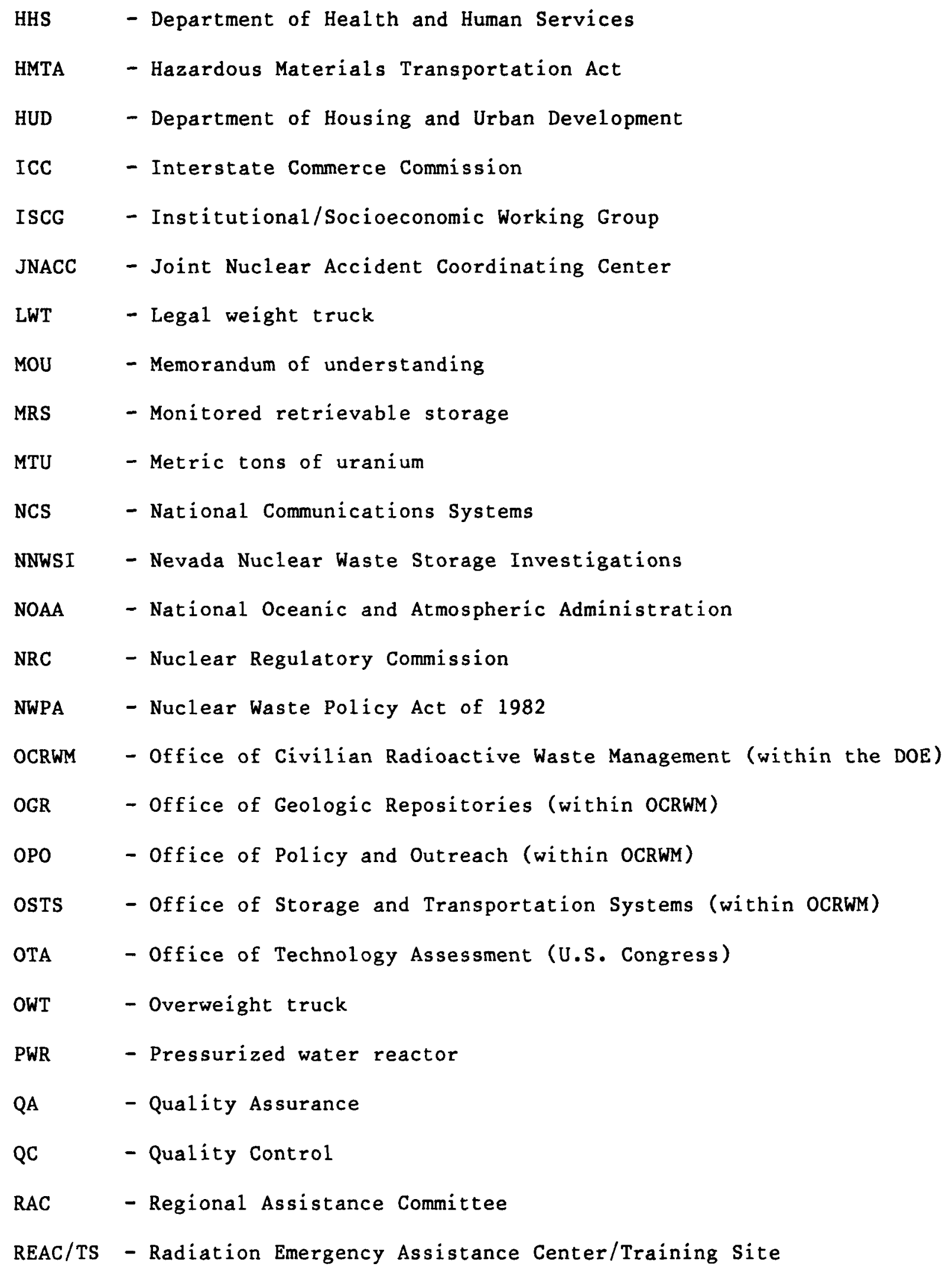




$\begin{array}{ll}\text { R\&D } & \text { - Research and development } \\ \text { RFP } & \text { - Request for Proposals } \\ \text { RRU } & \text { - Regular route - unrestricted } \\ \text { RSPA } & \text { - Research and Special Programs Administration } \\ \text { SARP } & \text { - Safety analysis report for packaging } \\ \text { SRPO } & \text { - Salt Repository Project Office } \\ \text { USDA } & - \text { U.S. Department of Agriculture }\end{array}$




\section{GLOSSARY*}

Act - the Nuclear Waste Policy Act of 1982 (42 USC 10101 et seg.).

affected Indian Tribe - any Indian Tribe (1) within whose reservation boundaries a monitored retrievable storage facility, a test and evaluation facility, or a repository for high-level radioactive waste or spent fuel is proposed to be located; or (2) whose federally defined possessory or usage rights to other lands outside the reservation's boundaries arising out of Congressionally ratified treaties may be substantially and adversely affected by the locating of such a facility, provided that the Secretary of the Interior finds, upon the petition of the appropriate governmental officials of the Tribe, that such effects are both substantial and adverse to the Tribe.

authorized system - the waste-management system authorized by the Act and consisting of a geologic repository, the necessary transportation system for moving the wastes to the repository, the provision for Federal interim storage, and cooperation with the private sector in demonstrating the dry storage of spent fuel at reactor sites.

carriage equipment - any vehicle and associated equipment used to transport waste to NWPA facilities.

carrier - for NWPA transportation, a person (including companies) engaged in transporting waste by land or water to NWPA facilities.

cask - a container for shipping spent nuclear fuel or high-level waste that meets all applicable regulatory requirements.

commercial high-level radioactive waste - the high-level radioactive waste resulting from the reprocessing of spent fuel from commercial nuclear reactors.

commercial nuclear reactor - a civilian nuclear power plant operated to produce heat for generating electricity.

communication network - see "network."

consolidation - an operation during which the upper and lower tie plates of spent-fuel assemblies are removed, the spacer grids and any other structural members of the assembly are removed, and the fuel tubes are collected and formed into a closely packed bundle for insertion into a canister.

*For definitions of acronyms, see the preceding list of acronyms. 
consultation-and-cooperation ( $C \& C$ ) agreement - the agreement required by the Nuclear Waste Policy Act. The Secretary of Energy is required to attempt to enter into $C \& C$ agreements with potential repository and MRS host States and with affected Indian Tribes.

defense waste - waste derived from atomic-energy defense activities.

dual-purpose cask - a cask that could serve as a storage module as well as a transport cask.

emergency response - the proceedings and activities carried out by Federal, State, and local officials in response to a transportation accident involving radioactive waste.

Federal interim storage - see "interim storage facility."

ful1-service contract - a contract under which a single contractor will provide all transportation services required to ship and dispose of civilian radioactive waste.

geologic repository - a facility, to be licensed by the NRC, that is intended to be used for the disposal of radioactive waste in geologic formations.

high-level radioactive waste (HLW) - (1) the highly radioactive material resulting from the reprocessing of spent nuclear fuel, including liquid waste produced directly in reprocessing and any solid material derived from such 1 iquid waste that contains fission products in sufficient concentrations; and (2) other highly radioactive material that the Nuclear Regulatory Commission determines by rule, or the DOE determines by order, consistent with existing 1 aw, to require permanent isolation.

improved-performance system - a waste-management system that includes an MRS facility as an integral part.

integrated waste-management system - a waste-management system in which all components and elements are optimized to work with the other components and elements. This system is usually meant to include an integral MRS facility.

interim storage facility - a federally owned and operated system that would provide storage for no more than 1,900 metric tons of spent fuel from commercial reactors whose owners cannot reasonably provide adequate storage capacity at the reactor site.

institution - a legal entity or an organization having a common interest.

Mission Plan - full title: Mission Plan for the Civilian Radioactive Waste Management Program. Document required by the Act to discuss objectives, strategy, status, and management of the Civilian Radioactive Waste

Management Program. The Mission Plan was published in July 1985. 
monitored retrievable storage (MRS) - a concept for temporarily storing waste or spent fuel. The waste and spent fuel would be continuously monitored and would be stored in such a way that it could be retrieved for shipment to a repository. In the improved-performance system, the principal functions of an MRS facility would be spent-fuel consolidation, packaging, and other waste-handling activities.

network - an interrelated group whose interests and interactions focus on waste transportation.

Nuclear Waste Fund (NWF) - the fund established by the Act to ensure that the costs of waste management are borne by the owners and generators of the waste.

OCRWM Bulletin - publication of program activity issued on a regular basis by the OCRWM's office of Policy and Outreach.

package - pertaining to transportation, the packaging and its radioactive contents.

packaging - pertaining to transportation, the assembly of components necessary to ensure compliance with DOT regulations. It may consist of one or more receptacles, absorbent materials, spacing structures, thermal insulation, radiation shielding, and devices for cooling or absorbing mechanical shocks.

packaging certification - the certification by the NRC that packaging used for the transport of spent fuel and high-level radioactive waste is sufficient to prevent the loss or dispersion of its radioactive contents, provides adequate radiation shielding and heat dissipation, and prevents the occurrence of spontaneous nuclear reactions under normal (incidentfree) and accident conditions of transportation.

quality assurance (QA) - all planned and systematic actions necessary to provide adequate confidence that a structure, system, or component will perform satisfactorily in service. When the product is a report of a significant study or investigation, QA also comprises those planned and systematic actions necessary to provide adequate confidence in the validity and integrity of the reported data, methods and procedures, and in the protection, retrievability, and possible replicability of the data. QA includes a multidisciplinary system of quality controls backed by quality verification activities that demonstrate the completeness and appropriateness of achieved quality.

quality control ( $Q C$ ) - a quality assurance activity which consists of a comprehensive process of identifying and specifying technical quality criteria and requirements; controlling work performance by applying technical standards, procedures, and statistical control and measurement methods.

radioactive waste - high-level waste (HLW), spent fuel, and other radioactive materials that are received for emplacement in a geologic repository. 
repository - see "geologic repository."

reprocessing - the mechanical and chemical process by which irradiated (spent) nuclear fuel is separated into waste material to be disposed of, and useful materials, such as thorium, uranium, and plutonium, to be reused as nuclear fuel.

request for proposals - a formal announcement in the Commerce Business Daily of the Federal Government's intent to purchase certain goods or services and an invitation for vendors to submit a bid to supply these goods or services. The announcement coincides with the issuance of a comprehensive document entitled "Request for Proposal" with all details of the requirements and all relevant Federal regulations.

shipper - party responsible for the movement of waste even though the material may be physically transported by someone else; under the NWPA, the DOE will be the shipper for waste shipments to NWPA facilities.

solidification - the conversion of liquid high-level waste to a solid form, such as glass.

spent-fuel rods - the metal tubes that contain uranium-bearing fuel pellets and are removed from a reactor after irradiation. Part of the spent-fuel assembly.

spent fuel - fuel that has been withdrawn from a nuclear reactor after irradiation.

storage - retention of high-level radioactive waste, spent fuel, or transuranic waste for subsequent disposal.

storage pool - a lined concrete chamber that is filled with water and is used for the temporary storage of spent fuel at a reactor site.

transit states - states through which shipments will pass on their way to States that host a repository or an MRS facility, if approved by Congress.

transportation business plan - the program document that will provide information on contracting procedures, equipment requirements, funding availability, and other areas of interest related to conducting the business of developing the transportation capability.

transportation service contractor - one or more private companies responsible for some or all of the following: assembling a transport fleet; making carriage arrangements; providing inspection, maintenance, and repair services; the training of security and operations personnel; and managing transportation operations.

waste-disposal system - the collection of facilities, equipment, personnel, and sites to be developed by the U.S. Department of Energy for the permanent disposal of spent fuel and high-level waste. 
waste management - the planning, execution, and surveillance of essential functions related to the control of radioactive waste, including treatment, solidification, temporary storage, and isolation. 
. 
A.1 Summary of Discussion Papers $\ldots \ldots \ldots \ldots \ldots \ldots \ldots \ldots \ldots \ldots \ldots \ldots \ldots \ldots \ldots$

A.2 Transportation of Defense Waste $\ldots \ldots \ldots \ldots \ldots \ldots \ldots \ldots \ldots \ldots \ldots \ldots \ldots \ldots$

A.3 Prenotification ...................................... A

A.4 Physical Protection Procedures ....................... A-22

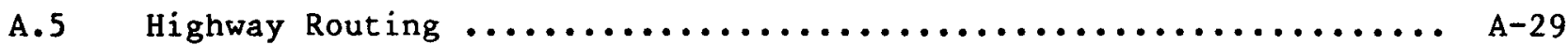

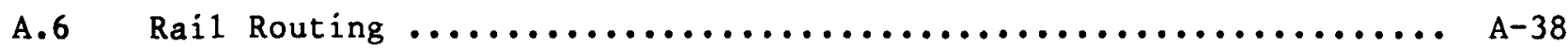

A.7 Inspection and Enforcement for Highway and Rail Shipments ...... A-44

A.8 Emergency Response .............................. A-51

A.9 Liability Coverage for Transportation to NWPA Facilities ....... A-62

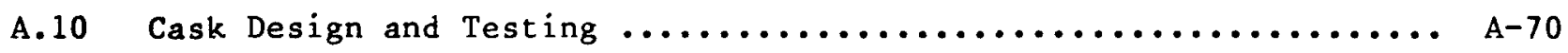

A.11 Overweight Truck Shipments ........................... A-78

A.12 Rail Service Analysis ............................. A-83

A.13 Mixture of Transportation Modes ....................... A-88

A.14 Transportation Infrastructure Improvements .................. A-94

A.15 OCRWM Training standards ................................ A-98

A.16 Transportation Operational Procedures ...................... A 105

A.17 State, Tribal, and Local Regulation of Transportation .......... A-113

\section{LIST OF FIGURES}

Figure A-1. Preliminary Schedule for Transportation Policy

Decisions and Activities ........................ A-4

\section{LIST OF TABLES}

Table A-1. Cask Testing Summary $\ldots \ldots \ldots \ldots \ldots \ldots \ldots \ldots \ldots \ldots \ldots \ldots \ldots$ 
•

$\bullet$

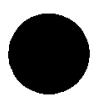


Appendix A

DISCUSSION OF TRANSPORTATION ISSUES

In an effort to foster a climate conducive to the timely identification and resolution of transportation issues, the Office of Civilian Radioactive Waste Management (OCRWM) of the Department of Energy (DOE) initiated dialogue in early 1984 with a wide range of parties having an interest in the transportation of radioactive waste. These interactions led to the identification of numerous issues related to procedural, operational, and financial implications of waste transportation. To foster public participation in the review, evaluation, and resolution of these issues, the OCRWM initiated the development of a series of transportation issue discussion papers in November 1984.

Nine papers (on highway routing, prenotification, emergency response, liability, overweight trucks, inspection and enforcement of highway shipments, inspection and enforcement of rail shipments, safeguard procedures, and cask design and testing) were subsequently released for comment. This document contains revisions of the original nine discussion papers and reviews an additional eight issues:

- The transportation of defense high-level waste.

- Mixture of transportation modes for shipments conducted under the Nuclear Waste Policy Act of 1982 (NWPA).

- The regulation of transportation by States, Indian Tribes, and local governments.

- Rail-service analysis.

- Infrastructure improvements.

- Rail routing.

- OCRWM training standards.

- Operational procedures.

The discussion of two identified issues--procedures for interaction with State, Tribal, and local governments and financial assistance--have been incorporated into Chapter 3 of the Transportation Institutional Plan. Also, the discussion papers on highway and rail inspection and enforcement have been combined into one paper. Thus, a total of 16 discussion papers are included in this appendix.

All discussion papers include background information, a review of related issue elements, preliminary OCRWM plans to address the issues, and estimated schedules for policy decisions. Discussion papers that were previously released have been rewritten in a new, standard format and reflect public comment, newly acquired information, and OCRWM program developments. 
It should be noted that the discussion papers vary considerably in both detail and length. This is appropriate because some of the issues, such as prenotification and routing, have existed for some time and have been the subject of considerable debate and study. Other issues, such as those related to infrastructure improvements and OCRWM training standards, have been more recently identified. In addition, there is some duplication of information and references among the discussion papers. This has been avoided where possible. However, it is expected that some of the discussion papers will be copied and distributed separately to accommodate individual interests. Thus, each paper must be able to stand on its own, and cross-references are therefore kept to a minimum.

The OCRWM continues to solicit comments on its discussions of the transportation issues. The comments received will be reflected in future, updated versions of the discussion papers to be included in the comprehensive transportation plan, scheduled to be published in 1987. To accommodate this publication schedule, all comments should be received in writing by December 31,1986 . Comments may be addressed to--

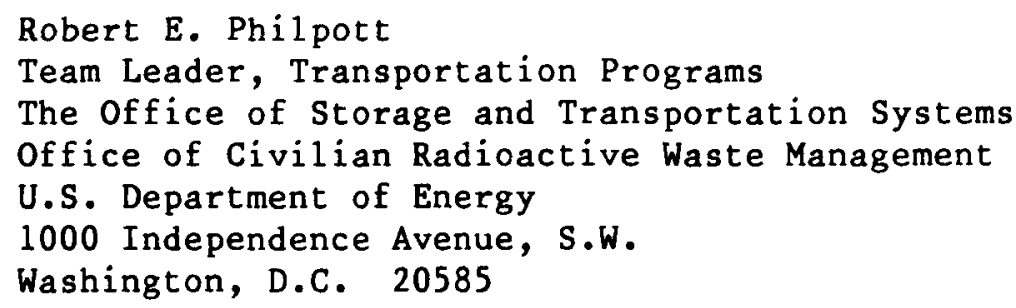

Should an earlier revision of a discussion paper be dictated by changing events or a policy decision, an interim release will be provided with the OCRWM Bulletin or through a special mailing. As an issue is resolved, it will be incorporated into the transportation plan as a procedure or as a policy.

A brief summary of major issue elements in each discussion paper is provided below (see Section A.1). Detailed discussion papers follow the summary (see Sections A.2 through A.17). 


\section{A.1 Summary of Discussion Papers}

To provide a broad overview of OCRWM transportation planning, activities, and related scheduling assumptions, a brief summary of major issue elements in individual discussion papers has been developed. The preliminary schedule for developing OCRWM procedures and policy decisions for each major transportation issue is detailed in Figure $A-1$. The preliminary schedule must be viewed in light of three important factors:

1. The schedule represents the latest time at which the OCRWM expects to establish policies and procedures for all issue elements; many elements of each major transportation issue will be addressed, and an OCRWM policy decision reached or procedure established, before that time.

2. The schedule is based on the assumption that all events related to the waste management program will proceed on an ideal schedule and does not recognize potential delays. Should activities related to the waste management program be delayed, timing assumptions will be ad justed accordingly.

3. The schedule reflects the assumption that a facility for monitored retrievable storage (MRS) will be developed, although Congressional approval of the facility will be required. This assumption was made in order to account for related transportation institutional issues.

The summaries of major issue elements in OCRWM discussion papers follow.

\section{A.1.1 Transportation of Defense Waste}

Radioactive waste generated in national research and development activities and defense activities is commonly referred to as defense waste. Defense waste is cur ently controlled and managed by the DOE's Office of Defense Programs.

On April 30, 1985, the President directed the DOE to proceed with arrangements for the disposal of defense high-level waste in a civilian geologic repository. On July 1, 1986, the OCRWM and the Office of Defense Programs formally agreed that the OCRWM will accept defense waste at designated loading facilities and make subsequent arrangements for the shipment of the waste to a repository. Shipments will be conducted using shipping casks certified by the Nuclear Regulatory Commission (NRC), and in full compliance with applicable Federal regulations and procedures established by the OCRWM.

\section{A.1.2 Prenotification}

In conducting shipments of commercial and defense waste to NWPA facilities, the OCRWM intends to comply with applicable prenotification requirements of the NRC. Such notification will be provided to States through whose jurisdictions waste is transported. In addition, the OCRWM will work 


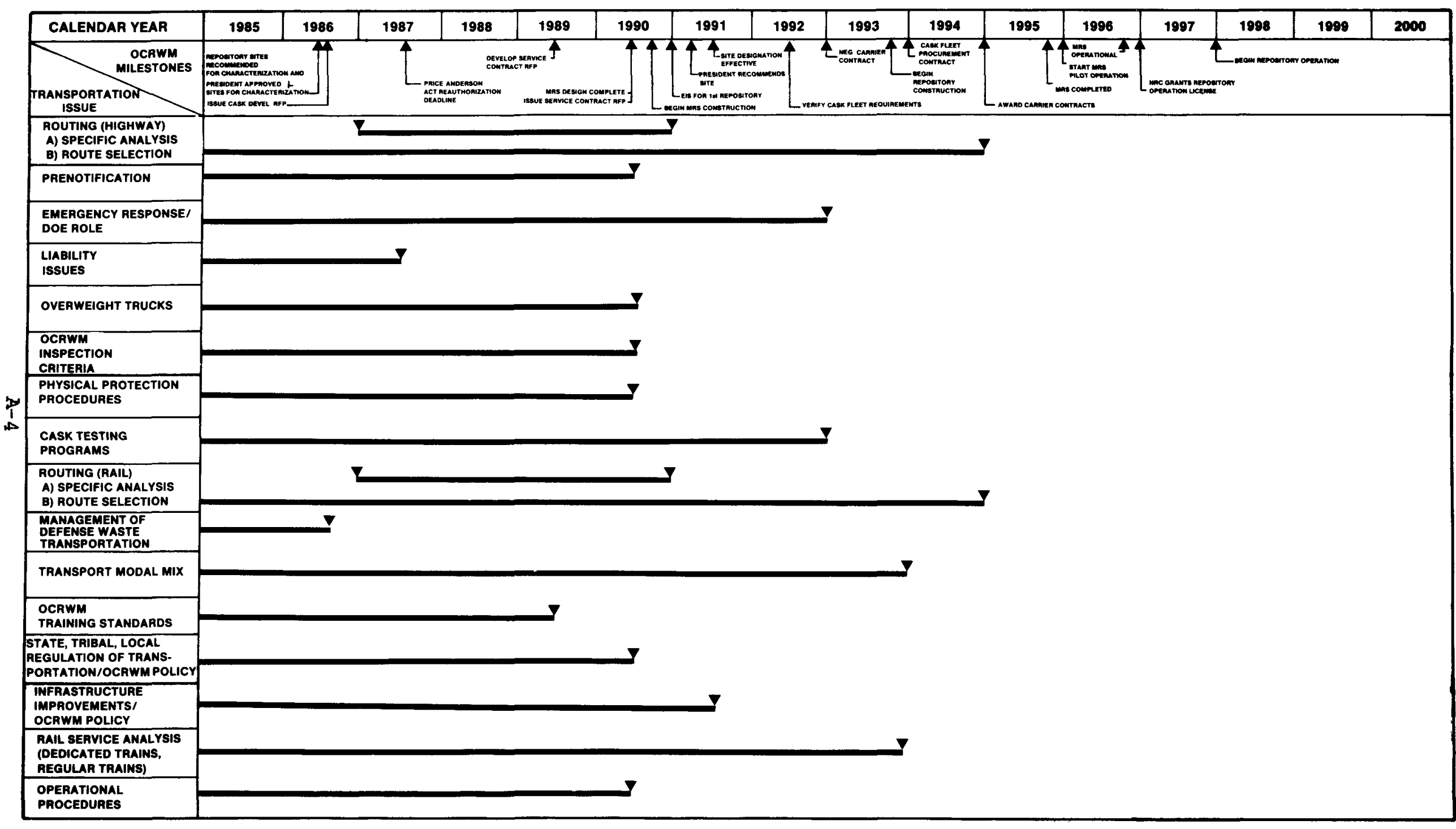

Figure A-1. Preliminary schedule for transportation policy decisions and activities. 
with other DOE offices, the Department of the Interior, and Indian Tribal governments to identify Tribal governments that might appropriately be notified by the OCRWM prior to the shipment of radioactive waste through Indian reservations. Shipments of spent fuel for OCRWM research and development activities are currently being conducted under existing DOE procedures requiring generic notification and "courtesy communication." Additional methods for providing shipment notification (including the potential use of real-time satellite tracking) are now being evaluated by the DOE. A rudimentary OCRWM prenotification system is expected to be applied to the OCRWM's research and development shipments by 1988. A more comprehensive notification system for OCRWM shipments is expected to be defined by 1990 .

\section{A.1.3 Physical Protection Procedures}

When transporting radioactive waste to NWPA facilities, the OCRWM will comply with applicable NRC requirements for the physical protection of shipments from acts of theft and sabotage. The OCRWM will therefore work with the NRC to review credible security threats and the appropriate level of physical protection that should be afforded to NWPA shipments. In working with the NRC, the OCRWM will present comments submitted by interested parties. Appropriate physical protection requirements for NWPA shipments are expected to be defined by 1990 .

\section{A.1.4 Highway Routing}

In shipping radioactive waste to NWPA facilities, the OCRWM will comply with all applicable Department of Transportation (DOT) routing requirements. Route-planning criteria will be developed as an element of transportation operational procedures contained in the OCRWM's comprehensive transportation plan; the criteria will direct the selection of routes that conform to all DOT requirements, and will further address such factors as appropriate stopping places and the preferred time of day for travel through urban areas. The criteria, expected to be completed by 1995, will be developed after consultation with interested parties in workshops. The earliest workshop is expected to be held in 1987 and will include initial discussions on other operational elements of the Transportation Plan.

The OCRWM will sponsor regional routing workshops to assist in the determination of appropriate parameters for a transportation analysis that will be conducted during the development of the environmental impact statement for candidate repository sites. The transportation analysis will use certain route-specific data. Topics of discussion at the workshops (expected to begin in 1 ate 1986) will include a review of computer model requirements, specific route factors that could be considered, and the availability of route-specific data.

\section{A.1.5 Rail Routing}

There are currently no Federal regulatory requirements for rail routing. (It should be noted, however, that the DOE has developed basic rail-routing guidelines for current DOE shipments of defense waste.) The OCRWM will consult with the DOT, the NRC, other affected DOE offices, railroad companies, and the Association of American Railroads to review the potential need for 
Federal regulatory requirements. The OCRWM will also develop appropriate rail-routing criteria for NWPA shipments. The procedures will generally parallel the route-planning criteria for highway shipments and will be established after consultation with interested parties.

Certain data for specific rail routes will be included in transportation analyses conducted during the development of an environmental impact statement for candidate repository sites. Potential parameters for such transportation analyses will be discussed in regional routing workshops, expected to begin in late 1986.

\section{A.1.6 Inspection and Enforcement--Highway and Rail}

The OCRWM believes that the resolution of concerns related to inspectionand-enforcement activities for shipments of radioactive waste is dependent on the close interaction with responsible Federal, State, and Tribal authorities, and that issue resolution could be greatly assisted by the development of a standardized, cooperative inspection system.

Accordingly, the OCRWM plans to contract with an organization having expertise in State safety inspections for highway transportation to assist in the development (by mid-1987, under current planning) of a proposal for a uniform inspection system. The professional organization would then attempt to gain consensus and approval of the proposal from appropriate State and Tribal authorities. Furthermore, the professional organization would support the OCRWM in briefing State and Tribal authorities on the proposed uniform system (through the use of regional workshops) in an attempt to foster a system of reciprocal recognition of inspections.

The OCRWM plans to support the definition of Federal, State, and Tribal inspection and enforcement roles for rail shipments of radioactive waste through the formation of a study group and workshops. It is expected that such activities will be initiated in 1988 .

A comprehensive inspection-and-enforcement program necessary to support NWPA transportation is expected to be in place by 1993.

\section{A.1.7 Emergency Response}

The OCRWM will work extensively with other Federal agencies, States, Tribes, and local governments to define roles in emergency response and assist in the development of uniform emergency-response capabilities. The OCRWM is now working with other government agencies to revise a document issued by the Federal Emergency Management Agency (FEMA); the document is designed to provide centralized planning guidance for any transportation accident involving radioactive materials. In addition, the OCRWM will work with other government agencies to formulate advisory guidelines for emergency-response activities related to NWPA transportation. The guidelines will address such factors as the maintenance and calibration of radiation-monitoring equipment, minimum training standards for emergency-response personnel, and the development of appropriate emergency-response drills. 
A policy decision that defines the appropriate role of the OCRWM in the development of a comprehensive emergency-response system for NWPA shipments is expected to be made by 1993.

\section{A.1.8 Liability Coverage for Transportation to NWPA Facilities}

The Price-Anderson Act (42 USC 2014 and 2210, as amended) currently provides extensive coverage for certain nuclear incidents; coverage under the Price-Anderson Act in its present form would extend to incidents involving NWPA transportation. The Price-Anderson Act is being reviewed by Congress for potential amendment and reauthorization. The OCRWM, in cooperation with other DOE offices, will schedule seminars to review liability coverage for NWPA activities within six months of final Congressional action (expected by mid-1987).

The OCRWM will also develop general public information materials to review liability coverage for NWPA transportation. In addition, written consultation-and-cooperation agreements developed pursuant to the NWPA will address State and Tribal liability concerns.

\section{A.1.9 Cask Design and Testing}

The OCRWM will use casks that have been certified by the NRC for commercial and defense waste shipments to NWPA facilities. Standards of the NRC will be applied to cask design and performance. The OCRWM will review, in consultation with the NRC and the DOT, the results of an NRC study that compares the current NRC standards for cask design and performance with actual serious accident conditions. The NRC study is expected to be completed in 1986.

The OCRWM will work to facilitate the understanding of NRC standards and their application to NWPA transportation through the issuance of public information circulars, the development of an informational videotape, and participation in briefing seminars. In addition, the OCRWM has and will continue to issue for review and comment technical materials related to its program for cask design, development, and procurement. The OCRWM is also developing a cask-testing plan to assist in the formulation of a cask-testing program. Through the use of such a cooperative process, an OCRWM prototype cask-testing program is expected to be developed by 1992 .

\section{A.1.10 Overweight Truck Shipments}

The potential use of overweight truck casks in the OCRWM transportation program offers an important alternative for reducing the number of highway shipments to NWPA facilities. The OCRWM is now evaluating Federal and State highway weight limits, the relationship between highway damage and vehicle weight, State permit requirements for overweight truck shipments, and the cost and safety factors associated with the use of overweight trucks. A summary report, to be issued in 1987, will be provided to States to support cooperative evaluations of the feasibility of using overweight trucks for NWPA shipments and the potential for developing nationally uniform and stable state permit procedures. The OCRWM also plans to form a study group in 1987 to 
promote the review of related issues and the establishment of potential criteria for uniform permit procedures.

The use of overweight trucks in the NWPA transportation program will ultimately depend on the extent to which national consensus can be reached on State permitting procedures. The OCRWM expects to decide by 1990 whether overweight trucks will be used for NWPA transportation.

\section{A.1.11 Rail-Service Analysis}

The OCRWM will review and evaluate regular rail service and dedicated train service for NWPA transportation. The evaluation of cost and risk factors associated with such types of rail service will be supported through several studies. One study will analyze the cost and risk of different transportation systems that apply measures for reducing radiation exposures to levels as low as reasonably achievable. A computer model will also be used to predict the optimum mix of transportation modes and shipping schedules that could be used for NWPA transportation. Summary reports on both evaluations will be made available for review and comment.

Regular and dedicated train service will be further examined in transportation analyses conducted during the development of an environmental impact statement for candidate repository sites. Regional workshops (expected to begin in late 1986) will be held to assist the OCRWM in defining appropriate parameters for such transportation analyses. Other methods will also be employed to ensure that real operational problems are fully considered before final fleet-composition is determined and procured.

\section{A.1.12 Mixture of Transportation Modes}

The OCRWM will evaluate the potential use of truck, rail, and barge transportation, and various intermodal configurations, for shipping radioactive waste to NWPA facilities. As noted above, an evaluation of the costs and risks associated with various modes of transportation, types of transportation service, and intermodal configurations will be conducted through several studies. In one study, alternative transportation systems will be evaluated in terms of the cost and risk factors associated with practices designed to reduce radiation exposures to levels as low as reasonably achievable. A computer model will also be used to predict the optimum mix of transportation modes and shipping schedules. The results of such studies will be factored into transportation analyses conducted during the development of an environmental impact statement for candidate repository sites.

To assist in the selection of appropriate modal mixes, the OCRWM will develop criteria that can be used to weigh the relative importance of costs, risks, and other factors associated with transportation. Real operational problems will be considered to assist in the determination of fleetcomposition. The OCRWM will make such criteria available for review and comment. The OCRWM expects that initial decisions on the modal mix for NWPA transportation will be made in 1993, at which time a contract for the development of a cask fleet will be awarded. 


\section{A.1.13 Infrastructure Improvements}

The OCRWM is evaluating the transportation infrastructure of reactor sites in order to determine what improvements in the vicinity of the site may be necessary for waste transportation to NWPA facilities. The costs and benefits of making such improvements will also be studied. The OCRWM will also evaluate (1) the need for other specific infrastructure improvements (including road and railbed upgrading and bridge improvements); (2) Federal and State responsibilities for such improvements; and (3) appropriate funding sources for the development, improvement, and maintenance of transportation infrastructure. The OCRWM will review infrastructure improvements needed for NWPA transportation on a case-by-case basis. In general, however, the OCRWM believes that NWPA transportation will not create any unique needs for infrastructure improvements. Under current OCRWM plans, such issues will be discussed in workshops and study groups formed to assist in the development of transportation operational procedures. The first such workshop is expected to be held in 1987 .

An OCRWM statement on the extent of infrastructure improvements needed for NWPA transportation and sources of assistance for such improvements is expected to be developed by 1991 .

\section{A.1.14 OCRWM Training Standards}

The OCRWM has begun to evaluate current training requirements and the development of training standards for various activities (e.g., driver training, transportation operations, and equipment maintenance) related to the transportation of waste to NWPA facilities. The OCRWM will work with the DOT, the NRC, and the DOE's Office of Defense Programs in an effort to determine appropriate intergovernmental mechanisms for addressing the need for more extensive Federal driver and operator training requirements. Such mechanisms may include--

- Technical studies.

- Specific workshops.

- Petitioning the DOT for a formal rulemaking, if determined to be necessary.

The OCRWM has begun to review appropriate driver and operator training standards for the NWPA transportation program based on current DOT regulatory requirements. It is expected that such training standards will be developed by mid-1989. Under current planning, the OCRWM standards will require the use of a uniform OCRWM driver and operator training program to be administered by transportation service contractors. The OCRWM is also considering the use of standard written examinations as part of a training program and for such examinations to be administered by the transportation service contractors.

In addition to developing driver and operator training standards, the OCRWM will develop training standards for operational procedures, cask inspection before use (acceptance tests), and cask maintenance. Al1 OCRWM training standards are expected to be developed by mid-1989 and will be 
included in the service contracts. The training programs developed under these OCRWM standards for operating procedures, acceptance tests, and cask maintenance will subsequently be performed by the OCRWM transportation service contractors.

\section{A.1.15 Transportation Operational Procedures}

The OCRWM's comprehensive transportation plan will include guidance on transportation operations. Transportation operational procedures are expected to be defined by 1990. The OCRWM expects to develop in 1987 a preliminary outline of transportation operational elements for the comprehensive transportation plan. Such elements include management methods, material-handling procedures, route-selection criteria, inspection criteria for various transportation operations, training standards, and strategies for negotiating shipping rates. The OCRWM plans to hold a workshop in 1987 to discuss the outline of operational elements.

The OCRWM is also conducting several studies to support the development of operational procedures and practices for the NWPA transportation system. Such studies include--

- An evaluation of the feasibility of truck convoys.

- An evaluation of the use of unmanned surveillance cars for rail transportation.

- An evaluation of the costs and risks associated with various transportation practices (e.g., the use of safe havens and restricted stopping times) and systems designed to reduce radiation exposures to levels as far below Federal limits as is practicable.

The OCRWM will make the findings of such studies available for review and comment.

\section{A.1.16 State, Tribal, and Local Regulation of}

Radioactive-Waste Transportation

The OCRWM will comply with all applicable and valid State, Tribal, and local transportation requirements. The OCRWM will make a special effort to further study and address issues related to Tribal regulatory authority and will use workshops to review relevant issues. In addition, the OCRWM will focus attention on the review of the regulatory power of individual Tribes as affected by Congressional acts, treaties, and Tribal constitutions and codes. By mid-1990, the OCRWM plans to issue a written policy statement of its plans to address State, Tribal, and local transportation requirements and restrictions that may affect the transportation of waste to NWPA facilities.

The OCRWM currently favors the use of regional workshops to assist in coordinated planning for transportation and the development of uniform rules that are consistent with Federal regulations. The OCRWM will consult with both the NRC and the DOT in an effort to establish a Federal interagency approach for addressing regulatory issues with State, Tribal, and local governments. 
The OCRWM will assist, as necessary, in the comprehensive compilation of State and local transportation requirements that is being performed by the Oak Ridge National Laboratory. Tribal requirements, if developed in the future, will be included in this compilation. 


\section{A.2 Transportation of Defense Waste}

\section{A.2.1 Overview}

Defense high-leve1 waste (defense waste), as defined in DOE Order 5820.2 (and consistent with the Environmental Protection Agency's proposed rule 40 CFR 191), is the highly radioactive waste that results from the reprocessing of spent nuclear fuel (including 1 iquid waste produced directly in reprocessing and any solid waste derived from the liquid) that contains a combination of transuranic waste and fission products in concentrations as to require permanent isolation. Defense high-level waste is currently controlled and managed by the DOE's office of Defense Programs.

On April 30, 1985, the President directed the OCRWM to proceed with arrangements to dispose of defense high-level waste with commercial nuclear waste in a civilian geologic repository. This decision was supported by an OCRWM evaluation of the use of civilian repositories for the disposal of such defense high-level waste. The OCRWM evaluation concluded that there were no compelling reasons related to health and safety, national security, regulations, transportation, or public acceptability to develop, build, and operate a repository for defense high-level waste only.

The following discussion reviews the DOE's policy for shipping defense waste to a repository and describes the current location and characteristics of the waste.

\section{Policy for Shipping Defense Waste to Repository}

On July 1, 1986, the OCRWM and the DOE's Office of Defense Programs formally agreed that the OCRWM will accept defense waste at designated loading facilities (adjacent to DOE defense waste processing facilities) and make subsequent arrangements for shipment of the waste to a repository. The waste will be loaded by the office of Defense Programs into casks certified by the NRC and provided by the OCRWM. Shipments will be conducted in full compliance with applicable Federal regulations and procedures established by the OCRWM for spent fuel and defense waste transfer to a repository. In addition, the OCRWM will comply with State, Tribal and local transportation requirements that are consistent with Federal law.

The OCRWM expects that a disposal contract for defense waste, and an appropriate scale for contributions to the Nuclear Waste Fund, will be developed in the near future.

\section{Source of Defense Waste}

Defense high-level waste is currently generated and stored at three DOE sites: the Savannah River Plant, the Idaho National Engineering Laboratory, and the Hanford Reservation. By the end of 1982, approximately 15 percent of the total curies of radioactivity in spent fuel and high-level waste in this country originated from atomic energy defense activities. Most of the remaining radioactivity is contained in commercial spent nuclear fuel. (U.S. DOE, An Evaluation of Commercial Repository Capacity for the Disposal of Defense High-Level Waste, DOE/DP/0020/1, 1985). By 2000, it is expected that 
the radioactivity in defense waste will be three percent of the total. A total of 10,000 metric tons of heavy metal of defense waste (or 20,000 canisters) is expected to be shipped to a civilian repository. As the OCRWM continues to evaluate transportation of defense waste, these figures may be altered.

At the Savannah River Plant, defense waste is stored in underground tanks. High-level waste from this site will be solidified in borosilicate glass in the onsite Defense Waste Processing Facility. This processing facility will produce approximately 500 canisters of borosilicate glass per year beginning in 1989. The immobilized high-level waste will be stored on site until a geologic repository becomes available to receive the waste.

At the Hanford Reservation, defense waste is stored in underground tanks. Most of the cesium, strontium and water have been removed from the high-level waste that is stored in 149 single-shell tanks. The high-level waste remaining in these tanks will be stabilized in place if, after the requisite environmental documentation, it is determined that the short-term risks and costs of retrieval and transportation outweigh the environmental benefits of disposal in a geologic repository. Should it be determined that the benefits of geologic disposal prevail, there will be an increase in the volume of defense waste to be processed and disposed of in a geologic repository.

The Idaho National Engineering Laboratory has been converting high-level liquid waste to a dry calcine and storing it in stainless steel bins which are in underground concrete vaults. While a final decision has not been made, the reference plan anticipates operation of an immobilization facility in 2007 . At that time, liquid and calcine wastes will be immobilized for geologic disposal at the rate of 500 canisters per year.

\section{A.2.2 Identification of Issue Elements}

Discussions between the OCRWM, the DOE's Office of Defense Programs, other Federal agencies and parties having an interest in the management of defense waste within the NWPA program have led to the identification of the following issues:

- The need to review specific transportation requirements that will be applied to defense waste shipments.

- Whether any shipments of defense waste will be classified for purposes of national security.

- The effect that a monitored retrievable storage facility (if approved by Congress) may have on the transportation of defense waste.

- The need to review emergency-response capabilities for potential transportation accidents involving defense waste.

- The need to review liability coverage for the transportation of defense waste to NWPA facilities. 


\section{A.2.3 Discussion of Issue Elements}

The following discussion contains a preliminary review of these issues and outlines the expected timing of policy decisions.

\section{Defense Waste Transportation Requirements}

As previously noted, shipments of defense waste to a repository will be made in full compliance with Federal regulations and procedures established by the OCRWM. Detailed discussion of overall OCRWM planning and related policy for NWPA shipments is included in the following sections of this Appendix. See, for example, the discussion of prenotification in Section A.3, physical protection procedures in Section A.4, and routing in Sections A.5 and A.6.

\section{Classified Shipments}

Under DOT regulations (49 CFR 173.7[b] and 177.806[b]), DOE shipments must meet all DOT transportation requirements unless the shipment is classified as needing certain exemptions for national security purposes. Shipments of defense waste to a repository will not be classified as needing special protection for national security purposes, and will comply with all applicable DOT transportation requirements.

\section{Potential Shipments to MRS Facilities}

Consistent with the terms of the NWPA, the OCRWM has evaluated the potential use of an MRS facility as an element of the waste management program. Under current OCRWM evaluations of the potential use of an MRS facility, it is assumed that defense waste would be shipped directly from DOE facilities to a repository.

\section{Emergency Response}

The OCRWM plans to conduct a cooperative review with the FEMA, other Federal agencies, States, Tribes, local governments, and all interested parties to define the extent of emergency response planning and the development of emergency-response capabilities needed to support NWPA transportation (see Appendix Section A.8). Current discussions between the OCRWM, the Office of Defense Programs, the FEMA and other Federal agencies have not identified any unique aspects of defense waste transportation that would require the development of a separate emergency-response program for defense waste shipments.

\section{Liability for Defense Waste Shipments}

Under current systems of 1 iability coverage, potential transportation accidents involving defense waste shipments made to NWPA facilities would be covered by (1) carrier insurance for general traffic accidents, and (2) the government indemnity provisions of the Price-Anderson Act for serious transportation accidents involving a release of radioactive materials. A discussion of liability coverage is included in Section A.9 of this Appendix. 


\section{A.3 Prenotification}

\section{A.3.1 Overview}

Procedures for notifying States of shipments of spent nuclear fuel and high-level waste have been established by regulations of the NRC, and by DOE guidelines. Prenotification requirements established by the NRC apply to NRClicensee shipments of commercial spent fuel and high-level waste, and are found in NRC regulations (10 CFR 73.37[f] and 71.97). DOE guidelines establish notification procedures for DOE shipments of nuclear waste generated in national defense activities and DOE shipments made for research-anddevelopment activities. The discussion that follows describes existing NRC and DOE notification procedures and identifies differences between agency requirements.

\section{NRC Prenotification Requirements}

Under NRC regulations, NRC 1 icensees who transport (by any mode), or deliver to a carrier for transport, certain specified quantities of spent fuel must arrange for a physical protection system to protect the shipment against acts of theft and sabotage (10 CFR 73.37). Mandatory "safeguard" procedures must include state prenotification of the shipment (10 CFR 73.37[f]). Before the transportation of spent fuel within or through a state, an NRC-1icensee must ensure that the governor of the State (or the governor's designee) is provided with written the notification. If delivered by mail, the notification must be postmarked at least seven days prior to shipment within or through a State; if delivered by messenger, notification must reach the office of the governor (or the governor's designee) at least four days in advance of shipment within or through the state. Information that must be provided to the states must include the following:

- The name, address, and telephone number of the shipper, carrier, and receiver.

- A description of the shipment in terms that are consistent with DOT regulations (49 CFR 172.202 and $172.203[d]$ ).

- A listing of the routes to be used within the State.

- The estimated time and date of departure from the point of shipping origin.

- The estimated date and time of entry into the state.

- A statement that the shipping information must be withheld from the public for at least 10 days after the shipment, or series of shipments, entered or originated in the state.

In addition, the governor (or governor's designee) must be notified of any schedule change that differs by more than six hours from the schedule information previously furnished. 
For NRC-1icensee shipments of certain specified quantities of radioactive waste other than spent nuclear fuel, NRC regulations also require that notification be given to a governor (or the governor's designee) before transport within or through the State (10 CFR 71.97). The information provided with the notification of such shipments is similar to that provided for spent-nuclear fuel shipments, except that the regulations do not require a 1 isting of the routes used for shipment within or through a State.

\section{Notification Procedures for DOE Shipments}

The DOE ships radioactive materials used in research and development and associated with national defense activities. Such shipments may be classified as needing special transportation procedures for security purposes and are therefore exempt from certain DOT transportation requirements ( 49 CFR 173.7[b]). DOE shipments that are not classified follow all DOT requirements normally applied to shipments of radioactive materials.

DOE notification procedures for unclassified spent-fuel shipments have recently been revised to more closely parallel NRC procedures. Under current procedures, the DOE periodically provides generic shipment notification to States. Such notification, provided in booklet form, reviews such factors as the types of materials that will be shipped, transportation packaging, 1iability coverage for transportation accidents, available emergency assistance, and carrier training. The generic notification, which is not shipment-specific and does not include a listing of transportation routes, was approved by the DOT as part of the physical protection system required in DOT regulations (49 CFR $173.22[\mathrm{c}])$.

In addition to generic notification, "courtesy communication" is provided to the governor of a State (or a governor's designee) before waste shipment (by any mode) through or within the state. Such communication is made by telephone before the initiation of shipping campaigns and includes--

- The expected length of the shipping campaign, the shipping schedule, and other general shipping information (i.e., the number of shipments per shipping campaign and the expected number of shipments per month).

- Planned transportation routes. Consistent with DOT regulations, such routes follow Interstate highways or alternative routes designated by State routing agencies. (State-requested alternative routes are used by the DOE).

- The type of transportation cask.

- The origin and destination of the shipment.

- The commercial carrier conducting the shipments.

- The appropriate emergency-response contact in the DOE organization. 
The exact time and date of shipment will normally not be provided; where there is a significant break in a shipping campaign (normally considered to be a period of 6 or more months), the DOE will provide additional notice on the renewal of shipping.

The DOE's new guidelines for prenotification apply only to DOE shipments of spent fuel.

\section{A.3.2 Identification of Issue Elements}

Discussions between the OCRWM and interested parties have led to the identification of the following issues related to the prenotification of NWPA shipment s:

- The prenotification system that will be applied to waste shipments to NWPA facilities.

- The prenotification system that will be applied to the shipments of spent fuel for research and development (R\&D) activities conducted pursuant to the NWPA and prior to the operation of NWPA facilities.

- The need for continued evaluation of existing prenotification systems.

- Options for developing additional notification procedures.

\section{A.3.3 Discussion of Issue Elements}

The following discussion contains a preliminary review of these issues; identifies, where possible, opportunities for public involvement in the development and consideration of various policy options; and outlines the expected timing of OCRWM policy decisions and transportation program activities.

Prenotification Procedures for Waste Shipments to NWPA Facilities

The OCRWM has stated its intent to follow all NRC transportation requirements (which at present include requirements for prenotification) that exist when shipments of commercial and defense waste are made to NWPA facilities (including a repository and, if approved by Congress, an MRS facility). Provision of such prenotification will be extended to all states through whose jurisdictions waste is transported. In addition, the OCRWM will work with appropriate DOE offices, the Department of the Interior, and Indian Tribal governments to determine those Indian Tribal governments that might appropriately be notified by the OCRWM before the transportation of waste through Indian reservations.

Additional prenotification procedures for shipments to NWPA facilities may be implemented after consultation with the NRC and interested parties. Such procedures will reflect experience gained from current shipping and technological developments like real-time tracking (see discussion below). By mid-1990, the OCRWM expects to complete ongoing evaluations of potential notification systems and specify appropriate procedures for prenotifying States and Tribes through whose jurisdictions waste will be transported to NWPA facilities. The timing of such a policy decision is related to the 
information that will be required to support an OCRWM request for proposals in 1990 for members of private industry to act as service contractors for transportation operations, if the use of service contractors is found to be a preferred option.*

The OCRWM also will specify such prenotification procedures as an integral part of consultation-and-cooperation ( $C \& C$ ) agreements developed under the NWPA. Pursuant to Sections $117(\mathrm{c})$ and $141(\mathrm{~h})$ of the NWPA, the secretary of Energy is authorized to seek to enter into written C\&C agreements with--

- Upon written request, any State notified by the DOE as having a potentially acceptable site for a repository and any affected Indian Tribes.

- States having a site approved for site characterization for a repository and any affected Indian Tribes.

- A host State for an MRS facility and any affected Indian Tribes, if an MRS facility is approved by Congress.

Written C\&C agreements will specify procedures by which the Secretary of Energy will notify such States and affected Indian Tribes before the transportation of any high-level waste and spent fuel into a State for temporary storage at an MRS facility or disposal in a repository. The agreements will be developed through a process of consultation with the Governor and legislature of such States and the governing bodies of affected Indian Tribes. The prenotification procedures included in such agreements will reflect the principles developed by the OCRWM for all waste shipments to NWPA facilities in order to avoid inconsistent and conflicting requirements.

\section{Prenotification Procedures for OCRWM R\&D Shipments}

The OCRWM will be making a number of shipments over the next 5 years in support of three major R\&D programs. Pursuant to Section 218 of the NWPA, the OCRWM has established a demonstration program, in cooperation with the private sector, for the dry storage of spent fuel at the sites of commercial nuclear power plants. The purpose of the program is to collect data to assist utilities in obtaining NRC approval of various dry-storage technologies. The

* The OCRWM is now investigating the use of service contractors who would be responsible for assembling a transportation fleet; making carriage arrangements; providing inspection, maintenance, and repair services; training security and operations personnel; and managing transportation operations. If the option of using service contractors is found to be efficient and cost-effective, one or more service contractors will be selected by competitive bidding. (For a more detailed discussion of plans to evaluate various management options, see Section A.16.) For the purpose of general discussion and the review of timing assumptions in these papers, it is assumed that service contractors will be used for managing transportation operations. 
NWPA also tasks the OCRWM to undertake a cooperative program with the utility owners of nuclear power plants to encourage the development of the technology for the consolidation of spent nuclear fuel rods. In addition, the OCRWM will be conducting spent-fuel shipments for use in a repository-related program to test the behavior and characteristics of spent fuel in various rock types.

Shipments of spent fuel for the OCRWM R\&D programs are currently being conducted under existing DOE procedures requiring generic notification and "courtesy communication" to States. Additional procedures are being considered as an integral part of the development of a fully operational NWPA transportation program. Such procedures will be developed through a cooperative process with all interested parties, will be consistent with NRC prenotification requirements, and may include the use of a real-time tracking system (see discussion below). After initial consultation with utilities, carriers, States, Indian Tribes, local governments, and other interested parties, the OCRWM has also determined that prenotification procedures for R\&D shipments should be extended to include Tribal governments having reservations through which shipments pass. The OCRWM will work with appropriate DOE offices, the Department of the Interior, and Tribal governments to determine appropriate prenotification contacts.

A rudimentary NWPA prenotification system is expected to be applied to the OCRWM's R\&D shipments by 1988 .

Evaluation of Current Notification Requirements and Information Needs

Some States, Indian Tribes, and local governments have indicated to the OCRWM their interest in gathering information on shipments of radioactive materials so that they can consider such information in local transportation planning, developing appropriate emergency-response capabilities, and arranging for transportation escorts. The information could also be used to facilitate inspection-and-enforcement activities and provide informed responses to requests for information. To support these activities, the OCRWM will work with such governments, Federal regulatory agencies, and other interested parties to review existing notification and information-gathering needs and procedures as well as their potential effect on waste shipments to NWPA facilities.

The mechanisms that the OCRWM will consider for conducting the review include--

- National workshops.

- Regional workshops to address more localized information needs.

- Contractual arrangements for the study of specific information needs and the development of recommendations for practical implementation procedures for NWPA shipping campaigns.

A schedule for conducting a review has not yet been established. The OCRWM expects however, that certain concerns related to prenotification will be addressed as an integral part of activities conducted to address the issues of emergency response (see Section A.8) and inspection and enforcement (see 
Section A.7). The OCRWM solicits public comment on appropriate mechanisms and the timing of activities to address prenotification and general information needs related to NWPA shipments.

Of use in the cooperative effort will be a study, directed by the DOT and supported by the DOE, of Federal, State, and local notification requirements (Assessment of State and Local Notification Requirements for Transportation of Radioactive and Other Hazardous Materials, BHARC-300-85-001, prepared for the U.S. Department of Transportation by the Battelle Human Affairs Research Center, Seattle, WA, 1985). The study reviewed Federal prenotification requirements and the extent to which State and local governments require additional notification. The study also evaluated the purposes, objectives, and effects of such notification systems.

A second and related study sponsored by the DOT and the DOE is evaluating the costs and effectiveness of State and local information-gathering procedures that are applied to shipments of hazardous materials (including radioactive materials). Among the information-gathering options to be studied are prenotification, registration, weigh-station counts, highway counts, and carrier or industry surveys. A final report is expected to be released in 1986.

In reviewing the application of State, Tribal, and local notification procedures to actual NWPA shipments, the OCRWM will review all requirements for consistency with Federal law. To address the validity of State, Tribal, and local requirements for transportation, the DOT issues advisory rulings in the form of inconsistency rulings or nonpreemption determinations; alternatively, the validity of such measures may be determined in a court of law. (For a detailed discussion of the effect of inconsistency, see Section A.17.) Inconsistency rulings issued to date by the DOT have declared that State or local prenotification requirements that are the same as the Federal requirements are in effect an adoption of Federal rules and are therefore consistent with Federal law. In contrast, the DOT has ruled that State and local prenotification requirements are inconsistent with Federal law where such requirements differ from Federal rules, either by requiring information to be submitted to different parties or by requiring the submittal of additional information, documentation, and/or certifications. (See, for example, Inconsistency Rulings IR-8 and IR-10 through 15, Federal Register, Vol. 49, p. 46632, November $27,1984$. )

The OCRWM believes that through cooperative planning by all interested parties, the NWPA transportation program will be responsive to the need of States, Indian Tribes, and local governments to gather shipment-specific information and will minimize the need for individual, varying notification procedures.

\section{Study of Additional Notification Methods}

The OCRWM intends to consider additional methods for meeting the objectives of current written and telephone prenotification. One such option is the application of a real-time shipment tracking system to NWPA shipments. 
The DOE is currently evaluating the use of satellite-tracking for DOE shipments of radioactive material. One system under serious consideration consists of three basic components: (1) individual shipment "transceivers;" (2) satellites in orbit above the United States; and (3) a powerful computer system at a ground location. Every shipment transceiver would have a unique identifying code; the pulse emitted from the transceiver would be received by the satellites and relayed by microwave to the ground station. The shipment's position and other digital information would then be encoded and relayed by satellite to other receivers established as part of the system.

The DOE plans to conduct a 6-month test of the satellite tracking system, with testing expected to begin by late 1986. If operation of the system proves successful, the OCRWM will evaluate the application of the system to NWPA shipments. Such an evaluation will be conducted in cooperation with States, Indian Tribes, and local governments. As previously noted, the OCRWM's prenotification system for NWPA shipments is expected to be defined by mid-1990, in order to support the issuance of a request for proposals for transportation service contractors (if the use of service contractors is found to be the preferred option). 


\section{A.4 Physical Protection Procedures}

\section{A.4.1 Overview}

Procedures for the physical protection of shipments of spent nuclear fuel from acts of theft and sabotage have been established by regulations of the NRC and DOE guidelines. Physical protection requirements established by the NRC apply to NRC-licensee shipments of commercial spent fuel, and are found in NRC regulations. DOE guidelines establish physical protection procedures for DOE shipments of spent fuel generated in national defense activities and research and development. The following discussion describes existing NRC and DOE physical protection procedures, efforts to revise those procedures, and differences between agency requirements. Also discussed are the original studies that formed the basis for the NRC's physical protection procedures and the subsequent confirmatory research of the NRC and the DOE, which predicted substantially reduced consequences as a result of the sabotage of a spent fuel shipment.

\section{NRC Physical Protection Requirements}

In June 1979, the NRC published regulations for the protection of commercial spent-fuel shipments from acts of theft and sabotage and invited public comment. In 1980 , after reviewing the regulations, the NRC published amendments. The NRC further amended the regulations in 1982 to include state prenotification requirements. The amended regulations are specified in 10 CFR $73.37(\mathrm{a})-(\mathrm{g})$. Known as physical protection or "safeguard" regulations, they are distinguished from other regulations published by the NRC and other Federal agencies that deal with safety issues affecting the environment and public health. The regulations in their current form reflected research conducted in the mid-1970s. In particular, an NRC-sponsored study suggested that the sabotage of spent-fuel shipments had the potential for producing serious radiological consequences in areas of high population density (see A. R. DuCharme et al., Transport of Radionuclides in Urban Environs: Working Draft Assessment, SAND77-1927, Sandia National Laboratories, Albuquerque, NM, 1978). The NRC concluded that to protect public health and minimize danger to life and property, it was prudent to require that certain safeguard measures be taken to protect spent-fuel shipments until a more precise and scientific analysis could be performed.

Under the NRC regulations, NRC 1 icensees who transport (by any mode), or deliver to a carrier for transport, certain specified quantities of spent fuel must arrange for a physical protection system to protect the shipment from acts of theft and sabotage. The actions required under such a physical protection system include the following:

- NRC approval of the route in advance of shipment.

- The development of specified procedures for coping with circumstances that threaten deliberate damage to the spent-fuel shipment.

- Provision of at least one escort to maintain visual surveillance of the shipment during stops. 
- Use of a communications center at a designated location to monitor the progress of the spent-fuel shipment.

- Calls made to the communications center by shipment escorts at least every two hours to relay the status of the shipment.

- The use of a written $\log$ for each shipment.

- Shipment planning to avoid scheduled intermediate stops to the extent possible.

- Advance arrangements with local law-enforcement agencies along the route (both highway and rail) to assist in their response to an emergency or a call for assistance.

In addition, a physical protection system for highway shipments must provide for at least two armed escorts when shipments pass through heavily populated areas. Heavily populated areas are characterized in terms of urbanized areas with total populations of 100,000 persons or more; transportation within 3 miles of the boundary of such an urban area, or anywhere within the urbanized area, is considered to be within a heavily populated area (see U.S. Nuclear Regulatory Commission, Physical Protection of Shipments of Irradiated Reactor Fuel; Interim Guidance, NUREG-0561-REV-1, Washington, D.C., 1980). In such areas, a transport vehicle must either (1) be occupied by at least two individuals, one of whom serves as an armed escort, and be accompanied by a local law-enforcement vehicle with at least one armed escort; or (2) be accompanied by two vehicles, each with at least one armed escort. Vehicles must also be equipped with devices to immobilize the cab or cargo-carrying portion of the vehicle.

For shipments by rail, at least one escort must be positioned at a location on the train that will permit observation of the shipment car while in motion. In heavily populated areas, a shipment must be accompanied by two armed guards, at least one of whom must be stationed in a position on the train that will permit observation of the shipment car while in motion.

Escorts for both highway and rail shipments must have the ability to communicate with the communications center and local law-enforcement agencies using radiotelephones or $C B$ radios. The NRC regulations also require that advance notice of highway and rail shipments be provided to the governor of a State or the governor's designee before transportation through or within the State. Such information cannot be publicly announced for at least 10 days (from the time that the shipment entered or originated within the State). Further discussion of prenotification requirements is included in Section A. 3 of this Appendix.

The NRC intended such physical protection requirements to remain in effect until the results of confirmatory research became available and could be analyzed. The NRC and the DOE subsequently sponsored separate but coordinated experimental testing programs. Both programs were designed to yield information about the release of radioactive material from a specified reference sabotage event that was defined in terms of the expertise of the saboteurs, the amount of explosives used, the type of charge employed, and the 
characteristics of the cask. The NRC-sponsored experiments used model (smal1scale) explosives against simulated casks containing spent fuel (see $E$. W. Schmidt et al., Final Report on Shipping Cask Sabotage Sources Team

Investigation, NUREG/CR-2472, Nuclear Regulatory Commission, Division of Risk Analysis, Washington, D.C., 1982). The program sponsored by the DOE included one full-scale and several small-scale experiments (see R. P. Sandoval et al., An Assessment of the Safety of Spent Fuel Transportation in Urban Environs, SAND82-2365, Sandia National Laboratories, A1buquerque, NM, 1983). The results of both of these studies suggested that the releases of respirable radioactive particles in a sabotage event and the consequences of inhaling such particles were substantially smaller than those predicted in the NRC-sponsored study (published in 1978) that had prompted the original physical protection requirements. That study had predicted several tens of early fatalities and hundreds of latent-cancer fatalities from the sabotage of a truck cask containing three fuel assemblies in a densely populated urban area. The subsequent DOE and NRC research predicted no early fatalities and approximately 0.4 latent-cancer fatality as a consequence of the sabotage of a three-assembly cask in a similarly populated area. Assumptions concerning the "age" of the spent fuel (i.e., the length of the cooling period after removal of the fuel from the reactor), the population density, and the lifetime of respirable particles were all postulated at worst- or near-worst-case levels. When such assumptions are changed to more closely resemble typical or normal transportation conditions, the resulting consequences are predicted to decline further.

As a result of the more recent DOE and NRC studies, the NRC has proposed amendments to existing physical protection requirements. The proposed amendments (published in the Federal Register, Vol. 49, p. 23867, on June 8, 1984) would apply only to shipments of spent fuel cooled 150 days or more and would eliminate NRC requirements for--

- Maintenance of a communications center (and contact with the communications center every two hours by escorts).

- Written logs.

- Advance arrangement with local law-enforcement agencies.

- Armed escorts in heavily populated areas.

- Advance route approval by the NRC.

Under the proposed amendments, all existing physical protection requirements would continue to apply to shipments of spent fuel cooled for less than 150 days. The NRC concluded that not enough information was available on the consequences of sabotage involving "hotter" fuel to justify regulatory modification of physical protection requirements for shipments of spent fuel that had been cooled for less than 150 days.

The NRC has not issued physical protection requirements for shipments of highly radioactive waste other than spent fuel. In reviewing the scope of existing regulations and the decision not to include physical protection requirements for high-level radioactive waste shipments, the NRC noted in 1980 
that few NRC-licensed facilities possess high-level waste and that no shipments of the waste were being conducted (Federal Register, Vol. 45, p. 37404, June 3, 1980). The NRC added that when such shipments were made, appropriate physical protection requirements would be issued.

\section{DOE Physical Protection Requirements}

The DOE has established guidelines for "interim" physical protection procedures for unclassified DOE shipments of spent fuel. Those procedures, specified in DOE Order No. 5632.2, were approved by the DOT in 1982 in accordance with DOT regulations (49 CFR 173.22[c]). In approving the DOE procedures, the DOT noted that they were not identical to those established by the NRC, but were as effective in limiting the possibility of theft or sabotage in the transportation of spent fuel.

Requirements under existing DOE physical protection procedures include the following:

- The use of one escort to accompany a driver in a transport vehicle (the escort may be a back-up driver) or the use of a second vehicle occupied by two escorts to accompany the transport vehicle.

- The establishment of a communications center, with calls made by carrier personnel at least every four hours.

- The use of two-way communications devices for contact with the communications center and law-enforcement agencies.

- The use of some form of vehicle-locating device to assist in response in the event of an emergency incident.

- Notice provided by the carrier to the DOE of planned highway routes.

- The use of Interstate highways or limited-access highways, avoiding high-density urban areas through the use of circumferential highways where practicable.

- Periodic generic prenotification provided by the DOE to state officials.

- Inspection before shipment for evidence of sabotage attempts.

Unlike existing NRC requirements, existing DOE physical protection procedures do not require the use of armed guards in heavily populated areas, the use of vehicle-immobilization devices for highway shipments, or advance route approval by the NRC.

DOE physical protection procedures are now being revised to more closely parallel the amendments proposed by the NRC in 1984 for the physical protection of shipments of commercial spent fuel cooled for 150 days or more. Such procedures would require--

- Continued use of escorts. 
- Continued use of two-way communications equipment with communications center and four-hour call-ins.

- The use of vehicle-immobilization devices for highway transportation.

- Continuing route selection in accordance with DOT routing regulations (49 CFR 177.825).

- Courtesy communications with states of shipment schedules and general routing information (and the subsequent protection of such information).

The DOE physical protection requirements apply only to DOE shipments of spent fuel.

\section{A.4.2 Identification of Issue Elements}

In reviewing the development of physical protection procedures that will be applied to NWPA shipments, the OCRWM, the NRC, the DOT, States, Indian Tribes, and other interested parties have identified the following issue elements :

- The physical protection system that will be applied to waste shipments to NWPA facilities.

- The need to review proposed modifications to NRC physical protection requirements and the benefits of existing requirements.

- The physical protection procedures that will be applied to OCRWM shipments of spent fuel made in support of research and development activities.

A preliminary review of those issues is included below. Opportunities for public involvement are identified, where possible, and the expected timing of OCRWM policy decisions is discussed.

\section{A.4.3 Discussion of Issue Elements}

Physical Protection Procedures for Waste Shipments to NWPA Facilities

The OCRWM has indicated its intent to comply with all NRC physical protection requirements that exist at the time of shipments of nuclear waste to NWPA facilities. The OCRWM will therefore work with the NRC to review credible security threats and the appropriate level of physical protection that should be afforded to NWPA shipments. Appropriate physical protection requirements applicable to waste shipments are expected to be defined by mid-1990, when a request for proposals for transportation service contracts will be released. The timing is related to the need for information that will be required to support the OCRWM request for proposals.

In working with the NRC, the OCRWM will present the comments received both in written response to the draft Transportation Institutional $\mathrm{Plan}$ and by 
participants at the OCRWM Transportation Institutional Plan Workshop held in November 1985. The following issues were identified in such comments and recommendations:

- The need to reconsider the necessity for secrecy requirements related to routing and scheduling information.

- The potential need to reassess credible threats to shipments of radioactive waste and to ensure that physical protection requirements adequately protect against such threats.

- The potential need to develop physical protection requirements for shipments of high-level waste.

Specific plans for addressing these issues have not yet been developed. The OCRWM expects, however, that plans will be defined by the spring of 1987 and will be announced in the OCRWM Bulletin, through notices in the Federal Register where appropriate, and in future editions of the OCRWM Transportation Plan. Options that will be considered by the OCRWM and the NRC for reviewing and studying physical protection issues include workshops and additional technical studies.

\section{Review of Proposed NRC Amendments}

Discussions between the OCRWM, States, Indian Tribes, utilities, and other interested parties generally have addressed the potential need to retain or strengthen existing NRC requirements rather than adopt the proposed NRC amendments or to further reduce the existing NRC requirements. Some States and Indian Tribes, for example, have expressed the view that indirect safety benefits will be lost if the NRC discontinues requirements for route approval and advance coordination with local law-enforcement agencies. Many such concerns relate not to physical security but to safety considerations predicated on the inherent interest of States, Indian Tribes, and local governments in avoiding or minimizing the possibility of any abnormal shipping event.

The DOE believes that the physical protection procedures proposed by the NRC in 1984 represent effective protective measures against the theft and sabotage of spent-fuel shipments and is in the process of developing similar requirements for DOE shipments of unclassified spent fuel. The OCRWM believes that an appropriate method of addressing general transportation safety concerns is to (1) work with States and Indian Tribes to assist in the designation of transportation routes, consistent with DOT regulations, that offer an appropriate level of safety (see Section A.5); and (2) reinforce State, Tribal, and local emergency-response capabilities through training assistance and direct Federal response to transportation accidents (see Section A.8).

\section{Physical Protection Procedures for}

R\&D Shipments

Over the next five years the OCRWM will be making a number of shipments for several research and development (R\&D) programs conducted under the NWPA. Such shipments will be subject to the revised DOE physical protection 
procedures, which more closely parallel the procedures proposed by the NRC in 1984 for licensee shipments of commercial spent fuel that has been cooled for 150 days or more. Those procedures will continue to be followed until such time as the OCRWM establishes, in cooperation with the NRC, a physical protection system uniformly applicable to all waste shipments to NWPA facilities. This NWPA security system is expected to be defined by mid-1990. 


\section{A.5 Highway Routing}

\section{A.5.1 Overview}

In 1982 , the DOT established final routing regulations for the highway transportation of "highway route controlled quantity radioactive materials," which include the spent nuclear fuel and high-level waste that will be shipped to NWPA facilities. The DOT routing rules are commonly referred to as HM-164 (the docket number assigned to the rulemaking proceeding), and were published in the Federal Register (Vol. 46, pp. 5298-5318, January 19, 1981) before being incorporated in the Code of Federal Regulations (Title 49, Parts 171, 172,173 , and 177).

In studying the need for routing rules, the DOT concluded that the public risk associated with the highway transportation of radioactive materials was too low to justify the imposition of local transportation bans and other severe transportation restrictions and that "the impact of piecemeal state and local restrictions on the transportation of all radioactive materials (signified) the need for nationally consistent routing rules" (Federal Register, Vo1. 46, p. 5299, January 19, 1981). The validity of the routing rules was subsequently challenged by the City of New York, but was upheld by a ruling of a Federal Court of Appeals; the Supreme Court of the United States dismissed the city's appeal of the ruling (City of New York v. U.S. Department of Transportation, 715 F. 2d 732 [1983]; appeal dismissed and cert. denied, $104 \mathrm{~S}$. Ct. 1403 [1984]).

A brief summary of the DOT's routing requirements follows.

\section{Use of Preferred Routes}

Under DOT regulations, carriers must use preferred highway routes selected to reduce the time in transit (49 CFR 177.825). Preferred routes consist of (1) an Interstate System highway, with the use of an Interstate System bypass or beltway around cities when available; and (2) alternative routes selected by a "State routing agency." Indian Tribal authorities having police powers to regulate and enforce highway-routing requirements are included in the definition of "State routing agency" (49 CFR 171.8) and may designate alternative highway routes within Tribal lands.

Route designation by State and Tribal governments must be preceded by substantive consultation with any other affected jurisdictions (including local jurisdictions) to ensure the consideration of all impacts and the continuity of designated routes (49 CFR 171.8).

\section{Route-Selection Methodology}

Route designation by States and Indian Tribes must be performed in accordance with a DOT guidance document entitled Guidelines for Selecting Preferred Highway Routes for Highway Route Controlled Quantity Shipments of Radioactive Materials (DOT/RSPA/MTB-84/22, June 1984) or based on an equivalent routing analysis that adequately considers the overall risk to the public (49 CFR 171.8). The DOT guidelines identify the important factors involved in a routing analysis and are designed to assist state and Tribal officials in 
the selection of routes that result in the lowest public risks from the transportation of "highway route controlled quantity radioactive materials." As the DOT has noted in the guidance document, the guidelines provide one methodology for estimating transportation risk factors; States and Indian Tribes are free to develop an equivalent method of risk assessment or identify other important risk factors relating to unique local situations.

The DOT route-selection methodology consists of five basic steps:

- The identification of available highway routes.

- The evaluation of route-comparison factors using specific data for each alternative highway route.

- The selection of a route that minimizes transportation impacts.

- The documentation of the entire routing analysis to serve as a basis for a routing decision.

- Consultation with affected jurisdictions.

Under the DOT route-selection methodology, it is assumed that the primary factor in route selection is the risk that is associated with the radioactive cargo being transported. Such an approach should result in the selection of a route that minimizes radiation exposure during normal transportation and under potential accident conditions. The DOT guidelines establish the following primary route-comparison factors (or factors by which routes should primarily be judged):

- Radiation exposure from normal transportation.

- Public-health risk from transportation accidents.

- Economic risk from the accidental release of radioactive materials.

The following secondary route-comparison factors are established under the DOT guidelines:

- Emergency-response effectiveness.

- Evacuation capabilities.

- The location of special facilities, such as hospitals or schools.

- General traffic fatalities and injury rates associated with the route and unrelated to the radioactive cargo being transported.

\section{Deviation from Preferred Routes}

In accordance with DOT regulations (49 CFR 177.825[b][2]), a carrier may deviate from a preferred route under the following circumstances: 
- When emergency conditions exist that would make continued use of the preferred route unsafe.

- To make necessary rest, refueling, and vehicle-repair stops.

- To the extent necessary to pick up, deliver, or transfer a package of radioactive material.

Where such a deviation is necessary, another route is to be selected with consideration given to such factors as transit time, population density, and the time of day and time of week during which transportation will occur (49 CFR $177.825[a])$.

\section{Written Route Plans}

A carrier who operates a motor vehicle that contains a package of "highway route controlled quantity radioactive materials" must prepare a written route plan before the shipment's departure. The plan must be provided to both the driver of the vehicle and the shipper, and it must contain the following information:

- The origin and destination of the shipment.

- The routes to be used (within the DOT system of preferred routes).

- All planned stops and estimated times of departure and arrival.

- Telephone numbers for emergency assistance in each State through which a shipment will travel.

Any variation between the written route plan and the routes actually used must be reported in a written amendment to the route plan delivered to the shipper within 30 days of the route deviation (49 CFR 177.825[c]).

\section{Route-P1an Filing}

All spent fuel shipments must comply with a physical protection plan established under NRC regulations or equivalent requirements approved by the DOT (49 CFR 177.22[c]). The NRC requires advance submission of a route plan, which is then filed with the DOT. The DOE also provides the DOT with a listing of routes used for its spent fuel shipments.

For shipments of highly radioactive waste other than spent fuel, DOT regulations require the shipper to submit a shipment report that includes the route plan; any deviations from the route plan must also be reported ( 49 CFR 173.22[d]). The report is to be filed with the DOT within 90 days after the shipment begins. The DOT maintains records of all such shipment reports. This information is available for review by the public.

\section{A.5.2 Identification of Issue Elements}

Discussions between the OCRWM and interested parties have indicated the need to address the practical application of DOT highway-routing regulations 
to the transportation of radioactive waste to NWPA facilities. Issues related to State and Tribal designation of alternative highway routes and actual routing procedures for NWPA shipments include--

- The potential role of the OCRWM in working with the states, the DOT, and Indian Tribes to ensure an understanding of the DOT routing regulations.

- The need to review and potentially revise the route-selection methodology contained in the DOT's guidance document for uniform use by States and Indian Tribes in designating highway routes.

- The extent to which the OCRWM will assist the States and Indian Tribes in highway-route designation.

- The need for the OCRWM to review the routing procedures that will be applied to waste shipments to NWPA facilities and the degree of control that the OCRWM will exercise in determining the specific highway routes (selected in accordance with the DOT routing regulations) for waste shipments to NWPA facilities.

- The need to review the routing procedures that the OCRWM will apply to shipments conducted for research and development activities.

- The need to specify the sanctions that may be imposed against a carrier where routing requirements are violated.

In addition, discussions between the OCRWM and interested parties have identified the need to review routing assumptions and the use of routespecific data in transportation cost and risk analyses conducted by the OCRWM for the environmental impact statement that will support the selection of a repository site.

\section{A.5.3 Discussion of Issue Elements}

The following discussion contains a preliminary review of issues related to highway routing; identifies, where possible, opportunities for public involvement in the development and consideration of various policy options; and outlines the expected timing of OCRWM policy decisions and activities related to the development of the NWPA transportation program.

Review of DOT Routing Regulations

Participants at the OCRWM Transportation Institutional Plan Workshop (Atlanta workshop) held in November 1985 noted the need of States and Tribes to fully understand the requirements of DOT routing regulations and their options for designating highway routes for the transportation of radioactive materials in "highway route controlled quantities." Workshop participants recommended that the DOT develop an information program on routing regulations and route-selection guidelines. The workshop participants further recommended that the OCRWM provide the DOT with financial support for such an information program. 
In response to those comments, the DOT and the OCRWM are reviewing various mechanisms for the effective dissemination of general information on DOT routing requirements and procedures for State and Tribal route designation. Options currently being considered include the development of written materials and scheduling a jointly sponsored seminar. In view of other NWPA activities and program scheduling demands, the OCRWM has not yet established a schedule for such activities.

Review of Route-Selection Methodology

Some participants at the Atlanta workshop recommended a careful review of DOT guidelines for the development of a route-selection methodology. As discussed above, DOT regulations require States and Tribes to apply an appropriate route-selection methodology when evaluating and subsequently designating highway routes as alternatives to the Interstate highways for the transportation of specific quantities of radioactive materials. The workshop participants suggested that the methodology established under current DOT guidelines should be supplemented with additional guidelines to address such issues as high-hazard areas, the need for detailed assessment of transportation risks, and the effect of transportation on environmentally sensitive areas; the workshop participants also suggested that the OCRWM take a lead role in developing a route-selection methodology applicable to all routing decisions associated with NWPA shipments.

The OCRWM believes that it is important to distinguish between the appropriate roles of the States, Indian Tribes, the DOT, and the OCRWM in addressing various routing issues. The OCRWM accepts the DOT regulations as implementing a national policy for the highway transportation and routing of all radioactive materials and supports the development and application of nationally consistent route-selection methodologies. The OCRWM will therefore participate in a review of route-selection methodologies to be used by States and Indian Tribes in designating alternative routes (applicable to the transportation of all "highway route controlled" quantities of radioactive materials), but believes that the DOT, States, and Indian Tribes share in the responsibility for such a review. As an initial step, the OCRWM plans to support the review of route-selection methodologies through financial arrangements with regional or representative organizations. Such activities are currently being conducted through contractual arrangements with the Western Interstate Energy Board and with the Southern States Energy Board. The OCRWM plans to contract with other regional organizations of northeastern and midwestern States, and Tribal organizations, in order to provide similar assistance. The OCRWM will work with the DOT, in coordination with states and Indian Tribes, to determine what additional assistance and activities are appropriate in the review of guidelines for State and Tribal route-selection methodologies.

As discussed in further detail below, the OCRWM will assume a primary role in developing criteria (to be addressed in the operational element of the comprehensive transportation plan) for NWPA route planning. The OCRWM will develop the criteria through a cooperative process with interested parties; such criteria are expected to be in place by 1995 . 
OCRWM Assistance in Route Evaluation and

Designation by States and Indian Tribes

Under DOT regulations, the designation of routes as alternatives to the Interstate highways for the transportation of radioactive materials is the responsibility of States and Indian Tribes. Upon request, however, the OCRWM will provide technical assistance to States and Indian Tribes for the evaluation and designation of routes through such mechanisms as--

- Providing access to a highway-routing model (HIGHWAY) maintained by the Oak Ridge National Laboratory. (The highway network data base used in the model was developed by Logistics Systems, Inc. and user fees may be required.)

- Providing access to computer codes developed for the OCRWM to estimate the risk associated with waste transportation.

- Providing access to computer codes developed for the OCRWM to derive transportation-cost estimates.

The OCRWM will work with States and Indian Tribes on both an individual and regional basis to provide access to future codes developed for transportation analyses and to determine other forms of technical assistance that may be appropriate.

States and Indian Tribes have also requested that the OCRWM provide financial assistance for route evaluation and designation. Under the NWPA, grants will be provided to states that contain a candidate site for a repository and to affected Indian Tribes. Those grants may be used to support route-evaluation activities as they are directly related to the siting of the repository within the State borders or Tribal lands. The related routing activities of States and Indian Tribes that will be affected by NWPA transportation (but not by the siting of NWPA facilities) will be supported through financial arrangements with regional organizations. Such activities are currently being conducted under contractual arrangements with the Western Interstate Energy Board and the Southern States Energy Board. The OCRWM plans to make similar arrangements with other regional organizations in the northeast and midwest and with Tribal organizations.

OCRWM Routing Procedures for Waste Shipments to NWPA Facilities

The OCRWM has stated its intent to develop NWPA shipping procedures that conform to all DOT shipping requirements, including requirements for highway routing. Some comments received by the OCRWM have urged the development of additional NWPA shipping procedures under which the OCRWM would direct carriers to use specific highways within the DOT system of "preferred routes" (that is, Interstate highways and alternative routes designated by States and Indian Tribes).

The OCRWM believes that routing decisions involved in shipping commercial and defense waste to NWPA facilities must balance the OCRWM's oversight role and the need to allow service contractors (assuming the use of service contractors is found to be the preferred transportation-management option) to 
make routing decisions at the start or during individual shipments in order to avoid adverse transportation conditions (e.g., local weather conditions and traffic delays).

To implement this policy, the OCRWM will develop NWPA route-planning criteria as an operational element of the transportation plan (see Section A.16). The criteria will be developed after consultation with all interested parties, and are expected to be in place by 1995. Plans for public involvement include the discussion of route-planning criteria in workshops (such discussions can be initiated at a Transportations Plan Workshop, expected to be held in the fall of 1987) and the release of the criteria for review and comment before their issuance in final form.

At a minimum, the OCRWM's route-planning criteria will conform to all DOT routing requirements, including those that require that routes be selected to reduce time in transit. The criteria will further require the selection of routes that avoid operational delays (such as road construction and/or repair activities) and adverse seasonal weather conditions. Route-planning criteria will also address such factors as--

- The preferred time of day for travel through urban areas.

- Appropriate stopping places for rest, vehicle refueling, and vehicle repair.

Written route plans would then be developed by service contractors based on the OCRWM route planning instructions. (As noted above, written route plans are currently required by DOT regulations.) The OCRWM also plans to submit (or direct service contractors to submit) reports to the DOT on al1 waste shipments to NWPA facilities. Such reports will include the route plans and information on any deviations from such route plans.

OCRWM Routing Procedures for R\&D Shipments

Over the next five years the OCRWM will be making a number of shipments for several R\&D programs conducted under the NWPA. Routing procedures for shipments directed by the OCRWM for R\&D currently meet all DOT routing requirements, but will be further refined to move toward the routing procedures (discussed above) that are planned for future waste shipments to NWPA facilities.

Under current procedures, spent fuel used in research and development is transported by carriers on preferred routes consisting of Interstate highways and alternative routes designated by States. The OCRWM has established a policy of contacting States before shipping campaigns to ensure that carriers are provided with a current 1 isting of all routes that have been designated as alternatives to Interstate highways. Indian Tribes, however, have not yet designated alternate routes. In response to suggestions of Indian Tribal representatives, the OCRWM also plans to contact Tribal governments to ensure accurate information on Tribal route-designation activities. The OCRWM will consult with other DOE offices, the Department of the Interior, individual Indian Tribes, and the pertinent Tribal organizations to determine appropriate contacts with Indian Tribal governments. 
The OCRWM presently provides carriers with general guidance on the selection of transportation routes for specific spent-fuel shipping campaigns. Such guidance includes direction as to the preferred times for shipping through urban areas and the use of seasonal routes in different regions of the United States to avoid unfavorable weather conditions. As an integral part of the development of uniform routing procedures for waste shipments to NWPA facilities, the OCRWM expects to begin developing route-planning criteria and to apply at least rudimentary criteria to $R \& D$ shipping campaigns by 1988 .

In accordance with DOT regulations, the OCRWM will continue to ensure that postshipment reports are filed with the DOT. Like all general shipping information currently maintained by the DOT, such information will be available to the public.

Sanctions for Carrier Violations of Routing Requirements

As recommended by participants at the Atlanta workshop, contracts between the OCRWM and transportation-service contractors for NWPA shipments will specify the requirements of DOT routing regulations and formally direct that all shipments be conducted on Interstate highways or on alternative routes designated by States and Tribal governments. Transportation-service contracts will include incentives for good performance and specify sanctions for routing violations. Such sanctions may include the suspension and/or the termination of contracts.

\section{Routing Factors in NWPA Transportation}

Cost and Risk Analyses for EIS

The OCRWM will use certain route-specific data in the transportation cost and risk analyses conducted for the environmental impact statement (EIS) that will support the selection of a repository site. Evaluations of transportation cost and risk are expected to begin in 1987 and to be completed in late 1990. To assist in determining the parameters to be considered in such transportation analyses, the OCRWM is considering the use of regional routing workshops (potentially scheduled to begin in late 1986). Topics of discussion will include--

- A review of the requirements for computer models used to predict the cost and risk of transportation.

- Appropriate methods for determining (for the purpose of analysis) feasible routes to potential NWPA-facility sites and the extent to which States and Indian Tribes have designated preferred highway routes as alternatives to the Interstate highway system (consistent with DOT regulations).

- Specific factors (e.g., population data and accident data for particular segments of highways) that could be considered in routespecific transportation cost and risk analyses.

- The availability of route-specific data and, where data are not readily available, appropriate methods for obtaining such data. 
The OCRWM will provide formal notice of workshops and other opportunities for participation in the OCRWM Bulletin, in letters of invitation, and in the Federal Register as appropriate. 


\section{A.6 Rail Routing}

\section{A.6.1 Overview}

The routing of rail shipments of radioactive materials differs from the routing of highway shipments for several reasons. First, while the DOT has established highway-routing requirements for the transportation of radioactive materials, no Federal rail-routing regulations have been promulgated. Second, rail transportation offers fewer routing alternatives than does highway transportation because fewer alternative rail routes are available and the condition of rail tracks can limit the number of acceptable routes. Third, and in contrast to the public highway system, rail lines are generally privately owned and maintained by rail companies. The specification of rail routes must take into account such factors as the ownership of rail lines, shipping rates, and track conditions. The discussion that follows briefly reviews such issues and summarizes several important rail-routing studies.

The Hazardous Materials Transportation Act (HMTA) of 1974 (49 USC 1801 et seg.) specifically grants the DOT the authority to prescribe routing regulations for any mode of transportation. Section 105(a) of the HMTA provides that the Secretary of Transportation may issue regulations governing any safety aspect of hazardous materials transportation including packaging, marking, labeling, placarding and routing. The hazardous materials regulations adopted by the DOT are found in Title 49 of the Code of Federal Regulations, Parts 170-179. Part 174 contains regulations applicable to rail carriers of all hazardous materials, including radioactive materials.

The DOT adopted highway routing regulations for certain larger quantities of radioactive materials in 1982. The rulemaking docket that established the highway routing rules is commonly known as HM-164. During its consideration of highway routing, the DOT addressed the question of whether routing rules should be established for other types of hazardous materials and other modes of transportation. In the preamble to its final rule, the DOT stated:

The advanced notice of proposed rulemaking and the notice of proposed rulemaking made clear the Department's intention to consider only routing requirements for radioactive materials shipped by highway, the focus of most state and local actions, rather than undertake a comprehensive regulatory proceeding to consider all classes of hazardous materials and all modes of transportation. The fact that this proceeding considers only one hazard class and one mode does not rule out future Federal actions for other hazardous materials and other modes of transportation (Eederal Register, Vo1. 46, p. 5300, January 19, 1981).

The potential need to establish DOT routing regulations for rail transportation of hazardous materials, including radioactive materials, has subsequently been discussed in Congressional hearings on several occasions. To date, however, the DOT has not supported the need for such regulations.

With few exceptions, railroads direct the routing of general rail traffic to achieve one goal: operating efficiency. Operating efficiency normally entails the minimum use of track and equipment resources and is usually 
achieved by routing all traffic over a single main line between origins and destinations. Exceptions have been made to this routing practice to accommodate oversize loads that need to bypass a certain restriction and loads of extreme hazard that are routed (under special arrangements with the shipper) to avoid certain situations like a particular rail yard. Both of these exceptions are relatively rare. Rail traffic may also be rerouted because of blockages on a rail line or structural failures of the rights-of-way, but such rerouting is infrequent and generally of short duration.

There has been relatively little research and analysis of the benefits and costs of formalized requirements for routing spent-fuel shipments by rail. This may be due to the private ownership of the rights-of-way and the more 1 imited number of routing alternatives. However, several studies sponsored by the DOT's Federal Railroad Administration (FRA) should be noted.

One study (U.S. Department of Transportation, Federal Railroad Administration, Special Routing of Spent Fuel Shipments, DOT/FRA/ORD-82/27, Washington, D.C., 1982) was initiated in the late 1970s, when "away-fromreactor" (AFR) storage sites were being evaluated as an option to relieve shortages in spent-fuel storage capacity at certain reactors. The FRA wanted to investigate the potential for reducing the risk of rail transportation by using several routing possibilities between certain reactors and certain potential AFR storage sites. Seven route pairs and two alternative routes between each facility were evaluated. The routes were chosen for evaluation because of potential differences in the following route-selection factors:

- Population density.

- Distance.

- Interchanges (and associated factors like the population density in areas adjacent to switchyards and stop times).

- The condition of rail tracks (categorized under a system of six rail classes).

- Track-specific accident rates.

- Carrier-specific accident rates.

- Weather patterns.

The study found no beneficial cost-versus-risk reduction relationship for any of the seven origin-destination pairs studied; that is, for all routes considered the low-risk route was also the low-cost route. The sensitivity analysis performed for the study also indicated that distance was the most sensitive variable for both cost and risk. Furthermore, the greatest risk reduction was found to occur when routes could be selected to minimize the distance traveled through high population zones.

Between 1980 and 1982 the DOT's Transportation Systems Center produced for the FRA several project reports that analyzed the aggregate national effects of rerouting hazardous-material shipments by rail to avoid population 
centers (U.S. Department of Transportation, Transportation Systems Center, Analysis of a National Policy for Routing Hazardous Materials on Railroads, SS-223-U-5-49, Washington, D.C., 1980; and U.S. Department of Transportation, Transportation Systems Center, Aggregate Effects of Rerouting Hazardous Material Railroad Shipments, Project Memorandum TM-223-U-1.1-5, Washington, D.C., 1982). These studies were conducted in response to evaluations and a subsequent report by the National Transportation Safety Board (National Transportation Safety Board, Analysis of Proceedings of the NTSB into Derailments and Hazardous Materials, Washington, D.C., 1982) that advocated a national rail-routing system for hazardous materials.

The objective of the second FRA study was to estimate the safety effects of a "population-avoidance" policy for routing rail shipments of hazardous materials. Hazardous-material flow patterns were first estimated, and then altered to reduce population exposure. The safety effects were assessed by estimating the population exposures and casualties expected from a release of hazardous materials in the event of a train derailment.

The study concluded that the total population exposure could be reduced by as much as 25 percent with the routing of shipments around population centers. However, total shipping distances were increased by 15 to 20 percent. In addition, because shipments were rerouted from mainline railroads, which connect population centers, to lower-quality secondary and branch 1 ines, the number of casualties expected from accidents actually increased by 1 percent. This analysis assumed that rail traffic would not be diverted from one rail company to another in order to reroute around population centers.

The study further evaluated the effects associated with rerouting that was made possible by employing several rail companies for carriage. The results indicated that casualties could be reduced by as much as 50 percent by such rerouting. However, this reduction could be achieved only with a substantial increase in shipping cost.

Perhaps the most enlightening finding of the second FRA study was the comparison of the effects on risk of "population-avoidance" routing and improvements in track conditions. The study found that the casualties expected from hazardous-material releases were far more sensitive to track upgrades than to any kind of rerouting policy. For example, expected casualties could be reduced as much as 60 percent by upgrading track conditions and without any rerouting at all. Of course, a track-upgrading program would be costly. Finally, the FRA study did note that, although a national rerouting policy may produce only marginal safety improvements in the aggregate, there could be significant localized improvements in safety by rerouting to avoid specific urban areas.

\section{A.6.2 Identification of Issue Elements}

In discussions between the OCRWM and interested parties, the following rail-routing issues have been identified:

- The need for the OCRWM to review with the DOT the potential need for Federal rail-routing regulations. 
- The need for the OCRWM to review the rail-routing procedures that will be applied to waste shipments to NWPA facilities and the degree of control that the OCRWM will exercise in determining specific rail routes.

- The need for the OCRWM to review rail-routing assumptions and the use of certain route-specific data in transportation cost and risk analyses conducted for the environmental impact statement that will support the selection of a repository site.

\section{A.6.3 Discussion of Issue Elements}

The discussion that follows contains a preliminary review of issues related to rail routing; identifies, where possible, opportunities for public involvement in the development and consideration of various policy options; and out 1 ines the expected timing of OCRWM policy decisions and activities.

Review of Need for Federal Rail-Routing Regulations

As previously noted, the Congress, in enacting the HMTA, authorized the DOT to promulgate national safety regulations for the transportation of hazardous (including radioactive) materials. The DOT's authority extends to the regulation of the routing of hazardous materials, where such regulation is determined to be necessary. The OCRWM will therefore work with the DOT to review the need for Federal rail-routing regulations that would apply to the transportation of radioactive materials. The OCRWM will also consult with the NRC, other affected DOE offices, railroad companies, and the Association of American Railroads during the review. Mechanisms for addressing the potential need for Federal rail-routing regulations may include--

- Technical studies to evaluate the need for rail-routing regulations.

- Workshops specifically designed to solicit the views and comments of the rail industry.

- Petitioning the DOT for a formal rulemaking if, after review, the OCRWM concludes that the routing of shipments of radioactive materials by rail requires regulation.

Information on progress made through discussions with the DOT, the NRC, other DOE offices, and railroad representatives; opportunities for public involvement in the review process; and scheduling details will be provided through the OCRWM Bulletin, the OCRWM's comprehensive transportation plan, and the Federal Register, as appropriate.

\section{OCRWM Rai1-Routing Procedures for NWPA Shipments}

While national rail-routing regulations may ultimately be established by the DOT, the OCRWM has begun to review appropriate rail-routing procedures for NWPA shipping campaigns. Some comments received by the OCRWM have urged the development of NWPA shipping procedures under which the OCRWM would direct the use of specific rail routes for shipments to NWPA facilities. 
The OCRWM is now investigating the use of service contractors who would be responsible for such activities as making carriage arrangements and managing transportation operations. The OCRWM's role in making rail-routing decisions for waste shipments to NWPA facilities must balance the OCRWM's oversight role for NWPA activities and the need to provide service contractors with the authority to make routing decisions at the start or during shipping campaigns in order to avoid unique and adverse local conditions (e.g., track repair or train derailments). The OCRWM therefore plans to develop NWPA route-planning criteria for rail shipments as part of the operational element to be contained in the OCRWM's comprehensive transportation plan. The criteria will parallel certain features of the OCRWM route-planning criteria developed for highway shipments to NWPA facilities (see Section A.5), will be developed after consultation with interested parties, and are expected to be in place by 1995. The OCRWM will facilitate public involvement in the development of route-planning criteria through--

- The use of workshops (initial discussions are planned as a topic for review at a Transportation Plan Workshop, tentatively scheduled for the fall of 1987).

- The release of route-planning criteria for review and comment before their issuance in final form.

At a minimum, the OCRWM's route-planning criteria for rail shipments will require the selection of rail routes that limit shipping costs and transit times, avoid population centers (where possible), and avoid adverse seasonal weather conditions.

The OCRWM also plans to submit (or direct service contractors to submit) reports to the DOT on all waste shipments to NWPA facilities. Such reports will include the rail routes used for NWPA shipping.

Rail-Routing Factors in NWPA Transportation Cost and Risk Analyses for EIS

The OCRWM will use certain route-specific data associated with rail, truck, and barge transportation in the transportation cost and risk analyses conducted for the environmental impact statement that will support the selection of a repository site. Detailed planning for such analyses will begin in 1986. The transportation analyses are expected to be completed in late 1990 and will include an analysis of the cost and risk associated with rail transportation.

To assist in planning and the definition of appropriate analysis parameters, the OCRWM is considering the use of regional workshops (potentially scheduled to begin in late 1986). The topics of discussion are expected to include the following:

- A review of the requirements for computer models used to predict the cost and risk of shipping spent fuel and high-level waste.

- Appropriate methods for determining feasible routes to potential NWPA facilities. 
- Specific factors (e.g., population data, marshaling yards, and accident data) that could be considered in cost and risk analyses.

- The availability of route-specific data and, where data are not readily available, appropriate methods for obtaining such data.

The OCRWM will provide formal notice of workshops and other opportunities for participation in the OCRWM Bulletin, in letters of invitation, and in the Federal Register, as appropriate. 


\section{A.7 Inspection and Enforcement for Highway and Rail Shipments}

\section{A.7.1 Overview}

Inspection-and-enforcement activities for the transportation of radioactive materials are shared by Federal and State agencies. Current inspection-and-enforcement activities, Federal training courses, and financial-assistance programs are reviewed below.

\section{NRC Inspection and Enforcement}

The NRC maintains an active inspection-and-enforcement program to ensure that its regulations and control procedures are met by NRC licensees. Under 10 CFR 71.93, licensees who intend to use an NRC-certified spent-fuel cask are required to notify the NRC at least 45 days before the fabrication of the cask. The NRC then performs quality assurance (QA) inspections during cask fabrication. In addition, suppliers (not necessarily NRC 1 icensees) of NRCcertified casks currently obtain an NRC-approved QA program. The NRC has developed an inspection program for the implementation of the QA programs of cask suppliers.

Furthermore, operators (registered users of NRC-certified casks) are required to have an NRC-approved QA program. Related activities are inspected by the NRC. Such inspections are normally conducted at points of shipping origin and include review of--

- Procedures for preparing of empty casks for transportation.

- Procedures for loading shipping casks on transport vehicles.

- Cask-maintenance programs (periodic cask testing, inspection, and adherence to replacement schedules).

- Physical protection plans and procedures.

- Radiation monitoríng.

Enforcement mechanisms for violations of NRC requirements include written citations and monetary penalties.

\section{DOT Inspection and Enforcement}

The DOT inspects radioactive-waste shipments to monitor compliance with the DOT's regulatory requirements. DOT inspectors are provided by the office of Research and Special Programs Administration and by the DOT's Federal Highway Administration (for highway shipments) the Federal Railroad Administration (for shipments by rail). Inspections monitor compliance with factors such as package marking and labeling, placarding, shipping papers, and radiation-dose rates. In addition, DOT inspections of highway shipments monitor vehicle safety and route plans. Inspections of shipments by rail also include a review of track safety, operating practices, power and equipment, and signal and train controls. 
DOT inspections of radioactive-waste shipments have generally involved a related series of shipments; in such a case, DOT inspectors have concentrated their efforts on the first shipment of a series. Enforcement mechanisms for violations of DOT requirements include written citations and monetary penalties.

\section{DOE Inspection and Enforcement}

When conducting shipments of radioactive waste (generated in national defense or R\&D activities), the DOE performs its own inspections of the cask and transportation vehicles, and reviews factors such as--

- Preparation of the cask for transportation.

- Vehicle loading.

- Vehicle safety.

- Marking and labeling.

- Placarding.

- Physical protection plans.

- Radiation emissions from the casks.

In many instances, DOE inspection activities are further assisted by the DOT. The enforcement procedures of the DOE are specified in contractor agreements, and include the suspension and termination of contracts to penalize contractors for noncompliance.

\section{State Inspection}

The DOT has encouraged substantial State participation in the implementation and enforcement of Federal regulations governing the transportation of hazardous (including radioactive) materials. States wishing to implement and enforce such Federal regulations are required to adopt the pertinent Federal regulations, train and certify inspection-and-enforcement personnel, and then conduct State inspection-and-enforcement activities in a manner consistent with Federally established procedures.

To assist in the development of State inspection-and-enforcement capabilities, the DOT initiated a States' Hazardous Materials Enforcement Program in 1981. The program was designed to foster Federal and State partnership in the inspection and enforcement for the safe transportation of hazardous materials (including radioactive materials). The program was administered through contracts with individual states, and provided incentives for State adoption of the Federal regulations in hazardous-material transportation. Federal funding for the program ended in 1985.

The program is succeeded by the Motor Carrier Safety Assistance Program, administered by the DOT's Bureau of Motor Carrier Safety. Under this fiveyear program, grants are to be provided to States to assist in the enforcement and development of safety regulations for commercial motor vehicles (including those applied to the transportation of hazardous materials). Two types of grants are available to the states: development grants, to be used by States to develop safety regulations, and implementation grants, which represent most of the funding and are to be used to cover State enforcement-and-inspection costs. In order to be eligible for an implementation grant, states must show 
that they have adopted Federal regulations governing motor-carrier safety and the transportation of hazardous materials or have enacted State regulations with equivalent transportation safety requirements. Authorized funding for the program was set at $\$ 10 \mathrm{million}$ in 1984 , with $\$ 10 \mathrm{milli}$ in increases per year until the program ends in 1988. Actual Congressional appropriations to date have been less than authorized funding.

The DOT's Federal Railroad Administration also has a program for State participation in rail-inspection activities. Financial assistance is provided on an annual basis through cost-sharing mechanisms to support cooperative State inspections of track safety, rail operating practices, power and other general equipment, and signal and train control. The program currently does not provide for state inspection activities related specifically to the transportation of hazardous (including radioactive) materials. Most State inspection activities conducted to date under the program have focused on track safety, and the safety of power and other general equipment.

\section{Training}

The DOT has developed a training program to support the enforcement activities of States. Such training is directed by the DOT's Transportation Safety Institute (based in Oklahoma City, Oklahoma) and is provided in locations selected by organizations or agencies sponsoring the class (at a set fee of $\$ 3,600$ for classes of up to 50 people).

In addition, the DOT's Federal Railroad Administration has funded the development of a computerized compliance training program. The program addresses the transportation by rail of radioactive and other hazardous materials. The program, developed with the assistance of the railroad industry, may prove useful to state inspection personnel.

The DOE also sponsors a series of radioactive material emergency response workshops throughout the country. The workshops, designed for regulatory and enforcement personnel as well as first responders to transportation incidents, cover four major topics: general hazardous materials, radioactive materials, radioactive materials shipments, and response to incidents involving radioactive materials.

\section{Review of Training Programs}

When reauthorizing the Hazardous Materials Transportation Act in 1984, Congress directed the FEMA and the DOT to undertake a survey of training programs offered for emergency response and enforcement activities related to the transportation of radioactive and other hazardous materials. The final results of the survey are expected to be submitted to Congress in the summer of 1986.

In addition, the Senate Committee on Commerce, Science and Transportation directed the U.S. Congress' Office of Technology Assessment (OTA) to conduct a study of hazardous-material transportation. The study includes a review of training programs for enforcement and is summarized in two documents. The first, issued in March 1986 (U.S. Congress, Office of Technology Assessment, Transportation of Hazardous Materials: State and Local Activities, 
OTA-SET-301, Washington, D.C., March 1986), offers a partial compilation of available training programs and identifies state and local concerns. The second document, released in July 1986, examines in further detail Federal regulations and technical programs (including those addressing enforcement activities) and assesses the extent to which they meet identified needs for the safe transportation of hazardous materials (see U.S. Congress, Office of Technology Assessment, Transportation of Hazardous Materials, OTA-SET-304, Washington, D.C., July 1986).

\section{A.7.2 Identification of Issue Elements}

Discussions between the OCRWM and interested parties have led to the identification of three major issue elements related to the inspection of NWPA shipments for compliance with transportation regulations:

- The need to define the potential role of the OCRWM in facilitating an intergovernmental evaluation of current inspection-and-enforcement procedures, the adequacy of such procedures, the roles of various government entities, and the level of inspection and enforcement needed for NWPA shipments.

- The need for the OCRWM to develop (through a cooperative process) its own set of inspection criteria.

- The need for the OCRWM to participate in the development of a system of reciprocity for inspections conducted by states and define the levels of technical or financial assistance that the OCRWM will provide for inspection-and-enforcement activities.

\section{A.7.3 Discussion of Issue Elements}

The following discussion reviews inspection-and-enforcement issues, opportunities for public involvement in the evaluation of policy options and OCRWM activities, and the schedule of OCRWM activities.

\section{Review of Current Inspection Procedures}

Some participants at the OCRWM Transportation Institutional Plan Workshop (Atlanta workshop) held in November 1985 recommended that the OCRWM, as a radioactive waste shipper under the NWPA, work with the DOT and the NRC to facilitate the review of--

- Current DOT and NRC inspection-and-enforcement procedures and the adequacy of such procedures for future NWPA shipments.

- The need to develop guides for uniform State-to-State inspection procedures and eventually standards for inspection and training for and by state inspection officials.

- The appropriate roles of Federal agencies and State and Tribal governments in inspection and enforcement. 
- The need to coordinate existing Federal, State, and private training programs.

The OCRWM will review recommendations related to inspection procedures with both the DOT and the NRC. Specific plans for addressing the issues, however, have not yet been developed. Options that will be considered include--

- The use of workshops involving Federal, State, and Tribal inspectionand-enforcement personnel, utilities, carriers, and other appropriate persons to clarify inspection-and-enforcement responsibilities and needs.

- The development of written guidance to clarify the Federal, State, and Tribal roles in inspection and enforcement for all modes of transportation.

- The use of information circulars to review training courses.

- Sponsoring technical surveys and studies to assess the adequacy of existing inspection-and-enforcement activities and determine the potential need for strengthened or additional programs.

The OCRWM expects that initial plans for addressing these issues will be developed by the spring of 1987 and will be announced in the OCRWM Bulletin; the Federal Register, where appropriate; and future editions of the OCRWM's comprehensive transportation plan. The implementation of these plans will be conducted in consultation with appropriate Federal agencies, States, and Indian Tribes.

OCRWM Inspection Criteria for NWPA Shipments

The inspection by OCRWM service contractors of casks and associated transportation equipment will be an important element of future NWPA transportation operations. The OCRWM will develop rigid inspection criteria and periodic compliance-testing procedures. Such criteria will comply with the Transportation Program Quality Assurance P1an (now being developed) and will be established in coordination with the NRC, the DOT, carrier industries, the utilities, States, Indian Tribes, local governments, and all other interested parties. The OCRWM considers the use of workshops to be an effective means of reviewing various policy alternatives and obtaining practical suggestions for the development of inspection criteria for NWPA shipments. Such criteria for NWPA shipments will be included in contracts with service contractors. Under current planning, the criteria will include inspection procedures related to--

- Cargo loading and unloading.

- Vehicle safety.

- Driver qualifications and safety records. 
- The preparation of shipping casks in compliance with all Federal regulations.

OCRWM actions in the event of safety and security violations will include the suspension and/or termination of transportation service or carrier contracts.

The development of inspection criteria for the NWPA transportation program is expected to be completed by mid-1990. The criteria will be made available for review and comment before being issued in final form.

A comprehensive inspection-and-enforcement program for NWPA transportation is expected to be defined by 1993 and will be addressed as an element of the transportation plan. The inspection-and-enforcement program will include--

- Inspection-and-enforcement criteria and procedures for service contractors.

- Training requirements for inspection activities of service contractors.

- The delineation of cooperative Federal, State, and Tribal inspection activities.

The schedule for the development of the program is directly related to the schedule of negotiations for service and rail carrier contracts.

\section{OCRWM Assistance for Inspection and Enforcement}

Participants at the OCRWM Atlanta workshop and persons interested in the development of the NWPA transportation program have suggested that the OCRWM support the development of a program that will establish the reciprocity of inspections conducted by States (and presumably Indian Tribes where they have independent authority in inspection and enforcement). Under the proposed system of reciprocal inspection agreements, an inspection conducted by one State would be honored by other States; the need for inspections of transportation personnel, transportation vehicles, and cargo would therefore be generally limited to the shipping origin and destination.

A similar system has been established by the Commercial Vehicle Safety Alliance (CVSA). The CVSA was formed in 1980 by the States of California, Oregon, Washington, and Idaho to establish uniform inspection methods and standards and to provide recognition for the inspection efforts (reciprocity) among the participating States. The organization has since grown to include, as of July 1986, 34 member States and 2 Canadian Provinces. The efforts of the CVSA toward multistate reciprocity of inspections are intended to prevent duplication of effort and to enhance the cost effectiveness of state inspection-and-enforcement activities. The activities of the CVSA are also intended to ensure that government efforts to increase highway safety are coordinated with the operational needs of the trucking industry. 
The OCRWM supports the concept of reciprocal inspection arrangements among States and Indian Tribes (where the Indian Tribes have the authority to conduct such activities). To assist in the development of such a program for NWPA shipments, the OCRWM will develop financial arrangements with a technical organization to support an evaluation of the inspection needs of states and Indian Tribes and formulate a model agreement for reciprocal inspections. Such an arrangement is expected to be in place by the summer of 1986; details will be provided in the OCRWM Bulletin.

The OCRWM plans to support the definition of Federal, state, and Tribal inspection and enforcement roles for rail shipments of radioactive waste through the formation of a study group and workshops. It is expected that such activities will be initiated in 1988 .

The extent of direct technical and financial assistance needed to support State and Tribal inspection-and-enforcement activities, training, and requirements for equipment related to inspections of NWPA shipments has not yet been determined. Under the NWPA (Sections 116[c][2][A] and 118[b][3][A]), however, financial assistance will be provided to states having a repository site selected for construction, and to all affected Indian Tribes, to mitigate impacts associated with the development of a repository. Local governments and affected Indian Tribes in States with a site under consideration for an MRS facility are also eligible for assistance to mitigate the impacts associated with the construction and operation of such a facility (Section 141[f] and $[\mathrm{h}])$. The OCRWM will review the potential need to provide such assistance for planning and the development of necessary inspection-and-enforcement capabilities.

Appropriate types and levels of assistance may be addressed in the consultation-and-cooperation agreements to be negotiated under Sections $117(\mathrm{c})$ and $141(\mathrm{~h})$ of the NWPA between--

- Upon request, States that have been formally notified by the DOE as containing a site that is potentially acceptable for development as a repository and the affected Indian Tribes.

- States containing a candidate repository site selected for characterization, and the affected Indian Tribes.

- A host State for an MRS facility (if such a facility is approved by Congress) and the affected Indian Tribes.

The extent and source of financial assistance that may be provided to other States, Tribes, and local governments for inspection and enforcement activities is not expected to be determined until 1993 (18 months after a repository site is selected). 


\section{A.8 Emergency Response}

\section{A.8.1 Overview}

The general roles of carriers, shippers, governmental entities, and Federal agencies in the event of an accident involving the transportation of radioactive materials can be summarized as follows:

- Carriers. The carrier has the initial responsibility for minimizing radiation hazards to the public and notifying state and local authorities, the shipper, the driver's own management, and appropriate Federal agencies of accidents. (See, for example, 49 CFR 171.15 and 49 CFR 177.861.)

- Shippers. The shipper is required to provide to the carrier, when shipment is made, information that should include any special precautions required for dealing with the shipment. (See 49 CFR 172.203[d] and 49 CFR 177.825[c][2].) If called in case of an accident, the shipper is also required to provide details of the shipment that may be necessary or helpful to support appropriate emergency response activities. In addition, shippers of spent fuel and high-level radioactive waste should provide carriers with 24-hour emergency contacts.

- States, Indian Tribes, and local governments. State and local governments have primary responsibility for implementing measures at the scene of the accident to protect life, property, and the environment. Necessary actions may include stopping traffic, extinguishing fires, and rescuing the injured. The extent to which Indian Tribal governments are responsible for responding to radiological emergencies on their land is presently unclear. Plans to address Tribal emergency response activities in future planning documents are discussed later in this section.

- Federal agencies. Federal agency assistance is available to support State and local government response measures; such assistance is provided on the request of State and local governments.

More detailed information on emergency-response planning and procedures is provided below.

\section{Federal Emergency-Response Roles and Planning Activities}

Under the provisions of Executive Order 12148 of July 20, 1979, the FEMA is responsible for establishing policies for and coordinating all civil defense and civil emergency planning, management, mitigation, and assistance functions of the Federal executive agencies. The Director of the FEMA is charged under this Executive Order with representing the President in working with State and local governments and the private sector to stimulate active participation in planning and implementing civil emergency-response and recovery programs. As used in the order, civil emergencies include emergencies or threats associated with transportation accidents involving radioactive materials. 
The FEMA subsequently was directed (under Executive Order 12241, dated September 29,1980 ) to prepare and publish a national contingency plan for the Federal response to accidents in commercial nuclear power plants. To fulfill this mandate, the FEMA published a master plan on December 23, 1980, for response to accidents in nuclear power plants. The master plan was subsequently broadened in scope to become the Federal Radiological Emergency Response Plan (FRERP), and to cover all types of peacetime radiological accidents, including transportation accidents. Following its release as an interim plan (on January 1, 1984), the FRERP was published on November 8, 1985 (Federal Register, Vol. 50, p. 46542), as an operational plan having the concurrence of the Federal agencies that have responsibilities in the event of a radiological emergency. Those agencies are--

- The Federal Emergency Management Agency (FEMA).

- The Department of Energy (DOE).

- The Department of Transportation (DOT).

- The Nuclear Regulatory Commission (NRC).

- The Environmental Protection Agency (EPA).

- The Department of the Interior (DOI).

- The Department of Defense (DOD).

- The Department of Commerce (DOC).

- The Department of Health and Human Services (HHS).

- The Department of Housing and Urban Development (HUD).

- The U.S. Department of Agriculture (USDA).

- The National Communications System (NCS).

To coordinate Federal radiological assistance under the FEMA plan, the DOE developed a draft Federal radiological monitoring and assessment plan (FRMAP). Although the FRMAP is part of the FRERP, it may be implemented separately. The FRMAP deals with the actual initiation and coordination of Federal radiological monitoring and assessment assistance. Under the plan, the DOE has the primary responsibility (if assistance is requested by State or local governments) to provide technical personnel and equipment to perform radiation monitoring, and evaluation activities in the event of a transportation accident involving high-level waste.

Other DOE emergency-response roles include the following:

- Assessing the accident and developing technical recommendations on protective action, in coordination with other appropriate agencies. 
- Maintaining and making available a common set of radiation-monitoring data.

- Providing technical and medical advice about the treatment of radioactive contamination.

- Assisting in early planning for the decontamination and recovery of the accident area and making recommendations to avoid the spread of contamination by improper emergency operations.

- Providing telecommunications support to other Federal agencies involved in radiation monitoring if such support is necessary.

DOE has eight regional teams of emergency response experts to assist in responding to accidents. After the DOE's initial emergency-response assistance has been completed, intermediate and long-term monitoring duties are to be transferred to the EPA if the need for Federal assistance continues.

\section{State and Local Planning}

The FEMA established the Federal Radiological Preparedness Coordinating Committee (FRPCC) and Regional Assistance Committees (RACs) through regulation ( 44 CFR Part 351) in order to coordinate Federal assistance to State and local governments for peacetime radiological emergencies.

The FRPCC is composed of ten Federal agencies: the FEMA, the DOE, the DOC, the DOD, the EPA, the HHS, the DOI, the NRC, the DOT, and the USDA. The FRPCC aids the FEMA in providing policy direction for the program of Federal assistance to state and local governments on their planning and preparedness activities for radiological emergencies. The FRPCC has subcommittees, including the Subcommittee on Transportation Accidents. This subcommittee coordinated the development of a guidance document, Guidance for Developing State and Local Radiological Emergency Response Plans and Preparedness for Transportation Accidents (FEMA REP-5, 1983). In addition to general information on transportation systems and casks, the FEMA REP-5 document provides planning objectives and guidance.

The state planning activities suggested in the document include--

- The development and distribution of a radiological-emergency-response plan addressing Federal, State, and local and private responsibilities and resources.

- The designation of a radiological-emergency response team.

- Coordinating a communications system of Federal, State, and local agencies involved in responses to radiological emergencies.

- Negotiating agreements with contiguous States addressing responses to incidents in proximity to a common border.

- The preparation, or assistance in preparing, and distribution of implementing instructions and operational procedures to be used by 
State, local, and/or other emergency-response personnel in carrying out their responsibilities.

Planning activities by local governments, according to the FEMA guidance document, should prepare local responders to--

- Administer emergency measures to save 1 ives and attend to the injured.

- Determine whether radioactive or other hazardous materials are present in the transportation incident and secure information about these materials.

- Notify appropriate authorities to obtain radiological expertise.

- Determine the actions required to prevent further damage to life or property.

The FEMA REP-5 document is now being revised and will include a discussion of Tribal emergency-response activities.

While the FRPCC has coordination responsibilities at the national level, the RACs provide coordinated Federal assistance directly to state and local governments. In general, the RACs are composed of the same membership as the FRPCC. Per specific request from State and local governments, Federal assistance is provided through the integrated efforts of the RACs and FEMA regional offices (to the extent that resources permit).

\section{Federal Emergency-Response Training}

The FEMA operates the Emergency Management Institute, based at the National Emergency Training Center, in Emmitsburg, Maryland. Courses offered by the Institute address such topics as radiological accident assessment, planning for radiological-emergency preparedness, and planning for radiological-emergency response teams. Information on the Emergency Management Institute and a schedule of courses can be obtained by writing to the FEMA National Emergency Training Center, Emmitsburg, MD, 20727.

The DOE has created the Radiation Emergency Assistance Center/Training Site (REAC/TS) at Oak Ridge, Tennessee. The REAC/TS, operated by the Oak Ridge Associated Universities, is a multipurpose facility designed to treat victims of radiological accidents. It is designed to handle any type of radiation-exposure accident that might occur at Oak Ridge or elsewhere. Specialized courses are presented periodically for physicians, health physicists, and paramedical personnel.

The DOE also sponsors a series of radioactive material emergency response workshops throughout the country. These one-day introductory courses cover basic emergency-response issues related to hazardous materials transportation incidents, with emphasis on accidents. The workshops are conducted on behaif of the DOE by the Science Applications International Corporation, a consulting firm based in Oak Ridge, Tennessee. Designed for regulatory and enforcement personnel as well as first responders to transportation incidents, the workshops cover four major topics: general hazardous materials, radioactive 
materials, radioactive-material shipments, and response to incidents involving radioactive materials.

The DOT is also involved in preparing states and local governments to respond to hazardous material transportation emergencies. The DOT supports the Transportation Safety Institute in Oklahoma City, Oklahoma. In addition, the DOT also has published and distributed the 1984 Emergency Response Guidebook: Guidebook for Hazardous Material Incidents (DOT/P-5800.3, 1983). The Guidebook was developed under the supervision of the DOT's Research and Special Programs Administration. The Guidebook contains an inventory of hazardous materials, including radioactive materials, and a series of 65 one-page guides listing potential hazards and recommended emergency actions. The Guidebook is intended to be carried, for immediate use, in every emergency service vehicle (fire, police, first aid, civil defense) in the United States. The guide will be revised every 3 years. Copies of the current edition can be obtained by writing to the U.S. Department of Transportation, Research and Special Programs Administration, Attention: DHM-50, Washington, D.C., 20590.

Additional training courses are offered by the EPA, which has established an emergency-response training center in Edison, New Jersey, and the National Oceanic and Atmospheric Administration (NOAA). The NOAA provides emergency response exercises for shipping accidents in ports and inland waterways.

\section{Review of Training Programs}

When reauthorizing the Hazardous Materials Transportation Act in 1984 , Congress directed the FEMA and the DOT to undertake a survey of training programs offered for emergency-response and inspection activities related to the transportation of hazardous materials (including radioactive materials). The final results of the survey are expected to be submitted to Congress in the summer of 1986.

In addition, the Senate Committee on Commerce, Science and Transportation directed the U.S. Congress' Office of Technology Assessment (OTA) to conduct a study of hazardous-material transportation. The study includes a review of training programs for emergency response and is summarized in two documents. The first, issued in March 1986 (U.S. Congress, Office of Technology Assessment, Transportation of Hazardous Materials: State and Local Activities, OTA-SET-301, Washington, D.C., March 1986), offers a partial compilation of available training programs and identifies state and local concerns. The second document, released in July 1986, examines in further detail Federal regulations and technical programs (including those addressing emergency response) and assesses the extent to which they meet identified needs for the safe transportation of hazardous materials (see U.S. Congress, Office of Technology Assessment, Transportation of Hazardous Materials, OTASET-304, Washington, D.C., July 1986).

The DOT's National Hazardous Materials Transportation Advisory Committee has also reviewed needs associated with emergency response to transportation accidents involving hazardous materials, and recently submitted recommendations to the Secretary of Transportation. 
The DOE operates, in conjunction with the Defense Nuclear Agency, the Joint Nuclear Accident Coordinating Center (JNACC). The purpose of the JNACC, which is headquartered at the Kirtland Air Force Base in Albuquerque, New Mexico, is to exchange and maintain information related to radiologicalassistance capabilities. The JNACC also functions as a point of coordination for assistance activities in connection with radiological accidents.

In addition, the DOT maintains the National Response Center in Washington, D.C. through the Coast Guard and in cooperation with the EPA to provide information and advice to all interested parties for meeting emergencies involving spills of hazardous substances.

\section{Industry Emergency Response Assistance}

The transportation industry is also working to promote emergency response capabilities for the transportation of radioactive materials. The railroad industry, through the Association of American Railroads (AAR), a trade organization, is undertaking the development of a model railroad industry nuclear emergency response plan. This project evolved from a workshop, sponsored by the AAR and the DOE in 1981, that examined the measures necessary to better prepare for possible accidents involving the transportation of radioactive waste on the nation's railroad system. At that meeting, the AAR, the DOE, the DOT, and the FEMA agreed to work together to prepare a model emergencyresponse plan for voluntary use by the nation's railroads.

While not concerned specifically with the transportation of radioactive materials, the U.S. chemical industry can provide some assistance with radiological accidents through its Chemical Transportation Emergency Center (CHEMTREC). The CHEMTREC, established by the Chemical Manufacturers Association, operates a 24-hour telephone hotline that takes calls concerning transportation accidents involving potentially hazardous chemicals, gives advice on immediate safety measures, and promptly contacts the shipper.

\section{Financial Assistance for Emergency Planning and Response}

The FEMA currently provides financial assistance under comprehensive cooperative agreements (CCA) to support various emergency-response activities, including those related to accidents involving radioactive materials. The FEMA projects a budget of $\$ 60$ million for fiscal year 1987 . Of that amount, approximately $\$ 55 \mathrm{milli}$ on would be allocated to states to support emergencyresponse activities.

The funding is intended to assist State and local governments to develop and enhance emergency-management systems to cope with all types of disasters and emergencies. While priority for CCA funding is given to planning for nuclear attack, the resources provided through CCA programs may be used for planning for response to peacetime disasters and emergencies, including transportation accidents involving radioactive materials. Such planning must be conducted within the context of emergency operating plans addressing all hazards. 
The CCAs are effected between specific States and FEMA. Under Statespecific CCAs, the following CCA program may be funded:

\section{CCA Program}

Emergency-management assistance (staff salaries and administrative costs)

Radiological instrument inspection, maintenance, and calibration

Radiological protection (generic planning and exercises)

Population protection planning (generic evacuation planning for all hazards)

Disaster-preparedness improvement $(\$ 25,000$ per State)

Training and education

\section{Federal share (\%)}

50

100

50

50

50

100

Financial assistance provided for training and education may be used to support the following training and education activities:

- Emergency-response training conducted by State and local governments (up to 100 percent funding by the FEMA).

- Training at the FEMA's own training center (FEMA pays for travel expenses and the cost of educational materials).

- Procuring equipment necessary for State and local training courses (up to 50 percent funding by the FEMA if approved by the FEMA).

It should be noted that the discussion of CCA and the funding of CCA programs is speculative at this time because of uncertainties about budget levels and priorities for fiscal year 1987.

\section{A.7.2 Identification of Issue Elements}

Discussions between the OCRWM and interested parties have focused on two separate issues related to planning for, and responding to, transportation accidents. First, commenters have requested that the OCRWM specify its expected role in coordinated emergency-response planning and the development of nationally uniform emergency-response capabilities for all transportation accidents involving radioactive and other hazardous materials. 
Second, the OCRWM has been requested to specify the extent to which it will assist States, Indian Tribes, and local governments in the development of emergency-response capabilities for potential NWPA transportation accidents. Related issue elements include--

- The need for centralized planning guidance applicable to NWPA transportation.

- The need to define potential emergency situations and to classify the potential hazards associated with different emergency situations.

- The need for specific definition of the appropriate emergency actions to be taken by first responders and the emergency-response teams provided by state, Tribal, local, and Federal governments.

- The need to review emergency-response plans and actual emergencyresponse capabilities as part of generic emergency management.

- The potential use of informal agreements to define the general responsibilities of individual states, Indian Tribes, and local governments for responding to emergency situations.

- The need to identify training requirements, equipment requirements, and appropriate procedures for the maintenance of equipment.

- The need to define sources and levels of financial assistance for emergency-response activities related to NWPA transportation.

\section{A.7.3 Discussion of Issue Elements}

The discussion that follows reviews emergency-response issues and options and, where possible, opportunities for public involvement in developing a national system for responding to potential emergencies related to NWPA transportation. In addition, the expected schedule of OCRWM activities is reviewed.

\section{Emergency Planning for All Accidents Involving Hazardous Materials}

Some participants at the OCRWM Transportation Institutional Plan Workshop (Atlanta workshop) in November 1985 suggested that the OCRWM participate with the FEMA and other Federal agencies in coordinated planning for the development of nationally uniform emergency-response capabilities for all accidents involving hazardous materials, not just the accidents involving radioactive materials (or the transportation of radioactive materials). The OCRWM supports the concept of integrated emergency-response planning and will work with the FEMA (the Federal agency with primary authority for directing and coordinating such planning activities) to facilitate such planning.

Guidance for Emergency-Response Planning

The OCRWM is coordinating its planning for potential radiological emergencies associated with NWPA activities through the FEMA's Federal Radiological Preparedness Coordinating Committee (FRPCC). The OCRWM is also 
serving on the FRPCC Subcommittee on Transportation Accidents. The activities of the subcommittee include the review of training needs for radiation emergencies and the revision of the FEMA REP-5 guidance document to assist in the development of State, Tribal, and local emergency-response plans for transportation accidents. It should be noted that the development of such plans is optional and not required under Federal 1 aw.

Under current plans, the revised document (which is scheduled for completion in the summer of 1986) will discuss emergency-response planning for transportation accidents involving both low-level and high-level radioactive material, and will suggest--

- Appropriate State planning activities and responsibilities for responding to transportation accidents.

- Appropriate Tribal planning activities and responsibilities for responding to transportation accidents on Tribal lands.

- Appropriate planning activities for local governments and responsibilities for providing local response to transportation accidents.

The revised guidance document will also contain a general discussion of--

- The general conditions expected in transportation accidents.

- Liability coverage for transportation accidents under the PriceAnderson Act.

- Procedures and services available for the cleanup and removal of radioactive materials spilled or released in potential transportation accidents.

- Training programs offered for emergency response.

The OCRWM expects that the revised document will provide centralized planning guidance for any transportation accident involving radioactive materials, including potential accidents involving the transportation of radioactive waste to NWPA facilities. In future revisions of the document, the OCRWM will further work to ensure that additional detail is provided on the potential hazards associated with different transportation emergency situations and that the document includes a clear definition of the roles of first responders and response teams provided by Federal agencies, the States, Indian Tribes, and local governments.

\section{Review of Emergency-Response Plans}

Upon the request of States, Indian Tribes, or local governments, the FEMA will review emergency-response plans. The OCRWM will consult with the FEMA to determine appropriate mechanisms for providing assistance in the review of those portions of plans that address radiation emergencies associated with potential NWPA transportation accidents. After such consultation, and by late 1986, the OCRWM expects to provide a definition of its role in assisting the 
FEMA in the review of emergency-response plans. This will be noted in the OCRWM Bulletin and in future editions of the OCRWM transportation plan.

Development of Cooperative Agreements

Discussions between the OCRWM and interested parties have addressed the current uncertainty in assigning the emergency-response duties of state, Tribal, and local governments. It has been suggested that informal, cooperative agreements between such governmental entities could be used to clarify emergency-response roles.

The OCRWM encourages the development, by States, Indian Tribes, and loca1 governments, of informal cooperative agreements that delineate emergencyresponse duties and promote the development of coordinated response plans. To assist in such efforts, the OCRWM will consider supporting or coordinating--

- Regional workshops to define the necessary scope of agreements.

- A survey of current agreements.

- The development of a model agreement.

The OCRWM solicits comments on the need for cooperative agreements and alternative mechanisms that might be used to promote coordinated emergencyresponse planning.

\section{Evaluation of Training and Equipment Needs}

The OCRWM will work in cooperation with the FEMA to evaluate the extent of training needed to support the emergency-response activities of state, Tribal, and local governments and assess requirements for radiation-monitoring equipment (and the maintenance of equipment) for NWPA transportation. Initial evaluations will focus on the needs of States that have been formally notified as having potentially acceptable sites for NWPA facilities, and affected Indian Tribes. It is expected that most training to support NWPA transportation can be provided by existing programs. The OCRWM will review, in cooperation with the FEMA and the DOT, the results of the FEMA and DOT survey of training courses, the OTA study, and the recommendations of the DOT's National Hazardous Materials Transportation Advisory Committee (discussed above) to determine whether additional areas of instruction are needed.

The OCRWM expects to define specific needs for training and equipment to support all NWPA emergency-preparedness activities by 1993 (18 months after the selection of a site for a repository). To assist in the development of uniform emergency-response capabilities, the OCRWM will work with the FEMA, States, Indian Tribes, and local governments to formulate--

- Guidelines for the maintenance and calibration of radiation-monitoring equi pment.

- Minimum training standards for emergency-response personnel at various levels of State, Tribal, and local government.

- Appropriate emergency-response drills. 
- A recommended equipment 1 ist for the specific radioactive materials being shipped.

(Such guidelines and standards will be of an advisory nature only and will not have the force and effect of law.) The OCRWM plans to schedule a workshop or initiate a study in 1987 to address the development of such standards and guidelines.

The OCRWM is also considering contracts or other financial arrangements with technical organizations to support an evaluation of vehicle communication services (or satellite tracking systems) that could be used to provide immediate instructions to emergency-response personnel in the event of transportation accidents.

Some participants at the Atlanta workshop recommended that initial training should be provided to the personnel of State and Tribal governments and that State and Tribal governments in turn should provide training for the response personnel of local governments. In general, the OCRWM believes that the provision of training in such a manner is an efficient means for developing broad-based emergency-response capabilities.

\section{Financial Assistance}

The extent of financial assistance needed to support emergency-response planning, training, and requirements for equipment has not yet been determined. An important consideration in this regard is the extent of continued Federal funding for FEMA activities. Under the NWPA, however, financial assistance will be provided to states containing a candidate site for a repository (i.e., a site selected for characterization) and all affected Indian Tribes; the OCRWM is considering the need to provide such assistance to support the evaluation of emergency-response capabilities as an element of site characterization programs.

Appropriate levels of financial assistance and emergency-response activities may further be addressed in the consultation-and-cooperation agreements developed under Section $117(\mathrm{c})$ and $141(\mathrm{~h})$ of the NWPA between the OCRWM and--

- Upon request, States that have been formally notified by the DOE as having a site that is potentially acceptable for development as a repository and affected Indian Tribes.

- States containing a candidate-repository site (i.e., a site selected for characterization) and affected Indian Tribes.

- A host State for an MRS facility and affected Indian Tribes, if an MRS facility is approved by Congress.

The extent to which financial assistance may be provided to other States, Indian Tribes, and local governments for emergency-response activities is not expected to be determined until 1993 ( 18 months after a site for a repository is seiected). 


\section{A.9 Liability Coverage for Transportation to NWPA Facilities}

\section{A.9.1 Overview}

Liability coverage is currently available to reimburse the public for damages suffered in the event of either general traffic accidents or serious radiological incidents occurring during the transportation of radioactive waste. A review of the sources of liability coverage and proposed modifications to the monetary limits and procedures for ensuring liability coverage for severe accidents involving NWPA transportation is provided below.

\section{Coverage for General Traffic Accidents}

Liability for personal and property damages suffered by the public as the result of general traffic accidents involving radioactive-waste shipments with no release of radioactive materials would be determined by the 1 aw of the State with the most significant relationship to the incident and the parties involved--normally the law of the State in which the accident occurred. Monetary coverage for those damages is the responsibility of the parties found to be liable for the accident.

For motor carriers of hazardous materials (including those that are radioactive), minimum limits of financial protection are required by the Motor Carrier Act of 1980 (49 USC 10101-11902[a], with supplemental regulations found in 49 CFR 387.7 and 387.9). The Motor Carrier Act presently requires $\$ 5$ million insurance for each motor vehicle operated by carriers of certain types of hazardous materials, including spent nuclear fuel and high-level waste, in intrastate or interstate commerce.

While Federal law does not require similar financial protection for shipments of hazardous materials by rail, substantial levels of financial protection for such shipments are maintained by rail companies through selfinsurance and/or commercial insurance. Large rail companies, for example, normally self-insure shipments of hazardous materials (including those that are radioactive) for amounts of up to $\$ 5$ to $\$ 10 \mathrm{million}$. Liability coverage for damages that exceed those amounts is provided through commercial insurance; coverage under such insurance generally extends to levels of $\$ 60$ million. (See for example, a general discussion of liability coverage for hazardous material transportation included in a report issued by the U.S. Department of Transportation, Research and Special Programs Administration, entitled "Levels of Financial Responsibility for Liquefied Natural Gas and Liquefied Petroleum Gas Facilities," May 30, 1981.)

Under current OCRWM planning, future liability coverage for general traffic accidents involving the transportation of waste to NWPA facilities would also be provided through carrier insurance. The extent of liability for damages would be determined under State law.

\section{Coverage for Accidents Under the Price-Anderson Act}

The Price-Anderson Act of 1957 (42 USC 2014 and 2210, as amended) provides 1 iability coverage for damages suffered by the public as the result 
of "nuclear incidents" at certain federally licensed facilities and Federal contractor-operated facilities and "nuclear incidents" occurring during the course of radioactive materials transportation to or from such facilities. Under the Price-Anderson Act, a "nuclear incident" includes "any occurrence... within the United States causing, within or outside the United States, bodily injury, sickness, disease, or death, or loss of or damage to property, or loss of or use of property, arising out of or resulting from the radioactive, toxic, explosive, or other hazardous properties" of specified nuclear materials. Such nuclear materials include spent nuclear fuel and high-level waste.

State law would generally be used to determine liability and the extent of damages suffered by the public as the result of a covered nuclear incident. The Price-Anderson Act in turn establishes procedures for paying for those damages through a system of private insurance and retroactive assessments from the utilities or by government indemnity.

Under the system of private insurance mandated by Price-Anderson, NRClicensed nuclear power plants with a capacity of more than 100 electric megawatts are required to provide financial protection in an amount equal to the maximum amount of insurance commercially available--currently $\$ 160$ million. If the damage arising from a nuclear incident exceeds this coverage, a second layer of coverage is provided through "industry retrospective premiums." Excess damages would be divided equally among all nuclear power plants with a capacity of more than 100 megawatts, and each plant could be assessed up to $\$ 5 \mathrm{million}$ per incident. With 101 large reactors presently licensed (as of July 7, 1986), such coverage provided for nuclear incidents amounts to an additional $\$ 505 \mathrm{million}$. Together with the basic coverage carried by large nuclear power plants in the amount of $\$ 160 \mathrm{million}, \$ 665$ million is currently available to compensate the public for accidents arising at a large nuclear power plant or in the transportation of radioactive materials to or from the plant.

Under the Price-Anderson Act's government indemnity system, the DOE is authorized to indemnify (or insure) the activities of its contractors that are conducted for the benefit of the United States and involve "the risk of public liability for a substantial nuclear incident." In the event of a nuclear incident arising out of or in connection with a contractual activity, indemnity agreements of the DOE and its contractors provide that the contractor and any other person who may be liable will be indemnified by the DOE; indemnity coverage further extends to nuclear incidents arising in the course of transportation to or from contractor locations. The liability limit for such coverage, as specified under the present provisions of the Price-Anderson Act, is $\$ 500$ million. The DOE does not require contractors to carry additional liability insurance, since the cost of such activities would ultimately be passed on to the DOE.

Liability coverage under both the private insurance and government indemnity systems extends to all potentially liable parties (except the DOE and the NRC which instead would be covered under the Federal Tort Claims Act, 28 USC 2671-2680). To the extent that public damage exceeds the monetary limits on liability under the private insurance and government indemnity systems, all responsible parties are relieved of further liability; however, Congress is 
then required to investigate the incident and has the discretion to provide whatever additional compensation or assistance is deemed necessary and appropriate.

The Price-Anderson Act places restrictions on the use of State law in the event of an "extraordinary nuclear occurrence" (ENO), that is, those nuclear incidents associated with specified activities (involving nuclear power plants, facilities involved with the production of certain nuclear materials, transportation to or from such facilities, or in the management of nuclear weapons) which involve substantial offsite damages to persons or property. When the Federal Government determines that an ENO has occurred, certain defenses available under state law must be waived. One waiver requires the imposition of strict liability, regardless of whether state law would normally require proof of a defendant's negligence. Defenses related to governmental immunity would also be waived, as would certain defenses related to a State statute of limitations for filing a lawsuit. The Price-Anderson Act declares that in the event of an ENO, suits may be brought within "three years from the date on which the claimant first knew, or reasonably could have known, of his injury or damage and the cause thereof, but in no event more than twenty years after the date of the nuclear incident." A State statute of limitations that is more restrictive than the Price-Anderson requirement would be waived in the event of an ENO. (In other words, the statute of limitations more favorable to a claimant would be applied.)

\section{DOE Indemnity Coverage for Factors Related to Transportation}

As previously noted, liability coverage under the Price-Anderson Act extends to nuclear incidents occurring during transportation to or from covered facilities, including large nuclear power plants and DOE contractoroperated facilities. The extent of coverage through DOE indemnity agreements for acts of theft and sabotage, for precautionary evacuations, and for emergency response is discussed briefly below.

Coverage for Acts of Theft and Sabotage. Under the Price-Anderson system, liability coverage extends to damages suffered by the public through acts of theft or sabotage occurring during the normal course of transporting radioactive materials. Coverage in such an instance stems largely from the ability to trace responsibility for, and control of, the radioactive material involved in the incident to a particular source, such as the Federal Government, a utility, or other entity, covered under the Price-Anderson Act. Where the radioactive material is diverted from the normal course of transportation and the material that subsequently causes damage cannot be traced to any particular source, the incident is generally thought to fall outside the scope of the Price-Anderson system; in such a case, Congress has the authority to review the incident and any associated damages and to provide appropriate compensation.

Precautionary Evacuations. In certain instances, coverage under the Price-Anderson system may also extend to precautionary evacuations conducted in the event of an accident involving the transportation of radioactive materials. Under DOE indemnity agreements, 1iability coverage is triggered where an evacuation, either precautionary or after the event, is conducted in response to a "nuclear incident" as defined by the Price-Anderson Act (see 
definition above). DOE indemnity coverage would not extend to precautionary evacuations conducted in the event of transportation accidents that do not meet the definition of a "nuclear incident."

Emergency Response and Clean Up Costs. An additional issue of particular interest to States, Indian Tribes, and local governments is the coverage of costs associated with emergency response and cleanup in the event of a transportation accident involving radioactive materials. Typical costs associated with emergency response (e.g., police response, fire protection, 1ife-saving measures, and excluding the public from the accident area) would normally not be covered under DOE indemnity agreements. States, Indian Tribes, and local governments have a general duty to respond and provide emergency assistance in the event of any accident. Where an accident involves the transportation of radioactive materials, substantial Federal emergency assistance is available on the request of those governments (see Section A.8). The DOE views cleanup activities and cleanup costs associated with a transportation accident (e.g., the removal of accident debris, decontamination, and radiation monitoring) to be an element of property damage appropriately reimbursable by the DOE.

\section{Coverage for Radioactive-Waste Management}

Since the enactment of the NWPA, the DOE has indicated that indemnity agreements based on the Price-Anderson Act will be provided for the operation of any DOE facility associated with the waste-management program (e.g., a geologic repository or a monitored-retrievable-storage facility, if approved by Congress). Indemnity coverage will also be extended to transportation activities associated with the waste-management program (see 10 CFR Part 961; Article XIII of the standard contract for the disposal of spent nuclear fuel and/or high-level waste).

Under the present Price-Anderson system, liability coverage for the transportation of radioactive waste from commercial nuclear power plants to NWPA facilities would stem from the utilities' insurance policies. As noted above, such insurance currently provides $\$ 665$ million to cover damages related to a nuclear incident occurring during transportation to or from the nuclear power plant.

Furthermore, under the existing Price-Anderson system, liability coverage for transportation from DOE facilities where defense waste is stored to NWPA facilities, and transportation between NWPA facilities, would be covered under the indemnity agreements of DOE contractors who operate the facilities (and under the present Price-Anderson system $\$ 500$ million would be available for any one incident). It should be noted, however, that the Price-Anderson Act's waiver of defenses provision (requiring that restrictions be placed on the use of certain legal defenses in the event of an ENO) currently would not extend to radioactive waste storage and disposal facilities or to transportation between such facilities.

Recommendations for Amendments to the Price-Anderson Act

While the present language of the Price-Anderson Act is sufficiently flexible to permit public liability coverage for radioactive-waste transportation, numerous alternatives to the existing system have been proposed during 
the current review of this Act by Congress. Unless the Price-Anderson Act is extended by Congress, authority to extend the system to cover new commercial facilities and to continue coverage at DOE facilities will expire in August 1987. Various Congressional bills have proposed specific amendments that would affect 1 iability coverage for transportation to waste-management facilities. In general, such amendments would either significantly increase the limits on liability or provide for unlimited liability. Several bills extend the Price-Anderson Act's waiver of defenses provision to NWPA activities and provide in part for expenditures from the Nuclear Waste Fund in the event of accidents related to waste-management activities. Recommendations to Congress for the reform of the existing liability coverage system under the Price-Anderson Act are briefly reviewed below.

The Department of Energy. The DOE has recommended extension of the Price-Anderson Act with a continued limitation on liability. Additional DOE proposals include--

- An increase in liability coverage under DOE indemnity agreements to a level comparable to that of large commercial utilities.

- Explicit coverage under the Price-Anderson Act for radioactive-waste operations.

- Extension of the Price-Anderson Act's waiver of defenses provisions (requiring that restrictions be placed on the use of certain defenses under State law) to incidents related to the transportation, storage, and disposal of commercial and defense radioactive waste.

- Payment of public liability claims for waste-management activities from the Nuclear Waste Fund (which in turn is financed through fees paid by the waste generators), consistent with the policy stated in the NWPA that costs of carrying out waste-management activities should be borne by the waste generators.

- Retaining the present system of coverage for acts of theft and sabotage that result in diversions from the course of transportation (discussed above).

- Retaining DOE indemnity coverage for precautionary evacuations in those instances where there has been an actual (rather than threatened) "nuclear incident" (see discussions above).

The Nuclear Regulatory Commission. On record at the last Congressional hearing on the Price-Anderson Act, a majority of the NRC Commissioners supported a Senate proposal (Senate Bill 1225) to extend the Price-Anderson Act with certain modifications. Under the proposal, 1 iability coverage under the Price-Anderson's insurance system would be raised significantly: industry retrospective premiums would be raised from $\$ 5$ million to an amount between $\$ 15$ and $\$ 20$ million. Total coverage under the insurance system would be between $\$ 1.675$ billion and $\$ 2.180$ billion (assuming 101 reactors). Indemnity coverage would be increased to an equivalent level. Liability coverage would be specifically extended to the transportation, storage, and disposal of radioactive waste, and the waiver of defenses provision would be made applicable to all DOE waste-management activities. 
Utilities. Representatives of the electric utilities have urged an extension of the Price-Anderson Act and a retention of liability limits. Further proposals include raising liability limits under the Price-Anderson's insurance system through an increase in retrospective premium payments, clarifying procedural mechanisms to ensure full compensation to the public in the event that all proceeds under the insurance and indemnity systems are exhausted, and providing specific coverage for claims arising out of the activities of the Federal Government or its contractors in the repository program or related transportation. One representative organization has stated its opposition to the use of the Nuclear Waste Fund to cover liability stemming from waste-management activities; it argued that the use of those funds unfairly puts utilities in the position of insuring the Federal Government and its contractors.

States. Several States have suggested the need for new legislation under which the DOE would be required to assume strict and unlimited liability for public damages involving waste-management activities; there would be no DOE defense to payment of claims. Under additional state proposals, the DOE would be authorized to use the Nuclear Waste Fund for limited reimbursement for public damages. Coverage for damages in excess of such an amount would be drawn from the U.S. Treasury.

Environmental Interest Groups. One environmental interest group has urged the amendment of the Price-Anderson Act to ensure strict and unlimited liability coverage for both NRC-licensee and DOE-contractor activities. Further recommendations related to the NWPA program include the following: use of the Nuclear Waste Fund to compensate for damages resulting from activities conducted under the NWPA; compensation for any damages suffered as the result of theft or sabotage, including those instances where radioactive material is diverted from the normal course of transportation; coverage of all precautionary evacuations, including those conducted where a release of radioactive material is expected but does not occur; and coverage of the emergencyresponse costs incurred by state and local governments as a result of accidents involving radioactive materials.

\section{A.9.2 Identification of Issue Elements}

The amendment and extension of the Price-Anderson Act or provisions of liability coverage through new legislative measures are ultimately dependent on Congressional action. As noted above, the DOE has offered recommendations related to extension of the Price-Anderson Act and in many instances agreement has not been reached with other parties having an interest in the NWPA wastemanagement program. While certain basic DOE policy positions on the amendment and extension of the Price-Anderson Act have been established, the OCRWM has identified the following options for addressing issues related to liability coverage for NWPA activities:

- The development of a public information program that addresses 1iability coverage for NWPA activities under the revised liability system developed by Congress and clearly defines these costs that will be covered in the event of an NWPA transportation accident. 
- A liability seminar to address transportation issues in greater detail.

- Specific coverage of liability issues in written agreements developed under the NWPA.

\section{A.9.3 Discussion of Issue Elements}

The discussion that follows presents a preliminary review of these issues; identifies, where possible, opportunities for public involvement in the development and consideration of various OCRWM policy options; and out1 ines the expected schedule of OCRWM policy decisions and transportationprogram activities.

\section{Development of Public Information Program}

As noted in Chapter 3 of the Transportation Institutional Plan, the OCRWM will develop a transportation public information program. An associated program plan will identify public information materials that will be developed, describe a process of coordination with the transportation network to assist in the development of such materials, and outline mechanisms for information dissemination. Public-information material on liability coverage for NWPA transportation will be developed under the program.

\section{Liability Seminar}

Participants at the OCRWM Transportation Institutional Plan Workshop in November 1985 noted that the basic system of liability coverage for "nuclear incidents" will be established through Congressional action (expected to be taken by August 1987, at which time authority to extend the Price-Anderson system to cover new commercial facilities and continue coverage at DOE facilities would expire unless reauthorized). Workshop participants therefore recommended that the OCRWM hold a seminar after such Congressional action related to the Price-Anderson Act in order to review resulting 1 iability coverage for NWPA activities, including transportation.

In response to that recommendation, the OCRWM (in cooperation with other DOE offices) will schedule a seminar to review liability coverage for NWPA transportation within six months of final Congressional action. The OCRWM will be prepared to discuss various 1 iability issues, including--

- The estimated scope and magnitude of liability for potential transportation accidents.

- Coverage for defense-waste shipments.

- Potential liability that cask manufacturers and suppliers may incur in the event of transportation accidents.

- Coverage for evacuations conducted in response to transportation accidents. 
- Coverage for potential acts of theft and sabotage occurring during transportation.

- Appropriate sources of coverage for costs associated with emergency response and accident clean up.

Discussion of Liability Coverage in Written Agreements

Pursuant to Sections $117(\mathrm{c})$ and $141(\mathrm{~h})$ of the NWPA, the Secretary of Energy is authorized to enter into written agreements with--

- Upon written request, any State notified by the DOE as having a potentially acceptable site for a repository and any affected Indian Tribes.

- States containing a candidate-repository site (i.e., a site selected for characterization) and any affected Indian Tribes.

- A host State for an MRS facility and affected Indian Tribes, if an MRS facility is approved by Congress.

In developing those written consultation-and-cooperation agreements, the OCRWM will work individually with States and Indian Tribes to identify and address questions of state and Tribal liability arising from transportation accidents .

It should again be noted that the Price-Anderson Act in its present form would provide coverage for damages suffered by the public as the result of a "nuclear incident" occurring during NWPA transportation. Such coverage would extend to all liable parties (except for the DOE and the NRC). However, the Price-Anderson Act's broad coverage would not extend to liability for damage caused by general traffic accidents (those accidents that do not involve damage caused by radioactive material); coverage for damages in such a case would remain the responsibility of the parties actually liable for the traffic accident. 


\section{A.10 Cask Design and Testing}

\section{A.10.1 Overview}

The OCRWM is responsible for the design, development, and testing of the shipping casks (packaging) used for the transportation of spent fuel and highlevel waste to NWPA facilities. Regulations of the DOT authorize the DOE to certify such casks against standards that are equivalent to those established by the NRC ( 49 CFR 173.7[d]). While it has the authority to certify its own casks, the DOE has decided that casks approved by the NRC will be used for shipments of radioactive waste to NWPA facilities.* The discussion that follows reviews NRC requirements for cask design.

NRC regulations ( 10 CFR 71) provide that a shipping cask must prevent the loss or dispersion of its radioactive contents, provide for adequate shielding against radiation and for the dissipation of heat, and prevent "nuclear criticality" (the critical point at which a spontaneous nuclear reaction occurs) under both normal and accident conditions of transportation.

Normal conditions of transportation that must be considered in cask design are specified in the NRC's regulations (10 CFR 71.71 ) in terms of--

- Heat $\left(100^{\circ} \mathrm{F}\right.$ or $\left.38^{\circ} \mathrm{C}\right)$, and cold environments $\left(-40^{\circ} \mathrm{F}\right.$ or $\left.-40^{\circ} \mathrm{C}\right)$.

- Pressure changes (where external pressure is reduced to 3.5 pounds per square inch and increased to 20 pounds per square inch).

- Vibration (the vibration normal in transportation).

- Water spray (a water spray that simulates exposure to a rainfall of approximately 2 inches [ 5 centimeters] per hour for at least 1 hour).

- Impact (a free fall from a distance of from 4 feet to 1 foot $[1.2$ to 0.3 meter], depending on the package weight).

- Compression tests.

- Penetration tests (measuring the impact of a vertical steel cylinder, with a hemispherical end, a diameter of $1 \frac{1}{4}$ inches [ 3.2 centimeters] with a 13 pound [ $6 \mathrm{kilogram}$ ] mass when dropped from a height of 40 inches [ 1 meter] onto the exposed surface of the package that is expected to be most vulnerable to puncture).

* Such an intention was stated in (1) a procedural agreement with the NRC that directed that casks approved by the NRC would be used for shipments of radioactive waste from NRC- 1 icensed facilities to NWPA facilities (Federal Register, Vol. 48, p. 51875, November 14, 1983), and (2) a formal agreement reached by the OCRWM and the DOE's Office of Defense Programs on July 1 , 1986 that provides (in part) that defense waste will be transported by the OCRWM to repositories in casks certified by the NRC. 
Hypothetical accident conditions that must be considered are specified in NRC regulations at 10 CFR 71.73 . Cask tests must be conducted in the following sequence:

- Free drop (30 feet [ 9 meters] onto a flat, essentially unyielding surface,* striking the surface in a position for which maximum damage is expected).

- Puncture (a free drop of a cask for a distance of 40 inches [ 1 meter] onto the upper end of a vertical steel bar with the dimensions of 6 inches [ 15 centimeters] diameter, not less than 8 inches [ 20 centimeters] long, and having its top rounded to a radius of not more than a quarter of an inch [6 millimeters]).

- Thermal (exposure of the cask to not less than 30 minutes of heat at temperatures of $1,475^{\circ} \mathrm{F}$ or $800^{\circ} \mathrm{C}$ ).

- Water immersion (a fissile material cask must be immersed below at least 3 feet [ 0.9 meter] of water for at least 8 hours, and in a position where maximum leakage is expected).

In addition, all casks must be evaluated under a separate test involving exposure to water pressure equivalent to immersion below at least 50 feet ( 15 meters) of water for a period of not less than 8 hours.

Test conditions different from those specified in 10 CFR 71.71 and 71.73 may be approved by the NRC if the controls proposed by the shipper are demonstrated to be adequate to assure the safety of the shipment ( 10 CFR 71.41[c]).

The performance of casks under test conditions may be evaluated by either subjecting a sample cask or scale model to test, or by use of engineering analyses. Applications submitted to the NRC for the approval of a cask design must also specify operating procedures, acceptance tests, and a caskmaintenance program. Operating procedures involve loading and unloading a package, and preparing an empty cask for transport. Applicants must demonstrate that occupational radiation exposures will comply with external radiation standards for casks as specified in 10 CFR 71.47. Acceptance tests are tests to be performed prior to first use of a cask, and include visual inspection, leak tests, tests for radiation shielding, and tests of the component parts of a cask, such as valves and gaskets. A cask-maintenance program must be designed to ensure continued performance of the cask, and includes periodic cask-testing, inspection, and replacement schedules.

* The "unyielding surface" criteria require that the result of the impact be borne completely by the cask. Drops from heights 2.5 to 3 times greater onto normal hard surfaces would be comparable. 


\section{A.10.2 Identification of Issue Elements}

Discussions between the OCRWM and interested parties have addressed plans for the design, development, and testing of casks used for waste transportation to NWPA facilities. The following issues have been identified in such discussions:

- The need to review the adequacy of NRC cask design and performance standards in terms of actual accident conditions.

- The need to explain NRC standards and their application to the NWPA program in a manner that is understandable to those who do not have technical backgrounds.

- The need for the OCRWM to review its plans for a cask-testing program.

- The need to review the OCRWM's plans to develop and apply quality assurance standards to cask design, development, and testing.

\section{A.10.3 Discussion of Issue Elements}

The discussion that follows reviews issues associated with the development of casks for the NWPA program; identifies, where possible, opportunities for public involvement in the development and consideration of various policy options; and outlines the expected scheduling of OCRWM policy decisions and transportation program activities.

\section{NRC Cask Design and Performance Standards}

In discussions with the OCRWM, some interested parties have questioned the adequacy of NRC cask design and performance standards, and the application of such standards to the NWPA cask-development program. Identified concerns include (1) whether NRC standards are stringent enough to encompass real transportation environments under normal and accident conditions; and (2) whether one set of standards can adequately. address the spectrum of conditions associated with real highway, rail, and barge accidents.

The NRC cask design and performance standards were developed through a process of public rulemaking and extensive public review. The OCRWM accepts the NRC standards as establishing uniform cask design and performance requirements for the United States, and has indicated that it will apply such standards to the design of casks to be used for the transportation of waste to NWPA facilities.

The NRC is conducting a "modal study" to compare actual serious accident conditions for different modes of transportation with current cask design and performance standards. The study is expected to be completed in 1986. The OCRWM will address the study's conclusions in consultation with the NRC and the DOT. Should the NRC make changes in cask design and performance standards in response to the study's conclusions (or as the result of future shipping experience), the OCRWM will modify its cask-design requirements. 
Some interested parties have expressed particular concern with the potential need to review requirements of the NRC to evaluate cask designs in terms of thermal tests under hypothetical accident conditions of transportation. The OCRWM will review both accident data and the related findings of the NRC modal study, and consult with the NRC and the DOT to determine whether additional study is required. The OCRWM will also compare current NRC requirements for thermal tests with international standards, and review Federal thermal test-standards that have been established for packaging used for the transportation of other hazardous materials. It should be noted that the adequacy of thermal tests for casks has been examined in past technical studies. Such studies typically concluded that casks are capable of absorbing high levels of heat without being damaged, and that current standards provide significant margins of safety. (See, for example, R. Pope et al., An Assessment of Accident Thermal Testing and Analysis Procedures for Radioactive Materials Shipping Packages, 80-HT-38, American Society of Mechanical Engineers, Washington, D.C., 1981.)

As specific OCRWM plans are developed to address issues related to the adequacy of cask design and performance standards, information will be provided through notice in the OCRWM Bulletin and in future editions of the OCRWM transportation plan.

\section{Public Information Program}

To assist in the understanding of NRC cask design and performance standards, the OCRWM recently participated in a "cask safety seminar" sponsored by the Western Interstate Energy Board. The seminar included a review of Federal requirements for cask design and testing, and their application to the NWPA cask-development program. The OCRWM is working to identify additional organizations that have an interest in such seminars.

In addition, the OCRWM has developed a public information circular that includes a general overview of cask design and testing requirements (U.S. Department of Energy, Office of Civilian Radioactive Waste Management, Transporting Spent Nuclear Fuel: An Overview, DOE/RW-0065, Washington, D.C., 1986). If interest warrants, the OCRWM will develop additional informational materials as part of its public-information program.

The OCRWM is considering development of a short educational videotape for nontechnical audiences that would describe the engineering process used to design and develop spent fuel shipping casks in accordance with applicable Federal and international standards. The videotape would describe the characteristics of spent fuel and how it is transported, the design of casks, the testing of cask models and component parts, the NRC certification process, and the fabrication of prototype casks. Should the decision be made to produce the film, the OCRWM would make necessary arrangements for copies of the film to be provided to interested organizations and governmental bodies.

\section{NWPA Cask Development Program}

The OCRWM's activities related to the NWPA cask-development program are reviewed in the Transportation Business Plan (U.S. Department of Energy, Office of Civilian Radioactive Waste Management, Transportation Business Plan, 
DOE/RW-0046, Washington, D.C., 1985). Briefly, the casks to be developed will fall into four categories: (1) casks for moving fuel from reactors to a repository or to an MRS facility (if such a facility is approved by Congress); (2) casks for moving fuel from an MRS facility to a repository; (3) casks for transporting nonstandard fuel and nonfuel components; and (4) casks for transporting defense high-level waste.

The current phase of cask design activity is focusing on the "fromreactor" casks, which will constitute the major part of the cask fleet and are projected to be capable of carrying at least 80 percent of the fuel to be shipped. These casks can be used for shipping to an MRS facility, if such a facility is approved by Congress, or the casks can be used for direct shipping to a repository. Because the "from-reactor" casks must be shipped from over 100 different nuclear plants, the interface requirements will present significant design challenges. The OCRWM's objective will be to minimize the number of different casks required while maximizing cask capacities and safety.

Al1 surface modes of transportation (truck, rail, and barge) will be considered in designing the "from-reactor" cask. Both overweight and legal weight truck cask designs will be pursued. Under current planning, rail casks will be designed with either 100-ton weight limits (to ensure a gross vehicle weight that will allow unrestricted travel in general commerce) or with weight limits of 125 tons (for casks that could be used for both transportation and storage). Because not all reactors are accessible by rail, truck-cask designs that facilitate intermodal transfer to railcars will be encouraged. The OCRWM expects that a maximum of 120 "from-reactor casks" will be required for transportation using only truck, and 70 casks will be required for shipments involving only rail transportation. These estimates are based on a truck-cask capacity of two spent fuel assemblies from pressurized water reactors (PWR) or five assemblies from boiling water reactors (BWR), and a rail-cask capacity of 14 PWR assemblies or 36 BWR assemblies.

In support of this phase of cask design, the OCRWM directed the issuance of an information package in February, 1986 (U.S. Department of Energy, Idaho Operations Office, Information Package for the "From-Reactor" Cask Program, Idaho Falls, Idaho, 1986). The information package contained draft materials (on such factors as performance specifications and interface guidelines) that will support the preparation of a request for proposals (RFP) for cask design and development. The RFP, in turn, will be designed to ensure a competitive process for the selection of contractors to design, obtain NRC certification, fabricate, and test prototype casks to transport spent fuel from reactors to an MRS facility or a repository.

To facilitate the review of the OCRWM's plans for cask procurement and the development of an RFP, the OCRWM also sponsored a meeting in March 1986. The meeting was open to industry representatives and all other interested parties. Written comments provided by interested parties on the planned RFP will be considered by an evaluation board. The RFP is expected to be issued in the summer of 1986; 60 days will be allowed for prospective contractors to respond. The OCRWM expects to begin award of contracts by the end of 1986 . 
A second phase of design effort will be for a "from-MRS" cask (if an MRS facility is approved by Congress). This design would incorporate standardized features to accommodate identical interfaces at an MRS facility and a repository. In addition, the consolidation and other fuel-package preparation that could take place at an MRS facility would permit the design of casks having a uniform waste capacity.

The primary mode of transportation for the "from-MRs" fleet would be rail. Design features for rail casks could include weights of up to 150 tons, integration of the cask into the rail car, and potential cask capacities of 25 metric tons of uranium (MTU). It is projected that cask handing would be conducted using automated remote control equipment. It is estimated that as many as 30 of the "from-MRs" casks would be needed for the transfer of spent fuel to the repository.

A third and smaller design phase will be for those casks needed to accommodate nonstandard fuel and radioactive non-fuel components; such waste will be shipped directly to the repository. Development of these casks will have secondary priority in the program until the "from-reactor" cask-design phase is well advanced.

In addition, the OCRWM will be responsible for the design and development of casks for the shipment of defense high-level waste (currently stored at DOE facilities) to repositories. Preliminary planning for this design effort has begun. (It should also be noted that the OCRWM will coordinate with the DOE's Office of Nuclear Energy and the New York State Energy Research and Development Administration for the design and development of casks for shipping commercial high-level waste from West Valley, New York.)

\section{OCRWM Cask-Testing Program}

Interested parties have submitted numerous suggestions to the OCRWM for the development of a cask-testing program. Suggested testing programs range from those that would test casks using both analytic techniques and model testing as necessary to meet NRC requirements, to programs that would require the destructive testing of full-scale casks under conditions that result in cask failure. In an effort to address all such suggestions in the development of an NWPA cask testing program, the OCRWM is developing a cask-testing plan. The plan will establish the OCRWM's testing policy and the role of participants (including the OCRWM and other DOE program offices, oversight organizations, testing organizations, the utilities, carriers, and public representatives). The plan will further define appropriate types of cask tests (see Table A-l). Such tests will include--

- Engineering tests of cask materials and component parts.

- Design verification of $1 / 4$ scale models for rail casks, $1 / 2$ scale models for truck casks, thermal testing, and other tests as determined to be appropriate by the OCRWM following consultation with interested parties.

- Acceptance testing after cask fabrication. 
Table A-1. Cask Testing Summary

\begin{tabular}{|c|c|c|c|c|c|}
\hline Type & $\begin{array}{l}\text { Responsible } \\
\text { Organizations }\end{array}$ & Tests & Hardware & $\begin{array}{l}\text { Relative Point } \\
\text { in Schedule }\end{array}$ & Location \\
\hline $\begin{array}{l}\text { Engineering } \\
\text { Testing }\end{array}$ & $\begin{array}{l}\text { Cask development } \\
\text { contractor }\end{array}$ & $\begin{array}{l}\text { Materials and cask } \\
\text { components as determined } \\
\text { by contractor according } \\
\text { to plan approved by OCRWM }\end{array}$ & $\begin{array}{l}\text { Material specimens } \\
\text { and cask components }\end{array}$ & Through final design & $\begin{array}{l}\text { Any shop or lab meeting } \\
Q A \text { and test requirements }\end{array}$ \\
\hline $\begin{array}{l}\text { Design } \\
\text { Verification }\end{array}$ & $\begin{array}{l}\text { Cask development } \\
\text { contractor }\end{array}$ & $\begin{array}{l}\text { Structural tests on models } \\
\text { and thermal tests on } \\
\text { component sections as } \\
\text { determined by contractor } \\
\text { according to plan approved } \\
\text { by OCRWM }\end{array}$ & $\begin{array}{l}\text { Scale-models and } \\
\text { components }\end{array}$ & $\begin{array}{l}\text { Upon completion of } \\
\text { preliminary design }\end{array}$ & $\begin{array}{l}\text { OCRWM-approved independent } \\
\text { test facility }\end{array}$ \\
\hline $\begin{array}{l}\text { Acceptance } \\
\text { Testing }\end{array}$ & $\begin{array}{l}\text { Cask development } \\
\text { contractor }\end{array}$ & $\begin{array}{l}\text { Postfabrication inspections } \\
\text { and nondestructive acceptance } \\
\text { tests as specified by } \\
\text { contractor in a safety } \\
\text { analysis report submitted } \\
\text { to NRC }\end{array}$ & Prototype cask & $\begin{array}{l}\text { After prototype } \\
\text { fabrication }\end{array}$ & $\begin{array}{l}\text { OCRWM-approved test } \\
\text { facility }\end{array}$ \\
\hline $\begin{array}{l}\text { Operational } \\
\text { Testing }\end{array}$ & $\begin{array}{l}\text { OCRWM/utilities } \\
\text { (with contractor } \\
\text { support) }\end{array}$ & $\begin{array}{l}\text { Facility interface and } \\
\text { handling, transport oper- } \\
\text { ations, and intermodal } \\
\text { transfer tests }\end{array}$ & Prototype cask & $\begin{array}{l}\text { After prototype } \\
\text { fabrication, prior } \\
\text { to fleet unit } \\
\text { procurement }\end{array}$ & $\begin{array}{l}\text { Reactor, MRS facility, or } \\
\text { repository sites }\end{array}$ \\
\hline $\begin{array}{l}\text { Confirmatory } \\
\text { Demonstrations }\end{array}$ & OCRWM & $\begin{array}{l}\text { Scenarios and test environ- } \\
\text { ments to be defined }\end{array}$ & Prototype cask & To be determined & To be determined \\
\hline
\end{tabular}


- Operational testing of cask interface and handling features.

In addition, the plan will address the potential use of confirmatory, demonstration testing under conditions that exceed Federal test requirements. In order to assist in the definition of the appropriate parameters for potential demonstration testing, the OCRWM is considering the formation of a study group to evaluate different testing options.

A draft cask-testing plan is expected to be developed by the fall of 1986, and will be made available for review and comment. Notice of the draft plan's completion will be provided in the OCRWM Bulletin. An OCRWM prototype cask-testing program is expected to be developed by 1992 . Such timing is related to the OCRWM's verification of cask fleet requirements for waste transportation to a repository by 1992. The testing of cask prototypes is expected to begin by 1993 .

\section{Quality Assurance Standards}

An integral part of the OCRWM's cask design and testing program will be the development of a comprehensive program of quality assurance and quality control. The program will fully comply with NRC requirements and be developed in consultation with the NRC. Activities conducted under this program will include monitoring the design, manufacture, testing, inspection and maintenance of the casks. In addition, the preparation, handling, and storage of casks will be monitored by the OCRWM to ensure that standards of safety are being met. The detailed definition of the quality assurance and quality control program is currently under development. A transportation quality assurance plan is expected to be completed by the fall of 1986, and will be available for review. Notice of the plan's completion will be provided in the OCRWM Bullet in. 


\section{A.11 Overweight Truck Shipments}

\section{A.11.1 Overview}

There are a number of modal alternatives available to the OCRWM for NWPA transportation (see also the discussion of transportation modes in Section A.13). Highway, rail, and barge shipments, as well as intermodal shipments, are all possible, and the OCRWM intends to maintain the option to utilize all modes, as appropriate. The OCRWM's evaluation of various factors related to highway transportation will include a review of issues associated with vehicle weight limitations. It is important to note the relationship between the various levels of government concerning the highway system and vehicle weight control in the United States. The present Federal-aid highway system consists of $810,000 \mathrm{miles}$, which is approximately 20 percent of the total $4.7 \mathrm{million}$ miles of roadway in the United States. Included within the Federal-aid system is 42,000 miles of Interstate highways. Generally, States with roadways that are designated part of the Federal-aid system are eligible for matching Federal funds to construct and maintain the roads. State programs for the construction and maintenance of Interstate highways are eligible for up to 90 percent Federal funding, and as much as 75 percent Federal funding is provided for programs for the construction and maintenance of non-Interstate highways. Thus, funding for the construction and maintenance of the Federal-aid system is a shared responsibility between the Federal and State governments. The roadways, however, remain under primary control of the state in which they are located; however, States must provide reasonable access to the national network (23 CFR Part 658). State activities include vehicle size and weight regulation and enforcement.

Federal size and weight limits were first prescribed by the Federal-Aid Highway Act of 1956 (23 USC 101 et seq.) and most recently were amended by the Surface Transportation Assistance Act of 1982 (49 USC 2311-2313, with implementing regulations found at 23 CFR Part 658). The maximum gross vehicle weight 1 imit now allowed on the Interstate system by Federal 1 aw is 80,000 pounds (although exceptions do exist). Since States are required to allow weights up to this limit or face the loss of highway funds, Federal Interstate limits are "uniform" for the first time. Vehicles can operate in excess of this uniform limit only under a permit issued by the State in which the vehicle is operating. Although State governments have principal responsibility for vehicle size and weight control in the U.S., some local governments and toll facilities have autonomous authority to establish and enforce their own limits. Non-Interstate highway limits are not subject to the Federal limits and are controlled almost entirely by the states, so long as such control does not pose an undue burden on interstate commerce.

Casks presently used for the highway shipment of spent nuclear fuel and high-level radioactive waste have a low payload-to-weight ratio. Currently available legal weight truck casks include those with a payload of only one spent fuel element from a pressurized water reactor (PWR), or two spent fuel elements from a boiling water reactor (BWR). A transport vehicle with such a loaded cask is close to the legal gross vehicle weight limits (the operation of a truck in excess of such weight limits would require a state permit). Future casks will require less shielding because much of the spent fuel to be moved will have aged considerably. However, there are some indications that 
the maximum capacity of future legal-weight truck casks may only be 2 PWR/5 BWR spent fuel elements.

Thus, overweight truck casks offer an important alternative for substantially increasing highway shipment productivity. The overweight casks that are currently available include those with payloads of 3 PWR and 7 BWR assemblies and future designs could accommodate payloads of 4 PWR and 10 BWR assemblies.

\section{A.11.2 Identification of Issues}

Current generation casks were designed to accommodate the age of spent fuel and the highway weight limitations of the $1960 \mathrm{~s}$ and $1970 \mathrm{~s}$. This included the massive shielding required for 6-month-old spent fuel and a gross vehicle weight limitation of 73,280 pounds. However, the spent fuel to be moved in the 1990s will have aged 5 years or more. The gross vehicle weight limitation for the Interstate highway system has been increased to 80,000 pounds. Indications are that these changes could allow the design of a 25-ton legal-weight truck cask with a payload of 2 PWR/5 BWR spent fuel elements. The older fuel and the higher vehicle weight allowances may also allow the development of a 40-ton overweight truck cask with a payload on the order of 4 PWR/10 BWR spent fuel elements. The use of such overweight truck casks offers the promise of significantly reducing the number of shipments that will be made to NWPA facilities. However, a number of related issues must also be addressed and will affect an OCRWM decision on the type of truck cask fleet that will be used for NWPA shipments. Discussions between the OCRWM and interested parties have addressed the potential development and use of overweight truck casks for future NWPA transportation and have focused on the following issue elements:

- Current plans to evaluate the use of larger shipping casks (including the potential highway shipment of heavyweight rail casks from reactor sites to existing rail lines for subsequent transport by rail), and factors that will determine whether larger casks and overweight trucks should be used for waste transportation to NWPA facilities.

- The potential need for the OCRWM to classify truck weights and the associated damage to highways, and establish a maximum weight 1 imit beyond which highway damage would be considered unacceptable.

- The need for the OCRWM to evaluate state permitting requirements for overweight truck shipments and to determine the potential for developing national consensus on overweight truck permitting requirements and procedures.

\section{A.11.3 Discussion of Issue Elements}

The discussion that follows reviews issues related to the potential use of overweight truck shipments for NWPA transportation, opportunities for public involvement in considering transportation alternatives, and the anticipated scheduling of OCRWM activities and policy decisions. 


\section{Evaluation of Overweight Truck Shipments}

Participants at the OCRWM Transportation Institutional P1an Workshop (Atlanta workshop) held in 1985, recommended that the OCRWM continue to study al1 options, including the use of overweight trucks, for transporting nuclear waste to NWPA facilities. Consistent with such a recommendation, present plans of the OCRWM for cask development extend to the design and development of both legal and overweight truck casks. In addition, the OCRWM directed Battelle Memorial Institute to conduct a preliminary study of the legal, political, administrative, and operational considerations associated with the use of overweight trucks. The study, which was released as a report in April 1986 (Battelle Memorial Institute, Office of Transportation Systems and Planning, Overweight Truck Shipments to Nuclear Waste Repositories: Legal, Political, Administrative, and Operational Considerations, BMI/OTSP-0I, Columbus, $\mathrm{OH}, 1986)$, includes a review of the following factors:

- The relationship of highway damage and vehicle weight.

- Highway weight limits established under Federal and State laws.

- The role of States in enforcing highway weight limits.

- State permitting requirements and procedures.

- The anticipated costs and safety considerations associated with overweight truck shipments of nuclear waste.

The report, which is available to the public, indicates specific factors that require further examination before a decision can be made on the appropriate composition of the NWPA truck-cask fleet. Under current program schedules, the OCRWM expects to decide by mid-1990 whether overweight trucks will be used for NWPA transportation. At that time, the OCRWM plans to issue a request for proposals for private companies to act as service contractors for transportation operations (assuming the use of such contractors is found to be the preferred management option). A related OCRWM decision on the configuration of a truck-cask fleet will be necessary to support the definition of service contractor responsibilities.

\section{Criteria for Acceptable Overweight Shipments}

Participants at the Atlanta workshop recommended that the OCRWM consider the potential need to classify vehicle weights and the related wear on highway pavement and infrastructure in order to establish those weights that would cause excessive and unacceptable damage. According to mathematical procedures developed by the American Association of State Highway and Transportation officials (AASHTO), the wear on highway pavement increases exponentially as additional weight is added to a given vehicle axle. However, AASHTO procedures further indicate that highway pavement wear can be diminished substantially by adding additional axles to a vehicle and/or by increasing the spacing between axles.

The Battelle overweight truck report reviews in detail the issues related to vehicle weight, vehicle design, and the associated wear on highway 
pavement. Preliminary evaluations conducted in the course of the Battelle study have applied AASHTO procedures and suggest that a properly designed overweight truck would cause only marginally greater wear on highway pavement than would legal weight trucks. (Over the life of the repository program, the use of overweight trucks would reduce the number of necessary highway shipments, and would be expected to cause less highway pavement wear than legal weight trucks.) The OCRWM currently believes, therefore, that the ability to modify truck designs in order to minimize highway damage caused by vehicle weight makes the classification of specific truck weights and the wear on highway pavement unnecessary.

\section{State Permitting Procedures}

Vehicle weight control is regulated principally by state governments; vehicles that exceed specified weight limits can be operated only under state permits. The effect of various state permitting requirements and procedures on shipping schedules and the cost of transportation will be an important consideration of the OCRWM in determining the feasibility of using larger shipping casks and overweight trucks for NWPA shipments. As noted above, the Battelle report includes a review of State permitting systems and procedures. Specific factors that are addressed in the report include the following:

- The range of maximum weights allowable under various state permit systems.

- The type and duration of various permit systems.

- State requirements for the allowable spacing of truck axles.

- Permit restrictions involving time-of-day and routing controls.

- Permit-fee structures.

- Permit application and approval procedures.

In 1987, the OCRWM plans to distribute a summary report (that includes many of the findings of the Battelle overweight truck study) to State authorities involved in the control and enforcement of vehicle weight requirements. The summary report is expected to facilitate initial discussions between the OCRWM and the States as to the feasibility of using overweight trucks for NWPA shipments and the potential for developing nationally uniform and stable permitting procedures.

Under current plans, the summary report would also be provided to a study group formed by the OCRWM to address issues related to state permitting requirements and procedures. Such a study group is expected to be established in 1987 through a contractual arrangement with the OCRWM. Potential participants in the study group might include State highway and transportation officials and representatives of cask manufacturers, the utilities, and carriers. Activities of the group would extend to a review of various state fee requirements, operational requirements, and enforcement procedures. As recommended by participants at the Atlanta workshop, the OCRWM would also support the study group's development of criteria for uniform state permitting 
requirements and procedures. As noted by workshop participants, such criteria, if developed through a consensus process, could subsequently be used by States to promote the development of consistent and stable permit systems. Further details related to the establishment of the study group will be provided in the OCRWM Bulletin. 


\section{A.12 Rail Service Analysis}

\section{A.12.1 Overview}

The OCRWM is currently evaluating two rail-service options for transporting spent fuel and high-level waste by rail to facilities developed under the NWPA: regular-train service and dedicated-train service.* Under regular-train service, trains typically carry a mixture of commodities for many customers and from several origins to several destinations; shipments are conducted using a variety of railroad-owned or leased equipment. Rates for regular-train service are generally determined by tariffs (a collection of established rates published by the railroad).

Dedicated-train service (also referred to as unit train service) generally involves the shipment of a single commodity for a single customer, from a single point of shipping origin to a single destination (with no intermediate stops at marshaling yards for additional cargo-loading). In addition, shipments made using dedicated-train service are conducted on a schedule and based upon rates negotiated by the railroad and the customer.

The shipment of spent fuel by train offers several advantages over the use of trucks, including the ability to transport larger casks and reduce the number of casks and shipments required, and the ability to dispatch multiple casks in a single shipment (which could be expected to reduce costs and to simplify security). The potential advantages of rail service would be further enhanced if the use of an MRS facility is approved by Congress. The fuel consolidation that would occur at an MRS facility would further reduce the number of shipments required and the associated transportation effects on the public.

The OCRWM has not made final decisions on the modes of transportation that will be used for NWPA shipments. However, for purposes of planning, certain transportation assumptions have been made. For example, the OCRWM has assumed that movements from an MRS facility to a repository would be made by dedicated train, and that movements from the reactors to the MRS facility or from the reactors directly to the repository would be made by regular train, with trucks used when rail access to a reactor is not available.

The policy of maintaining multiple options in planning requires that assumptions related to an MRS facility and repository not be "locked in" to any particular mode or configuration until completion of the necessary transportation risk and cost studies. The OCRWM expects that the use of several modes and several configurations within each mode may be required to provide optimal transportation service and to ensure the presence of competitive forces. The OCRWM therefore continues to consider all modes of transportation and configurations for NWPA shipments.

* As discussed below in Section A.12.3, "special train" service has been evaluated by the DOE and under current planning is not being considered as an option for NWPA transportation. 


\section{A.12.2 Identification of Issue Elements}

Discussions between the OCRWM and interested parties have led to the identification of the following issues related to the evaluation of various rail-service options for transporting spent fuel and high-level waste to NWPA facilities:

- The need to define and review various rail-service options for transporting spent fuel and high-level waste to NWPA facilities.

- The need to review the OCRWM's plans to evaluate the costs and benefits of using different types of rail service for NWPA transportation, and how such considerations will be factored into the subsequent selection of appropriate modes of transportation for NWPA shipments.

\section{A.12.3 Discussion of Issue Elements}

The discussion that follows reviews issues related to the consideration of rail-service options for NWPA transportation; outlines current studies that are underway; and identifies, where possible, opportunities for public involvement in the development and review of various OCRWM transportation activities.

Review of Rail-Service Options

In discussions related to the development of the NWPA transportation program, some interested parties have requested that the OCRWM evaluate the potential use of special-train service for NWPA transportation conducted by rail. Characteristics of special-train service for shipments of spent fuel or other radioactive waste include the following:

- No freight other than the spent fuel or other radioactive waste is carried.

- Special trains travel at speeds not faster than 35 miles per hour (56 kilometers per hour).

- When a special train passes or is passed by another train, one of the trains must come to a complete stop while the other train passes at a speed not faster than 56 kilometers per hour.

Detailed analyses of the cost and risk related to the transportation of radioactive materials using special-train service have been conducted in the past by the Interstate Commerce Commission (ICC) and the NRC. (See: U.S. Interstate Commerce Commission, Final Environmental Impact Statement on the Transportation of Radioactive Materials by Rail, Washington, D.C., 1977; U.S, Nuclear Regulatory Commission, Final Environmental Statement on the Transportation of Radioactive Materials by Air and Other Modes, NUREG-0170, Washington, D.C., 1977) The analyses of both the NRC and the ICC supported the conclusion that the use of special-train service was neither costeffective nor necessary for the safe transportation of radioactive materials. In particular, the ICC analysis noted that special-train service would only 
slightly decrease the environmental risk from a radiological standpoint under accident conditions, but would increase the environmental risk from nonradiological and radiological factors under normal conditions of transportation.

Similarly, ICC tariff rulings issued in the late 1970 s and early 1980s cancelled the rates charged for mandatory special-train service and declared that such service was unnecessary for the safe transportation of radioactive materials. The ICC rulings were subsequently upheld by a Federal court in Consolidated Rail Corp. v. ICC, 646 F.2d 642 (D.C. Circuit 1981), cert. denied, 459 U.S. $1047(1981)$. In the case, the court held that the ICC was entitled to assume that the use of special-train service was unnecessary since such transportation safety features were not required by either the DOT or the NRC.

The rates charged by railroads for shipping radioactive materials were again examined by the ICC in a recent case involving western and southern railroads (see Commonwealth Edison Co. et al. v. Aberdeen \& Rockfish Railroad Co. et al., Interstate Commerce Commission Decision No. 378915, June 19, 1986). The ICC found that the rates charged by the railroads for shipping such materials were several times that charged for regular train service, and in general were predicated on unjustified special services. The ICC further found that the railroads' reliance on unwarranted cost additives for shipping radioactive materials reflected their continued unwillingness to transport these commodities by regular train service, and that such a refusal constituted an unreasonable practice. The ICC noted the need for a uniform national rate policy for transporting radioactive materials, and concluded that earlier rates established by the ICC for eastern railroads should be the presumptive rate ceiling for the entire United States.

Consistent with the ICC and NRC environmental impact statements, the tariff rulings issued by the ICC, and the Federal court decision cited above, the OCRWM believes that the use of special-train service for NWPA shipments by rail is unnecessary for the safe transportation of radioactive materials. As a consequence, the OCRWM's evaluations of rail transportation do not include the study of special-train service. The OCRWM believes, however, that the safety concerns that prompted the development of special-train operating procedures can be effectively addressed in the development of the NWPA transportation program through cooperative planning with the rail industry and other interested parties.

The OCRWM is therefore focusing special attention on the following elements of the NWPA transportation program:

- The development, in close consultation with the Association of American Railroads, of a stringent cask design, development, and testing program, and a related quality assurance plan.

- Consideration of design features for rail casks that could facilitate recovery in the event of a transportation accident.

- The development of operational procedures for rail transportation as an element of the OCRWM transportation plan. 
- The development of a coordinated program for inspection-andenforcement activities.

The OCRWM will provide significant opportunities for public involvement in the development of such elements of the NWPA transportation program. Further discussion of related activities is included in Sections A.7, A.10, and A.16 of this Appendix.

As previously noted, the OCRWM is evaluating two other rail-service options for transporting spent fuel and high-level waste to NWPA facilities: regular-train service and dedicated-train service. The OCRWM has focused its recent analyses on the use of regular trains for shipments from reactors to an MRS facility or directly to a repository, and the potential use of dedicated trains for shipments from an MRS facility to a repository.

The OCRWM has directed the Battelle Memorial Institute to conduct a preliminary study of dedicated trains in terms of cost and operational factors; the study is expected to be completed in the fall of 1986 . The study assumes that spent fuel could be consolidated and packaged at an MRS facility; subsequent rail shipments to a repository could then be conducted using a dedicated train carrying several ( 5 to 10 ) large rail casks. Such rail casks would not be constrained by the cask-handling capabilities of various reactors, and therefore could be somewhat larger than the rail casks expected to be used for transportation from individual reactors to an MRS facility or a repository. Spent-fuel consolidation and the use of larger rail casks that could be transported using dedicated trains would significantly reduce the number of shipments to a repository.

\section{Rail Service Cost and Risk Evaluations}

In discussions with the OCRWM, interested parties have requested that the OCRWM specify its plans to evaluate the cost and risk associated with the transportation of radioactive materials using different types of rail service. Some parties have also requested that the OCRWM review the mechanisms by which such cost and risk considerations will be factored into future OCRWM decisions related to the selection of an appropriate modal mix for NWPA transportation.

The evaluation of the cost and risk of rail service options will be supported by several OCRWM studies. The OCRWM has initiated a study to evaluate the cost and risk associated with potential transportation systems under which reasonable efforts would be made to reduce radiation exposures to levels as far below Federal dose limits as is practicable -- that is, "as low as reasonably achievable" (ALARA). As part of the ALARA study, the OCRWM will evaluate the expected radiation doses and costs associated with various shipping alternatives, including regular-train service and dedicated-train service. The OCRWM expects to complete an interim report on the evaluation of a reference transportation system using ALARA principles by the summer of 1986; the interim report will include a preliminary identification of alternative transportation systems for continued study under ALARA principles. Notice of the availability of the interim report will be included in the OCRWM Bulletin, and comment will be solicited on the reference system and alternatives deserving further study. 
The OCRWM will also conduct a more detailed study of transportation cost and risk through the use of a transportation "network optimization" model. The OCRWM will use the model (expected to be developed by 1987) to predict the optimum modal mix and shipping schedules that could be used for NWPA transportation. Use of the model will enable the OCRWM to identify the optimum transportation system (which may include the use of regular and dedicated trains) for limiting cost and risk. The OCRWM expects to issue a summary report in 1987 to describe the optimization model and unit cost and risk factors. The summary report will be made available for review and comment.

Information provided by the OCRWM's evaluations using ALARA principles and the optimization model will be used to support the development of an environmental impact statement (EIS) for candidate repository sites. The OCRWM plans to use certain route-specific data associated with rail, truck, and barge transportation in the transportation cost and risk analyses conducted for the EIS. Detailed planning for such analyses will begin in 1986. The transportation analyses in support of the EIS are expected to be completed in late 1990, and to include an analysis of the cost and risk associated with transportation using regular-train service and dedicated-train service.

To assist in planning and in the definition of appropriate parameters for the EIS analysis, the OCRWM is considering the use of regional workshops (expected to begin in late 1986). Topics of discussion are expected to include the following:

- A review of the requirements for computer models that will be used to predict the cost and risk of shipping spent fuel and high-level waste.

- Appropriate methods for determining feasible routes to potential NWPA facilities.

- Specific factors that should be considered in cost and risk analyses.

- The availability of route-specific data, and where data are not readily available, appropriate methods for obtaining such data.

The OCRWM anticipates that initial decisions on the modal mix for NWPA transportation (which may include the use of regular and dedicated trains) will be made in 1993, at which time contracts for the development of a cask fleet will be awarded. The OCRWM's decisions related to the selection of appropriate rail-service options will be based on the same principles applied to the selection of other modes of transportation, and will ensure that NWPA transportation is conducted in a safe, efficient, and cost-effective manner. Methods will be employed to ensure that real operational problems are fully considered before final fleet-composition is determined and equipment is procured. 


\section{A.13 Mixture of Transportation Modes}

\section{A.13.1 Overview}

One important variable in planning for future transportation operations is the fraction of total spent fuel and high-level radioactive waste to be delivered to NWPA facilities by each mode of transport (truck, rail, and barge). In earlier years, most of the small quantity of spent fuel to be moved was transported by truck because the capital cost for equipment was lower than for rail, and motor carriers were able and willing to haul spent fuel at attractive rates. In the mid 1970s, as preparations were being made to move spent fuel in quantities of 1,500-2,000 metric tons of uranium (MTU) per year, the emphasis shifted to planning for rail transportation. In fact, the only truck transportation envisioned by industry was to accommodate nuclear reactor plants lacking rail service or facilities adequate to handle large rail casks. More recently, the DOE, in the Generic Environmental Impact Statement on the Management of Spent Fuel and High-Level Waste (DOE/EIS-0046, October 1980), made the assumption for analysis and planning that 90 percent of the total quantity of spent fuel would move by rail, a position comparable to that of the private sector in the mid-1970s.

The OCRWM has made preliminary analyses of NWPA fleet requirements with assumptions related to the mode of transportation ranging from 100 percent truck to 100 percent rail, and also a so-called "rail preference case" which assumes that 25 percent of NWPA transportation would be accomplished using truck and 75 percent using rail. However, it is the OCRWM's position that it is neither necessary nor desirable at this time to establish a firm quantitative position on the fraction of spent fuel and high-level radioactive waste to be transported by truck, rail, and barge. Cask development and operational planning will therefore proceed on a basis that will assure the capability and readiness to transport a significant quantity of spent fuel and high-level waste to NWPA facilities by each mode. The OCRWM will continue to solicit and analyze the many views and concerns related to modes of transport including relative safety, efficiency, capital costs, hauling costs, carrier capabilities and willingness to provide transportation services, shipping and receiving facility operations, environmental impacts, and overall public acceptance. To assist in a discussion of issues related to the use of various modes of transportation, the characteristics of each mode are described below.

\section{Legal Weight Truck}

The term "legal weight truck" (LWT) is the designation given to conventional tractor-semi-trailer units commonly seen on the highways which, when fully loaded, do not exceed a gross vehicle weight (GVW) of 80,000 pounds. Based on this weight unit (called "legal weight"), approximately two pressurized water reactor ( $P W R$ ) spent fuel elements or five boiling water reactor (BWR) fuel elements could be carried in the new generation of casks. Benefits of LWT shipments are low capital costs (less than $\$ 1$ million), rapid transit times ( 700 miles/day), flexible routing, and the capability and willingness of motor carriers to provide carriage services. In addition, essentially all spent fuel shipping and receiving facilities can accommodate the LWT casks. Some disadvantages of LWT transportation are low cask payloads and the associated need for a larger number of shipments. 


\section{Overweight Truck}

The term "overweight truck" (OWT) is the designation given to conventional tractor-semi-trailer units which have additional axles and wheels and, under special permits and restrictions, are allowed to exceed the Federally prescribed GVW limit of 80,000 pounds. In spent fuel transportation, the GVW could reach 120,000 pounds. Because of the higher GVW allowed, the payload of casks can be increased to approximately 4 PWR spent fuel elements or 10 BWR elements per cask. The cost for such casks is slightly higher, state permits would be required, and transit speeds may be lower than LWT because of certain travel restrictions. However, the OWT units have many of the same benefits as LWT (as discussed above).

\section{Regular Rail--Unrestricted}

The term "regular rail--unrestricted" (RRU) is the designation given to transport of larger casks, weighing up to 100 tons, on conventional flat cars in regular freight trains along with many other commodities in normal commerce. The GVW 1 imit on roadbeds and bridges for these units is 263,000 pounds. The payload of the new generation cask will be 14 PWR spent fuel elements or 36 BWR elements. The advantages of this mode are the larger payload, which in turn results in major reductions in shipping and receiving operations and fewer trips. The disadvantages are slow transit speed (100-300 miles/day), and rail-yard and interchange point delays.

\section{Heavyweight Rail*}

In general, the railroads can also carry casks weighing up to 300,000 pounds or more on special railcars. However, additional restrictions are placed on routing and schedules. This would increase hauling costs and possibly increase transit time. In either case, there is much less routing flexibility with rail than with either LWT or OWT.

\section{Tug-Barge/Motor Vessel}

The use of tug-barge combinations or self-propelled motor vessels on inland waterways and offshore may be possible for shipping waste from facilities (primarily reactors) located on or near navigable waterways. Casks would be loaded onto the barge or vessel using special heavy hauling wheeled vehicles and docking facilities near the reactors. These procedures are similar to those used in bringing heavy components (e.g., reactor vessels or steam generators weighing between 150 and 600 tons) to the facilities during construction.

* For purposes of this discussion only, the term heavyweight rail refers to those railcars weighing more than 263,000 pound, a weight identified by the Association of American Railroads as the limit for unrestricted operations. However, some individual railroads operate in excess of this 1 imit without restrictions. 
An advantage of this option is a greater load-carrying capability than that of LWT, OWT, and rail transportation. One primary disadvantage is slow transit time and, in turn, higher capital and operating costs. However, a study recently completed for the OCRWM (Argonne National Laboratory, Preliminary Assessment of Cost and Risk of Transporting Spent Nuclear Fuel by Barge, ANL/ER-TM-85-2, December, 1985) indicates that barge shipments become competitive with rail when six or more casks can be loaded onto the barge. The barge study also indicates that line-haul barge movements are feasible for the NWPA program if facilities are within 300 miles of a navigable waterway. Occupational radiation exposure may be higher because of additional tie-down operations at truck-to-barge and barge-to-rail transfer points. In addition, for offshore movements, routing would be restricted to routes having water depths that would enable salvage and recovery operations in the event of a transportation accident.

\section{$\underline{\text { Train-and-Barge }}$}

Train-and-barge intermodal transportation generally occurs with "short hauls" using rail service from the point of shipping origin or to shipping destinations (and sometimes both), with barge transportation providing "long hauls" in-between. This practice takes advantage of the ability of railroads to serve many origins and destinations, combined with the energy efficiency and lower cost of water transportation. Train and barge combinations usually transport high-bulk, low-value commodities that require the lowest possible transportation cost, or extra-heavy, high-dimensioned items that would be difficult to move by land transportation. The trains that exchange loads with the barges could be operated as regular or dedicated trains.

\section{Intermodal Transportation}

Intermodal transportation involves a combination of modes described above and has particular applicability to reactors without rail service but with facilities capable of handling 25 to 150 ton casks. In the simplest form of intermodal transport, LWT or OWT casks could be transported to a nearby railroad (within 5 to 10 miles) and transferred by mobile crane to a conventional railroad flat car. Similar operations could be carried out with 75 to 150 ton casks, except that much larger special trucks (up to 100 feet 1 ong and with numerous axles and wheels) and special cranes or roll-on-roll-off facilities would be required at transfer points. These operations would be similar to the barge/motor vessel loading operations mentioned above.

An important advantage of this mode is the elimination of low-capacity trucking at reactors without rail service. The principal disadvantages are slow transit time, higher shipping costs, and possibly an increase in occupational radiation exposures.

\section{A.13.2 Identification of Issue Elements}

Discussions between the OCRWM and interested parties have led to the identification of the following issues related to the evaluation and selection of modes of transportation for NWPA shipments: 
- The need for the OCRWM to review the process that will be used to select appropriate modal mixes for NWPA transportation, and the potential need to develop specific criteria for selecting the appropriate mix of transportation modes.

- The need to evaluate the costs and risks associated with barge transportation and the extent to which barge transportation could be used for NWPA shipments.

- The need for the OCRWM to specify its plans to identify and evaluate necessary interface requirements between different modes of transportation.

- The need for the OCRWM to specify its plans to study modal constraints at existing reactors and the costs of mitigating such factors.

- The need for the OCRWM to review any plans to develop and use transportation equipment that would facilitate the recovery of casks in the event of a serious transportation accident.

\section{A.13.3 Discussion of Issue Elements}

The discussion that follows reviews issues associated with the evaluation and selection of appropriate modal mixes for NWPA transportation; identifies, where possible, opportunities for public involvement in the development and review of various transportation options; and includes the expected scheduling of OCRWM activities.

Selection of Modes of Transportation

In discussions with the OCRWM, interested parties have requested that the OCRWM specify its plans to evaluate the cost and risk associated with different modes of transportation (truck, rail, and barge), and describe how such cost and risk considerations will be factored into the selection of an appropriate modal mix for NWPA transportation. In addition, some parties have requested that the OCRWM consider the potential need to develop criteria for selecting appropriate modes of transportation.

The evaluation of the cost and risk of various modal options will be supported by several OCRWM studies. The OCRWM has initiated a study to evaluate the cost and risk associated with potential transportation systems under which reasonable efforts would be made to reduce radiation exposures to levels as far below Federal dose 1 imits as is practicable--that is, "as low as reasonably achievable" (ALARA). As part of the ALARA study, the OCRWM will evaluate the expected radiation doses and costs associated with various shipping alternatives. The OCRWM expects to complete an interim report on the evaluation of a reference transportation system using ALARA principles by the summer of 1986; the interim report will include a preliminary identification of alternative transportation systems for continued study under ALARA principles. Notice of the availability of the interim report will be included in the OCRWM Bulletin, and comments will be solicited on the reference system and alternatives deserving further study. 
The OCRWM will also conduct a more detailed study of transportation cost and risk through the use of a transportation network optimization model. The OCRWM will use the model (expected to be developed by 1987) to predict the optimum modal mix and shipping schedules that could be used for NWPA transportation. Use of the optimization model should enable the OCRWM to identify the optimum transportation systems for limiting cost and risk. The OCRWM expects to issue a summary report in 1987 to describe the optimization model and unit cost and risk factors. The summary report will be made available for review and comment.

Information provided by OCRWM evaluations using ALARA principles and the optimization model will be used to support the development of an environmental impact statement for candidate repository sites. The OCRWM will also use certain route-specific data associated with rail, truck, and barge transportation in the transportation cost and risk analyses conducted for the environmental impact statement. Detailed planning for such analyses will begin in 1986. The transportation analyses are expected to be completed in late 1990.

To assist in the selection of appropriate modal mixes for NWPA transportation, the OCRWM will develop criteria that can be used to weigh the relative importance of costs, risks, and other effects associated with various modes of transportation and transportation systems. The OCRWM will make such criteria available for review and comment.

The OCRWM expects that initial decisions on the modal mix for NWPA transportation will be made by 1993, at which time a contract for the development of a cask fleet will be awarded. The OCRWM will, however, make an effort to determine the modal mix before 1993 to allow more time for States, Indian Tribes, and local governments to plan for NWPA transportation. In the interim, the OCRWM will continue to evaluate modal options and define operational procedures for truck, rail, and barge transportation. It should be noted that the OCRWM expects to adjust the modal mix during actual NWPA transportation operations in response to such factors as continued transportation analyses, changes in shipping rates, and modal constraints at reactors.

\section{Evaluation of Barge Transportation}

As previously noted, a preliminary evaluation of the potential use of barges in radioactive waste transportation was conducted by the Argonne National Laboratory for the OCRWM. The study, completed in December 1985, provides initial estimates of certain costs and risks associated with barge transportation. If found to be an attractive option in terms of cost and risk, barge transportation may be further evaluated in the ALARA study, using the transportation network optimization computer model, and in transportation analyses conducted during the development of an environmental impact statement for candidate repository sites.

\section{Evaluation of Modal Interface Requirements}

In discussions with the OCRWM, some interested parties have requested that the OCRWM specify its plans to identify and evaluate the interface 
requirements for conducting NWPA shipments using several different modes of transportation. Under current OCRWM plans, all casks would be designed to have features that allow transportation by truck, rail, and barge. Such "intermodal" design features would be specified in the OCRWM request for proposals for the design and development of casks that would be used for shipping spent fuel from reactors to a repository (or to an MRS facility, if approved by Congress); the request for proposals is scheduled for release in 1986.

\section{Evaluation of Moda1 Constraints at Reactors}

The OCRWM has initiated detailed studies of existing reactors to determine the constraints (including facility design features and transportation infrastructure) on the use of various modes of transportation for shipping spent fuel. The OCRWM expects to issue a report in 1988 on the study's findings; the report will be made available for review and comment.

Plans to Design Transportation Equipment to Facilitate Recovery in the Event of Accidents

As part of its program for developing casks for the transportation of spent fuel from reactors to NWPA facilities, the OCRWM has issued preliminary cask interface guidelines (see U.S. Department of Energy, Idaho Operations Office, Information Package for the From-Reactor Cask Program, Idaho Falls, ID, February 1986). The preliminary guidelines specify that cask designs should include means for retrieving the cask and related transportation equipment following an accident, and allow the cask to be returned to a transportable position. Such designs may include features that facilitate the use of cables or slings for accident-recovery purposes. The Associations of American Railroads will provide supplemental input on the appropriate design features for rail casks.

The OCRWM will review such design features, and develop final guidelines for application to the development of an NWPA cask fleet for waste transportation from reactors to NWPA facilities. Under current planning assumptions, final guidelines will be established by 1993, when the OCRWM will be finalizing contract requirements for the procurement of the cask fleet. 


\section{A.14 Transportation Infrastructure Improvements}

\section{A.14.1 Overview}

An important element of the NWPA transportation program will be the evaluation of transportation infrastructure. As used in this paper, infrastructure refers to physical transportation structures, including highways, bridges, rail-lines and rail-beds, and elements associated with navigable waterways. The following overview briefly reviews existing responsibilities and programs for the development and maintenance of transportation infrastructure.

Under provisions of the Federal-Aid Highway Act of 1956, a dedicated funding mechanism was established for constructing and maintaining the Federal-aid highway system. This system consists of 810,000 miles of highway, which is approximately 20 percent of the total $4.7 \mathrm{milli}$ ion miles of roadway in the United States. Included within the Federal-aid system are the 42,000 miles of Interstate and Defense Highway System roads (commonly referred to as Interstate highways); roads within that system will generally be used for the highway transportation of NWPA shipments (see discussion in Appendix Section A.5). Generally, States with roadways that are designated part of the Federal-aid system are eligible for matching Federal funds to construct and maintain the roads; State programs for the construction and maintenance of Interstate highways are eligible for up to 90 percent Federal funding, and programs for non-Interstate highways may be supported by as much as 75 percent Federal funding. Thus, funding for the construction and maintenance of the Federal-aid system is a shared responsibility between Federal and State governments. The DOT is the Federal agency that administers this cooperative funding arrangement.

The construction and maintenance of the rail network is the responsibility of the private railroad companies. Therefore, funding to accommodate any infrastructure improvements needed to support NWPA transportation would be accomplished under a different arrangement and would raise unique considerations.

The Corps of Engineers (within the Department of Defense) is responsible for managing and directing navigational activities in the Nation's waterways. To support such functions, the Corps of Engineers has conducted detailed reviews of the capacity of navigable waterways to meet national transportation needs.

\section{A.14.2 Identification of Issue Elements}

A number of questions have been raised about certain transportation infrastructure improvements (e.g., upgraded road and rail-beds, and bridge repairs or improvements) that may be necessary to support waste transportation to NWPA facilities, or that may be required as an element of mitigation activities associated with the waste management program. Concern has also been expressed that infrastructure condition and the potential need for improvements be included as an NWPA facility-siting consideration. The following issues concerning transportation infrastructure improvements have been identified in discussions between the OCRWM and interested parties: 
- The criteria for utilizing NWPA funds for transportation infrastructure improvements that may be needed for NWPA transportation.

- The role of transportation infrastructure condition in the siting of NWPA facilities.

- The potential need to establish "adequacy" standards for transportation infrastructure and mechanisms for evaluating the infrastructure improvements that may be needed to attain or maintain an adequate infrastructure for NWPA transportation.

It should be noted that components of this issue are subsumed within other, more generic issues contained in Appendix A, such as (1) routing; (2) the selection of modes of transportation, and the effect of such factors on the overall NWPA siting and site-assessment process; and (3) the development of mechanisms to ensure the safe and cost-effective transportation of waste materials.

\section{A.14.3 Discussion of Issue Elements}

\section{The Criteria Under Which NWPA Funds Would} Be Used for Infrastructure Improvements

An important issue related to the potential need for transportation infrastructure improvements is the extent of the OCRWM's authority to use monies from the Nuclear Waste Fund to improve highway, rail and waterway features that are already being maintained by funds available from other Federal and State agencies. Where the use of the Nuclear Waste Fund is found to be justified, guidelines will be needed to determine when such improvements should be made utilizing NWPA funds. At the OCRWM's Transportation Institutional Plan Workshop held in November 1985, for example, commenters suggested that infrastructure improvements and/or development be supported by NWPA funds in those situations in which: (1) there was no alternative routing, (2) there would be substantial reduction in public exposure to the effects of transportation, and ( 3 ) there would be a subsequent reduction in transportation costs.

As stipulated in the NWPA (Sections 116[c][2][A] and 118[b][2][A]), the OCRWM will provide financial and technical assistance for impact mitigation to (1) States in which the construction of a repository has been authorized, and (2) any affected Indian Tribes.* Any State or Indian Tribe desiring assistance under these provisions must submit an impact report and impact assistance request to the Secretary of Energy. Once a construction authorization for a repository is granted, the Secretary must seek to enter into a binding agreement setting forth the amount of assistance that will be provided to the State or Indian Tribe. Consultation-and-cooperation (C\&C) agreements

* Similar provisions (applicable to local governments and affected Indian Tribes) are found in Section 141 ( $f$ ) of the NWPA for the mitigation of impacts associated with the construction of a monitored retrievable storage facility. 
between these jurisdictions and the OCRWM will provide guidance on the process for developing impact mitigation agreements. Included in these agreements would be consideration of transportation infrastructure improvements related to NWPA shipping.

There is no statutory direction, however, concerning mechanisms for determining responsibilities and requirements for infrastructure improvements outside these host or affected areas. Waste shipments through non-host states are not expected to create any unique needs for infrastructure improvements, nor require maintenance in addition to that normally required for general transportation. Specific needs, however, for infrastructure improvements will be reviewed on a case-by-case basis. The OCRWM will work with such non-host States, Indian Tribes, and local governments to determine appropriate mechanisms for determining the need for infrastructure maintenance or improvements. Under current OCRWM plans, infrastructure improvement and funding issues will be discussed in workshops and study groups associated with the development of the OCRWM's comprehensive transportation plan. The first such workshop is expected to be held in the fall of 1987.

Infrastructure improvement funds may also be made available to upgrade links between utilities (reactors) and existing transportation lines (e.g., highways and rail-1ines). The costs and benefits of upgrading existing facilities and transportation 1 inks is now being evaluated. An OCRWM statement on the extent of infrastructure improvements required for NWPA transportation is expected to be developed by mid-1991, when a repository site is selected.

The Role of Transportation Infrastructure Condition in the siting Process

As the NWPA program proceeds toward the identification of a repository site and probable transportation routes, the potential need for infrastructure improvements will be evaluated in increasing detail. General transportation infrastructure conditions were considered in the environmental assessments for potential repository sites. In addition, transportation infrastructure issues will be addressed during the development of the repository environmental impact statement. The OCRWM will use certain route-specific data associated with rail, truck, and barge transportation in the transportation cost and risk analyses conducted for the environmental impact statement. Detailed planning for such analyses will begin in late 1986. The transportation analyses are expected to be completed in late 1990, and to include an analysis of certain factors related to transportation infrastructure.

To assist in planning and the definition of appropriate analysis parameters, the OCRWM is considering the use of regional workshops (potentially scheduled to begin in late 1986). Topics of discussion are expected to include the following:

- Appropriate methods for determining feasible routes to potential NWPA facilities.

- Specific factors that should be considered in cost and risk analyses. 
- The availability of route-specific data, and where data are not readily available, appropriate methods for obtaining such data.

The OCRWM will provide formal notice of routing activities in the OCRWM Bulletin and in the Federal Register, as appropriate.

\section{The Establishment of "Adequacy" Standards}

for Transportation Infrastructure

Some States have suggested that a prerequisite for addressing the need for transportation infrastructure improvements and infrastructure maintenance during transportation operations is the establishment of some criteria or guidelines by which existing transportation infrastructure can be determined to be adequate (i.e. not requiring improvement). Given the primary role of States in highway maintenance and of private companies in railway system maintenance, this issue will be discussed in detail in workshops and study groups associated with the development of the OCRWM Transportation Plan. It should be noted, however, that the OCRWM does not anticipate that the overall repository transportation program operations will create unique infrastructure needs, nor contribute significantly to the deterioration of the nation's transportation infrastructure. Infrastructure improvements needed to support NWPA transportation will generally be needed to support the transportation of other commodities. Therefore, the need for adequacy criteria for nationwide transportation infrastructure is currently considered to be unnecessary. As previously noted, the OCRWM plans to evaluate specific infrastructure needs on a case-by-case basis. Particular attention will be paid to the potential need for infrastructure improvements in States that host NWPA facilities. 


\section{A.15 OCRWM Training Standards}

\section{A.15.1 Overview}

An important element of the waste management program will be the deve1opment of OCRWM training standards needed to support various aspects of waste transportation to NWPA facilities. OCRWM training standards will be developed for activities related to driver instruction, cask maintenance and servicing, operating procedures, and shipment security. (A discussion of training issues related to inspection and enforcement, and emergency response, is included in Sections A.7 and A.8.) Training standards (for transportation operations) that are currently required under Federal law are reviewed below.

\section{Driver and Operator Training}

Regulations of the DOT (49 CFR 177.825[d]) require that drivers for highway shipments of radioactive materials in "highway route controlled quantities" (such materials include spent nuclear fuel and high-level waste) receive written training on--

- DOT requirements for transporting such radioactive materials.

- The properties and hazards of the radioactive materials being transported.

- Procedures to be followed in the event of an accident or other emergency.

Driver training must have occurred within 2 years of the transportation of radioactive materials, and drivers must have in their immediate possession a certificate showing that training has been provided. The DOT does not certify individual driver training programs. Compliance with driver training requirements instead is monitored through safety inspections conducted by the DOT's Research and Special Programs Administration and the Bureau of Motor Carrier Safety, and various State enforcement personnel.

Similar training requirements for rail carrier personnel have not been developed. Rail carriers, however, are required to comply with rail safety procedures and detailed requirements for shipping radioactive materials as specified in DOT regulations found in 49 CFR Part 174, Subpart K, and 49 CFR Parts 200-299.

In order to promote drivers' and operators' understanding of current regulations affecting the transportation of radioactive materials, the DOT currently offers training courses for the carrier industries through its Transportation Safety Institute, located in Oklahoma City, Oklahoma.

The DOE's Transportation Operations and Traffic Management section also offers "radioactive material transportation compliance and training" workshops. The workshops are held every several months, at varied locations in the United States. Training topics include identification requirements for radioactive materials, packaging, shipping regulations, and administration of pertinent regulations issued by the DOT, the NRC, and other Federal agencies. 
The workshops are operated for the DOE by Science Applications International Corporation of Oak Ridge, Tennessee.

\section{Operating Procedures and Cask Maintenance}

Applications to the NRC by NRC 1 icensees for cask approval must specify operating procedures, cask-acceptance tests, and a cask-maintenance program. Operating procedures are those that involve loading and unloading shipping casks, and preparing casks for transportation. Cask-acceptance tests are performed prior to the first use of a shipping cask, and include visual inspection, leak tests, tests for radiation shielding, and tests of the component parts (such as valves and gaskets) of a cask. The NRC requires that a caskmaintenance program ensure the continued performance of casks and include specific procedures for periodic cask testing, inspection, and replacement schedules.

The NRC has developed an inspection-and-enforcement program to monitor compliance with its regulations and control procedures. In accordance with DOT regulations (49 CFR $173.7[\mathrm{c}]$ ), the DOE applies equivalent operating procedures, acceptance tests, and cask-maintenance programs to the transportation of nuclear waste generated from activities related to national defense and research and development.

Training to Promote the Physical

Protection of Shipments

Regulations of the NRC (10 CFR 73.37) require NRC 1 icensees to provide a physical protection system to safeguard spent fuel shipments from acts of theft and sabotage. Included in such a system must be the use of shipment escorts who have successfully completed training for the appropriate response to acts of theft and sabotage. As specified in 10 CFR Part 73, Appendix D, such training must address procedures for--

- Route planning and selection.

- Vehicle operation.

- Routine stops.

- Detours and use of alternative routes.

- Equipment operation.

- Status reporting.

- Contacting law enforcement units.

- Reporting incidents.

- Responding to accidents, severe weather conditions, vehicle breakdown, communications problems, and radioactive "spills."

- Use of special equipment (flares, emergency lighting, etc.). 
- Calling for assistance.

- Use of immobilization features.

- Hostage situations.

- Avoiding suspicious situations.

Training must also include a description of--

- The radioactive cargo.

- Function and characteristics of the shipping casks.

- Radiation hazards.

- Federal, State, and local ordinances relative to the shipment of radioactive materials.

- Responsible agencies.

The NRC 1 icensee is also required to ensure that armed individuals serving as shipment escorts, other than members of local law-enforcement agencies, have completed a weapons training and qualifications program.

Regulations of the DOT (49 CFR 173.22[c]) require the DOE to apply a physical protection system to DOE spent fuel shipments; the system must provide a level of protection that is equivalent to NRC requirements. Physical protection procedures have been developed by the DOE and approved by the DOT. To support the implementation of DOE physical protection procedures, the DOE requires related instruction. Such instruction basically parallels NRC requirements, except those related to weapons training. The DOE does not require the use of armed guards; further discussion of this issue is included in Section A.4 (Physical Protection Procedures).

\section{A.15.2 Identification of Issue Elements}

Discussions between the OCRWM and interested parties have addressed both the extent of current Federal training requirements and plans of the OCRWM to develop formal training standards for all aspects of NWPA transportation based on Federal requirements. The following 1 ist of associated issue elements has been identified through those discussions:

- The need to develop a mechanism to review the potential necessity for nationally uniform driver and operator courses, exams, and certification, and who should pay for such training.

- The need for OCRWM to develop formal training standards for all OCRWM activities related to the transportation program for shipping radioactive waste to NWPA facilities. 
- The need to review the training standards that will be applied to OCRWM shipments of nuclear waste for research and development activities.

As previously noted, a discussion of training issues related to inspection and enforcement, and emergency response, is included in Sections A. 7 and A.8.

\section{A.15.3 Discussion of Issue Elements}

The discussion that follows contains discussion of training issues; identifies plans for public involvement in the development of OCRWM training standards; and includes the expected schedule for OCRWM activities.

Review of Driver and Operator Training Requirements

Some participants at the OCRWM Transportation Institutional Plan Workshop, held in November 1985, suggested that the OCRWM develop a mechanism to involve all parties (including the DOT, the NRC, and carrier industries) in an evaluation of the need for the certification of drivers of motor vehicles and operators of other modes of transportation through a system of nationally uniform courses and written exams. If such training was determined to be needed, the workshop participants further suggested the following options for implementing a training program:

- The NRC and the DOT could oversee a program of training and exams.

- An independent agency could act to certify drivers of motor vehicles and operators in other shipping modes.

- The OCRWM, with potential assistance from a contractor, could design and administer a training course for NWPA shipments.

- Training courses could be developed by nongovernmental organizations to meet OCRWM requirements.

Such recommendations seem to focus on two separate issues:

- The potential need for the DOT to revise its regulations that specify driver and operator training requirements for shipments of all hazardous materials, including highly radioactive materials.

- The need for the OCRWM to develop its own driver and operator training standards, consistent with DOT regulations, for NWPA shipments.

In reviewing the need for the DOT to revise its regulations, the OCRWM first wishes to note that the Congress, in enacting the Hazardous Materials Transportation Act, authorized the DOT to promulgate national safety regulations for the transportation of all hazardous materials, including radioactive materials. Such authority extends to the regulation of driver and operator training. In issuing current regulations requiring training for drivers of motor vehicles used to transport radioactive materials, the DOT considered the need to inspect and certify carrier training programs. The DOT concluded that 
regulations that set out major training requirements, while allowing carriers the flexibility to develop individualized training programs for different hazardous materials and associated hazards, provided an efficient method for achieving desired safety objectives (Federal Register, Vol. 46, p. 5311, January 19 , 1981).

The OCRWM believes that the DOT has the primary authority to review the need for national driver and operator training programs and exams. The OCRWM will, however, work with the DOT, the NRC, and the DOE's Office of Defense Programs in an effort to determine an appropriate intergovernmental mechanism for addressing the issue. Such mechanisms may include--

- Technical studies to evaluate driver and operator training needs and the adequacy of existing training programs.

- Workshops specifically designed to solicit the views and identify the needs of the carrier industry and unions.

- Petitioning the DOT for a formal rulemaking if, after review, the OCRWM concludes that driver and operator training programs need further regulation.

In discussions with the DOT, the NRC and the DOE's Office of Defense Programs, the OCRWM will present all comments that have been submitted to the OCRWM by parties having an interest in the development of the NWPA transportation program. Progress made through such discussions, opportunities for public involvement in the review process, and scheduling details will be provided through notice in the OCRWM Bulletin and future editions of the OCRWM transportation plan.

While national driver and operator training requirements may ultimately be revised by the DOT, the OCRWM has begun to review appropriate driver and operator training standards for the NWPA transportation program based on current DOT regulatory requirements. Driver and operator training standards will be one operational element addressed in the OCRWM transportation plan; the need to define appropriate driver and operator training standards is expected to be one topic of discussion in a workshop scheduled for the fall of 1987 to review the development of the comprehensive transportation plan. Under current program schedule assumptions, the OCRWM anticipates that such training standards will be developed by mid-1989, in order to support the development of a request for proposals for transportation service contracts.

Under current planning, the OCRWM standards would require the use of a uniform OCRWM driver and operator training program, to be administered by transportation service contractors (if the use of such contractors is found to be the preferred option). Topics to be covered in such training include--

- Equipment and vehicle operation.

- Description of radioactive cargo and associated hazards.

- Procedures at stops. 
- Shipment reporting.

- Procedures to be followed in the event of vehicle breakdowns and mechanical failures.

- Procedures to be followed in severe weather conditions.

- Appropriate procedures to be followed in the event of transportation accidents, and instruction on communication procedures with local lawenforcement personnel and OCRWM contacts.

- Security procedures to be followed to protect shipments against acts of theft and sabotage.

- Instruction on the use of on-board radiation monitoring equipment.

- Instruction on routine vehicle safety and maintenance checks.

- Instruction on Federal, State, Tribal, and local shipping requirements, including those pertaining to placarding, routing, and safety procedures.

- Specific route conditions requiring special training (e.g., mountain driving).

The OCRWM is also considering the use of standard written exams as part of a driver and operator training program; such exams could be administered by 1 transportation service contractors. It should be noted that under OCRWM standards, driver and operator qualification for waste shipments to NWPA facilities would be established by the successful completion of a training course and a review of past performance records. Such standards will be specified in transportation service contracts. OCRWM training standards for truck drivers and the operating personnel for other modes of transportation will be made available for review prior to being issued in final form. Such standards will, however, be subject to revision as necessary to comply with all future Federal requirements. The costs of administering a driver and operator training program will ultimately be borne by the OCRWM, and will be addressed in contracts with transportation service contractors.

\section{OCRWM Training Standards for NWPA}

\section{Shipments}

In addition to developing driver and operator training standards (as part of operational procedures addressed in the comprehensive transportation plan), the OCRWM will develop training standards for NWPA program activities related to operational procedures, cask inspection prior to use (acceptance tests), and the implementation of a cask-maintenance program. Such standards will be developed to support all activities that must be specified in an application to the NRC for cask approval. Consistent with a Memorandum of Understanding (published in the Federal Register, Vol. 48, p. 51875, November 14, 1983) with the NRC and a formal agreement with the DOE's Office of Defense Programs, the OCRWM will seek NRC approval of all casks to be used for shipping commercial and defense waste to NWPA facilities. 
Training standards for shipment escorts will also be developed in compliance with NRC physical protection requirements, and will supplement the training standards for truck drivers and rail and barge operator personnel. Subjects expected to be included in such a training program for escorts, consistent with existing NRC guidelines (10 CFR Part 73, Appendix D), include--

- Vehicle operation.

- Procedures at stops.

- Route planning and procedures for selecting necessary detours.

- Communications discipline.

- Procedures for reporting security incidents.

- Use of immobilization features.

- Procedures for handling potential hostage situations.

- Procedures for identifying and avoiding situations in which cargo safety is threatened.

Al1 OCRWM training standards are expected to be developed by mid-1989 to correspond with the OCRWM's development of a request for proposals for transportation service contracts. Training standards will be included in transportation service contracts, and will be made available for review before being finalized.

Under current planning assumptions, training programs developed under OCRWM standards for operating procedures, acceptance tests, cask maintenance, and shipment escorts would subsequently be conducted by OCRWM transportation service contractors. The costs associated with such training programs would be covered by the OCRWM, and would be addressed in transportation service contracts.

\section{Training Standards for R\&D Shipments}

As noted in section A.3, the OCRWM will be making a number of shipments over the next 5 years in support of several research and development (R\&D) programs conducted pursuant to the NWPA. Such shipments will be conducted using existing DOE training standards for carrier training, cask-acceptance tests, operating procedures, and cask maintenance. Those procedures will continue to be followed until such time as the OCRWM establishes training standards that can be uniformly applied to all OCRWM shipments to NWPA facilities. OCRWM training standards are expected to be defined by mid-1989. 


\section{A.16 Transportation Operational Procedures}

\section{A.16.1 Overview}

Consistent with schedules set forth in the NWPA for the operation of a repository and in evaluations of the OCRWM related to the potential use of an MRS facility, the supporting transportation system should reach operational capability in 1996. Under current planning, the OCRWM expects to define general operational procedures by 1990; such procedures will be included in a request for proposals for service contracts (assuming that the use of service contractors is found to be the preferred management option). The OCRWM expects to develop by 1987 a preliminary outline of operational factors that the OCRWM believes should be included in the comprehensive transportation plan. The OCRWM also plans to hold a workshop in the fall of 1987 to discuss the outline of operational factors. Many of the operational procedures and factors have been identified as issues of interest or concern and are the subject of the majority of the discussion papers included in this document. As these issues are resolved and related decisions are made, the procedures will be defined for operating the NWPA transportation system.

The NWPA transportation system will draw on the nuclear waste shipping experience of the DOE, the electric utilities and the transportation industry, but it will also employ procedures unique to the requirements of NWPA implementation. A systems-integration approach will be utilized to support the development of the transportation operational procedures needed to accommodate critical interfaces of the overall waste management and disposal system. Decisions related to the potential use of an MRS facility, the location of the repository, and the design of casks are significant factors in determining the NWPA transportation system and services to be used.

\section{A.16.2 Identification of Issue Elements}

In addition to the operational issues being discussed in other sections of this Appendix, a number of procedural considerations have been identified by the OCRWM through discussions with interested parties. The OCRWM has been asked to address the following issues and procedural considerations:

- The transportation operations-management structure that the OCRWM wil1 develop for shipping commercial waste to NWPA facilities.

- The operational procedures that will be applied to NWPA transportation activities.

- The need for the OCRWM to evaluate issues related to its role in emergency-response activities.

- The OCRWM's strategy for rate negotiation.

- Mechanisms for evaluating special services.

- The OCRWM's plans for the ownership and the utilization of transportation equipment. 
- The OCRWM's plans to evaluate methods for, and associated costs of, limiting radiation doses to levels which are "as low as reasonably achievable" (also referred to as the ALARA concept), and application of the ALARA concept to transportation activities conducted under the NWPA.

- The potential development and use of "safe havens" along major transport routes.

- The OCRWM's plans to address the request of some interested parties for the evaluation of potential use of different identification numbers for new and spent nuclear fuel, and/or color-coded casks for shipments of radioactive materials, in order to assist emergency response personnel in accident situations where shipping papers or other means of identifying a cargo are not available.

- The potential imposition of stricter limitations on stopping times of nuclear waste shipments destined for NWPA facilities.

- The potential need to develop uniform requirements for on-board communication equipment and radiation-detecting equipment.

- The possible use of truck convoys for NWPA shipments.

- The possible required use of cabooses for rail shipments to NWPA facilities.

\section{A.16.3 Discussion of Issue Elements}

The discussion that follows contains a preliminary review of issues associated with transportation operational procedures; identifies, where possible, opportunities for public involvement in the development and consideration of various policy options; and outlines the expected schedule of OCRWM transportation program activities.

\section{Operations Management Structure}

The OCRWM will take title to commercial spent nuclear fuel and high-level radioactive waste at the point of generation and/or storage, and will accept defense waste at designated loading facilities adjacent to DOE defense waste processing facilities. At that point, the OCRWM will become the shipper of the material and is responsible for the transportation and disposal of the radioactive material.

The OCRWM plans (as required by the NWPA) to use private industry to the maximum extent possible to provide transportation support to the waste management system. A management-configuration study will be initiated in early 1987 to (a) identify viable management structures (i.e., total private operation, combination private/Federal operation, total Federal operation); (b) evaluate possible functional configurations (e.g., full-service contractors, the grouping of functions under a small number of contractors, or the use of highly specialized contractors); (c) perform in-depth research regarding industry's willingness and capabilities to provide the most efficient organization 
structures; and (d) evaluate and rank the most workable of the structures based on OCRWM criteria. This study will include an assessment of industry's willingness and capabilities to provide equipment and services and identifying legal and financial constraints. It will also review potential regulatory impacts and any similar systems (private and Government) currently in operation.

The OCRWM anticipates that a request for proposals (RFP) for the study will be announced in mid-1986. The award of the contract for the study is anticipated in early 1987. The study period could vary, but preliminary planning indicates that this process should be completed by early 1988, with the most desirable options identified to the OCRWM. The results will be made available for comments. The OCRWM will consider the report and comments in making the selection of the operational structure.

Along with the described study effort, the evaluation criteria and associated weighting factors (to be utilized in selecting the type of operations structure) are to be developed. Some of the preliminary evaluation criteria suggested are cost, degree of private sector involvement, flexibility, potential for disruption, regulatory acceptability, external perceptions, and responsiveness to OCRWM management.

The OCRWM will also initiate a program in 1986 to gather data on both past and future waste shipments. This will be used as a management aid and as a source for public information.

\section{Operational Procedures}

The OCRWM will ensure that all shipment operations performed or directed by the transportation service contractor will be conducted in a manner consistent with governing regulations that relate to the transportation of radioactive materials and safe operational procedures. Once these procedures are developed, they will be included in a Transportation Operations Procedure Manual for contractor compliance. The Operations Procedures Manual will be developed to serve as a management guide and control system for the OCRWM and contractor management. This manual will reinforce compliance with and adherence to OCRWM policy and procedures.

A contractor will be selected to develop, design, and continuously update this procedures manual. The manual will act as a road map to provide guidelines for uniformity in overall transportation operations, similar to other manuals that exist in the transportation industry today. Many of the procedures in the manual will have evolved as a result of the interaction between the OCRWM and the communication network in addressing and resolving identified operational issues. A preliminary out 1 ine of the contents of the manual is shown below:

\section{(1) Preoperational Preparations}

- Management control system

- Carrier evaluation criteria

- Rate negotiations

- Computer tools 
- Operations plan

- Equipment criteria

- Interfaces with utilities, States, Indian Tribes, and local governments

- Criteria and facilities for maintenance and repair

- "Dry run" operations

- Preparation for "nonstandard" shipments

\section{(2) Operational Scheduling}

- Arrival of cask and transporter

- Selection of carrier

- Negotiation of rates/terms

- Delivery of cask to be loaded

- Loading of shipment

- Delay procedures

(3) Shipment Checkout Procedures

- Review of documentation and procedures

- Physical inspection of shipment, equipment, etc.

- Acceptance of title

- Preparation of shipping papers

- Training standards check

- Dispatch of shipment

- Notification of appropriate authorities

(4) Shipment in Transit (Rail or Truck)

- Routing

- Safeguards

- Tracking

- Emergency procedures

- Interfaces with State, Tribal, and local authorities

(5) Shipment Receipt (Storage or Repository)

- Scheduling

- Inspection

- Unloading

- Decontamination check-out procedure

- Release of equipment

(6) Maintenance/Repair

- Scheduled

- Cask

- Transport equipment

- Unscheduled

- Cask

- Transport equipment 


\section{OCRWM Role in Emergency Response}

The method by which the OCRWM will interface with emergency response operations is expected to be resolved by 1993. One option that the OCRWM will consider is the use of a central control office that will function as an operations center and an emergency response center. As the issue of OCRWM participation and support in emergency planning and response related to NWPA transportation operations is resolved, related operational procedures will be developed. Such procedures will be addressed as an element of the OCRWM's transportation plan. Further discussion of emergency response issues is included in Section A.8 of this Appendix.

\section{$\underline{\text { Rates }}$}

The OCRWM will develop a strategy for the negotiation of rates; rates will be only one factor used in the selection of carriers. The OCRWM will ensure that current cost models or new models are used to determine and negotiate a fair and equitable rate for the transportation of radioactive materials. The public will be informed of the transportation costs expended.

\section{Special Services}

Transportation operations will require use of several types of services such as tracking, expediting, and escorting. Requirements for these services will be included in the RFP for management of the transportation system.

Equipment and Equipment Utilization

Transportation operations will require the most modern, safe, and effective (in terms of cost and operational factors) equipment available. One issue being addressed by the OCRWM is whether equipment will be federally owned, privately owned, federally leased, or privately leased. It should be noted that regardless of ownership, the transportation equipment will be designed and built to DOT, NRC, and OCRWM specifications. This requirement will result in enhanced operational efficiency and safety. The public will have access to material that describes OCRWM-specification requirements for transportation equipment.

The OCRWM transportation operations policy will require that the equipment be maintained in a manner that provides the safest and most efficient transportation. This will be accomplished by requiring contractors to prepare vehicle condition reports, to perform pretrip inspections and to maintain accurate maintenance records that verify compliance. The OCRWM will use a contractor to perform inspections or audits that ensure proper maintenance and adherence to regulatory requirements. These activities as well as their results will be made available to the public. It should be noted that all contractor activities, including inspections, must adhere to stringent quality assurance and quality control standards developed by the OCRWM.

\section{ALARA Study}

The OCRWM has initiated a study to evaluate the costs and risks associated with potential NWPA transportation systems under which reasonable efforts 
would be made to reduce radiation exposures to levels as far below Federal dose limits as is practicable--that is, "as low as reasonably achievable" (ALARA). As part of the ALARA study, the OCRWM will evaluate the expected radiation doses and costs associated with various shipping alternatives.

The OCRWM expects to complete an interim report on the evaluation of a reference transportation system using ALARA principles by the summer of 1986. The interim report will include a preliminary identification of alternative transportation systems for continued study using ALARA principles. Notice of the availability of the interim report will be included in the OCRWM Bulletin, and public comment will be solicited on reference system and alternatives deserving further study.

Where public interest warrants, a review of ALARA principles and the OCRWM's study could be topics of discussion at a workshop on the development of the NWPA transportation plan and operational procedures. The OCRWM expects to hold the workshop in the fall of 1987.

\section{Safe Havens}

The use of safe havens (that is, specific stopping areas along major transportation routes) for NWPA transportation is one factor that will be included in the OCRWM's ALARA study. Under current plans, the study will address the potential use of rest-stops and equipment maintenance and repair facilities for truck shipments. For rail shipments, the study will address the potential use of preplanned stops and exclusion areas at selected rail yards.

\section{Placarding and Shipment Identification Systems}

Some interested parties have requested that the OCRWM investigate the use of different identification numbers or systems for NWPA transportation to assist emergency response personnel in their determination of appropriate actions in accident situations. Similarly, a recent study conducted by the U.S. Congress' Office of Technology Assessment included recommendations that (1) placarding requirements for hazardous material shipments be designed to more accurately reflect the degrees of associated hazards; and (2) shipping papers be required to include more information on the nature of the hazard posed by a hazardous material cargo and appropriate mitigation techniques in the event of an accident. (See: U.S. Congress, Office of Technology Assessment, Transportation of Hazardous Materials: State and Local Activities, OTA-SET-301, Washington, D.C., 1986.)

Under current DOT regulations, placards for certain shipments of radioactive materials must use the word "RADIOACTIVE" to indicate that radioactive cargo is being carried. In addition, identification numbers for hazardous materials have been developed by the DOT, taking into consideration the requirements of the United Nations Committee on Dangerous Goods. Identification numbers for specific types of radioactive cargo must be included on shipping papers. It should be noted that under current DOT regulations, spent fuel and fresh nuclear fuel (which has lower associated hazards than spent fuel) have the same identification numbers. Such identification numbers are in turn included in a DOT emergency response guidebook (provided to all 
emergency response services) that identifies appropriate emergency response and mitigation activities in the event of transportation accidents involving each type of hazardous material. (See: U.S. Department of Transportation, Research and Special Programs, The 1984 Emergency Response Guidebook: Guidebook for Hazardous Material Incidents, DOT/P-5800.3, Washington, D.C., 1984.) The guidebook directs conservative emergency response and mitigation activities for accidents involving the transportation of spent fuel, fresh nuclear fuel, and high-level radioactive materials.

The OCRWM recognizes that identification procedures for NWPA shipments must conform to a nationally uniform system of requirements for placarding and shipping papers. The OCRWM therefore plans to address issues related to placarding, other package-identification mechanisms, and shipping paper requirements for NWPA shipments in cooperation with the DOT and the FEMA. In addition, the OCRWM will review--

- The potential use of supplemental markers on NWPA shipments (consistent with current DOT regulations) that indicate appropriate identification numbers.

- The potential need to develop an identification number for spent nuclear fuel that is different from the number assigned to fresh fuel, and appropriate emergency response activities for the two types of radioactive material. (This activity would have to be closely coordinated with the DOT and the FEMA.)

Specific plans to address such issues will be announced in the OCRWM Bulletin, and through notices in the Federal Register, where appropriate. addition, the issues can be further discussed in an OCRWM workshop on the development of transportation operational procedures and the comprehensive transportation plan; the workshop is expected to be held in the fall of 1987.

\section{Stops During Shipping}

The OCRWM's ALARA study will address the effect of stops during transit on transportation costs and risks. Both the length of stops and the location of stops will be evaluated in the study.

The Federal restrictions on stopping times will be reviewed in coordination with the DOT. Current DOT regulations prohibit unnecessary delays during the highway transportation of hazardous (including radioactive) materials (49 CFR 177.853). DOT regulations also impose a time limitation for the transportation of radioactive materials by rail. Rail carriers must forward each shipment of radioactive materials prompty, and within 48 hours after acceptance at the originating point of shipment or upon receipt at a rail yard, transfer station, or interchange point (49 CFR 174.14). Weekends and holidays are excluded when calculating the 48-hour limit. The 48-hour 1 imit is also not applied where only biweekly or weekly service is available; in such a case, the shipment must be forwarded on the first available train. Updates on discussions with the DOT will be provided in the OCRWM Bulletin, and in future revisions of the OCRWM comprehensive transportation plan. 
It should be noted that the OCRWM will also develop a policy on stopping times for shipments to NWPA facilities as an element of planning for transportation operations. If public interest warrants, discussions on appropriate stopping times will be included as an agenda item at the OCRWM workshop on the development of transportation operational procedures (expected to be held in the fall of 1987).

\section{Communication and Monitoring Equipment}

Some interested parties have suggested that the OCRWM conduct an intergovernmental review with the NRC, the DOT, and the FEMA on the need for Federal requirements for on-board communications equipment and radiation monitoring equipment for shipments of spent fuel and high-level waste. The OCRWM will consult with such agencies to review the potential need for such requirements. Updates on such discussions, and notice of opportunities for public involvement will be provided in the OCRWM Bulletin.

The OCRWM will also address, as an element of the comprehensive transportation plan, any necessary requirements for radiation monitoring equipment and communication equipment for all NWPA shipments.

\section{Truck Convoys}

The OCRWM has directed a study on the feasibility of using truck convoys for NWPA shipments. The report is expected to be completed in 1987, and will be made available for review and comment.

\section{Use of Cabooses for Rail Shipments}

Some interested parties have requested that the OCRWM consider the use of cabooses for NWPA shipments. Currently, requirements for the use of cabooses in commercial rail shipping vary among states and rail companies. The OCRWM will therefore consult with individual States and rail companies in order to determine the need for cabooses for NWPA rail transportation. The OCRWM is also working with the Association of American Railroads to evaluate the feasibility and potential use of unmanned surveillance cars for rail shipments. Such cars would be operated in front of trains to monitor track condition. Further details of the study will be provided in the first edition of the OCRWM transportation plan, scheduled for release in draft form in the fall of 1987. 


\section{A.17 State, Tribal, and Local Regulation of Transportation}

\section{A.17.1 Overview}

The regulation of interstate transportation has historically been shared by Federal, State, and local governments.* Problems associated with transportation have often fallen under a national scheme of regulation to ensure the free flow of interstate commerce and, where necessary, to provide adequately for national safety. The regulation of certain aspects of transportation, however, is frequently within State and local authority as well. The transportation of spent nuclear fuel and high-level waste and related issues of transportation safety have elicited new questions and of ten opposing views as to the appropriate regulatory roles of Federal, State, and local governments. Extensive Federal regulation developed to promote a national scheme of transportation safety for radioactive-waste shipments is increasingly supplemented by State and local transportation rules designed to address local safety concerns. The following discussion reviews general constitutional principles, Federal $1 \mathrm{aw}$, and general patterns of recent Federal agency and court rulings that address the relationship between Federal, State, and local authorities to regulate the transportation of radioactive waste. This discussion is not intended to present a definitive analysis of the applicable legal principles but rather is offered to provide a general awareness of the legal framework in which NWPA shipments will be conducted.

\section{Constitutional Principles}

The Constitution of the United States establishes the essential relationship between Federal and State regulatory powers. A study of general constitutional principles, as interpreted and applied by courts of law, suggests a basic framework for defining governmental authority to regulate the transportation of radioactive waste.

Supremacy Clause. The supremacy clause of the Constitution (U.S. Const., Art. VI, c1. 2) declares that Federal law "shall be the Supreme Law of the Land." Appropriate subjects of Federal legislation extend to the regulation of commerce among the States (U.S. Const., Art. I, sect. 8, cl. 3). Virtually all forms of activity involving or concerning two or more States (including the transportation of materials having little or no commercial value) are covered under the term "commerce."

However, the Constitution also recognizes that certain powers not delegated to the Federal government are reserved for the States (U.S. Const., Amend. X); those powers may be further delegated by the States to local governments. The exercise of such "police powers" is related to the need of States (and localities) to regulate local conditions in order to promote or protect public health, safety, and welfare. In practical terms, the exercise

* The authority of Indian Tribes to regulate transportation is discussed separately in this section in order to address specific issues related to the unique status of Tribes as governmental units within the Federal system. 
of police powers typically extends to such activities as land-use planning, police protection, response to emergency situations, and the regulation of local traffic conditions.

When Congress exercises a granted power such as the regulation of commerce, the Federal legislation may supercede State authority and preempt State law under the supremacy clause. However, Congress has typically not acted on an all-encompassing basis, and Congressional entry into a field of regulation does not necessarily preclude all state authority to regulate activities under its police powers. In considering preemption cases under the supremacy clause, courts generally "start with the assumption that the historic police powers of the States were not to be superceded by (Federal law) unless that was the clear and manifest purpose of Congress" (Rice v. Santa Fe Elevator Corp., 331 U.S. 218 [1947]). One of the legitimate inquiries is then whether Congress has either explicitly or implicitly declared that States are prohibited from regulating various aspects of an activity. (See, for example, Ray v. Atlantic Richfield, 435 U.S. 151 [1978].)

As the Supreme Court noted in the Rice case, absent explicit preemptive language, the Congressional "purpose may be evidenced in several ways. The scheme of Federal regulation may be so pervasive as to make reasonable the inference that Congress left no room for the States to supplement it.... Or, an act of Congress may touch a field in which the Federal interest is so dominant that the Federal system will be assumed to preclude enforcement of State laws on the same subject...." As further noted in the Atlantic Richfield case, even if Congress has not completely foreclosed State legislation in a particular area, a state statute is void to the extent that it actually conflicts with a valid Federal statute. A conflict will normally be found where (1) compliance with both Federal and State regulations is a physical impossibility, or (2) the State law stands as an obstacle to the accomplishment of the full purposes and objectives of Congress.

Commerce Clause. Where Congress has acted, either expressly or implicitly, to regulate an aspect of interstate commerce, the validity of state and local requirements is determined under the supremacy-clause principles described above. Where Congress has not acted to regulate an aspect of commerce, the Constitution has been interpreted as containing an implied limit on the power of States and localities to enact laws that interfere with the free and efficient flow of interstate commerce (U.S. Const., Art. I, sect. 8, c1. 3). As previously noted, the term "commerce" extends to virtually all activities involving or concerning two or more states; such activities may involve the transportation of goods (such as radioactive waste) having little or no commercial value.

Under such a "commerce clause" examination, courts normally consider first the underlying purpose of State and local requirements. Where a State or local requirement or restriction effectively creates a barrier against the free movement of goods into or through a jurisdiction, the measure is generally found to have an underlying intent to discriminate against transportation originating outside the jurisdiction and unfairly insulate local residents from the impacts associated with transportation. In such cases, a virtually absolute rule of invalidity has been applied by the courts. (See, for example, Philadelphia v. New Jersey, 437 U.S. 617 [1978].) 
A violation of the commerce clause may also be found where a state or local requirement does not discriminate against transportation originating outside the jurisdiction but impairs the free flow of interstate commerce to too great a degree. The validity of nondiscriminatory State and local measures is determined using a balancing test that weighs the burden on commerce in relation to local benefits. The extent of permissible burdens on interstate commerce depends on the nature of the local interest involved and whether such a local interest could be promoted equally well by using a measure with less effect on interstate commerce. (See, for example, pike v. Bruce Church, Inc., 397 U.S. 137 [1970].)

Equal Protection. Even where State and local transportation regulations meet the requirements of the supremacy clause and the commerce clause, they still must satisfy the equal-protection clause of the Constitution (U.S. Const., Amend. XIV). Under the guarantees of the equal-protection clause, general classification schemes of State and local regulation must be rationally related to legitimate police-power objectives. State and local transportation requirements that arbitrarily single out certain commodities would be unconstitutional as a violation of the equal-protection clause.

\section{Federal Regulatory Authority}

Taking such general constitutional principles into account, the balance between Federal, State, and local authority to regulate the transportation of radioactive waste can first be examined in relation to the extent to which Congress has specifically authorized Federal regulation in that area. Under Congressional legislation, Federal regulation of radioactive-waste transportation extends to requirements for liability coverage (see Section A.9) and operational procedures. The comprehensive Federal regulation of transportation operations is divided primarily between the NRC and the DOT. The transportation requirements of the two Federal agencies have focused on safety measures designed to protect public health and safety on a nationwide basis. In certain instances, State and local transportation requirements duplicate, supplement, or conflict with Federal law.

Regulation by the Nuclear Regulatory Commission. Under the Atomic Energy Act of 1954 as amended (42 USC 2011 et seg.) and the Energy Reorganization Act of 1974 (42 USC 5801 et seg.), the NRC is directed to regulate the private nuclear industry for purposes of protecting public health and safety and the defense and security of the United States. In exercising its grant of authority, the NRC has issued regulations for shipments of nuclear waste that exceed specified quantities and radioactive limits. Those regulations fall into three major categories: (1) safety regulation of shipments through cask (packaging) design requirements; (2) physical protection of certain shipments (including those of spent nuclear fuel) from acts of theft and sabotage during transport; and (3) advance notification to governors of states prior to shipments into or through the state.

Regulation by the Department of Transportation. The NRC's regulation of shipments of radioactive materials, including radioactive waste, is coordinated with that of the DOT (as specified in a Memorandum of Understanding, published in the Federal Register, Vol. 44, p. 38690, July 2, 1979). Congress has extended authority to the DOT to regulate various aspects of transpor- 
tation under several laws. Two significant laws affecting the authority of State and local governments to regulate transportation of radioactive waste are the Hazardous Materials Transportation Act of 1974, hereafter referred to as the HMTA (49 USC 1801 et seg.) and the Federal Railroad Safety Act (45 USC 421 et seg.).

Pursuant to the HMTA, the Secretary of Transportation is authorized to issue regulations for the safe transportation of hazardous materials (including radioactive materials). Section 112 of the HMTA provides that any requirement of states and localities that is inconsistent with the HMTA and such implementing regulations is preempted. Section 112, however, also provides one exception to a general rule of preemption. Inconsistent rules of States and localities may be found by the DOT to be legitimate and not preempted by Federal law if such requirements (1) offer an equal or greater level of protection to the public than is afforded by the HMTA and its regulations, and (2) do not unreasonably burden commerce. The HMTA further provides for the establishment of regulatory guidelines for an advisory DOT determination of potential inconsistency and preemption of State and local laws.

Pursuant to the Congressional grant of regulatory authority under the HMTA, the DOT has issued regulations that establish procedures for seeking agency advisory determinations of inconsistency. Applications to the DOT for inconsistency rulings may be made by States and local governments to test the validity of a transportation requirement or by any party affected by the requirement. The DOT may also initiate such proceedings on its own motion. In determining whether a State or local requirement is inconsistent with the HMTA and supplemental regulations, the DOT considers (1) whether compliance with both the state or local requirement and the HMTA and its regulations is possible, and (2) the extent to which the state or local requirement is an obstacle to the accomplishment and execution of the HMTA and its regulations (49 CFR 107.209[c]). Such a test follows the standards applied by courts in reviewing State and local requirements for consistency with Federal law under the supremacy clause of the Constitution.

Under DOT regulations, a State or local government having a transportation requirement that is inconsistent with the HMTA and its regulations may further seek from the DOT a determination that waives Federal preemption (49 CFR 107.215). Pursuant to HMTA, a waiver from preemption is granted by the DOT where the state or local requirement (1) is found to afford the public a level of safety at least equal to that afforded by the HMTA and its regulations, and (2) does not place an unreasonable burden on interstate commerce. Such a test is similar to court standards for examining state and local requirements under the commerce clause of the Constitution. To determine whether a State or local requirement burdens interstate commerce, the DOT considers the following factors: (1) the extent to which a state or local requirement causes increased costs or an impairment of transportation efficiency; (2) whether the State or local requirement has a rational basis; (3) whether the requirement achieves its stated purpose; and (4) whether there is a need for uniformity with regard to the regulatory matter, and if so, whether the State or local requirement competes or conflicts with the requirements of other States and local governments (49 CFR 107.221). 
The DOT recently issued its first nonpreemption determination, and in doing so, further defined the criteria for issuance of a waiver from preemption to include a "threshold test" (Federal Register, Vol. 50, p. 37308, September 12, 1985). Under the "threshold test," a jurisdiction seeking a waiver of preemption must demonstrate such exceptional circumstances as would warrant the extraordinary remedy. Such exceptional circumstances would exist where a Federal regulation, which provides an adequate level of safety on a nationwide basis, fails to provide an adequate level of safety in a given locale because of unique physical conditions.*

The DOT has also issued regulations applicable to the operational aspects of radioactive waste transportation. The regulations delineate the responsibilities of the DOT in regulating carriers and the conditions of transportation, and extend to such activities as handling, storage, the marking and labeling of transportation packages, placarding, and vehicle and driver requirements. In addition, the DOT regulations establish a highway routing rule for shipments of "highway route controlled quantity radioactive materials," which include spent fuel and high-level waste. The routing rule requires the use of interstate highways (and the use of beltways around urban areas, where possible) or alternative routes designated by the States after risk analysis and consultation with any affected local jurisdictions or other States (49 CFR $177.825[\mathrm{~b}]$ ).

The DOT regulations described above are applicable to all radioactivewaste shipments conducted by the DOE except in those cases where an exemption is required for national security purposes (49 CFR 173.7[b] and 177.806[b]). The DOT regulations also specify that the DOE may certify its own transportation packages using standards that are equivalent to NRC standards ( 49 CFR 173.7[d]). For DOE shipments of spent nuclear fuel, DOT regulations require the DOE to provide physical protection from acts of theft and sabotage using procedures (approved by the DOT) that are equivalent to those of the NRC (49 CFR 173.22[c]).

Of special note in the DOT regulations is a policy statement in Appendix A of 49 CFR Part 177 intended to provide guidance as to those State and local rules that the DOT considers to be inconsistent with its requirements for the highway transportation of radioactive materials. Inconsistent State and local rules 1 isted in Appendix A include those that--

- Prohibit highway shipments between any two points without providing an alternate route for the duration of the prohibition.

- Require additional placarding, personnel, equipment, or escorts.

* The DOT applied the "threshold test" to a transportation requirement of the City of New York (banning the transportation of spent fuel within the city) that had previously been ruled inconsistent, and found that a waiver from preemption was not warranted. This nonpreemption determination is currently under appeal; the OCRWM will follow the proceedings and provide an update in the next iteration of the transportation plan. 
- Require prenotification.

- Require accident or incident reporting other than as immediately necessary for emergency assistance.

- Conflict with Federal physical protection requirements.

- Unnecessarily delay transportation.

While the DOT's policy statement is advisory and does not have the force and effect of $1 \mathrm{aw}$, it provides important guidance on patterns of DOT rulings in inconsistency proceedings. The courts have also shown substantial deference to DOT's views relative to shipments of radioactive materials. It should be noted that parties who are adversely affected by State or local regulations need not seek a DOT advisory ruling before challenging the regulations in a court of law.

In addition to the regulations established under the HMTA governing the transportation of hazardous materials, general standards for highway transportation have been established under the Motor Carrier Safety Act by the DOT's Federal Highway Administration (49 CFR Parts 300-399).

Similarly, aspects of rail safety are subject to regulations issued under the HMTA (and its implementing regulations) and the Federal Rail Safety Act (FRSA). In enacting the FRSA, the Congress included the following provision:

The Congress declares that laws, rules, regulations, orders, and standards relating to railroad safety shall be nationally uniform to the extent practicable. A State may adopt or continue in force any law, rule, regulation, order, or standard relating to railroad safety until such time as the Secretary has adopted a rule, regulation, order, or standard covering the subject matter of such state requirement. A State may adopt or continue in force an additional or more stringent law, rule, regulation, order, or standard relating to railroad safety when necessary to eliminate or reduce an essentially local safety hazard, and when not incompatible with any Federal law, rule, regulation, order, or standard, and when not creating an undue burden on interstate commerce. (45 USC 434)

In accordance with Congressional direction, the DOT's Federal Railroad Administration has established rail-safety standards (49 CFR Parts 200-299).

Patterns of DOT and Court Rulings

Both advisory rulings of the DOT and court decisions offer important guidelines for the definition of the "consistency" of State and local regulations with Federal law and the appropriate regulatory roles of Federal, State, and local governments. 
Findings of Invalidity. The validity of State and local transportation requirements is normally first tested by the courts and the DOT by applying constitutional supremacy-clause principles. As a general rule, state and local requirements that are related to nuclear safety or address aspects of transportation already specifically regulated by the DOT and the NRC can be argued to be preempted.

Such a conclusion is supported by a Supreme Court discussion of preemption under the Atomic Energy Act (AEA) in Pacific Gas and Electric v. Energy Resources Commission, 461 U.S. 190 (1983). While addressing an issue other than regulatory authority for the transportation of radioactive materials, the Supreme Court noted that the Atomic Energy Act provided the Federal government "with exclusive jurisdiction to 1 icense the transfer, delivery, receipt, acquisition, possession, and use of nuclear materials.... Upon these subjects, no role was left for the States." The Supreme Court further noted: "State safety regulation is not preempted only when it conflicts with Federal law. Rather, the Federal government has occupied the entire field of nuclear safety concerns, except the limited power expressly ceded to the States." Powers ceded to the States under pervasive NRC regulation, the Court added, were limited to three activities: (1) the opportunity to enter into agreements with the NRC to control certain nuclear material in specified quantities not sufficient to form a critical mass (such material would not include the types of radioactive waste addressed in this paper); (2) the regulation of radioactive air emissions from nuclear power plants; and (3) the imposition of certain siting and land-use requirements for nuclear power plants.

In another case (Jersey Central Power and Light Company v. Township of Lacey, 772 F.2d 1103 (3rd Cir. 1985]), the legality of a local ordinance prohibiting spent fuel shipment was challenged. The Third Circuit observed that it is "beyond dispute" that Congress intended "federal law (to) regulate the radiological safety aspects of...nuclear power...including the storage and shipment of spent fuel." The court thus found the ordinances in question preempted by the AEA and thereby invalid under the supremacy clause. The court alternatively found the ordinances preempted by the HMTA and implementing regulations in the event Supreme Court review was granted and it disagreed with the court's AEA preemption analysis.

Two other significant recent Federal decisions have interpreted the AEA to preempt State rules prohibiting the transportation and storage within the State of radioactive waste generated outside the state. In the first case, Illinois v. G.E., the Federal Court of Appeals for the Seventh Circuit invalidated an Illinois statute (that banned the transportation and storage of spent fuel generated outside the State) on the grounds that it was preempted by the pervasive AEA regulatory scheme whose legislative history "compels the conclusion that the (AEA) equally preempts state regulation of the storage and shipment for storage, interstate and intrastate alike, of spent nuclear fuel." (I1linois V.G.E., 683 F.2d 206, 215 [7th Cir. 1982], cert. denied sub nom Hartigan v.G.E., 461 U.S. 913 [1983]). The Federal Court of Appeals for the 
Ninth Circuit found a similar Washington prohibition on low-level radioactive waste storage and transportation violative of the Supremacy clause "because it (sought) to regulate legitimate federal activity and to avoid the preemption of the AEA" in the case of Washington State Building and Construction Trades Council v. Spellman (684 F.2d 627,630 (9th Cir. 1982), cert. denied sub nom Don't Waste Washington Legal Defense Foundation $v$. Washington et a1., 461 U.S. 913 [1983]).

The preemptive effect of Federal regulations established under the Federal Rail Safety Act (FRSA) has also been subjected to judicial review. In the case of National Association of Regulatory Utility Commissioners v. Coleman (542 F.2d 1 ] [3rd Cir. 1976]), the authority of the Federal Railroad Administration to issue preemptive accident reporting regulations was contested. The Federal Court of Appeals for the Third Circuit concluded that Section 434 of the FRSA evidenced a "total preemptive intent" and that the legislative history disclosed an "overwhelming expression of Congressional intent to preempt State rail safety standards once Federal standards have been adopted...." The court rejected the plaintiffs' argument that the FRSA applied only to substantive State safety requirements that were inconsistent with Federal regulations, and not to nonsubstantive requirements, such as accident reporting. The court further concluded that the state accident reporting requirements did not fall within the "local hazard" exception to Federal statutory preemption under Section 434 of the FRSA since the State requirements were "largely duplicative of Federal reporting requirements and not directed toward the elimination of any unique, local hazard..." Citing the legislative history of the FRSA, the court indicated that the "local hazard" exception was not intended "to permit a State to establish statewide standards superimposed on national standards covering the same subject matter." Another decision of significant to rail shipments of spent fuel is State of Wisconsin v. Northern States Power Company (State of Wisconsin, Dane County Circuit Court: \#85-CV-0032, 6/6/85), in which the court granted the defendants' motion for summary judgement against the state of Wisconsin with respect to the State's suit to enjoin shipments of spent fuel. The court said that its decision was grounded on Federal preemption arising from the "interlocking nature of (the Federal) regulatory scheme."

Similarly, the DOT has suggested that Federal regulation of transportation safety for radioactive materials under the HMTA and supplemental regulations has been so detailed and pervasive as to preclude independent state or local requirements that apply because of the hazardous nature of the cargo. In Inconsistency Ruling IR-8 (Federal Register, Vo1. 49, p. 46643, November 27,1984 ), the DOT added:

The extent to which State and local government may regulate the interstate transportation of radioactive materials is limited to: (1) Traffic control or emergency restrictions which affect all transportation without regard to cargo; (2) designation of alternate preferred routes in accordance with 49 CFR 177.825; (3) adoption of Federal regulations or consistent state/local regulations; and (4) enforcement of consistent regulations or those for which a waiver or preemption has been granted pursuant to 49 CFR 107.221. 
DOT advisory rulings that address the consistency of State and local regulations with Federal law have generally declared those regulations to be inconsistent where directly related to concerns with the safety of radioactive material transportation or regulating some aspect of transportation in a manner different from that established under Federal law. Examples of such State and local regulations are those that establish different systems requirements for liability coverage, packaging and containers, additional transportation personnel and escorts, and shipment prenotification. (See, for example, the DOT's Inconsistency Rulings IR-7 through 15, published in the Federal Register, Vol. 49, p. 46632, November 27, 1984.)

Where no obvious incongruity exists, the DOT will further examine a State or local requirement for its effect on certain transportation goals. Goals emphasized in DOT rulings include the need to avoid unnecessary transportation delays and promote uniform regulatory requirements to enhance the safety of radioactive materials transportation and the need to ensure that state or local requirements do not result in the unfair or discriminatory rerouting of shipments of radioactive materials to adjacent jurisdictions. Restrictive measures in the form of absolute transportation bans through a jurisdiction and State-wide transportation curfews have been found to obstruct such Federal goals. (See, for example, DOT Inconsistency Ruling IR-16, published in the Federal Register, Vo1. 50, p. 20872, May 20, 1985, and DOT Inconsistency Ruling IR-2, published in the Federal Register, Vol. 44, p. 75566, December 20, 1979.)

As previously discussed, even where State and local regulations survive such an examination for consistency with Federal law under the supremacy clause, they may still face constitutional hurdles in the form of the commerce clause and the equal-protection clause.

Valid State and Local Regulations. Despite the stringent standards of the courts and the DOT, some forms of State and local regulation have been regularly upheld. Such regulations can be characterized as affecting the transportation of radioactive materials indirectly and only as necessary to effectively support the exercise of traditional police-power responsibilities for general transportation and public safety. A review of both DOT inconsistency rulings and court cases (addressing, in some instances, state or local requirements that have an effect on the transportation of hazardous materials other than radioactive waste) provides some insight as to activities falling within the scope of legitimate State and local regulatory authority with respect to transportation of radioactive material. These activities include--

- Vehicle inspection by State officials at loading and unloading points, to ensure compliance with State and Federal requirements (where the enforcement of Federal regulations has been delegated to the States). (See, for example, American Trucking Associations, Inc. v. Larson, 683 F.2d 787 [3rd Cir. 1982] and DOT Inconsistency Rulings IR-8 and IR-15, Federal Register, Vol. 49, pp. 46637 and 46660, November 27, 1984.) 
- Immediate accident reporting to appropriate state or local officials to facilitate emergency response. (See, for example, National Tank Truck Carriers, Inc. v. Burke, 698 F.2d 559 (1st Cir. 1983) and DOT Inconsistency Ruling IR-3, Federal Register, Vo1. 46, p. 13918, March 26, 1981.)

- Local regulation of traffic, including restrictions concerning the actual operation of motor vehicles and penalty actions for traffic violations. (See, for example, DOT Inconsistency Ruling IR-2, Federal Register, Vol. 44, p. 75566, December 20, 1979.)

The extent to which States and local governments can enforce permit and fee requirements directed at transporters of radioactive waste remains somewhat unclear. States have traditionally imposed permit and fee systems for highway transportation involving overweight trucks; those systems sometimes continue to be enforced even where they extend to overweight shipments of radioactive waste.

In contrast, the validity of permit and fee systems that are directly related to the hazardous nature of cargo being shipped, but are imposed for the purpose of supporting State and local police-power responsibilities, has not been firmly established. The DOT has declared that States and local governments have no authority "to impose a permit requirement on shipments of radioactive material which applies because of the hazardous nature of the cargo" (Inconsistency Ruling IR-8, Federal Register, Vo1. 49, p. 46643, November 27, 1984). A Federal court of appeals, however, has upheld one State fee system applicable to all shipments of hazardous (including radioactive) materials (New Hampshire Motor Transport Association v. Flynn, 751 F.2d 43 [1st Cir. 1984]). Under that system, an annual license fee of $\$ 25$ (or a $\$ 15$ fee for single trips) is charged to transporters of hazardous materials and waste to support state activities related to emergency response, the enforcement of hazardous materials regulations, and a State hazardous-waste-cleanup fund. The court concluded that the 1 icense fees were reasonable in relation to the service supplied by the state and did not significantly delay transportation in violation of the DOT's "speedy-transport mandate."

The court further acknowledged the concern of the trucking industry that the imposition of similar fees by all or many of the States would greatly raise transportation costs and seriously burden interstate commerce. The court suggested that if such a circumstance should arise, the DOT remained free to promulgate a regulation prohibiting or controlling the imposition of excessive license fees. (The applicability of this case to NWPA shipments has not been determined.)

In a very recent inconsistency ruling, the DOT ruled that an Illinois "transit fee" of $\$ 1,000$ per spent fuel cask was not inconsistent with the HMTA or its implementing regulations (Federal Register, Vo1. 51, p. 20925, June 9, 1986). The DOT ruling discusses and distinguishes previous DOT rulings; it should be noted that the ruling does not address the issue of preemption under either the Atomic Energy Act or the U.S. Constitution. The OCRWM will review the ruling and its potential effect on NWPA shipping in the next iteration of the transportation plan. 
The extent to which Indian Tribes can regulate the transportation of spent fuel and high-level radioactive waste through reservations is presently unclear. General regulatory powers vary between Indian Tribes and continue to be defined by the development of Tribal codes and judicial review of Congressional acts, treaties, and Tribal constitutions. This section will briefly review basic tenets of Indian $1 \mathrm{aw}$, and identify major areas of uncertainty in the effort to define the authority of Indian Tribes to regulate the transportation of radioactive waste.

Sovereign Powers of Indian Tribes. A basic rule of Indian law is that Indian Tribes possess certain sovereign rights to regulate their members and their territories. Such power, however, is limited by several factors. First, Tribal power may be limited by acts of Congress. Such a restriction on Tribal regulatory authority stems from the Federal government's inherent power over Indian Tribes. Tribal power may be further limited by treaties or other agreements between Indian Tribes and the Federal government. Finally, Tribal power may also be limited by a Tribe's own constitution, laws, or regulatory codes.

Tribal Regulation of Transportation. Even where it is assumed that treaties or an Indian Tribe's constitution, laws, or regulatory codes regulate transportation on Indian lands, the extent to which Federal statutes related to radioactive waste transportation limit Tribal powers must also be examined. A Federal statute does not necessarily have to specifically address limitations on Tribal powers in order to have preemptive effect. The general rule is that where a Federal statute is of a comprehensive nature, the law applies to everyone, including Indian Tribes, unless otherwise stated. (See, for example, Federal Power Commission v. Tuscarora Indian Nation, 362 U.S. 99 [1960].)

Under such reasoning, Federal statutes such as the Atomic Energy Act (AEA) and the Hazardous Materials Transportation Act (HMTA), and regulations of the NRC and the DOT, that address aspects of nuclear safety and establish a comprehensive regulatory system for the transportation of radioactive materials, can be argued to apply equally to States, Indian Tribes, and loca1 governments. Such a conclusion is further supported by DOT routing regulations issued under the HMTA, which recognize the authority of both State and Tribal "routing agencies" to designate highway routes for the transportation of radioactive materials. (See 49 CFR Sections 171.8 and 177.825.)

The extent to which Indian Tribes can regulate radioactive waste transportation, however, is unclear. The OCRWM is unaware of any court cases that address the issue. Furthermore, a report prepared by the Council of Energy Resource Tribes notes that no Indian Tribes are known to have enacted codes that regulate the transportation of radioactive materials; several Indian Tribes, the report states, have passed resolutions that ban such transportation from their reservations, but resolutions do not have the force of law associated with Tribal codes (see L. Friel, and W. M. Rogers, Jr., Tribal Regulatory and Liability Issues Concerning Radioactive Materials, Background Report No. 3, Council of Energy Resource Tribes, Denver, C0, 1985). 
The OCRWM is unable to draw firm conclusions on the extent to which Indian Tribes can regulate the transportation of radioactive waste without further study of specific treaties, Congressional acts, and Tribal constitutions and codes. Where, however, Indian Tribes can regulate such transportation on reservations, previous DOT rulings and the court cases discussed in the preceeding section of this chapter provide some guidance as to the types of rules that are likely to be found valid. In general, acceptable regulations will cause only slight transportation delays, create 1 ittle or no burden on interstate commerce, and promote the HMTA's purpose of ensuring safe transportation. Invalid rules generally include those which discriminate against shipments from another jurisdiction, unnecessarily duplicate the Federal regulations, create absolute bans on shipments, or cause significant delays in transportation.

\section{A.17.2 Identification of Issue Elements}

Discussions between the OCRWM and interested parties have led to the identification of the following issues related to the appropriate balance of authority to regulate NWPA transportation:

- The extent to which the OCRWM will comply with the transportation requirements of States, Indian Tribes, and local governments.

- The need to plan specific activities to address regulatory issues through informal means.

- The potential role of the OCRWM in compiling a comprehensive summary of all State, Tribal, and local transportation requirements.

\section{A.17.3 Discussion of Issue Elements}

The following discussion reviews options of the OCRWM for addressing issues related to the regulation of various aspects of NWPA transportation by States, Indian Tribes, and local governments. Opportunities for public involvement in the development of OCRWM policy options are identified where possible. The anticipated timing of related policy decisions is also addressed.

OCRWM Compliance with Transportation Requirements of States, Indian Tribes, and Local Governments

The OCRWM will comply with all legally valid State, Tribal, and local transportation requirements when conducting waste shipments under the NWPA. As discussed above, however, the validity of State, Tribal, and local requirements is still in the process of being defined by the DOT and court rulings. The OCRWM, through consultation with the DOE's Office of General Counsel, will continue to study the appropriate areas of Federal, State, Tribal, and local regulatory authority for the transportation of radioactive waste through an examination of DOT advisory rulings and court decisions. All editions of the comprehensive transportation plan will continue to outline DOT and court rulings, and note progress toward a definition of regulatory authority. 
The OCRWM will make a special effort to further study and address issues related to regulatory authority of Indian Tribes. To assist in this effort, the OCRWM will consider the use of workshops to (1) review the current extent of Federal regulation and general patterns in DOT and court rulings, and (2) identify specific needs of Indian Tribes related to planning for NWPA transportation. The OCRWM will contact representative Indian organizations and individual Indian Tribes in order to determine the value of workshops; any scheduling plans will be noted in the OCRWM Bulletin. In addition, the OCRWM will consult with individual Indian Tribes, Tribal organizations, other DOE offices, and the Department of the Interior to review the regulatory powers of individual Tribes as affected by Congressional acts, treaties, and Tribal constitutions and codes.

The OCRWM also plans to issue a written policy statement by mid-1990 of agency plans to address State, Tribal, and local transportation requirements and restrictions that may affect the transportation of nuclear waste to NWPA facilities. The issuance of the policy statement is intended to assist all affected jurisdictions in timely planning for NWPA transportation, and to advise potential bidders on transportation service contracts of the requirements that must be considered and incorporated into contract proposals. The timing of the OCRWM policy statement is related to the anticipated issuance of a request for proposals for service contracts.

\section{OCRWM Role in Efforts To Clarify}

Regulatory Roles

Participants at the Transportation Institutional Plan Workshop, held in November 1985, noted that the DOT and the NRC have the primary authority over the Federal regulation of radioactive waste transportation, and that the definition of the appropriate Federal, State, Tribal, and local regulatory roles will be affected by activities of other Federal agencies, the Congress, and the courts. Workshop participants suggested, however that the OCRWM, as a shipper of radioactive waste under the NWPA, actively participate in less formal efforts to clarify the regulatory roles of various governmental agencies for such activities as emergency response, inspection, and enforcement through discussion of the following issues:

- The potential need for special transportation requirements in states having facilities from which waste will be shipped and in states having NWPA facilities located within their boundaries, and the need to coordinate such requirements with associated Indian Tribes and local governments.

- The need for a negotiated intergovernmental approach to address and resolve transportation regulatory issues, and the role that the OCRWM may play in facilitating such an activity.

- The need for the OCRWM to participate in an evaluation of the use of interstate agreements in order to facilitate the development of nationally uniform transportation requirements. 
In an effort to address such issues, the OCRWM will work with states, Indian Tribes, and local governments on an individual and regional basis to define the anticipated needs of such governmental entities to monitor and control the transportation of radioactive waste to NWPA facilities. The OCRWM currently favors the use of regional workshops in order to assist in coordinated planning for transportation and the development of uniform rules that are consistent with Federal regulation. The OCRWM has not established specific plans for such activities, and solicits comments on the appropriate timing of workshops and the desired scope of discussions.

The OCRWM will also consult with both the NRC and the DOT in an effort to establish a Federal interagency approach for addressing regulatory issues with State, Tribal, and local governments. Again, no detailed plans have yet been established, and public comment is solicited. Progress toward developing plans and future scheduling details will be noted in the OCRWM Bulletin.

The OCRWM will further work to support an evaluation of interstate agreements through the funding of studies by representative organizations. One such contract is now being considered with an organization having expertise in vehicle inspection and enforcement; one element of the contract would require the study of the potential use of interstate agreements for the inspection of NWPA shipments.

\section{Compilation of State and Local}

Transportation Requirements

The OCRWM has received requests that a catalogue of all State, Tribal and local legislative requirements for transportation be included as an integral element of a comprehensive NWPA transportation plan. Such a cataloguing service is currently provided under the direction of the DOE by the Oak Ridge National Laboratory. As part of this service, a report is issued periodically to review current legislative requirements, the geographic areas affected by such requirements, and the history of the legislation. The most recent report, entitled Transportation of Radioactive and Hazardous Materials: A Summary of State and Local Legislative Requirements for the Period Ending December 31, 1985 (ORNL/TM-9985), is available upon request from the office of Information Research and Analysis, Information Resources Organization, Oak Ridge National Laboratory, Oak Ridge, Tennessee, 37831. The OCRWM will work with the Oak Ridge National Laboratory to ensure that requirements of Indian Tribes, if developed in the future, are included in the survey. (To assist in the maintenance of comprehensive legislative information, the OCRWM requests that Indian Tribes notify it or the Oak Ridge National Laboratory of any pertinent transportation requirements.)

The OCRWM believes that the large volume of existing information on state and local transportation requirements makes the inclusion of such material in an NWPA transportation plan impractical. The OCRWM will, however, provide future notice of the availability of updated material from the Oak Ridge National Laboratory through publication in the OCRWM Bulletin. 
APPENDIX B

FEDERAL AGENCY TRANSPORTATION RESPONSIBILITIES AND APPLICABLE REGULATIONS AND ORDERS

\section{Department of Transportation}

The Department of Transportation Act of 1966 recognized the need to organize transportation policies to assure national economic growth, security, and stability, and therefore, established the Department of Transportation (DOT). The DOT is thus empowered to be the lead agency with jurisdiction over the regulation of commercial nuclear materials transportation. It carries out its responsibilities through five administrations (Federal Highway Administration, Federal Railroad Administration, Federal Aviation Administration, Research and Special Programs Administration, and U.S. Coast Guard) and its various offices.

The Federal Railroad Safety Act of 1970 was enacted to promote safety in railroad operations and to reduce railroad-related accidents, deaths, injuries, and damage involving any carrier of hazardous materials, including nuclear materials. The Secretary of Transportation, through the Federal Railroad Administration, has the responsibility for prescribing appropriate rules, regulations, orders, and standards for all areas of railroad safety, including nuclear materials transportation.

Because of increasing public concern, the Hazardous Materials Transportation Act of 1974 (HMTA) was passed to minimize risks to 1 ife and property (that are inherent in commercial transportation of hazardous materials) by increasing the regulatory and enforcement authority of the Secretary of Transportation. The HMTA is the principal Federal statute that governs the regulation of hazardous materials transportation and the relationship between Federal, State, and local regulation in this field. The HMTA outlines the areas over which DOT has authority (e.g., packaging, labeling, and routing). It also prohibits transportation of nuclear materials on passenger aircraft unless the materials are to be used for research or medical diagnosis/treatment.

The Code of Federal Regulations describes the details and procedures for nuclear materials transportation required by the DOT.

49 CFR Part 106

Subpart B describes general rulemaking procedures for the issuance, amendment, and repeal of DOT regulations.

49 CFR Part 107

49 CFR Part 107 describes procedures utilized by the DOT in carrying out its duties under the laws pertaining to the transportation of hazardous materials. 
Subpart B describes procedures by which exemption may be obtained from the DOT requirements on the basis of equivalent levels of safety.

Subpart $C$ describes procedures by which a state or a political subdivision of a state having a requirement pertaining to the transportation of hazardous materials may obtain a ruling as to whether the requirement is inconsistent with Federal 1aw. Procedures for DOT nonpreemption determinations are also discussed.

Subpart $D$ describes the various enforcement authorities of the DOT and the associated sanctions and prescribes the procedures governing the exercise of authority and the imposition of sanctions.

\section{CFR Part 171}

49 CFR Part 171 describes the DOT requirements governing the transportation of hazardous materials and the manufacture, fabrication, marking, maintenance, reconditioning, repairing or testing of a package or container used in such transportation.

\section{CER Part 172}

49 CFR Part 172 defines nuclear materials as hazardous, and states ways in which the hazardous properties of each shipment are to be made known to the proper authorities and the public through use of shipping papers, marking requirements, placarding and labeling.

Subpart B 1ists the materials designated by the DOT as hazardous for commercial transportation. A table includes a description of nuclear materials, and requirements for the shipping name, class, labeling, and packaging.

Subpart $C$ gives the requirements for the shipping papers for all hazardous materials, including nuclear materials, with a description of the materials and the shippers' certifications.

Subpart D discusses marking requirements (e.g., proper shipping name) according to type of package and mode of transport.

Subpart $E$ focuses on the required labels, based on the properties and amounts of all hazardous materials (including radioactive materials) being carried.

Subpart $F$ describes the placard required (placement on vehicle, shape, message) depending on material being transported.

\section{CFR Part 173}

Subpart I defines the types, classes, and quantities of radioactive materials including fissile materials. This subpart also outlines general packaging and shipment requirements for approved packages, and for international shipments and foreign-made packages. The latter must meet International Atomic Energy Agency requirements. The discussion of 
packaging requirements is based on the individual radioactive properties of the individual nuclear materials. The packaging properties considered include leak resistance, corrosion resistance, absorption rate, cushioning, and resistance to explosive materials.

\section{CFR Part 174}

Subpart $\mathrm{K}$ states the special requirements for radioactive materials carried by rail. This includes loading requirements, number of packages to be placed per car, labeling, decontamination and cleaning of cars after use, and actions to take following incidents involving leakage. Subpart $\mathrm{K}$ focuses on the general shipping regulations for nuclear materials for carriage by rail.

\section{CER Part 176}

Subpart $M$ gives the requirements for nuclear materials transportation by vessel. Three major issues of interest are the location (placement) of each package on the vessel; the actions to be taken following leakage or shifting of radioactive materials; and contamination control for the compartments used for the nuclear materials transportation.

\section{CFR Part 177}

49 CFR Part 177 presents requirements for the transportation of hazardous materials by public highway; i.e., reporting procedures for accidents and missing shipments; rules for the use of labels, etc. Of special note is Section 177.825 , which provides routing and training requirements for highway shipments of radioactive materials. Appendix A of 49 CFR Part 177 provides a DOT policy statement of the relationships between Federal, State, and local routing requirements.

\section{CFR Chapter 1}

Chapter 1 describes Coast Guard regulations that affect shippers and carriers of nuclear materials in a general fashion, such as aids to navigation, navigation requirements for inland waters, anchorages, security of vessels, bridges, marine oil pollution liability and compensation, boating safety, etc.

\section{CFR Chapter 1}

Chapter 1 of Title 23 provides background information about the general management and administration of the Federal Highway Administration and its functional responsibilities; for example, research and development, engineering and traffic operations, etc.

\section{CFR}

Sections throughout Title 46 of the Code of Federal Regulations pertain to barge transport. 


\section{CFR Chapter 2}

Chapter 2 of 49 CFR is a discussion of the operating structure for the Federal Railroad Administration and of the numerous regulatory areas under DOT jurisdiction; for example, safety enforcement procedures, noise emission compliance regulations, track safety standards, freight car standards, power brakes, signal systems, etc.

\section{CFR Chapter 3}

Chapter 3 is divided into two parts that, together, outline the general and safety regulations for motor carrier transportation. Subchapter A, "General Regulations," describes the organization and delegation of powers and duties within the FHWA and explains bridge and toll rules and noise emission standards. Subchapter B, on motor carrier safety regulations, deals with a number of issues that affect general motor carrier arrangements with States, qualifications of drivers, and reporting of accidents.

\section{CFR Chapter 5}

Chapter 5 details the institutional structure and responsibilities of the National Highway Traffic Safety Administration (NHTSA), and presents guidelines for highway safety. The former focuses on the bureaucratic structure of the NHTSA, delegation of powers and tasks, informationgathering powers, and adjudicative procedures.

This chapter does not deal with nuclear materials transportation per se, but does affect such commerce by outlining safety procedures that concern all shippers and carriers that utilize national highways.

\section{Nuclear Regulatory Commission}

The Energy Reorganization Act of 1974 abolished the Atomic Energy Commission and divided its roles and tasks between two agencies. The Energy Research and Development Administration (now the DOE) was given responsibility for nuclear energy research, development, and demonstration activities, and also for military applications and naval reactor programs. The Nuclear Regulatory Commission was given the responsibility for 1 icensing and regulating commercial activities.

The NRC has three offices that review the transportation of nuclear materials: the Office of Nuclear Material Safety and Safeguards, the Office of Inspection and Enforcement, and the Office of Nuclear Regulatory Research.

The Transportation Certification Branch of the Office of Nuclear Materials Safety and Safeguards evaluates the design of packages used for high-level radioactive waste and spent fuel transportation, according to standards developed and implemented by the NRC.

The Office of Inspection and Enforcement has responsibility for the development and promulgation of the inspection program and procedures used in inspection of the transportation activities of its licensees, including the 
fabrication and use of spent fuel and high-level waste packages, according to applicable NRC and DOT regulations. It also provides related training to the inspectors from its five regional offices who carry out the actual inspections of transportation activities, as well as oversight of the program.

Through the Transportation Research Branch of the Office of Nuclear Regulatory Research the NRC contracts for research deemed necessary for performing licensing and regulatory functions related to high-level nuclear materials transportation. The Office of Nuclear Regulatory Research is responsible for writing regulations, including those that affect transportation of high-level radioactive waste and spent nuclear fuel.

The Code of Federal Regulations describes the details and procedures for nuclear materials transportation required by the NRC.

\section{CFR Part 9}

The regulations in 10 CFR Part 9 implement: (1) the provisions of the Freedom of Information Act, with respect to availability of NRC records to the public for inspection and copying; (2) the provisions of the Privacy Act, with respect to disclosure and availability of certain NRC records maintained on individuals; and (3) the provisions of the U.S. Government in the Sunshine Act, with respect to opening NRC meetings to public observation.

10 CFR Part 9 influences nuclear materials transportation by contributing to the public information process. The regulations provide the public with opportunities to be knowledgeable about NRC decisions and policies on transportation as well as other related issues.

\section{CFR Part 19}

The regulations in 10 CFR Part 19 formulate requirements for notices, instructions, and reports by licensees to individuals participating in licensed activities, and options available to such individuals for ascertaining 1 icensee compliance with the provisions of the Atomic Energy Act (as amended); Title II of the Energy Reorganization Act; and regulations, orders, and 1 icenses regarding radiological working conditions.

10 CFR Part 19 affects nuclear materials transportation by assuring that all individuals working in any type of restricted area shall be kept informed of storage, use, or transfer of nuclear materials, and of related radiation levels. Workers will be advised of health precautions and procedures to minimize radiation exposure during transport. The regulations provide for NRC inspector consultation with workers concerning matters of occupational radiation protection and other related concerns. Moreover, 10 CFR Part 19 establishes procedures for addressing violations of these regulations. 
10 CFR Part 20 sets out the standards for personnel protection against radiation. It establishes a foundation by defining units in a radiation dose and units of radioactivity in general. Several additional topics are covered in this part. First, standards on permissible doses, levels, and concentrations include such issues as dose standards for people in restricted and unrestricted areas, exposure of children, medical diagnosis and therapy, etc. Second, standards on precautionary procedures include worker and personnel monitoring for radiation doses; caution signs, labels, signals and controls; procedures for handling and storing packages, etc. Third, standards on waste disposal address procedures for obtaining approval of proposed disposal procedures and different methods of disposal, such as in soil and by incineration. Finally, standards are set out to clarify the requirements for records, reports, and notification of incidents.

\section{CFR Part 21}

The regulations in 10 CFR Part 21 establish procedures and requirements for reporting defects in nuclear components and materials and for noncompliance with components and materials manufacturing standards. The regulations apply to any individual director or responsible officer of a firm constructing, owning, operating, or supplying the components or materials of an NRC 1 icensed or regulated facility. If the responsible person has information reasonably indicating: 1) that the component or material fails to meet the standards, or 2) that serious defects may exist and create a safety hazard, they must immediately notify the NRC of such failure to comply or such defect. 10 CFR Part 21 affects nuclear materials transportation by requiring manufacturers and suppliers of components and materials to identify faulty products.

\section{CFR Part 51}

10 CFR Part 51 establishes standards for protecting the environment against the potential hazards presented by the nuclear industry. Specifically, it establishes requirements for environmental impact statements; environmental reports of all nuclear facilities at the construction permit and operating license stages; environmental reports and administrative procedures for materials licensing; and, finally, for administrative procedures on communicating with the public (for example, through public hearing and notices in the Federal Register).

10 CFR Part 51 establishes radiation standards to protect the environment against exposure to radiation during transport, delivery, and disposal activities; and outlines public hearing procedures on transportation and disposal methods, and requirements for notices to the public.

\section{CFR Part 71}

10 CFR Part 71 establishes criteria for shipping licensed nuclear materials in various types of packages. The discussion focuses on several areas. First, general licensing procedures for shipment are 
set out. Second, the requirements for the actual license application (e.g., package description, package evaluation, quality assurance) are explained. Third, NRC standards for all packaging are laid out according to type of material to be contained. Fourth, procedures are specified for prenotification to states prior to shipments of specified quantities of nuclear waste other than spent fuel. Finally, operating procedures, quality assurance instructions, and inspection and testing requirements are described.

\section{CER Part 73}

10 CFR Part 73 prescribes requirements for the establishment and maintenance of physical protection systems.

Section 73.37 addresses physical protection requirements for spent nuclear fuel in transit, including shipper and carrier requirements for planning and scheduling, obtaining advance approval of routes prior to shipment, prenotifying states prior to shipment, and arrangements to be made with law enforcement agencies along the route in the event of an emergency.

\section{National Transportation Safety Board}

The mission of the National Transportation Safety Board, created in 1971, is to promote transportation safety by conducting independent investigations of accidents and other safety problems and by formulating safety improvement recommendations.

The Board is responsible for investigating accidents and determining their cause, making safety recommendations, and reporting the facts and circumstances of all transportation accidents that are catastrophic, involve problems of recurring character, or should otherwise be investigated in the judgment of the Board. In addition, the Board makes recommendations on matters pertaining to transportation safety and accident prevention.

The Board previously reported to the DOT, but the Independent Safety Board Act of 1974 declared the National Transportation Safety Board an independent body and strengthened its power to investigate transportation accidents and make recommendations on regulations.

The section of the Code of Federal Regulations that describes the details and procedures for nuclear materials transportation according to the National Transportation Safety Board is Title 49, Chapter VIII. The regulations make provisions for independent inquiries and determinations about causes of transportation accidents, and make recommendations on safe highway carriage of nuclear materials.

\section{Interstate Commerce Commission}

The Interstate Commerce Commission (ICC) regulates certain economic aspects of interstate surface transportation, including trains, trucks, buses, 
inland waterway and coastal shipping, freight forwarders, and express companies. The regulations vary with the type of transportation; however, they generally involve certification of carriers seeking to provide transportation for the public, rates, adequacy of service, purchases, and mergers. The ICC's mission is to ensure that regulated carriers will provide the public with rates and services that are fair and reasonable.

On matters within its jurisdiction in the transportation economics area, the ICC acts to prevent unlawful discrimination, destructive competition, and rebating. It also has jurisdiction over the use, control, supply, movement, distribution, exchange, interchange, and return of railroad equipment. Under certain conditions, it is authorized to direct the handling and movement of traffic over a railroad and distribution over other 1 ines of railroads.

In the transportation service area, the ICC grants operating authority to trucking companies, bus lines, freight forwarders, water carriers, and transportation brokers.

Nuclear materials transportation is impacted through the authority entrusted to the ICC to establish rules and tariffs for carrier traffic, to certify and license carriers, and to establish the value of property owned and used by each carrier.

The section in the Code of Federal Regulations that describes the details and procedures for nuclear materials transportation according to the ICC is Title 49, Chapter $X$, Subchapter $D$. Under the guidelines discussed in Subchapter $D$ on tariffs and schedules, the ICC regulates economic aspects of surface nuclear materials shipments including rate setting for all modes of transport except aircraft.

\section{Federal Emergency Management Agency}

Under the provisions of Executive Order 12148 (July 20, 1979), the Federal Emergency Management Agency (FEMA) is responsible for establishing Federal policies for, and coordinating, all civil emergency planning, management, mitigation, and assistance functions of Federal executive agencies. In addition, the FEMA is responsible for coordinating Federal and state participation in developing emergency response plans.

Under this mandate, the FEMA has assumed the responsibility for coordinating the development of the interim Federal Radiological Emergency Response Plan (49 Fed. Reg. 35896). The interim plan has application in the event of an accident involving the transportation of spent fuel and radioactive waste, and is designed to provide coordinated Federal response in support of State and local governments. It is important to note that under the FEMA's coordinated response plan, State and local governments have primary emergency responsibilities, and Federal assistance is to be made available only if requested.

In order to assist State and local agencies in developing and testing radiological emergency response plans, the FEMA established the Federal Radiological Preparedness Coordinating Committee (FRPCC). In December 1982, 
the FRPCC's Subcommittee on Transportation Accidents (composed of representatives from the DOE, NRC, FEMA, and other Federal and State agencies) issued a draft guidance document to provide a basis for state and local governments to develop emergency plans and improve emergency preparedness for transportation accidents involving radioactive materials. The guidance document, entitled Guidance for Developing State and Local Radiological Emergency Response P1ans and Preparedness for Transportation Accidents, provides optional support to State and local governments in their planning efforts.

\section{U.S. Environmental Protection Agency}

In 1970, the Presidential Reorganization Plan No. 3 established the Environmental Protection Agency (EPA). The EPA has authority to establish generally applicable environmental standards for the protection of the environment from radioactive materials.

As specified in the interim Federal Radiological Emergency Response P1an issued by the FEMA, the EPA also is responsible for providing assistance to other Federal agencies and State, Tribal, and local governments in the event of radiological emergencies (including transportation accidents involving radioactive materials). Under the interim plan, the EPA is to assist the DOE in monitoring radioactivity levels in the environment in the event of a radiological emergency, and assist (as needed) in developing recommended measures to protect public health and safety.

\section{U.S. Army Corps of Engineers}

The Corps of Engineers has regulations, promulgated under 33 USC 1 et seq., pertaining to navigational activities in the Nation's waters. These regulations can be found in 33 CFR Part 209. 
APPENDIX C

SUMMARY OF AGENCY AGREEMENTS

Memorandum of Understanding: Transportation of Radioactive Materials

Agencies: Department of Transportation (DOT), and Nuclear Regulatory

Comission (NRC)

Date of Publication: July 2, 1979 Reference: 4 Fed. Reg. 38690

Title: Transportation of Radioactive Materials; Memorandum of Understanding

Summary: The DOT is responsible for regulating safety in the transportation of all hazardous materials, while the NRC is responsible for regulating safety in receipt, possession, and transfer of radioactive materials. This agreement delineates agency responsibilities as follows:

- DOT: Regulates carriers of radioactive material and the conditions of transport (e.g., routing, handling and storage, vehicle requirements, and driver requirements). Develops packaging standards for radioactive materials not exceeding Type A quantities and for low specific activity radioactive materials.

- NRC: Regulates those who possess and use radioactive material, and the design, construction, use, and maintenance of shipping containers for radioactive material exceeding certain quantity and radioactive limits (which includes containers for spent fuel and nuclear waste). In addition, the NRC enforces special transport controls (physical protection requirements) to protect against acts of sabotage. In all transportation accidents or incidents involving actual or suspected leakage of packages regulated by the NRC, the Memorandum of Understanding assigns the NRC the responsibility to act as lead agency for investigating the cause of the leakage and preparing a report of the investigation. 


\section{Memorandum of Understanding: Transportation Packaging}

Agencies: Department of Energy (DOE), and Nuclear Regulatory Commission (NRC)

Date of Publication: November 14, 1983 Reference: 48 Fed. Reg. 51875

Title: Spent Fuel and High-Level Waste Transportation Packaging; NRC/DOE Procedural Agreement

Summary: Pursuant to DOT regulations (49 CFR Section $173 / 7[d]$ ), the DOE has the authority to certify its packaging for radioactive materials using standards that are equivalent to NRC requirements (found in 10 CFR Part 71 ). However, pursuant to the procedural agreement reached by the DOE and NRC in 1983, the DOE has announced its intent to use packaging approved by the NRC for DOE shipments performed under the NWPA from NRC-licensed facilities to NWPA facilities. (A DOE intra-agency agreement signed in July 1986 extended the commitment to use NRC-certified packages to also include high-level waste shipments from DOE processing facilities to NWPA facilities.) The DOE/NRC agreement further provides procedures for consultation and information exchange in order to resolve issues related to packaging design, testing, and certification. 
Memorandum of Understanding: Transportation of Radioactive Materials

Agencies: Department of Transportation (DOT), and Department of Energy (DOE) Date of Publication: November 18, 1985 Reference: 50 Fed. Reg. 47421

Title: Transportation of Radioactive Materials Under the Nuclear Waste Policy Act

Summary: The purpose of this agreement is to delineate the respective responsibilities and establish common planning assumptions which the DOT Research and Special Programs Administration (RSPA) and the DOE Office of Civilian Radioactive Waste Management (OCRWM) will observe in the implementation of transportation requirements under the NWPA. This agreement will ensure that adequate procedures are established for consultation and exchange of information and will define the objectives and responsibilities that will govern the relationship between RSPA and OCRWM in managing transportation activities assigned by existing law.

To assure the safe and efficient transportation of spent fuel and highlevel radioactive waste performed under the NWPA and to avoid duplication of effort, RSPA and OCRWM agree, subject to their respective statutory authorities, as follows:

- Management of the transportation of spent fuel and high-level radioactive wastes under the NWPA resides with OCRWM. Transportation will be performed in full compliance with all applicable regulations as promulgated by the DOT as part of its overall body of Federal regulations governing the packaging and transportation of radioactive materials. Further, OCRWM recognizes the state and local interests in nuclear waste transportation and will comply with State or local laws and regulations pertaining to transportation that are not inconsistent with the HMTA or regulations promulgated thereunder.

- Transportation of spent nuclear fuel and high-level radioactive waste resulting from atomic energy defense activities, research and development activities of the Secretary of Energy, or both, to any repository developed under the NWPA will be subject to applicable DOT regulations.

- RSPA and OCRWM agree to exchange information, consult each other, and provide appropriate support within the areas of their responsibilities. Timely response will be provided by each party to requests derived from this agreement and other relevant laws, regulations, and administrative procedures.

- Development and execution of an effective transportation safety regulatory compliance and inspection policy shall be a common area of interest. It is expected that this policy will address the preshipment, enroute, and postshipment phases of the transportation function and will allow for the utilization of State, as well as Federal resources as appropriate. 


\section{APPENDIX D \\ DIRECTORY OF ORGANIZATIONAL CONTACTS}

I. GOVERNMENT

A. STATE

Contacts for States which have been selected for site characterization for a repository are:

NEVADA

GOVERNOR: Richard H. Bryan (702/885-5670)

Governor of Nevada

Carson City, NV 89710

Key Contact:

Nevada Agency for Nuclear Projects

Capitol Complex

Evergreen Center, Suite 252

1802 N. Carson St.

Carson City, NV 89710

(702/885-3744)

$\underline{\text { TEXAS }}$

GOVERNOR: Mark White (512/463-2000)

Governor of Texas

Austin, TX 78711

Key Contact:

Nuclear Waste Programs Office

Office of the Governor

Box 12428

Austin, TX 78711

(512/475-1577)

\section{WASHINGTON}

GOVERNOR:

Booth Gardner (206/753-6780)

Governor of Washington

Olympia, WA 98504-0413

Key Contact: High Level Nuclear Waste Management office

Mail Stop PV-11

01 ympi a, WA 98504

(206/459-6670 or 6678)

$$
\text { D-1 }
$$


Agency contacts which have been identified for other States are 1 isted below. These were obtained from the lists of Governor's designees for either receiving NRC shipment prenotification or as contacts for the NWPA program in general.

\section{ALABAMA}

GOVERNOR: George Wallace (205/261-3592)

Governor of Alabama

Montgomery, AL 36130

Key Contact: Alabama Department of Public Safety

P.0. Box 1511

Montgomery, AL 36192

(205/261-4378)

ARIZONA

GOVERNOR: Bruce E. Babbitt (602/255-4331)

Governor of Arizona

Phoenix, AZ 85007

Key Contact: Radiation Regulatory Agency

4814 South 40 Street

Phoenix, AZ 85040

$(602 / 255-4845)$

\section{ARKANSAS}

GOVERNOR:

Bill Clinton (501/371-2345)

Governor of Arkansas

Little Rock, AR 72201

Key Contact: Division of Radiation Control

Department of Health

4815 West Markham Street

Little Rock, AR 72201

(501/661-2136)

\section{CALIFORNIA}

GOVERNOR: George Deukmejian (916/445-2843)

Governor of California

Sacramento, CA 95814

Key Contact: California Highway Patrol

P.0. Box 942898

Sacramento, CA 94298-0001

(961/445-3253) 
California Department of Health Services

Radiologic Health Branch

714 P Street

Sacramento, CA 95814

(916/322-2073)

COLORADO

GOVERNOR: Richard D. Lamm (303/866-2471)

Governor of Colorado

Denver, CO $\mathbf{8 0 2 0 3}$

Key Contacts: Office of the Governor

122 State Capitol, Room 122

Denver, CO 80222

(303/866-2120)

Colorado State Patrol

1325 S. Colorado Blvd.

Building 700B

Denver, $C O 80222$

(303/691-8107)

CONNECTICUT

GOVERNOR: William A. O'Neill (203/566-4840)

Governor of Connecticut

Hartford, CT 06106

Key Contacts: State Department of Environmental Protection

165 Capitol Avenue

Hartford, CT 06106

$(203 / 566-2110)$

Department of Environmental Protection

Marine Sciences Institute

University of Connecticut

Groton, CT 06340

(203/466-1020)

DELAWARE

GOVERNOR: Michael N. Castle (302/736-4101)

Governor of Delaware

Dover, DE 19901

Key Contact: Department of Public Safety

P.O. Box 818

Dover, DE 19903

$(302 / 736-4321)$ 


\section{FLORIDA}

GOVERNOR: Robert D. Graham (904/488-2272)

Governor of Florida

Tallahassee, FL 32301

Key Contact: Department of Health and Rehabilitative Services

P.O. Box 15490

Or1 ando, FL 32858

(305/299-0580)

\section{GEORGIA}

GOVERNOR: Joe Frank Harris (404/656-1776)

Governor of Georgia

Atlanta, GA 30334

Key Contacts: Department of Natural Resources

270 Washington Street, S.W.

Atlanta, GA 30334

(404/656-3500)

Department of Transportation

940 Virginia Avenue

Hapeville, GA 30354

(404/656-5435)

Georgia Geologic Survey

19 Martin Luther King Jr. Drive, S.W.

Atlanta, GA 30334

(404/656-3214)

IDAHO

GOVERNOR: John V. Evans (208/334-2100)

Governor of Idaho

Boise, ID 83720

Key Contact: Idaho Department of Health and Welfare 450 West State Street

Boise, ID 83720

$(208 / 334-4107)$

\section{ILLINOIS}

GOVERNOR: James R. Thompson (217/782-6830)

Governor of I11inois

Springfield, IL 62706 
Key Contact: Illinois Department of Nuclear Safety 1035 Outer Park Drive, 5th Floor Springfield, IL 62704 (217/546-8100)

INDIANA

GOVERNOR: Robert D. Orr (317/232-4567)

Governor of Indiana

Indianapolis, IN 46204

Key Contact: Indiana State Police 301 State Office Building 100 North Senate Avenue Indianapolis, IN 46204 (312/232-8248)

IOWA

GOVERNOR: Terry Brandstad (515/281-5211) Governor of Iowa Des Moines, IA 50319

Key Contact: Office of Disaster Services Hoover State office Building Des Moines, IA 50319 (515/281-3231)

KANSAS

GOVERNOR: John Car1in (913/296-3232)

Governor of Kansas

Topeka, KS 66612

Key Contact: The Adjutant General's Department Division of Emergency Preparedness P.0. Box C-300

Topeka, KS 66601 (913/233-9253)

$\underline{\text { KENTUCKY }}$

GOVERNOR: Martha L. Collins (502/564-2611)

Governor of Kentucky

Frankfort, KY 40601

Key Contact: Department of Health Services

275 East Main Street

Frankfort, KY 40621

$(502 / 564-3700)$ 
LOUISIANA

GOVERNOR: Edwin Edwards (504/342-7015)

Governor of Louisiana

Baton Rouge, LA 70824

Key Contacts: Department of Environmental Quality

Air Quality and Nuclear Energy Division

P.0. Box 14690

Baton Rouge, LA 70898

$(504 / 925-4518)$

Louisiana Nuclear Waste Program

2133 Silverside Dr., Suite L

Baton Rouge, LA 70808

$(504 / 342-7460)$

Louisiana State Police

265 South Foster Drive

P. 0. Box 66614

Baton Rouge, LA 70896

(504/925-6117)

MAINE

GOVERNOR: Joseph E. Brennan (207/289-3531)

Governor of Maine

Augusta, ME 04330

Key Contacts: Special Assistant to the

Governor

(207/289-3531)

Department of Public Safety

State House Station 42

Augusta, ME 04333

(207/289-2155)

Maine Geological Survey

State House Station 22

Augusta, ME 04333

(207/289-2801)

\section{MARYLAND}

GOVERNOR: Harry Hughes (301/269-3901)

Governor of Maryland

Annapolis, MD 21404 
Key Contact: Office of Environmental Programs Department of Health and Mental Hygiene 201 W. Preston Street

Baltimore, MD 21201

(301/383-2740)

Maryland State Police

1201 Reisterstown Road

Pikesville, MD 21208

(301/486-3101)

\section{MASSACHUSETTS}

GOVERNOR: Michael Dukakis (617/727-3600)

Governor of Massachusetts

Boston, MA 02133

Key Contacts: Executive Office of Environmental

Affairs

$(617 / 727-2200)$

Radiation Control Program

Department of Public Health

150 Tremont Street - 7th Floor

Boston, MA 02111

(617/727-6214)

\section{MICHIGAN}

GOVERNOR: James Blanchard (517/373-3410)

Governor of Michigan

Lansing, MI 48909

Key Contacts: Department of Transportation

State of Michigan

P.0. Box 30050

Lansing, MI 48909

(517/373-2090)

Michigan Department of State Police

714 S. Harrison Road

East Lansing, MI 48823

$(517 / 337-6100)$

Environmental and Occupational

Health Services Administration

Department of Public Health

3500 North Logan

P. 0. Box 30035

Lansing, MI 48909

(517/373-1578) 


\section{MINNESOTA}

GOVERNOR: Rudy Perpich (612/292-3391)

Governor of Minnesota

St. Paul, MN 55155

Key Contacts: Special Assistant to the Governor (612/296-3391)

Division of Emergency Services

B5 State Capitol

St. Paul, MN 55155

(612/296-2233)

Pollution Control Agency

550 Cedar Street

St. Paul, MN 55101

(612/296-9037)

Minnesota State Planning Agency

550 Cedar Street

St. Paul, MN 55101

$(612 / 296-9037)$

\section{MISSISSIPPI}

GOVERNOR:

William Allain (601/359-3100)

Governor of Mississippi

Jackson, MS 39205

Key Contacts: Assistant to the Governor

New Capitol B1dg.

Jackson, MS 39205

(601/359-3100)

Emergency Management Agency

P. 0. Box 4501

Fondren Station

Jackson, MS 39216

(601/359-9100)

Mississippi Department of Energy and Transportation

300 Watkins Bldg.

510 George Street

Jackson, MS 39202-3096

(601/961-4733) 


\section{MISSOURI}

GOVERNOR: John Ashcroft (314/751-3222)

Governor of Missouri

Jefferson City, MO 65102

Key Contacts: Department of Health and Public Welfare

State office Bldg.

Jefferson City, MO 65101

(314/751-2335)

State Emergency Management Agency

1717 Industrial Drive

P.0. Box 116

Jefferson City, MO 65102

MONTANA

GOVERNOR: Ted Schwinden (406/444-3111)

Governor of Montana

Helena, MT 59620

Key Contact: Occupational Health Bureau

Department of Health and Environmental Sciences

Cogswel1 Building, A-113

Helena, MT 59620

(406/444-3671)

NEBRASKA

GOVERNOR: Robert Kerrey (402/471-2244)

Governor of Nebraska

Lincoln, NE 68509

Key Contacts: Nebraska Energy Office

P.0. Box 95085

Lincoln, NE 68509

(402/471-2867)

Nebraska State Patrol

P.0. Box 94907, State House

Lincoln, NE 68509

(402/471-2406)

NEW HAMPSHIRE

GOVERNOR: John H. Sununu (603/271-2121)

Governor of New Hampshire

Concord, NH 03301 
Key Contact: Office of State Planning, Environmental Aid State Capitol

107 North Main

Concord, NH 03301

$(603 / 271-2121)$

Department of Safety

James H. Hayes Building

Hazen Drive

Concord, NH 03305

(603/271-3636)

\section{NEW JERSEY}

GOVERNOR:

Thomas H. Kean (609/292-6000)

Governor of New Jersey

Trenton, NJ 08625

Key Contact: Division of Environmental Quality

Department of Environmental Protection

Labor \& Industry B1dg. Room 1109

John Finch Plaza CN-027

Trenton, NJ 08625

$(609 / 292-5383$ or 2885$)$

NEW MEXICO

GOVERNOR: TOny Anaya (505/827-3000)

Governor of New Mexico

Santa $\mathrm{Fe}$, NM 87503

Key Contact: Motor Transportation Divisior.

New Mexico Transportation Department

P.0. Box 1028

Santa Fe, NM 87503

(505/827-4653)

Radiation Protection Bureau

Environmental Improvement Division

P. 0. Box 968

1190 St. Francis Drive

Santa Fe, NM 87504-0968

(505/827-2959)

NEW YORK

GOVERNOR: Mario Cuomo (518/474-8390)

Governor of New York

Albany, NY 12224 
Key Contacts: Energy Research and Development Authority

Empire State Plaza

Albany, NY 12223

$(518 / 465-6251)$

Bureau of Energy and Radiation

Division of Regulatory Affairs

NY State Dept. of Environmental Conservation

50 Wolf Road

Albany, NY 12233

(518/457-5915)

State Emergency Management Office

Public Security Building

State Campus, Albany, NY 12226

(518/457-2222)

NORTH CAROLINA

GOVERNOR: James G. Martin (919/733-5811)

Governor of North Carolina

Raleigh, NC 27611

Key Contacts: Department of Natural Resources and Community Development

P.0. Box 27687

Raleigh, NC 27611

(919/733-6376)

Highway Patrol Headquarters

P. O. Box 27687

Raleigh, NC 27611

$(919 / 733-7952)$

NORTH DAKOTA

GOVERNOR: George Sinner (701/224-2200)

Governor of North Dakota

Bismarck, ND 58505

Key Contact: North Dakota Department of Health

Missouri office Bldg.

1200 Missouri Ave., Room 304

Box 5520

Bismarck, ND 58502-5520

$(701 / 224-2348)$

$\underline{\text { OHIO }}$

GOVERNOR: Richard F. Celeste (614/466-3555)

Governor of Ohio

Columbus, $\mathrm{OH} \quad 43215$

$$
\text { D-11 }
$$


Key Contact: Disaster Services Agency

2825 Granville Road

Worthington, $\mathrm{OH} \quad 43085$

(614/889-7157)

OKLAHOMA

GOVERNOR: George Nigh (405/521-2342)

Governor of Oklahoma

Oklahoma City, OK 75105

Key Contact: Department of Public Safety

3600 North Eastern Avenue

Oklahoma City, OK 73111

(405/424-4011)

\section{OREGON}

GOVERNOR: Victor G. Atiyeh (503/378-3100)

Governor of Oregon

Salem, OR 97310

Key Contact: Radiation Control Section

State Health Division

Department of Human Resources

P.0. Box 231

Portland, OR 97207

(503/229-5797)

Oregon Department of Energy

625 Marion Street, NE

Salem, OR 97310

(503/378-6469)

\section{PENNSYLVANIA}

GOVERNOR: Dick Thornburgh (717/787-2500)

Governor of Pennsylvania

Harrisburg, PA 17120

Key Contacts: Bureau of Radiation Protection

Department of Environmental Protection

P.0. Box 2063

Harrisburg, PA 17120

$(717 / 787-2480)$

Pennsylvania Emergency Management Agency

P. 0. Box 3321

Harrisburg, PA 17105

(717/783-8150) 
RHODE ISLAND

GOVERNOR: $\quad$ Edward DiPrete (401/277-2080)

Governor of Rhode Island

Providence, RI 02903

Key Contacts: Office of Environmental Coordination

Rhode Island Department of Environmental

Management

83 Park Street

Providence, RI 02903

(401/277-6800)

Office of State Planning

Department of Administration

265 Melrose Street

Providence, RI 02907

$(401 / 277-2656)$

Division of Public Utilities and Carriers

100 Orange Street

Providence, RI 02903

$(401 / 277-3500)$

SOUTH CAROLINA

GOVERNOR: Richard W. Riley (803/758-3208)

Governor of South Carolina

Columbia, SC 29211

Key Contacts: Deputy Senior Executive Assistant to the Governor State House

Columbia, SC 29211

(803/758-3208)

Division of Energy and Environment

Governor's office

1205 Pendleton Street, 4th Floor

Columbus, SC 29201

$(803 / 758-7874)$

Department of Health and Environmental Control

2600 Bull Street

Columbia, SC 29201

$(803 / 758-7806)$

SOUTH DAKOTA

GOVERNOR: William J. Janklow (605/773-3212)

Governor of South Dakota

Pierre, SD 57501 
Key Contact: Emergency and Disaster Services

Capitol Building, Basement

Pierre, SD 57501

(605/773-3231)

\section{TENNESSEE}

GOVERNOR:

Lamar Alexander (615/741-2001)

Governor of Tennessee

Nashville, TN 37219

Key Contact: Governor's Safe Growth Team

Suite 1600

James K. Polk Building

Nashville, TN 37219

(615/741-5782)

State Emergency Operations Center 3041 Sidco Drive

Nashville, TN 37204

$(615 / 252-3300)$

UTAH

GOVERNOR: Norman H. Bangerter ( $801 / 533-5231$ )

Governor of Utah

Salt Lake City, UT 84114

Key Contact: Utah High Level Nuclear Waste office 355 West North Temple

3 Triad Center, Suite 330

Salt Lake City, UT 84180-1203

$(801 / 538-5545)$

Bureau of Radiation Control

State office Building

Room 3253

P. 0. Box 45500

Salt Lake City, UT 84145-0500

(801/533-6734)

VERMONT

GOVERNOR: Madeline M. Kunin (802/828-3333)

Governor of Vermont

Montpelier, VT 05602

Key Contacts: Agency of Environmental Conservation State office B1dg.

Montpelier, VT 05602

$(802 / 828-3365)$ 


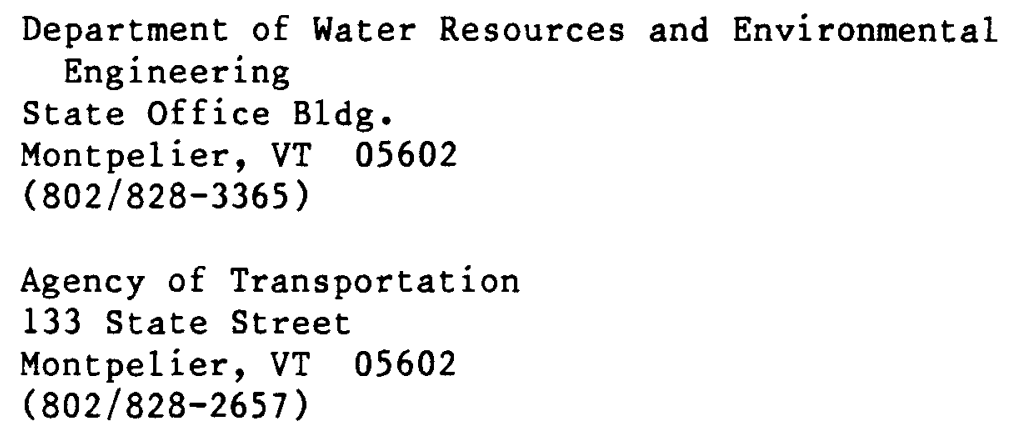

\section{VIRGINIA}

GOVERNOR: Gerald L. Baliles (804/786-2211)

Governor of Virginia

Richmond, VA 23219

Key Contact: Division of Solid and Hazardous Waste Management

11th Floor, Monroe Bldg.

101 North 14 th Street

Richmond, VA 23219

(804/225-2667)

Department of Emergency Services Commonwealth of Virginia

310 Turner Road

Richmond, VA 23225

(804/323-2300)

\section{WEST VIRGINIA}

GOVERNOR: Arch A. Moore Jr. (304/348-2000)

Governor of West Virginia

Charleston, WV 25305

Key Contact: Department of Public Safety

725 Jefferson Road

South Charleston, WV 25309

(304/746-2111)

\section{WISCONSIN}

GOVERNOR: Anthony S. Earl (608/266-1212)

Governor of Wisconsin

Madison, WI 53707-7863

Key Contact: Wisconsin Radioactive Waste Review Board 331 S. State Capitol

Madison, WI 53702

(608/266-1832) 
Division of Emergency Government

4802 Sheboygan Ave., Room 99A

P. O. Box 7865

Madison, WI 53707

(608/266-3232)

\section{WYOMING}

GOVERNOR :

Ed Herschler (307/777-7434)

Governor of Wyoming

Cheyenne, WY 82002

Key Contact: Radiological Health Services

Department of Health and Social Services

Hathaway Building

Cheyenne, WY 82002

(307/777-7956) 
B. TRIBAL

The following tribal governments have been identified as having

"affected Tribe status."

CONFEDERATED TRIBES OF THE UMATILLA RESERVATION

P.0. BOX 638

Pendleton, OR 97801

$(503 / 276-3165)$

NEZ PERCE TRIBE

P.O. Box 305

Lapwai, ID 83540

(208/843-2253)

YAKIMA INDIAN NATION

P.0. BOX 151

Toppenish, WA 98948

C. FEDERAL AGENCIES

DEPARTMENT OF ENERGY (DOE)

Ben Rusche, Director

Office of Civilian Radioactive Waste Management

U.S. Department of Energy

Washington, DC 20585

(202/252-6850)

Roger Hilley, Associate Director for

Storage and Transportation Systems

office of Civilian Radioactive Waste Management U.S. Department of Energy

Washington, DC 20585

(202/252-5292)

Lake Barrett, Director

Transportation and Waste Systems Division

Office of Storage and Transportation Systems

Office of Civilian Radioactive Waste Management

U.S. Department of Energy

Washington, DC 20585

(202/252-6047)

Robert E. Philpott

Team Leader, Transportation Programs

Transportation and Waste Systems Division

Office of Civilian Radioactive Waste Management

U.S. Department of Energy

Washington, DC 20585

(202/252-9620) 
Roger Gale, Director

Office of Policy and Outreach

Office of Civilian Radioactive Waste Management

U.S. Department of Energy

Washington, DC 20585

(202/252-2277)

Susan Denny

Transportation and Waste Systems Division

Office of Civilian Radioactive Waste Management

U.S. Department of Energy

Washington, DC 20585

(202/252-2439)

Judith Holm

U.S, Department of Energy

Chicago Operations office

Technology Management Division

Transportation Program office

9800 S. Cass

Argonne, IL 60439

(312/972-2410)

DEPARTMENT OF TRANSPORTATION (DOT)

Office of Hazardous Materials Transportation

Research and Special Programs Administration

400 Seventh Street, S.W.

Washington, DC 20590

(202/472-2698)

Federal Railroad Administration

400 Seventh Street, S.W.

Washington, DC 20590

(202/426-8675)

NUCLEAR REGULATORY COMMISSION (NRC)

Office of Nuclear Material Safety and Safeguards Washington, DC 20555

(301/427-4063 or 4066$)$

ENVIRONMENTAL PROTECTION AGENCY (EPA)

Standards Division, Office of Radiation Programs Crystal Mall Building 2

1921 Jefferson Davis Highway

Arlington, VA 20460

(202/557-8610) 
FEDERAL EMERGENCY

MANAGEMENT AGENCY (FEMA)

Office of Natural and Technological Hazards Program

Federal Center Plaza

500 C Street, S.W.

Washington, DC 20472

(202/287-0210)

\section{ARMY CORPS OF ENGINEERS}

Policy Review and Initiative Division

Civil Works Directorate

Office of the Chief of Engineers

Pulaski Building

20 Massachusetts Avenue, N.W.

Washington, DC 20314

(202/272-0118) 